UC-32

Reporting Date: April 1974 Issued: May 1974

\title{
XSMOD: A Code for the Modification of the Los Alamo: Master Data File
}

\author{
by \\ Martha S. Hoyt \\ Frank McGirt
}


This report was prepared as an account of work sponsored by the United States Government. Neither the United States nor the United States Atomic Energy Commission, nor any of their employees, nor any of their contractors, subcontractors, or their employees, makes any warranty, express or implied, or assumes any legal liability or responsibility for the accuracy, completeness or usefulness of any information, apparatus, product or process dis closed, or represents that its use would not infringe privately owned rights.

In the interest of prompt distribution, this LAMS report was not edited by the Technical Information staff.

Printed in the United States of America. Available from

National Technical Iniormation Service

U.S. Department of Commerce 5285 Port Royal Road

Springfield, Virginia 22151

Price: Printed Copy $\$ 5.45$ Microtiche $\$ 1.45$ 
XSNOD: A CODE FOR THE MODIFICATION

OF THE LOS ALAMOS MASTER DATA FILE

by

Martha S. Hoyt and Frank McGirt
NOTICE

This report was prepured as an account of work sponsored by the United States Government. Neither the United States nor the United States Atomic Enary. Caminission, rot any of their employeot, not any of their contractors, subcontractors, of thatr employees, makes any warranty, express or implied, or assumes any makes any warranty, express or impiled, of asermestitity or responsibility for the accuracy, comlogul liability or responsibilily for the sceurecy, completeness or usefuliness of sny information, spparatus,
product or process disclosed, or cepresents that its use would not infringe privately owned rights.

\section{ABSTRACT}

XSNOD is a COC GOOO FORTRAN cJde which allows modifications to group and/or cross-section sets in the Los Nlamos Master Data Filc. The code uses the DATATRAN data manipulation language and is modular in structure. Data sets may be added to or deleted from the library; they may be retrieved from the library and printed or may be written to a tape or disk file in a format acceptable to processing codes. A description of the code, flow diagrams, a code listing and instructions for using the code are included.

\section{INTRODUCTION}

Over the past several years Roger Lazarus at the Los Mlanos Scientific Laboratory (LASL) collected cross-section data from the lvaluated Nuclear CrossSection Library of the Lawrence Livermore Laboratory (LLL) and from the Uniied Kingdom Atomic Energy Authority Nuclear Data Library (UK) and developed a library of his own on the Misic. To make multigroup processing possible he also built up a library of group sets. The combined library of group sets and cross-section data is the Los Alunos Master Data File (LANDI:).

l.dzarus and lirank Meliint decided to transfer the cross-section etfort to one of the large computcrs in the cicl. The thultigroup processing code levxs was rewritten for the cuc 6000 by Nargaret Asprey.' Lazarus' MASLAC code L.1BO6 ${ }^{2}$ prepared a library tape for use by lexis on the 6600 . Mcliirt decided to use the DArsikd ${ }^{3}$ system to create the 6000 library. DATATIA is a user-oriented data manipulation language developed at the knolls Atomic power laboratory. It is a tool for saving, retrioving and moditying data in a simple manner. The DATATkA system available at LASl. is described in Rof. 4.
The DATATRAN libraries currently available on the 6600 have come from two sources: 1) The original LAMIDI was converted to the 6600 DATATRAN version by processing the library tape prepared by LIBG6 with Martha Hoyt's XSDTLIB' code; 2) A DATATRAN library of the latest LLL data was created on the 6600 by XSSYOD.

XSWOD is a 6600 code which provides a means of modifying a DATATRu library. It can add, delete or print group sets and/or cross-section sets with angular distributions; print out the table of contents of the DATATRA directory; prepare a library tape of the entire library or selected data sets for input to livxs; prepare linkago to Evxs if the user wishes to make use of the modular execution feature provided by the DAlitRax system. The capability of changing part of a data sot has not been implemented at this rime.

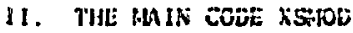

XSMOU recalls the dircetory to the DATATKAN library, calls the module kDJOBS to read the jols requests and set up tho necessary retrievals, acts as a control program to call upon individual modules or subroutines to perform the tasks reyuested, 
defines and saves the directory if it was modified, and sets up linkage with EVXS if requested. Flow diagrams for the main code and all modules are in Appendix A. The FORTRAN code listing is in Appendix $B$.

The modules called and their functions are these:

RDJOBS Read in job requests, set up add, tape and retrieve lists, call RECLIB to scan library tape and transfer requested blocks to ECS.

ADDG Add and/or list a group set.

ADDXS Add a cross-section set.

LISTXS Print a cross-section set.

TAPE Prepare a file TAPEl in the same format as that produced by LIB66.

Communication with modules is accomplished by means of DATATRAN N.lists, which are defined in Ref. 4.

XSMOD also calls the following subroutines:

DELETE Delete a group or cross-section set from the DATATRAN library directory.

CONTENT Print contents of DATATRAN directory.

CHANGE Print message and return to main code.

This is a dummy subroutine which can be replaced by a module if the CHANGE keyword is implemented.

Communication with the subroutines is standard, i.e., by arguments and common.

The subroutine DELETE modifies the directory by replacing with zeroes all directory information associated with the group identification number (GID) or cross-section identification number (SID) being deleted. The directory structure is described in detail in the section MODULE RDJOBS. DELETE madifies only the directory since removal of the data set is not necessary. To remove the data set from the library tape a separate DTPURGE job must be done. That job is described in Ref. 4 , and the information needed as input for it is printed out by the subroutine DELETE. When all the DELETE's requested on a single card have been done, the directory is closed up and the item count is modified. The current directories are defined in N.lists to be available to all modules, and the directory save flag is set so that a new directory will be saved at the end of the job.

The subroutine CONTENT prints out the list of GID's and S1D's in the directory at the time the CONTENT card is processed. It also prints the directory recall number and the save fligh wilich indicates whether or not the recall nurber is valiu.

\section{I11. MODULE RDJOBS}

The option cards, which communicate to the main code the jobs which the user wants to do, are read by the module RIJJaBS. The implenented keywords and the jobs they do are as follows:

ADD SID Add specified cross-section sets to the DATATRAN library and print.

ADD GID Add specified group sets to the IATNTRS library and print .

DELETE SID Jelete specjfied cross-section sets from the DATATRAN library directory.

DELETE GID Delete specified group sets from the DATATRAN library directory.

LIST SID Print specified cross-section sets from the DATATRAN library.

LIST GID Print specified group sets from the DATATRAN library.

TAPE ALL Write the entire DATATIR library to TAPl:1.

TAPE SID Write specified cross-section sets to TAPE 1 .

TAPE GID Write specified group sets to ThPl:1. CONTENTS Print table of contents of the vatirlid. library.

EVXS Link with Evxs code.

LAST Last option card.

These cards are read by tormat $(110,2 X, 1016)$. The keyword must start in column 1. Up to 10 (i1D)'s or SID's may be specified on a single card. The first ID specified must end in column 18. Remaining lJ's must occupy the rightmost portion of successive 6column fields.

RDJOBS defines as FORTRAN variables the DATATRA library directories for the GID's and SlD's in the library. The entire directory B.DIRECT consists of seven records which contain the following information:

Record 1 N.DIRGID.1/ GID's in the library

2 N.DIRGID.2/ DATATRAN library recall numbers

3 N.DIRGID.3/ Numbers of words for :ild sets

4 N.DIRSID.l/ SW's in the library

5 N.DIRSID.2/ DATATRAN library reeall numbers

6 N.DIRSID.3/ Numbers of words for SID sets 
7 N.IID

Recall number of the directory

The GID's and SID's are simple integers in the di-

rectory. They appear in the order in which they were added to the library. The recall numbers in Records 2 and 5 are orciered so that they correspond to the GID's and SID's in Records 1 and 4, e.g., the nth word of Record 2 is the recall number of the $n$th GID in Record 1. Records 3 and 6 contain the numbers of words in the blocks saved for given GID's and SID's. These also are ordered to correspond to Records 1 and 4 . lior retrieval of the information associated with a given GID or SID, the recall number and number of words in the block are essential. When a job requiring retrieval of a GID or SID is requested, the directory is searched for the given GID or SIV and the corresponding recall number and number of words inte picked up. This information is passod to the module RECLIB ${ }^{6}$ which scans the DArATRAN library tape once and puts into ECS all information which will be recalled in the job. The actual recall of the information into core is done by constructing a particuiar recall surd image in various modules at the time the information is needed.

RD.JOBS calls the subrout ine READOMT to read in the option cards. An entire card, i.c., keyword, specified 61D's or SID's and blank fields, is read into the array kuIMA; and printed. The keyword is compared with all allowed keywords until a match is found. By moans of a computed 60 ro, control passes to a part of the code which makes lists, sets flags. and sets indices for reading the next card. The keytords and the processing which takes place at this point are given below:

ADD SiD Add SIU's from this card to the list IADDX and increase tho count $0 z^{*}$ items in the list.

AUD riID add Glu's from this card to the list LADDG and increase the count of items in the 1 ist.

DELET: SID Increase indices to read the noxt card. DELETI: GID Increase indices to read tho noxt card. LIST SID Call subroutine TLAH'LST to add EID's from this card to a tcmporary list for retrioval.

LIST GID Call subroutino TLNPLST to add GIV's from tnis card to a temporary list for retrioval.

TAPE ALL Set flag IALL $=1$.
TAPE SID Add SID's from this card to the list ITAPX and increase the count of items in the list.

TAPE GID Add GID's from this card to the list ITAPG and increase the count of items in the list.

CONTENTS Increase indices to read the next card. LAST Indicates all option cards have been read. Process lists.

Encountering the LAST card ends reading of option cards. If a TAPE ALL has been requested, the list IADDS is put in increasing numerical order, the list ITAPG is filled from the GID directory and put in increasing numerical order. The list IADDG is merged into I'APG with the GID's from IADUG flagged minus. The flagged GID's are not retrieved from the library in the module TAPE but are read from a diskfile.

The lists ITAPX and IADDX are processed in the same way for the SID's. If a TAPE ALL was not requested, the tape lists ITAPG and ITAPX are put in increasing numerical order and compared with the corresponding add lists IAUVC and IADDX. GID's and SID's which appear on both lises arc flaggod minus in the tape lists. The tape lists contain all GID's and SID's to bo written to TAPEl; the add lists contain all GID's and SID's to be added to the I ibrary during this job. If tape and/or add lists are copty, their processing is skipped. READOPT roturns to RDJOBS IX and 16 , the number of SIU's and number of GID's to be writton to TAPEl.

HUJOBS now propares the input lists for module RECL1B. Threo lists are required:

$X . R E E L=$ MHAl Identifjer for the library tape N.RECLID List of recall numbers and associatcd numbers of words in pairs of all information on the library tape to which access is allowed, i.c., all clo's and SI0's in the directory

N. USE Recall numbers of all GlD's and SID's to bo retricved in this job

To prepare the list N.USt, RuJOBS calls subroutine USELST or ontry UStid.L if the ontiro library is to be rotrioved. USLLST removes any duplications from the GIU and SID lists made in TEMIPLST. It searches the directory for the GID's and sid's to he recalled and puts the corresponding tecall number into an 
array to be returned to RDJOBS. It keeps count of the GID's and SID's to be retrieved and finally puts the recall numbers in increasing order. N.USE can then be constructed from the recall number arrays and counts returned. The module RECLIB transfers the information to be retrieved in this job from the library tape to ECS from where it is retrieved as needed.

RDJOBS then defines the DATATRAN list N.RDJOUT to return the following information to the main code: N.RDJOUT.1/ Entire option card array XKDIMAG N.RDJOUT. 2/ $N(1)=$ number of SID in N.USE, $N(2)=$ number of GID in N.USE, IALL

N.RDJOUT.3/ GID tape list ITAPG

N. RDJOUT. 4 SID tape list ITAPX

\section{MODULE ADDXS}

ADUXS adds a cross section to the DATATRAN library from cards or tape. The input must be in the UK or LLL format. The format used by LLL is basically the same as $U K$. The differences are these: 1) For reactions in which more than one neutron come out, UK gives separate angular distribution and secondary energy data for each neutron. LLL gives only one angular distribtition and one secondary energy distribution to be applied to all neutrons. The LAMOF stores only one angular distribution for each reaction. All of the secondary energy data given is stored. 2) Cross-section data from $U K$ is given for the same encrgy mesh for all reactions. Data from LLL can be on a different mesh for each reaction. Original LLL tapes must be pre-procossed by lrank McGirt's LRLUR ${ }^{7}$ code which makes a common energy mesh for all reactions. The output of LRLUK is the input to ADDXS.

For cach nuclide to be added to the library, the following two cards are required in the input strcam:

Card 1: SID No., SOURCE, CTINU. NLX

Curd 2: 80 column descriptive mossage

The format for Card I is $(16,2 \lambda 6,16)$; the format for card 2 is $(8 \mathrm{M} / 0)$. The itoms or Card I are defincd os follows:

siv No. The identifjer number of this nuclide in the Jibrary

SOURCE "LLL" or "UK"

CTINo Indicator for card or tape input. "CARUS" or "TAPE"

NIN Nuclide identification number to be searched for on input tane or to be checked on input cards.

Example:

$\begin{array}{lllll}\text { col. } & 123456 & 1 & 1 & 2 \\ \end{array}$

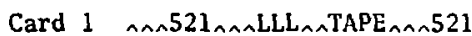

Card 2 LLL 521 S32 FROM TAPE $594634 / 16 / 73$ by MSH

The information from Card 1 is used for checking and for setting flags in the code. If the SID to be added is already in the library, a message is print. ed, and the code goes on to the next job. If SOURCE is UK, the first file on the tape is a directory to the tape. It is read and printed. The source fiag is set for future use. The tape is searched for NIN. If NIN is not found, a message is printed, and the code goes on to the next job.

The format for the input data is described in a widely circulated draft by $K$. Parker ${ }^{8}$. The data for each nuclide is divided into blocks. The first block, Block 0 , is a table of contents for the remaining blocks. It tells what kind of information (cross-section, angular distribution, secondary energy or fission) is given for each reaction, what block number contains that information and the number of cards in each block. The identifier numbers for the different kinds of data are:

1000 + reaction number for cross-section data

2000 + reaction number for angular distributions

$3000+$ reaction number for secondary energies

4000 + reaction number for energy-nu pairs.

The definitions of the reaction numoers for UK data are given in the document mentioned above. Definitions used by LLL vary slightly from the UK and are given in Ref. 9.

The kind of data contained in a given block is dotermined from the table in Block 0 . Control then passes to the appropriate subrout ine, READXS, READAD, READSEC, or READNU, to read in the card images, make appropriate checks on the data, and define DATATRAN arrays to save the data in the library. When all the blocks have been read, the DATATRAN cross-section control record is definod. This contains the following information:

ISID

ND( $\leq 25)$

$\operatorname{Ir} \operatorname{IDS}(N), N=1, N D$
S10 number in LANDF Nunber of angular distributions ID's of angular distributions in order in which they wero encounterod on input tapo 


\begin{tabular}{|c|c|}
\hline $\begin{array}{l}\text { SDES }(8 \text { words }) \\
\operatorname{IR}(\leq 50)\end{array}$ & $\begin{array}{l}\text { Description from Card } 2 \\
\text { Number of reactions }\end{array}$ \\
\hline $\operatorname{IT} \operatorname{IDR}(I), I=I, I R$ & $\begin{array}{l}\text { 1D of the angular distribution to } \\
\text { be used with the I'th reaction }(-7 \\
\text { if no angular distribution) }\end{array}$ \\
\hline $\operatorname{NES}(\leq 4000)$ & $\begin{array}{l}\text { Number of energies in the cross- } \\
\text { section mesh }\end{array}$ \\
\hline $\operatorname{ES}(I), I=1, N E S$ & Energies \\
\hline $\operatorname{IDR}(\mathrm{I}), I=1, \mathrm{IR}$ & ID's of reactions \\
\hline$M E(1), I=1, I R$ & $\begin{array}{l}\text { In I'th word, lower and upper } \\
\text { indices to the energy block for the } \\
\text { I'th reaction }\end{array}$ \\
\hline $\operatorname{IRS}(1), I=1, I R$ & $\begin{array}{l}\text { Number of secondary energy items } \\
\text { for I'th reaction }\end{array}$ \\
\hline $\mathrm{QR}(1), \mathrm{I}=1, \mathrm{IR}$ & $Q$ values \\
\hline 12 & Z-number \\
\hline MIXT & $\begin{array}{l}\text { Unused indicator for mixture or } \\
\text { element }\end{array}$ \\
\hline K2 & $\begin{array}{l}\text { Total number of words in secondary } \\
\text { energy blocks for all reactions }\end{array}$ \\
\hline$L L L$ & Source ( 0 for UK; 1 for LLL) \\
\hline
\end{tabular}

The DATATRAN array for this nuclide is defined ind saved on the library tape. It contains the following records:

N.CNTRL Cross-section control record described above

N.XS(I) One cross-section record for each reaction I

N.ESJ (J) One secondary energy record for each reaction $J$ that has secondary energies. Energy-nu data is included in this block.

N.ANGD(K) One angular distribution record for each angular distribution ( $K$ ) given.

When the DATATRAN save is made, the card needed to recall that array is punched out as a receipt. It contains the array name, the number of words in the block on the libraxy tape, and the recall ID number. The physical card is not needed for a later retrieve job since XSMGD is able to construct the card image from information in the directory. However, the information on that card must bo used to update the directory now. The punch file is rewound and the nane, number of words and recall ID number are read from it and stored in the directory. The count of items in the directory is increased, and the directory save tlag is set equal to the ID number. The new directory is defined in a DATATRAN $N$, array so that it can be returned to the main code, where the latest directory is saved at the end of the job. The directory is not saved now because in a single job the directory may be updated several times. The directory save flag is also returned. When th: latest directory is saved, its recall ID equals the value of the directory save flag plus one.

If the nuclide being added is requested on a TAPEl file in this same job for later processing by EVXS or for input to other libraries, it is writcen to the diskfile TAFE6 now. The TAPEl file must be written after all other options have been processed because its format is rigid. All requested groups must appear in ascending order in the first file. The SID files must also be in ascending numerical order. Writing to the temporary file TAPE6 is more efficient than retrieving since for retrieval it would be necessary for RECLIB to make a pass through the entire modified library.

The data for the added nuclide is listed by calling the module LISTXS.

The subroutine PRCT is called every time a card is read. It checks the sequenci $b$ information (nuclide ID number, block number, and card number) which appears in columns 73-80 of every card image. If a sequence error is found, a message is printed, and a flag set so that control goes to the error entry at 1000 .

Whenever any error is detected, the code trans fers to 1000 where IERR is set to the number of cards already read plus one. The code then skips the remaining cards for this nuclide and looks for the next job.

All of the SID's requested on a single ADD SID card are added before leaving the module ADDXS. For the standard return at 2000, the data tape, TAPE2, is rewound and the directory save $f$ lag is defined as an N.name to be returned to the main code.

A. Subroutine READXS

READXS reads cross-section data (identifier number 1000 + roaction number) and defines it in DATATRAN lists to be saved in the library. The data is checked for several kinds of discrepancies, and if an orror is suspected, the nuclide is not added to the library.

The card image format is described in detail in the draft by $k$. Harker, which was referenced earlier. The items which are checked by the code are: 
1) The sequence information on each card read.

2) The reaction type number. This is compared to what is expected from the table of contents.

3) The interpolation indicator. If :nterpolation is not $\log -\log$, a warning message is printed, and reading continues.

4) The number of cross sections. This must not be greater than the code dimension for the energy array.

5) Temperature. The code is not designed to treat temperature dependence.

One requirement of the UK format and of the present code is that the cross sections for all reactions of a given nuclide must be on the same energy mesh. For any single reaction the cross sections may start or end at any energy contained in the mesh. Thus only one energy array is set up and stored. An index array ME must be formed to contain the lower and upper indices to the energy mesh. For each reaction, then, there is a word in ME which contains the lower index in the leftmcst 36 bits and the upper index in the rightmost portion of the word.

Elastic scattering data is required for all nuclides entered in the LAMDF and occurs first on the input tape. Since its energy mesh is complete, the energy mesh for the nuclide is set up when the data for elastic scattering (1002) is read. The lowest energy is set equal to $1.0 \times 10^{-20}$. Then the energies and corresponding cross sections are read in. An energy of 1000 is stored at the high end. The energy array now contains two more energies than the data cards contained. The cross section corresponding to the energy $1.0 \times 10^{-20}$ is set equal to the first cross section read in, and the cross section corresponding to energy 1000 is set to the last cross section read in. The word for the ME array is constructed, and the DATATRAN list of cross sections for this reaction is defined.

For other reactions the energies must be checked against the master mesh. The first energy read is compared with all energies in the master mesh until a match is found. A cross section of $1.0 \times 10^{-20}$ is assigned to correspond to the energy preceding tho matched energy, and the energy index is saved to be used in constructing the index word in the ME array later. If the energy read in matches the second energy in the master mesh (The lowest energy in the master mesh is the dumny $1.0 \times 10^{-20}$ ), the cross section assigned to the lowest energy is the same as the cross section for the second energy. All succeeding energies read in are compared with those in the master mesh. If they do not agree, a message is printed and the job is dropped. When all cards in the block have been read, the cross section at the upper end is set to $1.0 \times 10^{-20}$ unless the energy corresponding to the last cross section read is the second highest (Highest was set to 1000.). In that case the cryss section corresponding to energy $=1000$ is set to that for the highest energy read. The word for the ME array is constructed, and the DATATRAN list of cross sections for this reaction is defined. Control returns to ADDXS.

\section{B. Subrout ine READAD}

The angular distribution for any given reaction is assumed to be isotropic unless a special angular distribution is given. For both isotropic and special angular distributions the center of mass system is used to describe the data for elastic and discrete inelastic reactions, and the laboratory system is used to describe data for all other reactions. A special angular distribution is always given for elastic scattering.

READAD reads angular distribution data (identifier number 2000 + reaction number) and defines j.t in DATATRAN lists to be saved in the library. All cards read are sequence checked. When the first card is read, the reaction type is compared to that expected from Block 0 , and the code checks to be sure the first angular distribution given is for elastic scattering. The system flag is checked to determine whether it follows the convention laboratory system for all reactions except elastic and discrete inelastic. If it does not, a warning message is printed. If the input is from LLL, the flag is corrected, because we have been assured by R. I. Howerton that the data follows the convention, but the flag is sometimes in error.

The identification number (TID) for the given angular distribution is formed. If the reaction is elastic, the TID is the same as the SID. For any other reaction the TID is formed by multiplying the SID by 100 and adding the two-digit reaction number.

The code chocks the flag IDATA to choose the appropriate read: Mu-T pairs or Legendre coefficient representation. Most of the angular distributions currently in the library are in the form of 
Mu-T pairs. A combination of the two representations is also possible but occurs so rarely that it was not considered worthwhile to code for that case.

Mu-T Pairs. Angular distributions are given for several different energies. The energies are stored in a separate array $E$, and the pairs are stored in the array TK. For each energy in the $E$ array there is a word in the index array MD which contains the lower and upper indices to the words of the TK block which correspond to the given energy. The lower index is contained in the leftmost 36 bits, and the upper index in the rightmost 24 . The pairs in the TK block are cosine of scattering angle $(\mathrm{Mu})$ and differential scattering probability ( $T$ ). If the lowest energy given is greater than $2.5 \times 10^{-8}$, the lowest energy in the array $E$ is set to $1.0 \times 10^{-11}$ and an isotropic distribution for that energy is entered into the TK block. After all the pairs have been read in, the integral over the cosine of the scattering angle is checked by trapezoidal rule to make sure the data has been normalized to 1 . If it has not been, the normalization is performed now. The DATATRAN list for the angular distribution for this reaction is then defined as follows:

$\begin{array}{ll}\text { ITIDS (ND) } & \text { TID number for this reaction } \\ \text { SDES ( } 8 \text { words) } & \text { Description of cross section for } \\ & \text { heading }\end{array}$

NED ( $<400) \quad$ Number of energies for which angular distributions are given

$E(J), J=1$, NED Energies in Mev

1SYS Flag: $1=$ center of mass; $2=1 \mathrm{ab}$ system

A Atomic weight

LEGN Number of Legendre coefficients

KT (<4000) Number of words in TK block

$T K(J), J=1, K T \quad$ Nu-T pairs or $N F, F_{1}, F_{2}, \ldots F_{N F}$

$M(J), J=1, N E D$ In $J^{\prime}$ th word, lower and upper indices to the part of the TK block which corresponds to the $J$ 'th energy

NINC Number of sub-divisions to use in integrating. Set $=40$.

\section{Control returns to ADDXS.}

The UK format allows multiple angular distributions for each outcoming neutron. The LAMDF accepts data for the first neutron only and skips the rest. It is assumed that the data for the first neutron applies to all neutrons. Multiple angular distribu- tions for one neutron, though seldom encountered, can be read and combined in the subroutine MULTI to make a single distribution which : then saved in the library.

Legendre Polynomial Representation. Legendre representation differs from Mu-T pairs only in the contents of the TK block. The $\mathrm{E}$ and $\mathrm{MD}$ arrays are formed in the same way for both representations. For the Legendre representation the TK block contains for each energy the number of coefficients NF followed by the coefficients.

On the input tape for each $l$ up to LMAX, energies and coefficients are given in pairs. The data is rearranged in the library so that for each energy the coefficients for all L's are tabulated. To do this all the energy-coefficient pairs are read into a temporary storage block. All of the different energies are then pieked out and stored in the $E$ block. Then for each energy the coefficients are found and stored in the TK block. A count of the coefficients, NF, is kept. If the coefficients for the highest L's are zero, they are removed from the TK block and NF is corrected.

\section{Subrout ine MULTI}

This subroutine reads several angular distributions for each neutron and combines them into one distribution which is stored in the liurary. The first distribution is read into the residual arrays $X M U$ and $T$. The $T$ values are multiplied by the probability for this distribution. The next dis'ribution is read into the temporary arrays XMUl and $T I$. The $\mathrm{Tl}$ values are multiplied by their probability. As each card is read into the temporary arrays, its Mu's are compared with those already in the MXU array. If a Mu exists in the XMU array but not in the XMJl array, it is inserted into the $X M U 1$ array and a corresponding $T 1$ value is inserted by linear interpolation. If a Mu exists in the XNUI array but not in the MXU array, it is inserted into the XMU array and a corresponding $T$ value is inserted by linear interpolation. When all the cards have been read in for this distribution, the values in the $T$ and $\mathrm{Tl}$ arrays are added and stored in $\mathrm{T}$. Then the next distribution is read into XMUI and T1 and combined as above. When all the distributions have been read in and combined, the final distribution exists in XMU and $T$. It is transferred to the $T K$ 
block, and $\mathrm{KT}$ is set to point at the current last word of the TK block. Control returns to READAD.

\section{Subroutine READSEC}

READSEC reads secondary energy data (identifier number 3000 + reaction number) and defines it in DATATRAN"lists to be saved in the library. The usual data biück and card sequence checks are made.

Secondary energy data is given so that the distributions may be calculated according to specific laws. The laws are nine in number, 1, 2, 3, 4, 5, $6,7,8,10$. Laws $1-7$ and 10 are described in Ref. 8 for UK libraries. Ref. 9 describes laws 3,8 and 10 as used in the LLL libraries. Briefly the laws are as follows:

1. Neutrons coming out with a known energy.

2. Energy of emitted neutrons dependent on discrete energy loss and reduction factor.

3. Continuous normalized spectrum independent of initial energy.

4. 5. 6. Normalized probability function; $\left(E^{1 / 2} E^{q}\right)=$ $f\left(E, E^{1} / E^{q}\right)$, where $q=0$ gives law $4, q=$ $1 / 2$ gives law 5 , and $q=1$ gives law 6 .

7. Four constants to define a normalized probability function to represent the fission spectrum.

8. Secondary neutron production cross sections as a function of $E, E^{\prime}$ with all secondaries covered.

10. Simple evaporation spectrum specified by a single parameter.

For each energy range one or more laws may apply and a weight is given with each law. The sum of these weights must equal the number of outcoming neutrons. In UK format each neutron may be represented by one or more laws. For a given energy the sum of all of the weights for all of the laws equals the number of outcoming neutrons. LLL does not tabulate data for individual neutrons, but gives one set of data with weights summing to 1 to apply to all neutrons.

The conventions of the LAMDF are such that special handling is necessary in entering LLL data. Law 3 data is accepted as is since LLL uses it to describe fission reactions and thus the number of neutrons out is a special case. Law 8 is reformatted to look like Law 3 to the processing codes. Since the one set of data represents all secondaries, the probabilities are divided by the number of neutrons out. The weight is multiplied by that same number since now the probabilities can be thought of as applying to only one neutron. For Law 10 the weight is multiplied by the number of neutrons out but the data is left as is since it applies to only one neutron.

The data is read into the ESJ tlock. When reading for a law begins, $J$ points to the first unused word is ES:. All numbers in the block are floating point; all prsitive numbers are reaction identifiers or data and ail negative numbers are markers. The significance of the markers is as follows:

- 4.0 denotes end of data for a given law

- 5.0 denotes end of data for a given neutron

- 2.0 denotes end of data for a given energy

- 1.0 denotes end of data for a given reaction.

The end of neutron marker, - 5.0, is not used in the straightforward way implied above. Since LLL data does not provide for individual neutrons, a -5.0 is always followed by a -2.0 when it is entered into the LAMDF. The processing code EVXS expects this combination. Therefore something special must be done to make UK data compatible with the above restriction. The - 5.0 marker is not used to denote end of neutron but is paired with the -2.0 for end of energy. Data for individual neutrons is separated only by the end of law marker, - 4.0. The sum of the weights equals the number of outcoming neutrons as required. In some cases the same law may be represented more than once since originally it was meant to describe different neutrons, but this causes no problem in EVXS. Thus the same storage configuration in the ESJ block can arise from having several laws describe one neutron or from having two or more neutrons. The sum of the weights tells which case it is.

The ESJ block contains the following information:

NRT Reaction number in floating point, e.g., 16.0

$E_{i} \quad$ Lower bound of the energy range throughout which the following laws apply. The ranges are in order of increasing energy.

$w_{k} \quad$ Weight associated with following law number.

Law $k$ Law number

Data Required data for the law given above

-4.0 End of law marker 
$w_{k}+1$

$\operatorname{Law}_{K}+1$

Data

-4.0 End of law

-5.0 End of neutron

-2.0 End of energy

$E_{i}+1$ Next energy

$w_{\mathrm{k}}$

Law $_{k}$

Data

-

$-4.0$

$-5.0$

$-2.0$

-1.0 End of reaction

For fission some additional information may appear at the end of this block. It is described in SUBROUTINE READNU. The total number of words in the ESJ block, including the markers, is equal to $J$ and is saved in IRS. If no extra fission data follows, the ESJ block for this reaction is defined in a DATATRAN list, and control returns to ADDXS.

Secondary energy distributions are supposedly normalized. For laws 1 and 2 the code compares the sum of the probabilities to 1 . For laws $3,4,5$ and 6 the code uses trapezoidal rule to evaluate the integral over the probabilities and compares the result to 1 . If the sum or integral differs significantly from 1 , a warning message is printed. In the interests of preserving original data, no normalization is performed in the LAMDF. If the user expects normalized data for his code, he must do the normalization himself.

\section{E. Subroutine READNU}

READNU reads energy-nu pairs for the fission reactions 4018 and 4019 into the ESJ block. A 4000 block never appears alone but follows some secondary energy (3000) block. Thus an ESJ block will already have been started. READNU gets the ESJ pointer by adding 1 to IRS(IR) which contains the number of items already in the ESJ block. The first quantity stored in ESJ by READNU is the floating point reac$t$ ion number 4018.0 or 4019.0 . The energy-nu pairs are then read in and the marker -1.0 is stored at the end. The corrected number of iterns in the ESJ block is stored in IRS(IR); the DATATRAN list is defined, and control returns to ADDXS.

v. MODULE LISTXS

LISTXS lists a cross-section set from the $1 \mathrm{i}-$ brary. When a cross-section set is added to the $1 i$ brary, it is listed automatically. As part of the ADD process, the data exists as DATATRAN Iists in ECS. The code simply defines the FORTRAN variables from these lists and proceeds to set up the print. A cross-section set already in the library may be listed by requesting it on a $L I, T$ SID card. It is retrieved from the DATATRAN library and printed.

The print format is essentially the same as that developed by $M$. Asprey for the EVLIST ${ }^{10}$ ode. It gives the following summary information for each reaction:

Reaction index

Reaction identifier

Angular distribution identifier

Lower and upper indices to the energy block

$Q$ value

Reaction title

Length of secondary energy block

The first seven reactions are set up for printing since eight (one for energy) is the maximum number of columns that fit on a page. Secondary energy data and markers in the ESJ block are printed for any of the first seven reactions for which an ESJ block exists. This is followed by the energy mesh and cross sections for the first seven reactions. Secondary energy data and cross sections are then printed for the remaining reactions. This is followed by data for each special angular distribution given. The following information is printed:

Energy index

Energy

Lower and upper indices to the TK block

TK block (Mu-T pairs or Legendre coefficients).

The cross-section print is set up in the SS block which holds up to 2000 cross sections for up to seven reactions. The block may be thought of as seven strips, each of which is 2000 words long. The number of strips and the maximum length needed are cleared. The cross sections for a reaction are 
brought into the array SIG which is large enough to hold all the data. They are then transferred into the first unused strip of SS starting at the I'th word of the strip, where I is the index to the energy to which the first cross section corresponds. The strip is then filled up to the 2000 th word. The count of strips used is kept. If data exists beyond the 2000th word, the strip just filled is written to ECS via DATATRAN statements and the code continues to transfer data from SIG into the same strip starting at the first word of the strip. When all data have been transferred from SIG, the second filling of the strip is written out to ECS and the first filling is restored. When all seven strips have been filled or when all reactions have been set up in SS, subroutine PRSIG is called to print SS. If a given nuclide has more than seven reactions, the SS block is cleared and set up to print the remaining ones.

The angular distributions are defined as FORTRAN variables from the DATATRAN lists and printed one at a time. If this listing is part of an ADD job, control returns to module ADDXS. If the listing was requested on a LIST SID card, the code checks for another request. When all requests have been filled, control returns to the main code.

At the present time there are three libraries from which listings can be made: UK, LLL, and RBL, which is the library which existed on the MANIAC. The libraries do not agree on their definitions of all reaction numbers. Table I shows the reaction numbers and the definitions for the three libraries. The TYPE, which is the number of outcoming neutrons, is given as it exists in the code. Each nuclide in the DATATRAN library is flagged to indicate which library it belongs to: $\mathrm{UK}, \mathrm{flag}=0$; LLL, flag=1; RBL, flag=2. The standard reaction titles in the code are for UK. Before a listing is made, the flag is checked, and the appropriate titles are changed if the nuclide is from the LLL or RBL library. The library being used is identified as part of the heading.

Subroutine PRESJ is called to print the secondary energy block. After the heading is printed, the code counts data items, which are positive, and prints them. Then it counts and prints the markers, which are negative. The sequence of count and print continues until all words in the block have been printed. Control returns to LISTXS.
TABLE I

REACTION DEFINITIONS

\begin{tabular}{|c|c|c|c|c|}
\hline $\begin{array}{l}\text { Reac- } \\
\text { tion } \\
\end{array}$ & Type & UK & $\mathrm{LLL}^{\mathrm{a}}$ & $\mathrm{RBL}^{\mathrm{a}}$ \\
\hline 1 & 1 & Total & & \\
\hline 2 & 1 & Elastic & & \\
\hline 3 & 1 & Nonelastic & $-\infty$ & \\
\hline 4 & 1 & Total $\mathrm{N}, \mathrm{N}^{\prime}$ & & \\
\hline 5 & 1 & $N, N^{\prime} 1$ & & \\
\hline 6 & 1 & $N, N^{1} 2$ & & \\
\hline 7 & 1 & $N, N \cdot 3$ & & \\
\hline 8 & 1 & $N, N^{\prime} 4$ & & \\
\hline 9 & 1 & $N, N^{\prime} 5$ & & \\
\hline 10 & 1 & $N, N^{\prime} 6$ & & \\
\hline 11 & 1 & $N, N ' 7$ & & \\
\hline 12 & 1 & $N, N \cdot 8$ & & \\
\hline 13 & 1 & $N, N+9$ & & \\
\hline 14 & 1 & $N, N^{\prime} 10$ & & \\
\hline 15 & 1 & $N, N^{\prime} C$ & & \\
\hline 16 & 2 & $\mathrm{~N}, 2 \mathrm{~N}$ & & \\
\hline 17 & 3 & $N, 3 N$ & & \\
\hline 18 & 0 & $\mathrm{~N}, \mathrm{~F}$ & & \\
\hline 19 & 0 & $N, F$ & & \\
\hline 20 & 1 & $N, N^{\prime} F$ & & -- \\
\hline 21 & 2 & $N, 2 N F$ & & $\cdots$ \\
\hline 22 & 1 & $\mathrm{~N}, N^{\prime} \mathrm{A}$ & & \\
\hline 23 & 1 & $N, N \cdot 3 A$ & & \\
\hline 24 & 2 & $\mathrm{~N}, 2 \mathrm{NA}$ & & \\
\hline 25 & 3 & $\mathrm{~N}, 3 \mathrm{NA}$ & & \\
\hline 26 & 2 & N, 2NISO & & \\
\hline 27 & 0 & $\begin{array}{l}\text { Absorption } \\
\quad(\text { fission }+n, \gamma)\end{array}$ & & $\mathrm{N}, \mathrm{N} \cdot \mathrm{P}$ \\
\hline 28 & 1 & $N, N^{\prime} P$ & & $N, N^{\prime} G$ ma \\
\hline 29 & 1 & $N, N \cdot 2 A$ & & $N, N^{\prime} D$ \\
\hline 30 & 2 & $\mathrm{~N}, 2 \mathrm{~N} 2 \mathrm{~A}$ & & $\mathrm{~N}, \mathrm{~N}^{\prime} \mathrm{He} 3$ \\
\hline 31 & 1 & --- & $N, N ' 11$ & $-\cdots$ \\
\hline 32 & 1 & -- & $N, N^{\prime} 12$ & $-\cdots$ \\
\hline 33 & 1 & $\cdots$ & $N, N^{\prime} 13$ & -- \\
\hline 34 & 1 & $\cdots$ & $N, N \cdot 14$ & -- \\
\hline 35 & 1 & -- & $N, N^{\prime} 15$ & $\cdots$ \\
\hline 36 & 1 & -- & $N, N^{\prime} 16$ & $\cdots$ \\
\hline 37 & 1 & $\cdots$ & $N, N^{\prime} 17$ & -- \\
\hline 38 & 1 & -- & $N, N \cdot 18$ & -- \\
\hline 39 & 1 & -- & $N, N^{\prime} 19$ & $\cdots$ \\
\hline 40 & 1 & --- & $N, N^{\prime} 20$ & $\cdots$ \\
\hline
\end{tabular}


TABLE I (cont)

Reac-

$$
\text { tion }
$$

Type
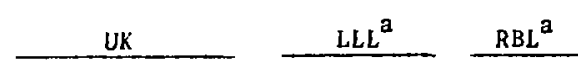

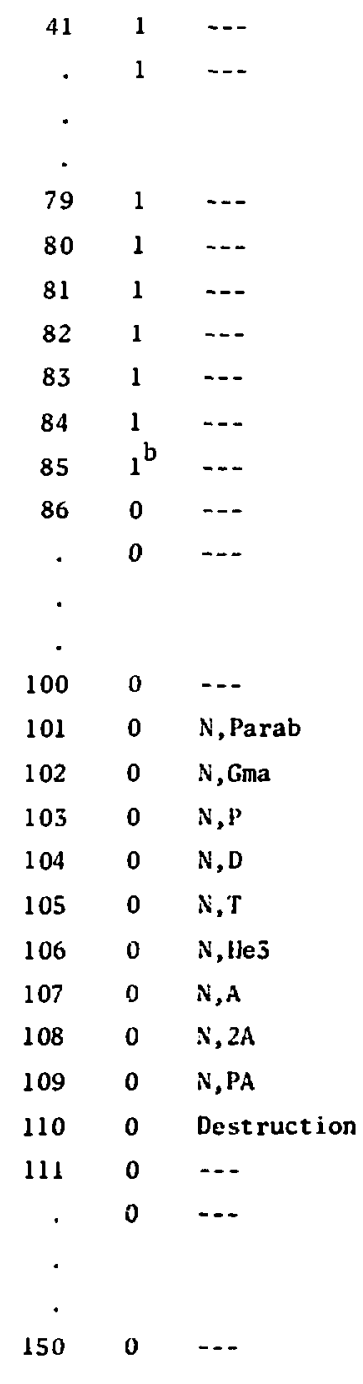

more levels -.-

if needed ...

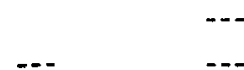

$\mathrm{N}, \mathrm{PN}$

$N, N \cdot D$

$N, N \cdot T$

$N, N^{\prime} \mathrm{He} 3$

$\mathrm{N}, 4 \mathrm{~N}$

$\cdots$

$\ldots$

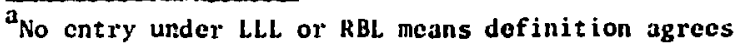
with UK. ... means definition unassigned.

${ }^{b}$ Code changes TYPL to 4 when adding LLLL nuelides having reaction 85 .

Subrout ine pksic prints the sS block. A print line contains the onergy indox, encrgy, and cross sections for up to sovoil reactions. If all cross sections for a given energy are zero, that line is omitted. If tho number of energies for a given nuclide is greater than 2000 , the data for the first
2000 are printed, and the SS block is set up for the remaining energies. This is done by clearing the amount of the SS block that is needed and filling it by strips from the DATATRAN lists that were written on ECS in LISTXS. When the set-up is complete, SS is printed. Control returns to LISTXS.

Subroutine RETREV is similar to the subroutine of iie same name included in module TAPE. The difference is that the RETREV in module LISTXS is concerned only with SID's.

vi. MODULE ADDG

The module ADDG does two jobs: it adds a group set to the library from cards; it retrieves a group set already in the library and lists it.

The following cards are required to add a group set to the library:

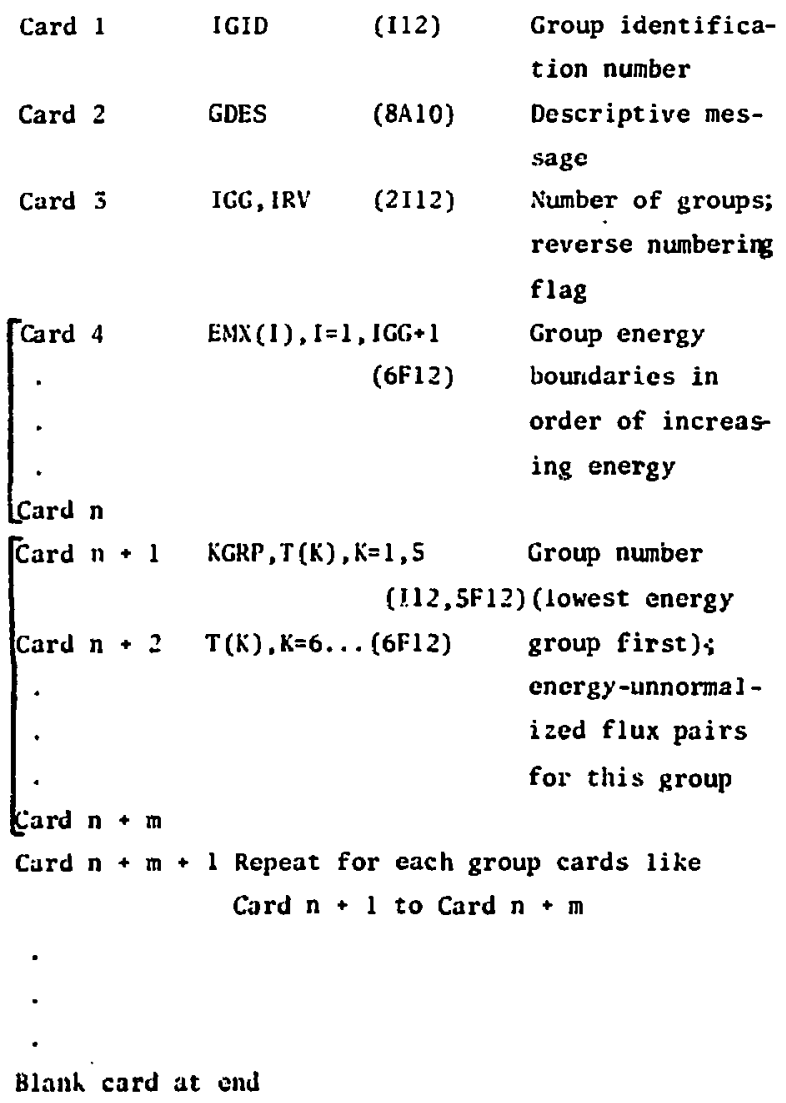

11 cards except Card 2 have o fields of 12 columns each, and all numbers are entered in the rightmost portion of the ficld. Columns 73-80 are not checked for sequencing information.

The code compares the group identification number (ICID) with that requested on the ADD GID card. If they are not the same, the cards for this IGID 
are skipped and the code goes on to the next job. The data cards for groups to be added must be in the same order as the GID's on the ADD GID card(s). Next the code checks whether the IGID to be added is aIready in the library. If so, a message is printed, the data cards are skipped, and the next job is tried.

The energy boundaries are read into the array EMX. They must be in order of increasing energy. The individual groups may be numbered such that the lowest number (1) denotes the lowest energy group or the highest number (IGG) denotes the lowest energy group. If the latter numbering scheme is desired, the reversing flag IRV on input Card 3 must be nonzero.

The main loop reads and processes one group at a time. The first card for each group contains the group nunber (checked for consistency with the reversing flag) followed by energy-flux pairs. Additional pairs are on following cards. The pairs are read into a temporary storage $T$. The energy of the first pair is compared with the energy of the lower boundary of this group, EMX(I). If they are not the same, an error message is printed, and the next job is begun. As each card is read, it is checked by the subrout ine LAST to determine whether it is the last card, to make sure the energies are in increasing order, and to make sure the energies do not exceed the upper boundary for this group. If an error is detected, the job is dropped, and the next one is begun. When all cards for one group have been read in, LAST returns $K T$, the number of items in the $T$ array, and processing begins.

For the special case of a flat flux the only card for the group contains the group number in the first field and -1 . in the second field. The code then sets up the $T$ array as follows:

$T(1)=$ EMX (1) lower energy boundary for this group $T(2)=1.0$

$T(3)=E M X(I+1)$ upper energy boundary for this group $T(4)=1.0$

The number of items in the $T$ array, $K T$, is set to 4 and processing for this group begins.

The flux is normalized and stored in the $\mathrm{PH}$ array. The energies are stored in the EX array. The average energy and average velocity for this group are calculated, and the index word for this group, MG(1), is constructed. The array MG contrins one word for each group within the group set. Euch of these words contains in the leftmost 36 bits and the rightmost 24 bits tho lower and upper indices respectively which point to the parts of the Pll and EK arrays which belong to this group. The upper energy boundary for a group is the same is the lower energy boundary for the next group. The boundary energy appears in both groups because the flux can be discontinuous across the boundary. The DATATRAN array for the input unormalized fluxes for this group is defined now, and reading for the next group begins.

When the energy-flux pairs for all groups have been read in and processed, the DATATRAN 1 ist for this GID is defined and saved:

\begin{tabular}{|c|c|}
\hline IGID & Group identification number \\
\hline GDES & Description from Card 2 \\
\hline IGG & Number of groups \\
\hline $\operatorname{MG}(I), I=1, I G G$ & $\begin{array}{l}\text { In I'th word lower and upper indices } \\
\text { to } P H \text { and EK blocks for I'th group }\end{array}$ \\
\hline $\operatorname{GE}(I), I=1, I G G$ & Average energy for each group \\
\hline KG & $\begin{array}{l}\text { Number of energy-flux pairs for the } \\
\text { group set }\end{array}$ \\
\hline$P H(I), I=1, K G$ & Normalized fluxes \\
\hline$E K(I), I=I, K G$ & Energies \\
\hline $\operatorname{VB}(I), I=1, I G G$ & Average velocity for each group \\
\hline IRV & $\begin{array}{l}\text { Reversing } f \text { lag. If }=0 \text {, lowest energy } \\
\text { group is } 1 \text {; if } \neq 0 \text {, lowest energy group } \\
\text { is IGG }\end{array}$ \\
\hline N.T(I) & $\begin{array}{l}\text { One DATATRAN record of unnormalized } \\
\text { input fluxes for each group }\end{array}$ \\
\hline
\end{tabular}

The directory is updated and returned to the main job along with the directory save flag in the same way as in module ADDXS. If the group set being added is requested on a TAPEl file, it is written to TAPE7 now. Again this procedure is the same as that in module NDDXS.

Next the data is listed. The following quantities are printed for each group: group number as indicated by reversing flag average energy average velocity energy-flux pair number energy normalized flux unnormalized input fIux flux per Mev indices to the $\mathrm{PH}$ and EK arrays 
The mint format is simbir ca that used by M. Asprey In lier teVt.ist code.

If there is a request to list a Glo already in the library, it is retrieved by the subroutine RETkl:x, the Fontkd variablos are defined frow the UATatkdi lists, and the above quwtities are printed. libraries which originsted on the Meviac Jo no: have avilable the average velocity and the uthorallifed input Flux. zeroes aro printed for these unavailablo quantitics. These librartos also do not pass along the reversing flag which indicates the input group numbering scheme. The chosen nusbering is highese group number for lakest enorgy group since this canvention is uscd in many colles.

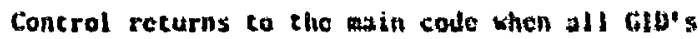
on a t.ist ciu card have been listed or wen all cilos on an Alb GID curd buve been added and listed.

V11. MOWULE TAME

The module TAlle prepares a filc. TAptil on disk or magnetic tape to be used as juput to bths or to be processed by Th-6 for their cross-saction library. All GID's and slo's in the datarkat library can be writecn to the file by using the TAPE ALL card. The file includes all data added to the library during this run. Selectes tith's al.d Sto's ay be writeon by using the TAPL dith and TAll SID cards. CID's appear on TAPl:L in ascending numerical order. They are all included as individual records of one filethe first filc on the tape. The sib's also are written in ascending fumerical ordor. Bach SID is in a separate filc. A double and of flle denotes the end of information on TAPE:

A tape identifier message is required in the input stream. It is read by format 8910 into an array of 100 words. Thus it is posslule to have is message 12 cards long. For shorter messages a blank: card is used to stop the read. The message is written at the beginning of Thit: and is in the same file as the GI0's. If no cito's are requested on TAPEl, the first file contains only the identificr messige.

The array ITAPG is a list ill asconding alusolute value numerical order of the Cild's to be written to TAPEl. If the GIl) was added during this run, it resides on the disk file TAPliz and is read from thers. A negative flag in tho ITAPC list indicutes this fact. Any Gid which is not flagged is retrieved from the DATATHAN library. Each GID roquested is brought into coro and witton out to TAPET. An ond of $5:$ te is writen after all 6IO's in the list have been witten.

The SIb's roquestod on TAPli are in the $l$ ist ITAis. This list also is in ascending absoluto value numerical order with minus flags on the SID's that kere added during this run. The added SID's are on the disk filo TAPEO. For a given SID the control rocord is brought into coro and written out to TAPEL. Thon the cross-soction records are brough In and writeen out ono at at the. Finally the angular distribution records are brought in and writecn out one at a time. thon these are finished, an end of file is witcen on TAPEl, and the nexe SID is processed. When all of the sI0's in the dist have been writeen, another end of file is writcen on Tapt. Control returns to the main cude.

The subrout ine RETkEV construets the recall card and and initates the retrieval of a particular kito (Glo or slo rtquested). It searches the appropriate directory for the kiU and pichs up the recall ident ification inuber assoeiated with it. It clooses the correct format to oncodo the DATATRAN name required for the recall card ieage. When control reatehes the recall card inage, the retricve is Wude. This acans that the Datatew jists for the requested kill are in bCS witing to be defined as FonTkal tariables in sall coro. Control roturns to TAPt.

A detajlod doseription of the TAPEl file is in hef. 1. Briefly the filc looks like this.

Filo 1 Record 1 :

TAD (100) Tapo doscription

US No. of cross sections

File 1 Hecord 2:

IGID Group set IV numbor

GDES (8) Groun description

IGG Number of energic:

MG(1), $1=1, I G G$ in I'th word, Jower and upper indices to Pll and EK values associatod with the I'th group

GE(I),J=1, IGG Vicighted ontrgy for oach group

Ni: Number of energy flux pairs

PII(K), $k=1, k G$ Normalized flux values

tK $(K), K=1, K G$ Energy values in Mov 
File 1 Record 3: (and following)

For each group there is a record like Record 2.

$\cdot$

$\cdot$

End of file

File 2 Record 1:

ISID Cross-section set ID number

ND Number of angular distributions

ITIDS(N), N=1,ND 1D's of angular distributions in order on tape

SDES (8) Cross-section description

IR Number of reactions

ITIDR(I), I=1, IR ID's of angular distribution to be used with $I^{\prime}$ th reaction $(-7$ if no angular distribution)

NES

$E S(J), J=1$, NES

IDR (I), I=1, IR

ME(I), I = I, IR

$\operatorname{lRS}(1), 1=1, \mathrm{IR}$

$Q R(1), 1=1,1 R$

12

MIXT

K2

LLL

Number of energies

Energies

Reaction ID's

In I'th word lower and upper in-

dices to the energy block for the I'th reaction

Number of secondary energy items

for $I^{\prime}$ th reaction

$Q$ values

2 number

Unused indicator for mixture or

element

Total number of words in secondary energy blocks for all reactions

Source (U for UK; 1 for LLL; 2 for RBL)

File 2 Record 2:

$\operatorname{SIG}(\mathrm{J})$

ESJ ( 1 )

Cross sections for one reaction

Secondary energy data for this

reaction if given

File 2 Record 3: (and following)

For each reaction there is a record like Record 2 .

There is a total of IR records, the last of which is numbered $I R+1$.

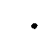

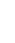

File 2 Record 1R+2:

IT1

SDES (8)

$\operatorname{NED}(<400)$
Angular distribution ID

Cross-section description

Number of energies for which dis-

tributions are given

\begin{tabular}{|c|c|}
\hline$E(I), I=1, N E D$ & Energies \\
\hline ISYS & $\begin{array}{l}\text { System f'ag ( } 1 \text { for data in center } \\
\text { of nlass; } 2 \text { for data in laboratory) }\end{array}$ \\
\hline A & Atomic weight \\
\hline LEGN & Number of Legendre coefficients \\
\hline $\mathrm{KT}(<4000)$ & Number of words in TK block \\
\hline $\mathrm{TK}(K), K=1, K T$ & Mu-T pairs or Legendre coefficients \\
\hline $\mathrm{MD}(1), \mathrm{I}=1, \mathrm{NED}$ & $\begin{array}{l}\text { In I'th word, lower and upper in- } \\
\text { dices to the part of the TX block } \\
\text { which corresponds to the I'th energy }\end{array}$ \\
\hline NINC & $\begin{array}{l}\text { Number of sub-divisions to use in } \\
\text { integrating }\end{array}$ \\
\hline
\end{tabular}

File 2 Record IR+3: (and following)

For each angular distribution there is a record like Record IR+2. There is a total of ND records, the last of which is numbered IR+ND+1

File 2 Record IR+ND+1:

Like Record IR+2

End of File

File 3 (and following)

Like File 2, One file for each SID

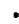

End of File (End of tape)

VIII. USING THE CODE

\section{A. Ovei-a11 Deck Setup}

The deck for running XSMOD is as follows: Control Card Deck

. 8-9

Update Input I Required only if adding to the $7-8-9$ cross-section library. Puts card image from OLDPL=DATA onto COMPILE= TAPE2.

Update Input II XSMOD code 7-8-9

Option Deck Tell XSMOD what jobs to do.

7-8-9

Data Deck Required by certain options. See Section C, Data Setup.

EOJ

.B. Control Card Setup

The following control card deck is used to run a typical job: 
\$JOB (NAME $=$ MH $\emptyset Y T, C L=U, A C=X X X, U A=X x x x x X X X X, T L=2 M$, $\$ 1 \mathrm{SC}=* 156000 \mathrm{~B}$,

$\$ 2 L C=2000000 B, P L=*, M X=66)$

RFL (6000)

ASSIGN MT , NEWT (PLB, LXXXXL00, SHB)

ASSIGN MT, DTLIB (PLB, LXXXXLO0, SHB)

ASSIGN MT, TAPEI (NLB, LXXXXXI.00, SHIB)

ASSIGN MT, DATA (PLB, LXXXXLLO, SHE)

ASSIGN AB, UPDATE2.

CФPYBF (UPDATE2,UPD)

RETURN (UPDATE2)

C $Ф$ PY (DTLIB, TAPE30)

RELTAPE (DTLIB)

REWIND (TAPE30)

CФPYBF (NEWT, ØLDPL)

COPYBF (NEWT, NØVAF)

CØPYBF (NEWT, CLASP)

CØPYBF (NEWT, DTPATH)

CØPYBF (NEWT, RDTF ILE)

C $Ф$ PYBF (NEWT, SCAN)

CØPYBF (NEWT , RECALL)

CØPYBF (NEWT, SøRT)

COPYBF (NEWT, INITIÁL)

CøPYBF (NEWT, DTCATLG)

.ELTAPE (NEWT)

lays.
QNSWCIII.

REWIND (RDTF ILE)

REWIND(LCO)

COPYBF (RDTFILE, LGO)

Required for

DATATRAN run.

RETURN (RDTFILE)

Contains OLDPL

of XSMOD as 1st

BKSP (LGO)

REWIND (UPD)

RFL (60600)

DATATRAK over-

$U P D(D, P=D A T A, C=T A P E 2, L=A 124)$

RELTAPE (DATA)

REWIND (UPD)

RFL (60000)

UPD $(P, L=A 124)$

Code XSKODD

RETURN (OLDPL)

RETURN (UPD)

COPYSBF (COMPILE)

RFL (156000)

SCAN (CONPILE)

Pra-compiler:

makes DATATRAN

statements ac-

ceptable to

FORTRAN compiler.

RETURN (SCAN)

RETURN (COMPILE)

RUN (S, I=DTAPE3)

RETURN (DTAPE3)

LФAD (LGO)

NøC $\varnothing$.

ONSWCH4 .

NOVAF.

Starts execution.

REWIND (TAPE30)

COPY (TAPE30,NEWLIB)

Use only if tape

EXIT.

NEWLIB assigned.
OLDPL for XSMOO

DATATRAN system

needed to run a DT job.
REWIND (TAPE30)

COPY (TAPE3O, NEWL IB

7-8-9

C. Data Setup

Certain options require additional information from

the input stream. Options and their requirements

are shown below. The required data cards are de-

scribed in detail in the modules which read them:

ADD SID

Card 1: SID No., Source, Ctind, Nin

Card 2: 80 column descriptive message 
Cards 1 and 2 are required for oach SID punched on the ADD SID card. The last Card 2 aust be followed by $7-8-9$.

ADD GID

Card 1: JGIV

Card 2: GDES

Cend 3: IGG, IRV

Card 4 to Card $n$ : sroup encrgy boundaries

Card $(n+1)$ to card $(n+m)$ : Group number and energyflux pairs

\section{BLank card}

\section{$7-8-9$}

Cards 1 through Blank are required for each GID punched on the ADD GID card. The last set must bu followed by a 7-8-9.

TAPE ALL, TAPE SID, TAPE GIU

Card 1 to Card ,1: Tape identifier message. n must be $<12$.

Blank card if $n<12$

EOJ

No data cards are required for the following options: DELETE SID, DELETE GID

LIST SID, LIST GID

CONTENTS

EVXS

LAST

In general options are processed in the order in which they appear on the option cards, and the required data must appear in the same order. The only exceptions are the tape options, TAPE ALL, TAPE SID, and TAPE GID. TAPE is always processed last and requires only one tape identifier message since only one tape is written. The tape identifier cards must be last in the data deck regardless of where the

TAPE card appears in the option deck.

Example

DELETE SID $\quad 551 \quad 554$

ADD GID $\quad 16$

TAPE GID

$\begin{array}{rr}35 & 16 \\ 501 & 520\end{array}$

Option deck
Data for ADD GID 16 (soveral cards)

$7-8-9$

Data for ADD 510 S01 (2 cards)

Data for ADD SID 520 (2 cards)

Data for ADD SID 536 (2 cards)

Data deck

7-8-9

Data for TAPE GID, TAPE SID

ECJ

D. Assigning the Library

The Jibrary which che DATATRAN system works on is called TAPE30. It can be read or written on at any time. To make sure that the library on : he magnetic tape is not ruined if the job fails during execution, the library on tape, DTLIB, should be copied to a diskfile, TAPE30, and released. If TAPE30 is modified during the job, TAPE30 must be copied to a blank magnetic tape, NEWLIB, after job execution is finished. To gain access to the Library on TAPE30, the code recalls the directory to that library.

Since a new directory and recall card are made every time the library is modified, the directory recall card and appropriate comnent cards are entered into the code by means of an UPDATE *IDENT in every run. The directory recall number is printed at the end of every job. The directory recall card looks like this: Col. 7 $\begin{array}{lll}4 & 5 & 7 \\ 4 & 8 & 1\end{array}$ RECALL D.DIRECT ERASE IN-1-DAY 1533IVRD RMHXI 60 The recall number ends in column 71 .

If the user wishes to create a new Iibrary, he must assign as his DTLIB a tape which contains a null directory. The null directory is recalled in the same way as any other directory. Its recall number is 3 . The code checks for an empty directory and re-routes its flow accordingly.

E. Use of IMAGE

The first block on every DATATRAN library tape is the module IMAGE, and XSMOD recalls it at the beginning of every job. It is useful for printing out DATATRAN lists and is called by the following sequence of statements:

N. LIST =name $(s)$ of list $(s)$

KALL IMAGE

IMAGE must be called only from a main program in a module or the main code. It may not be called within a subroutine.

F. Procedure for LLL Tapes

The following procedure has been used successfully to enter data from LLL tapes into the library with 
XSAOD:

(1) Determine the data structure on the LLL tape.

Assign the LLL tape PUS. Buffer in three records, get the length, print in octal. This can be done with Hoyt's DMPLLL. 11

(2) Piepare an UPDATE OLDPL of the raw data.

After determining the data structure from an examination of the output from (1), buffer in a record at a time and write out card images using $8 \mathrm{AlO}$ to a file TAPE2. Hoyt's LLLTAPE, ${ }^{12}$ possibly with some variation because of differences in record structure, will do this. Use TAPE2 as input to UPDATE.

(3) Prepare input for XSMCD.

Run McGirt's LRLUK ${ }^{7}$ with input from the UPDATE OLDPL made in (2). LRLUK puts all reactions for one nuclide on a common energy mesh, throws out the second representation of the same angular distribution (LLL gives both Mu-T pair and Legendre form), and ifgnores data for General Classification Numbers above 12. The output is card images on TAPE3. For convenience TAPE3 is used as input to make an UPDATE OLDPL. It is then possible to pick off only the nuclides the user wants to enter into the library without reading the entire tape.

(4) Run XSMOD to enter nuclides into the 1 ibrary. Use UPDATE to put nuclides to be entered into the library onto COMPILE=TAPE2.

\section{G. Linking with EVXS}

It is possible to link directly with EVXS after running XSMOD. The user may wish to do this if he needs to run with EVXS a group or cross-section set not previously in the library. The procedure is as follows:

(1) Request XSMOD to make the file TAPE1 containing all GID's and SID's needed by EVXS. TAPEI may be a diskfile. Request EVXS processing by using the keyword EVXS in the option deck.

(2) Alter EVXs:

Insert before program card: OVERLAY (EVXS,0,0). Change program card to elininate file name MADSK. Use file name TAPEl.

(3) Compile EVXS with the above changes, and make the absolute overlay file by using

RUN (S)

$\operatorname{LOAD}($ LGO)

NOCO.
(4) Run XSMOD. It will call EVXS when it is finished, Data in the input stream required by EVXS should be preceded by a 7-8-9 card to separate it from data required by XSMD. EVXS finishes normally. There is no return to XSMOD.

\section{REFERENCES}

1. M. W. Asprey, R. B. Lazarus, and R. E. Seamon, "EVXS: A Code to Generate Multigroup Cross Sections from the Los Alamos Master Data File," Los Alamos Scientific Laboratory report LA-4855 (in preparation).

2. R. B. Lazarus, Los Alamos Scientific Laboratory, LIB66, undocumented code for MANIAC computer, 1968 .

3. H. J. Kopp, J. D. Morris, and W. E. Schilling, "DATATRAN Modular Programming System for Digital Computers," KAPL-M-6997, Knolls Atomic Power Laboratory, Schenectady, New York (July 1968).

4. Frank McGirt, "LAMPS, Los Alamos Modular Programming System User's Manual," Los Alamos Scientific Laboratory report LA-4371 (November 1970)

5. Martha Hoyt, Los Alamos Scientific Laboratory, XSDTLIB, undocumented code for CDC 6600 computer, 1970.

6. W. E. Schilling, "DATATRan Note " 6," Knolls Atomic Power Laboratory, Schenectady, New York, (February 24, 1969). Schilling's module RECALL was re-named RECLIB at LASL to avoid a conflict in our version of the DATATRAN system.

7. Frank MeGirt, Los Alamos Scientific Laboratory, LRLUK, undocumented code for CDC 6600 computer, 1970.

8. K. Parker, "The Format and Conventions of the U. K.A.E.A. Nuclear Data Library as of June 1965," Atomic Weapons Research Establishment draft, Aldermaston, England (June 1965).

9. R. I. Howerton, et al., "An Integrated System for Production of Neutronics and Photonics Calculational Constants," volume 4, Lawrence Radiation Laboratory report UCRL-50400 Vol. 4 (April 15, 1971).

10. M. W. Asprey, Los Alamos Scientific Laboratory, EVLIST, undocumented code for CDC 6600 computer, 1969.

11. Martha Hoyt, Los Alamos Scientific Laboratory, DMPLLL, undocumented code for CDC 6600 computer, February 1972.

12. Martha Hoyt, Los Alamos Scientific Laboratory, LLLTAPE, undocumented code fos CDC 6600 computer, February 1972. 
APPENDIX A

FLOW DIAGRAMS 

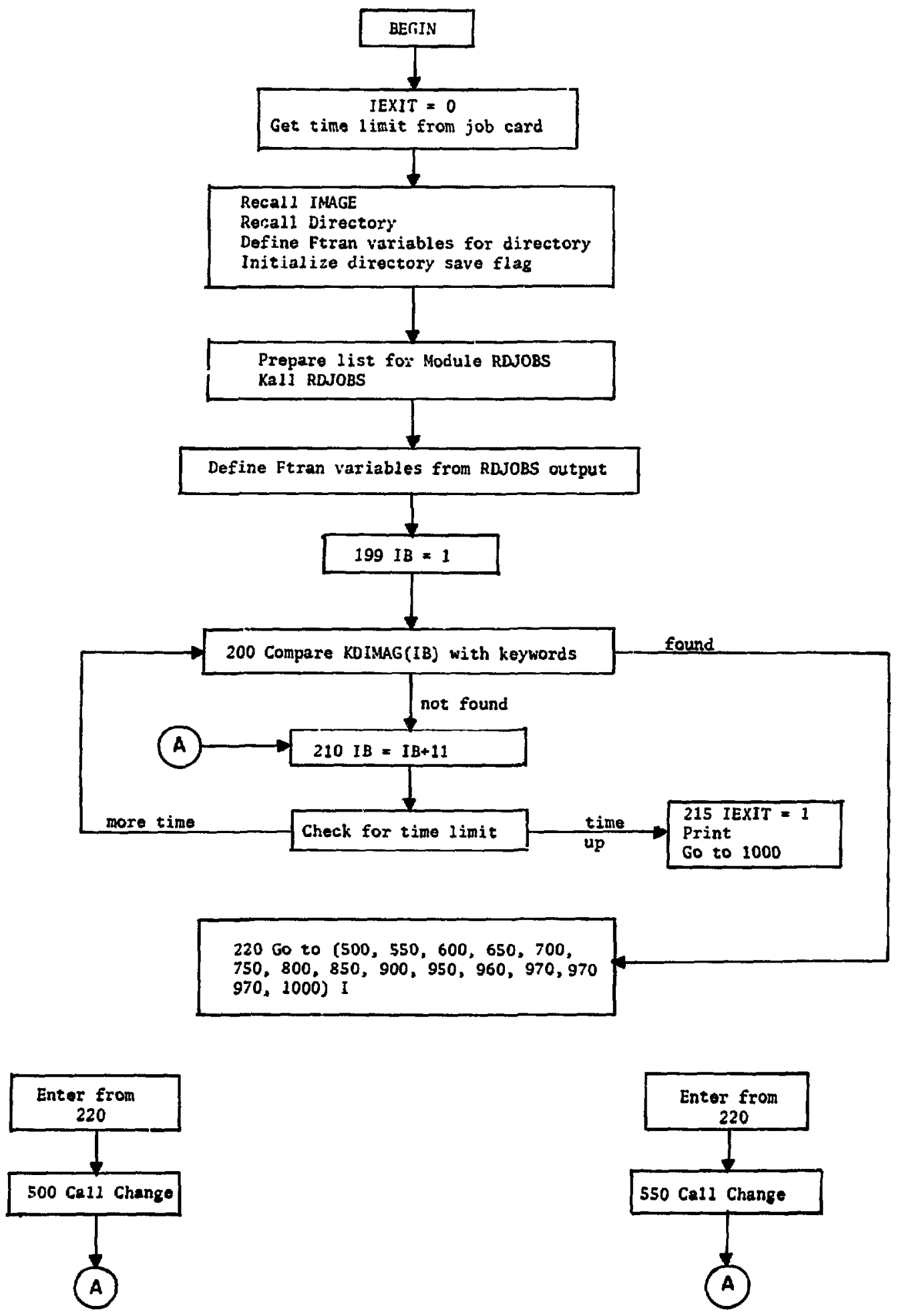

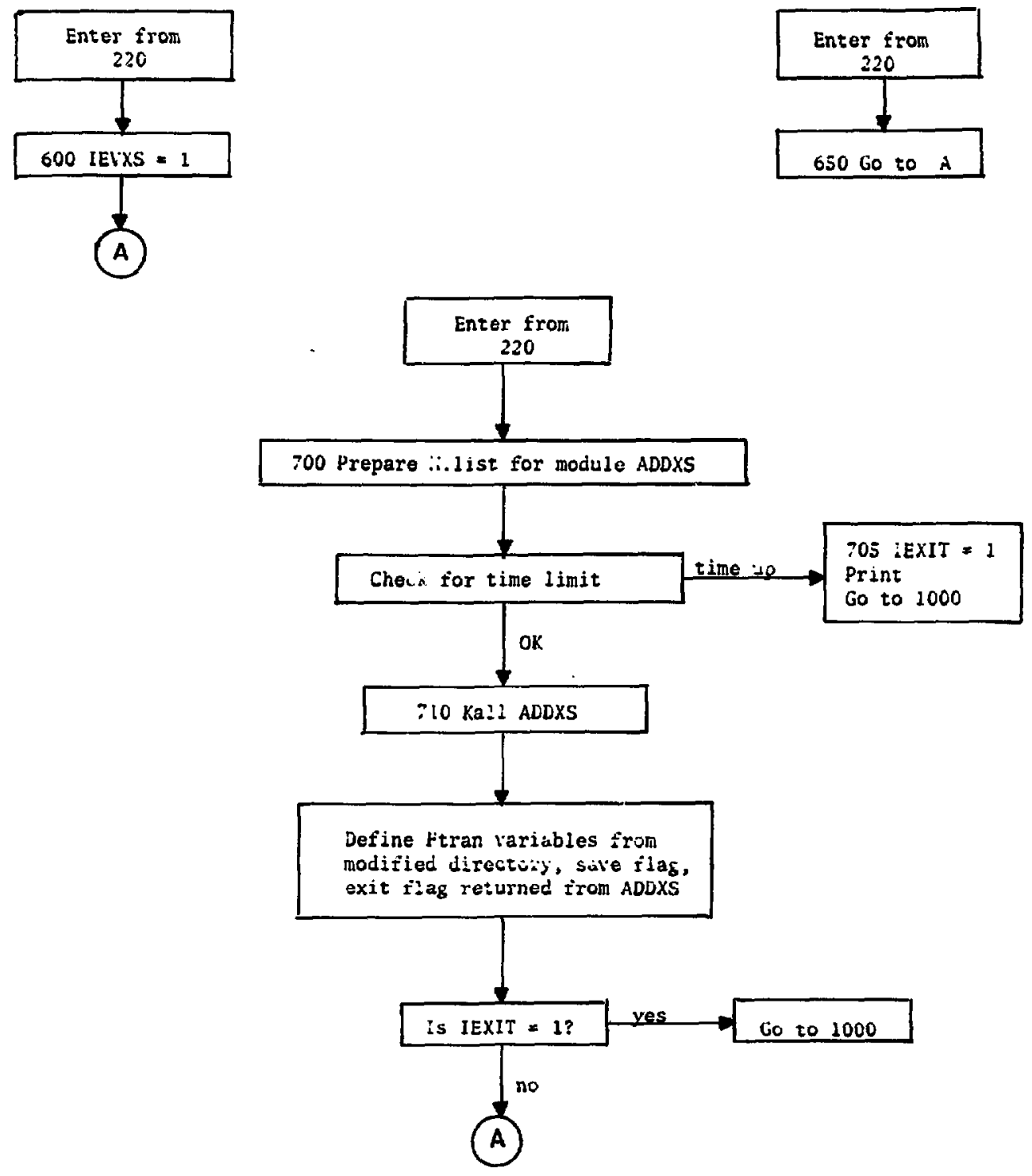

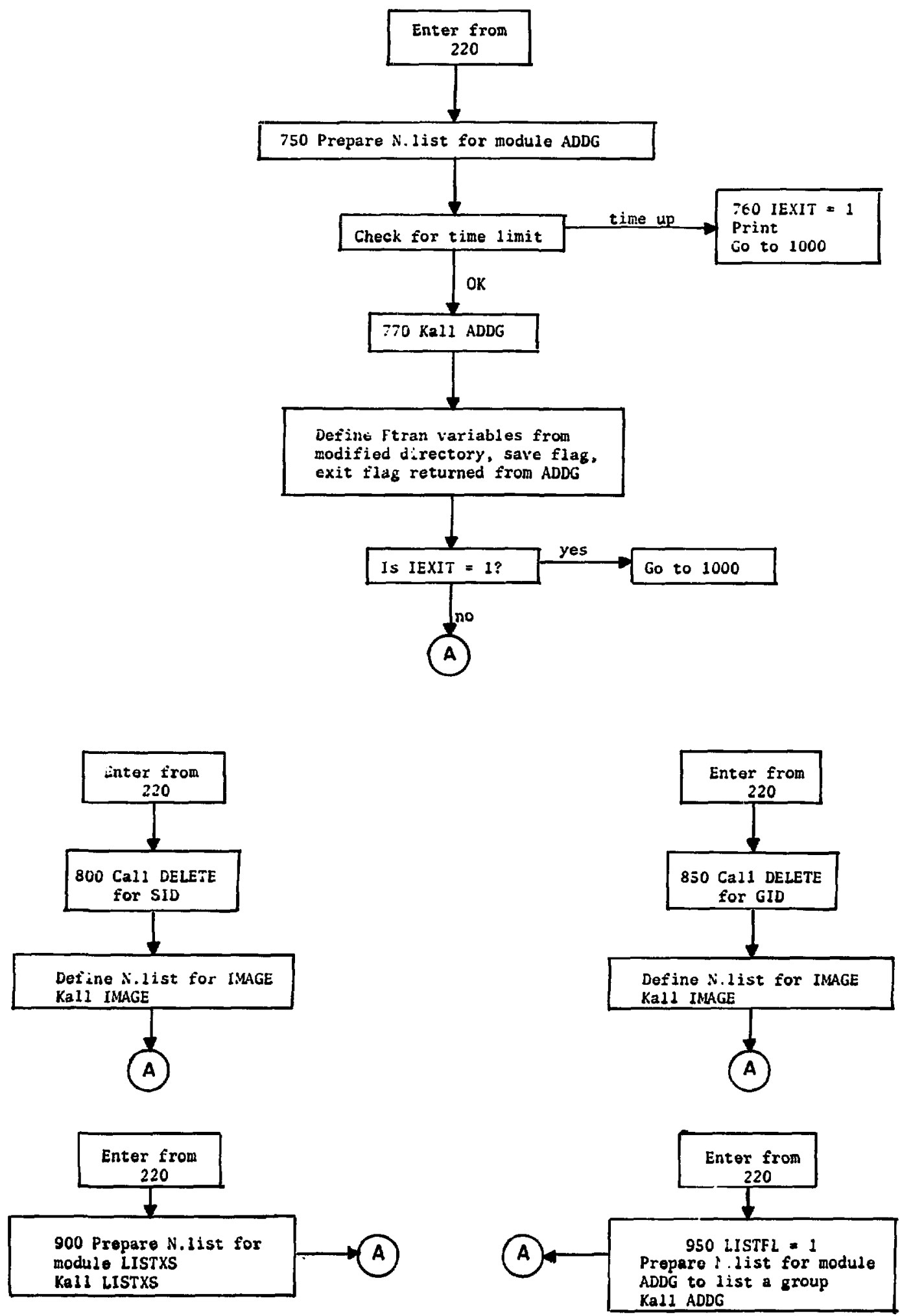

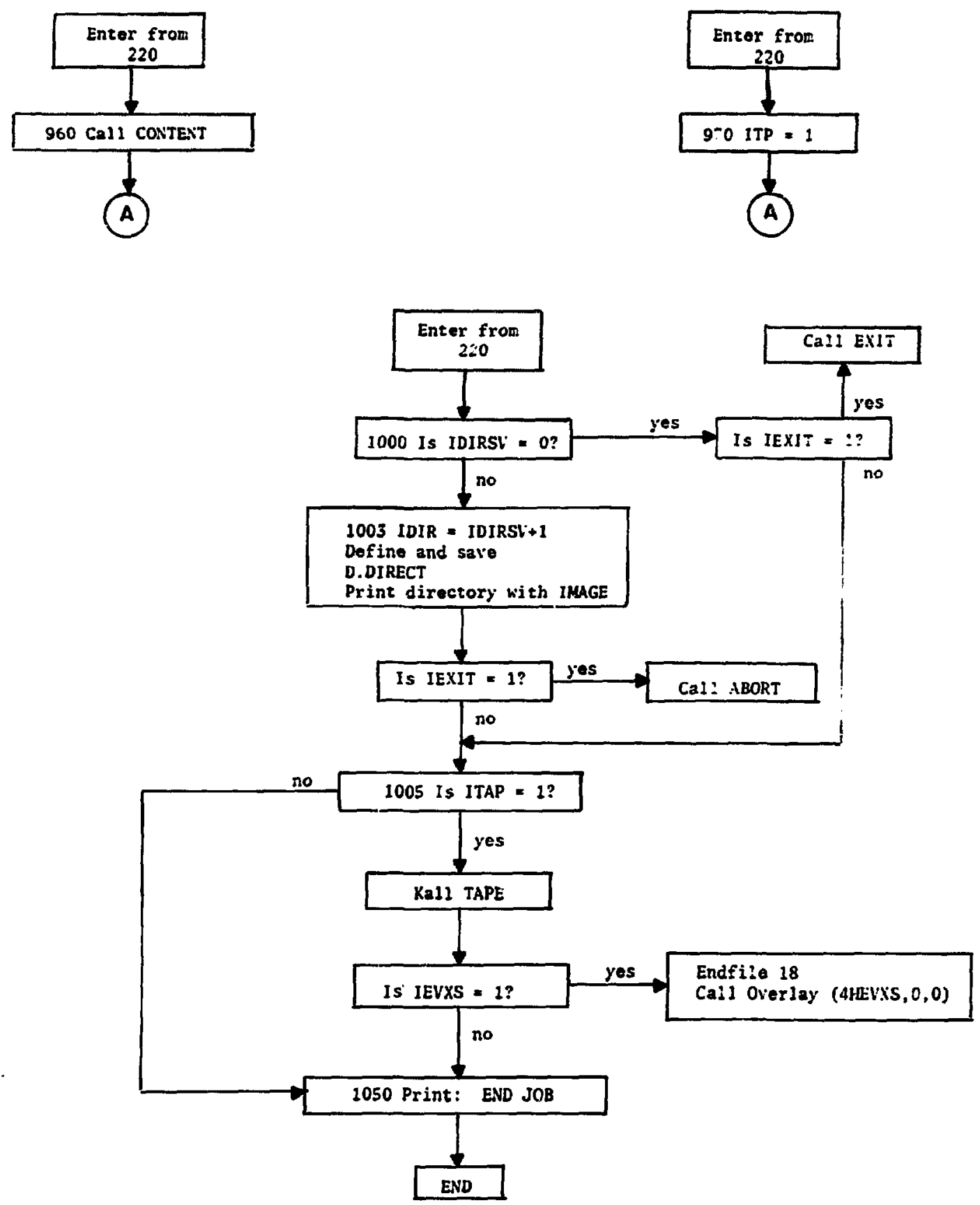


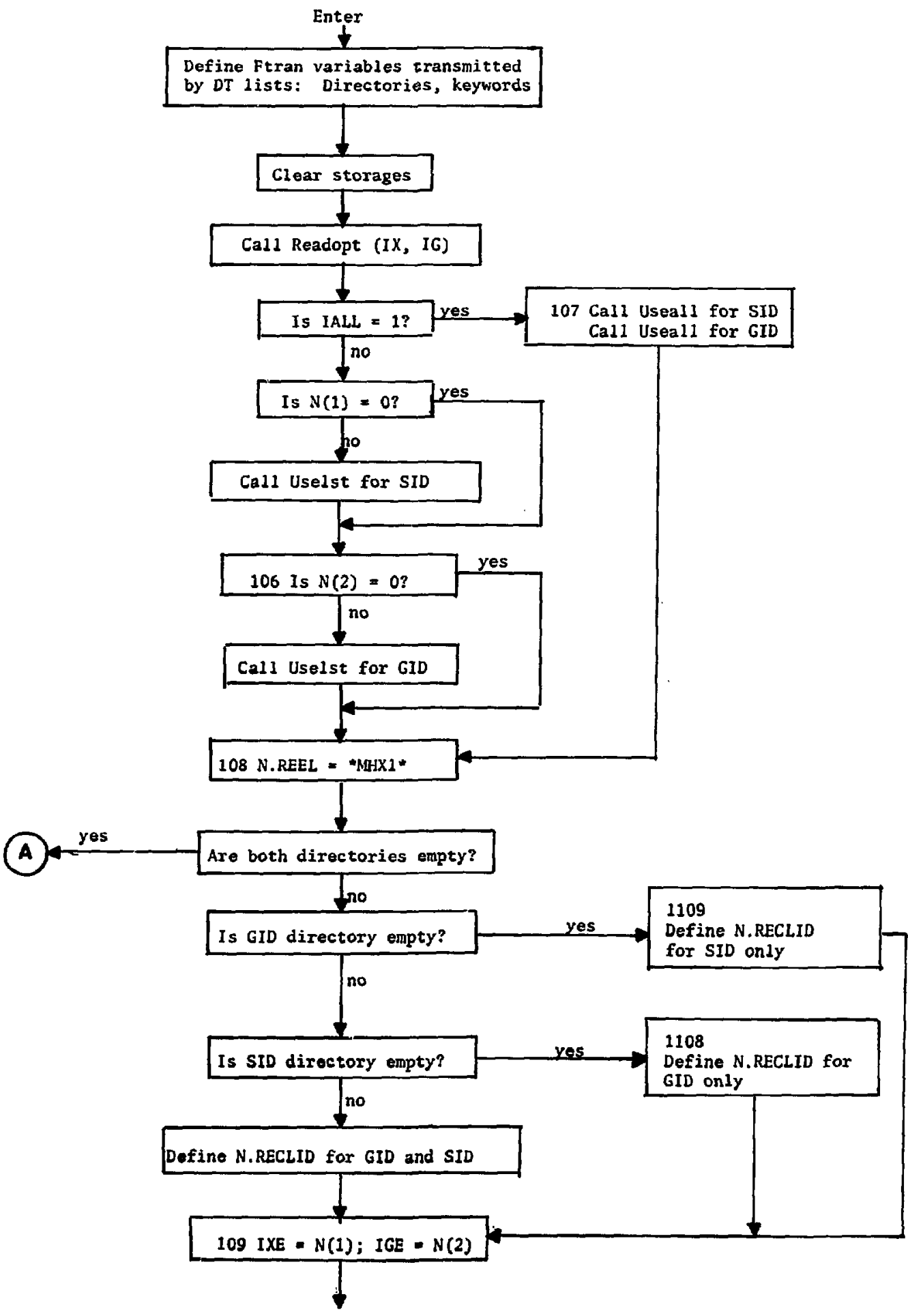




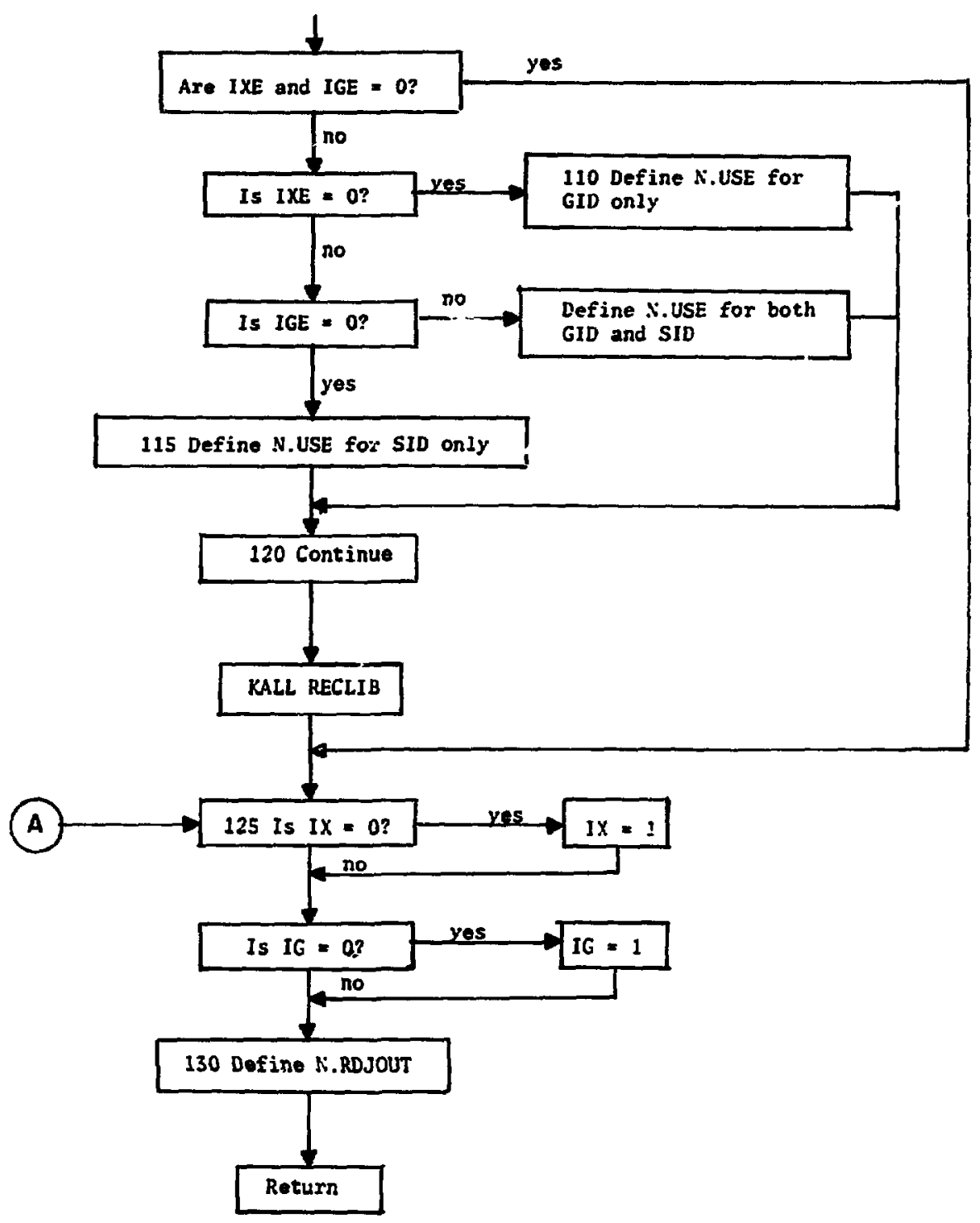



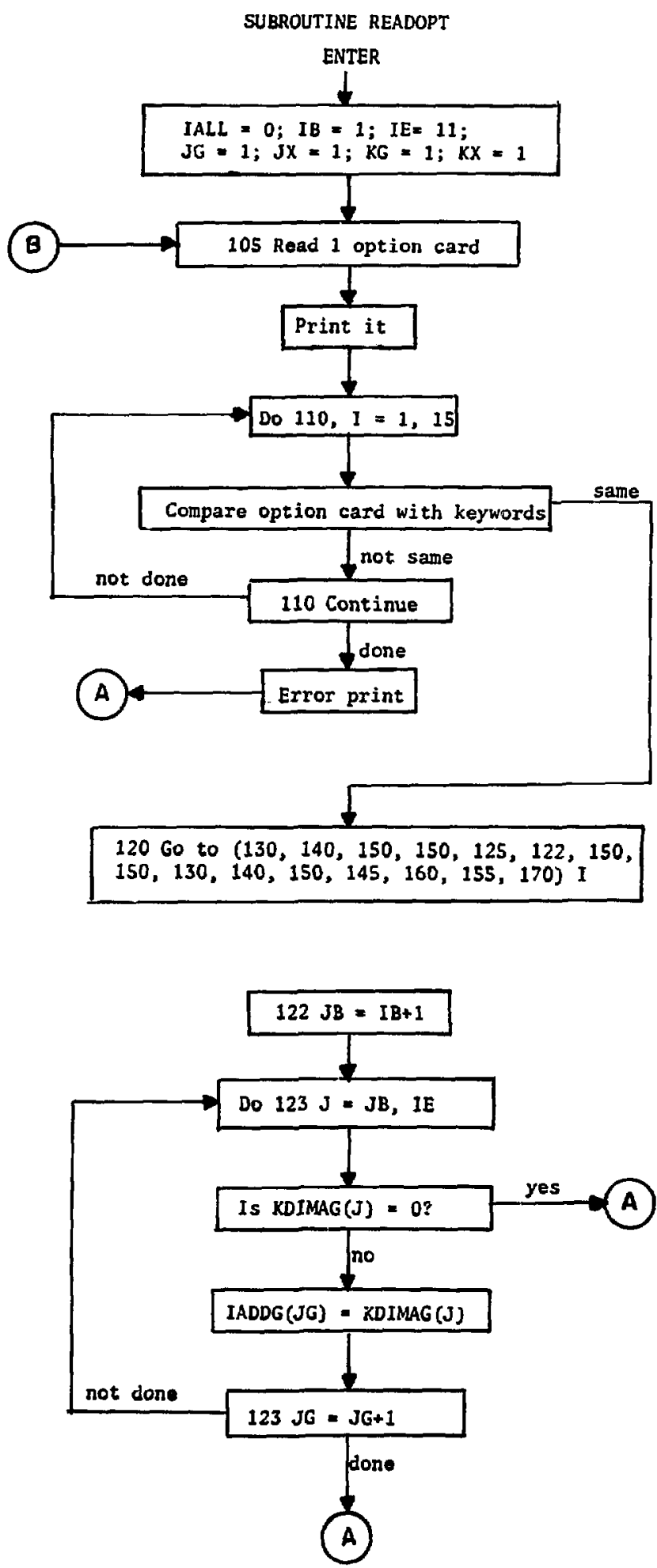

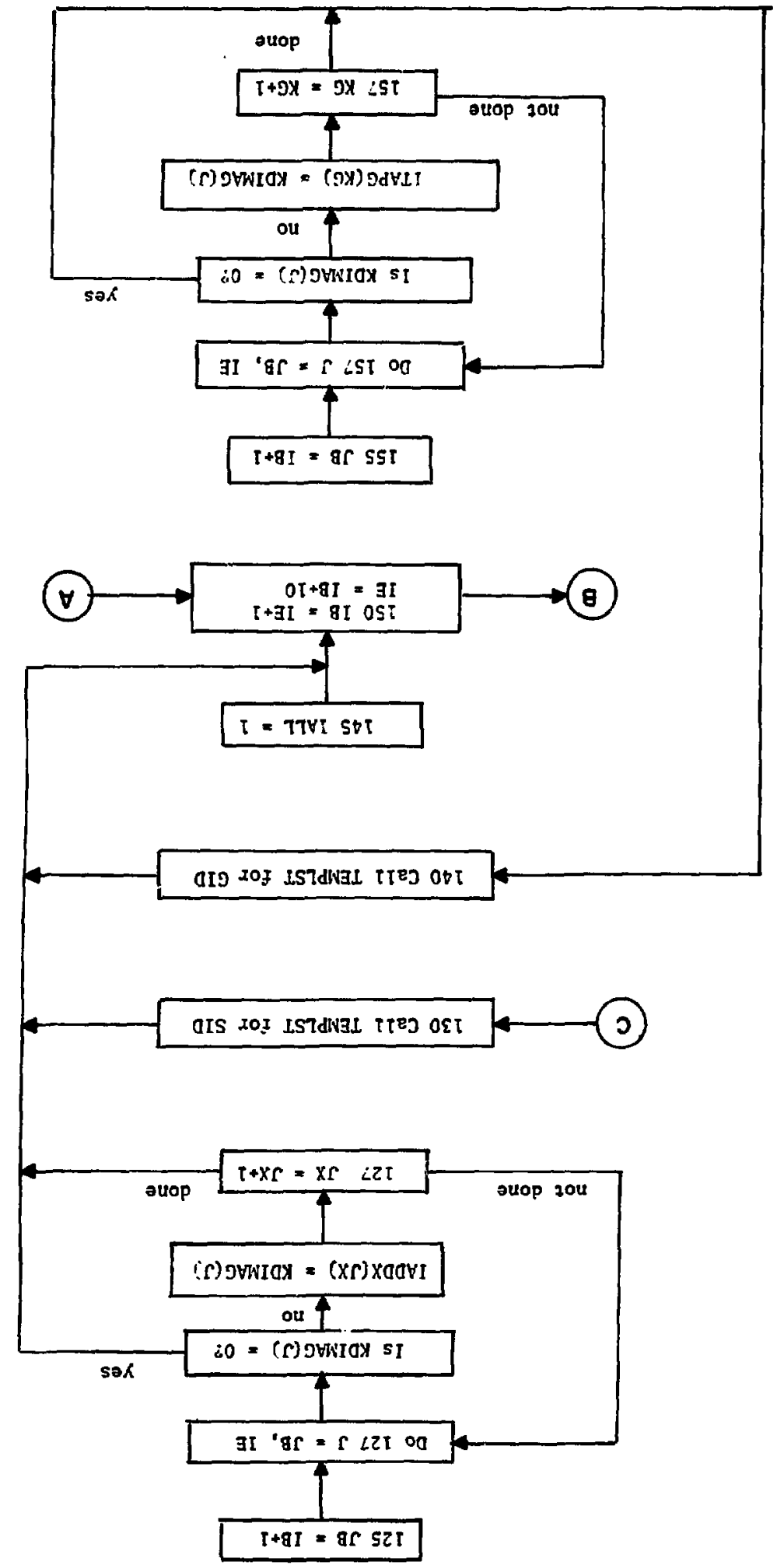

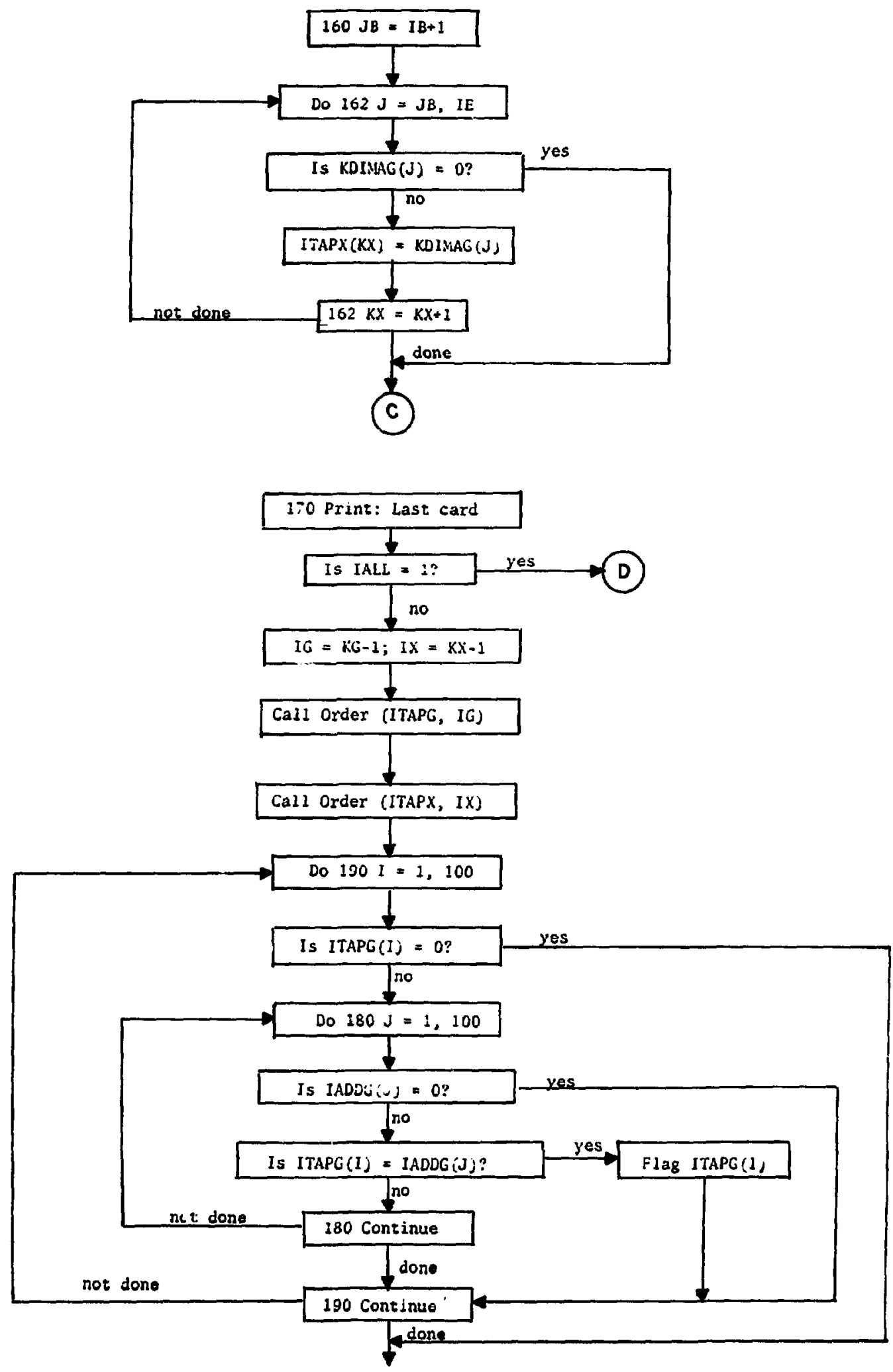

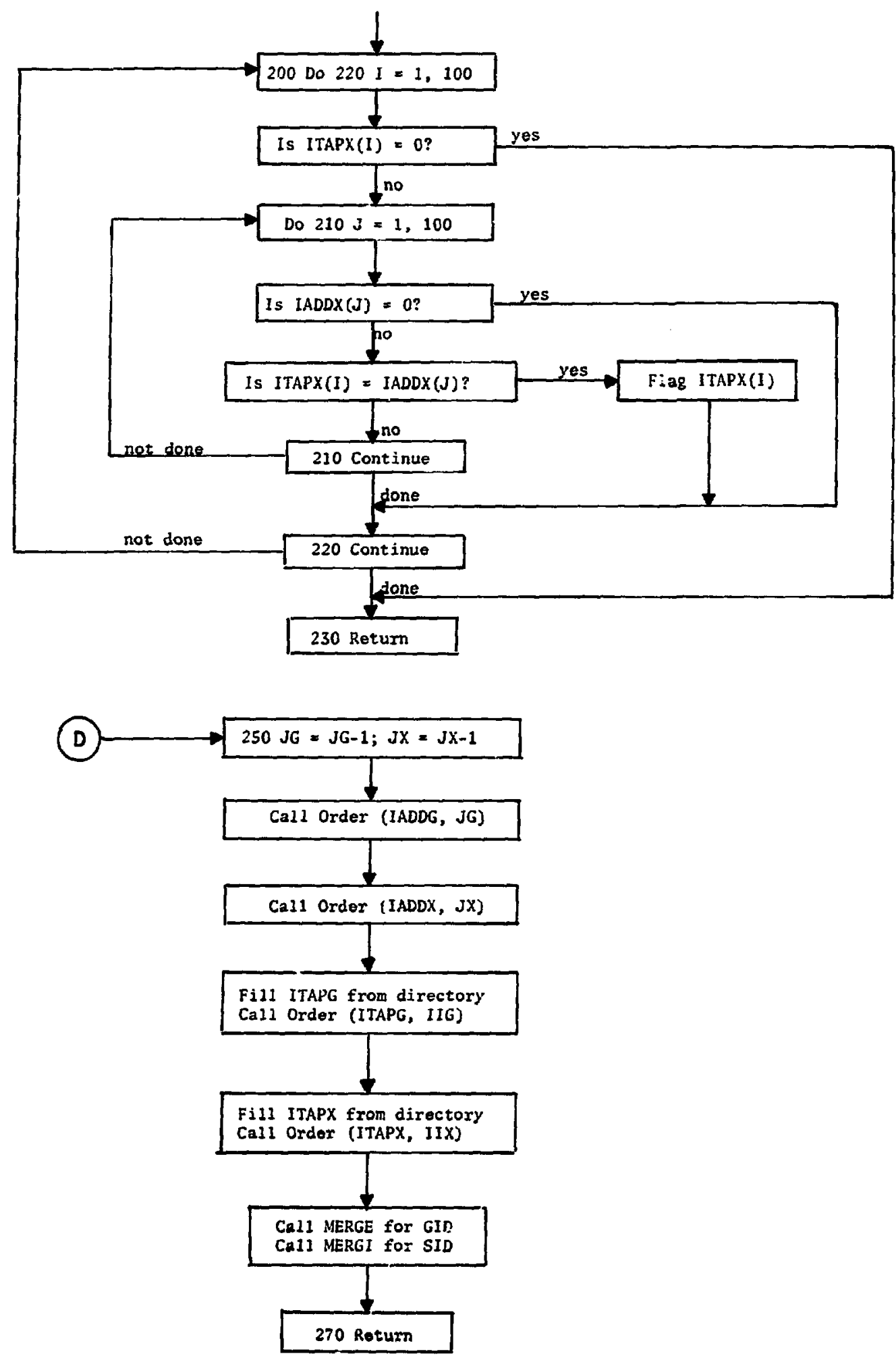
SUBROUTINE TEMPLST

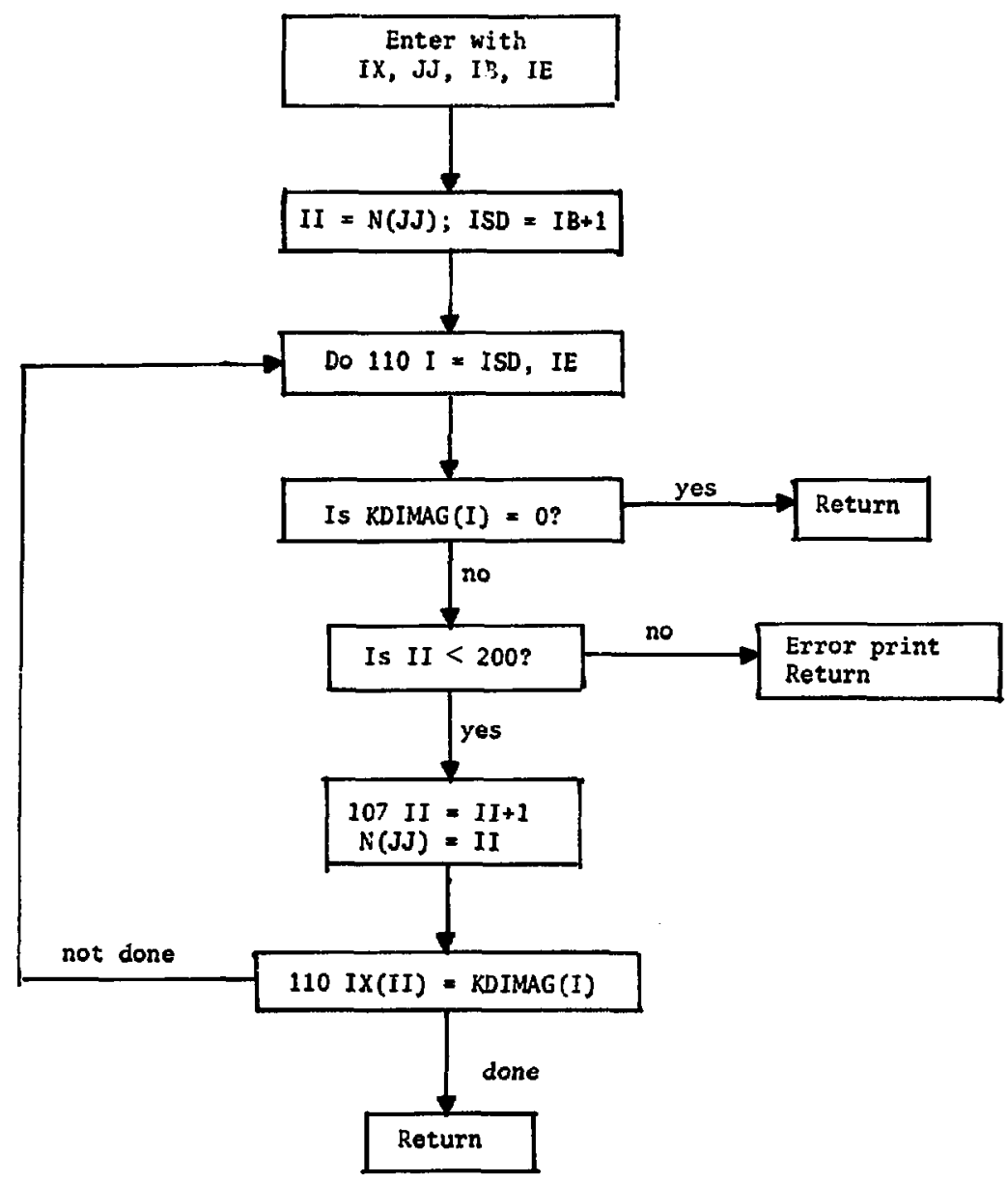




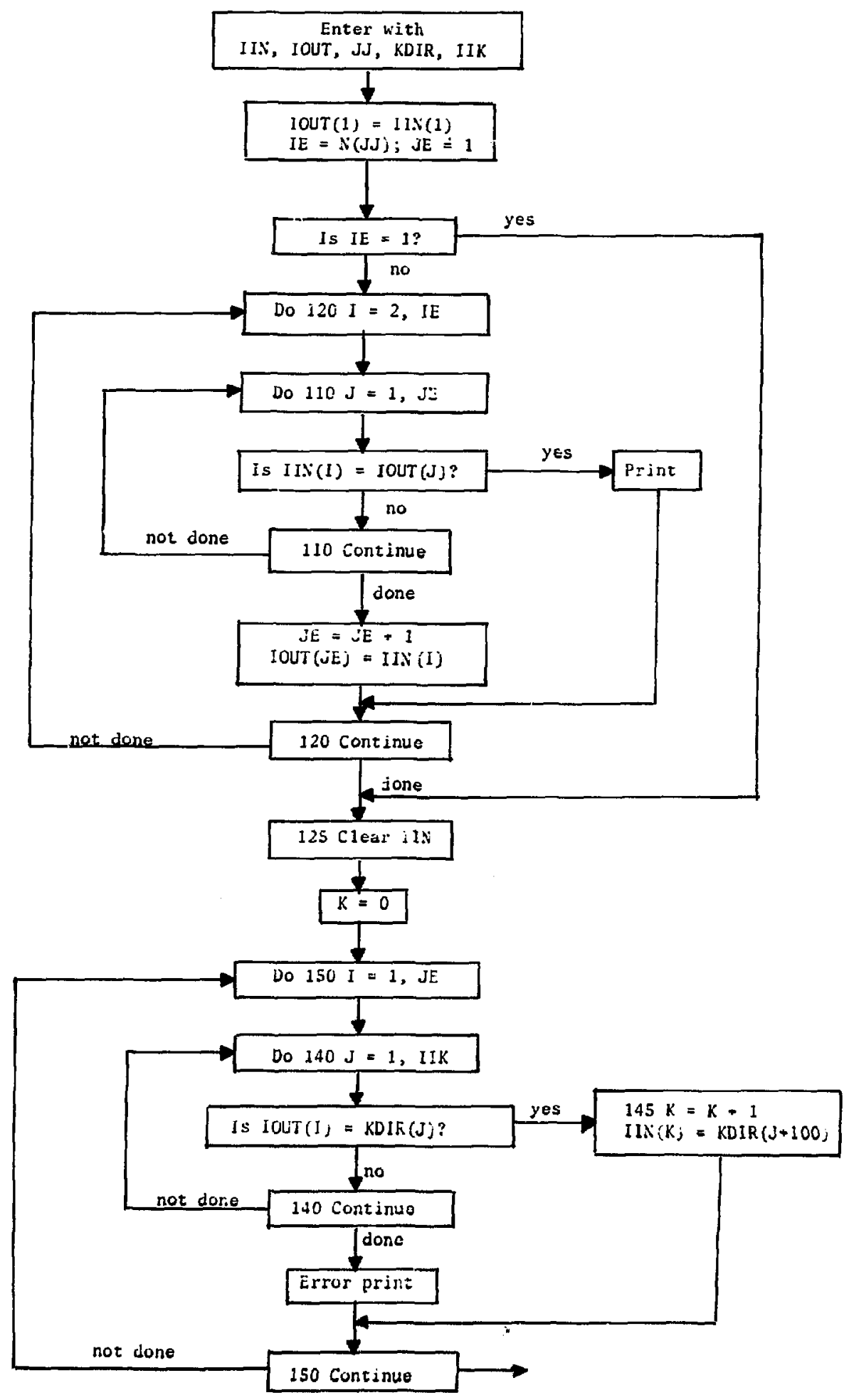




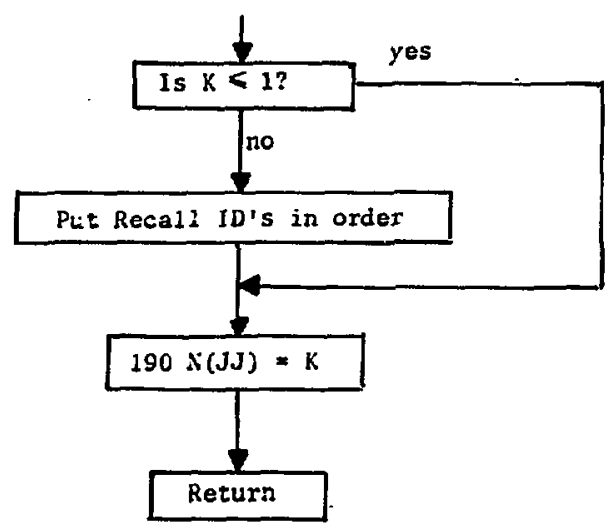

ENTRY USEALL

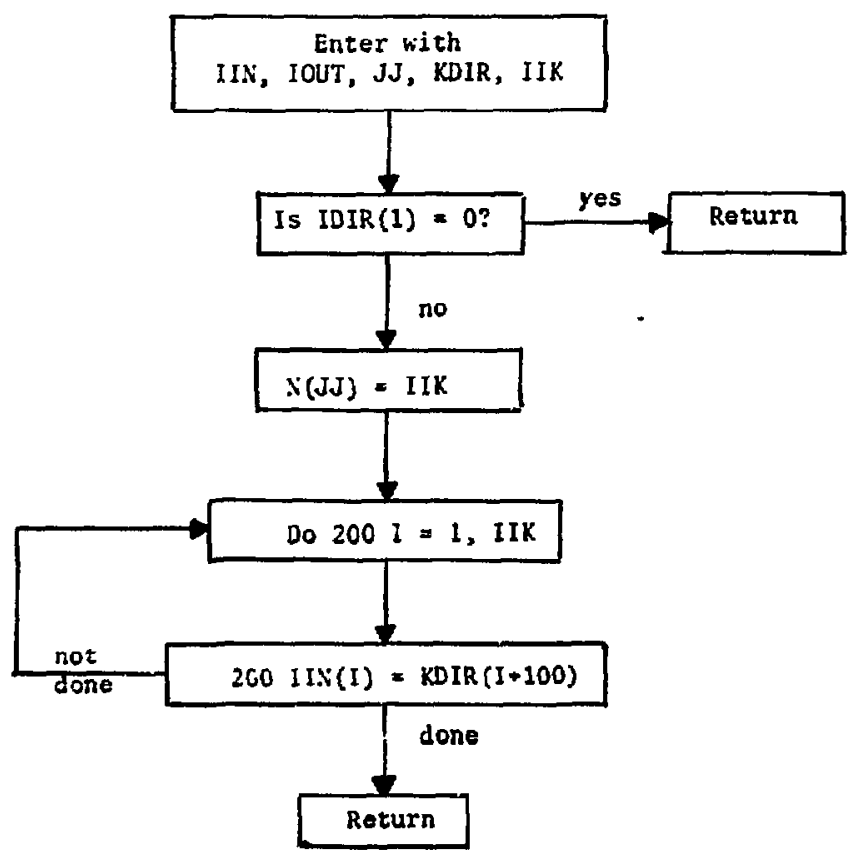


SUBROUTINE MERGE

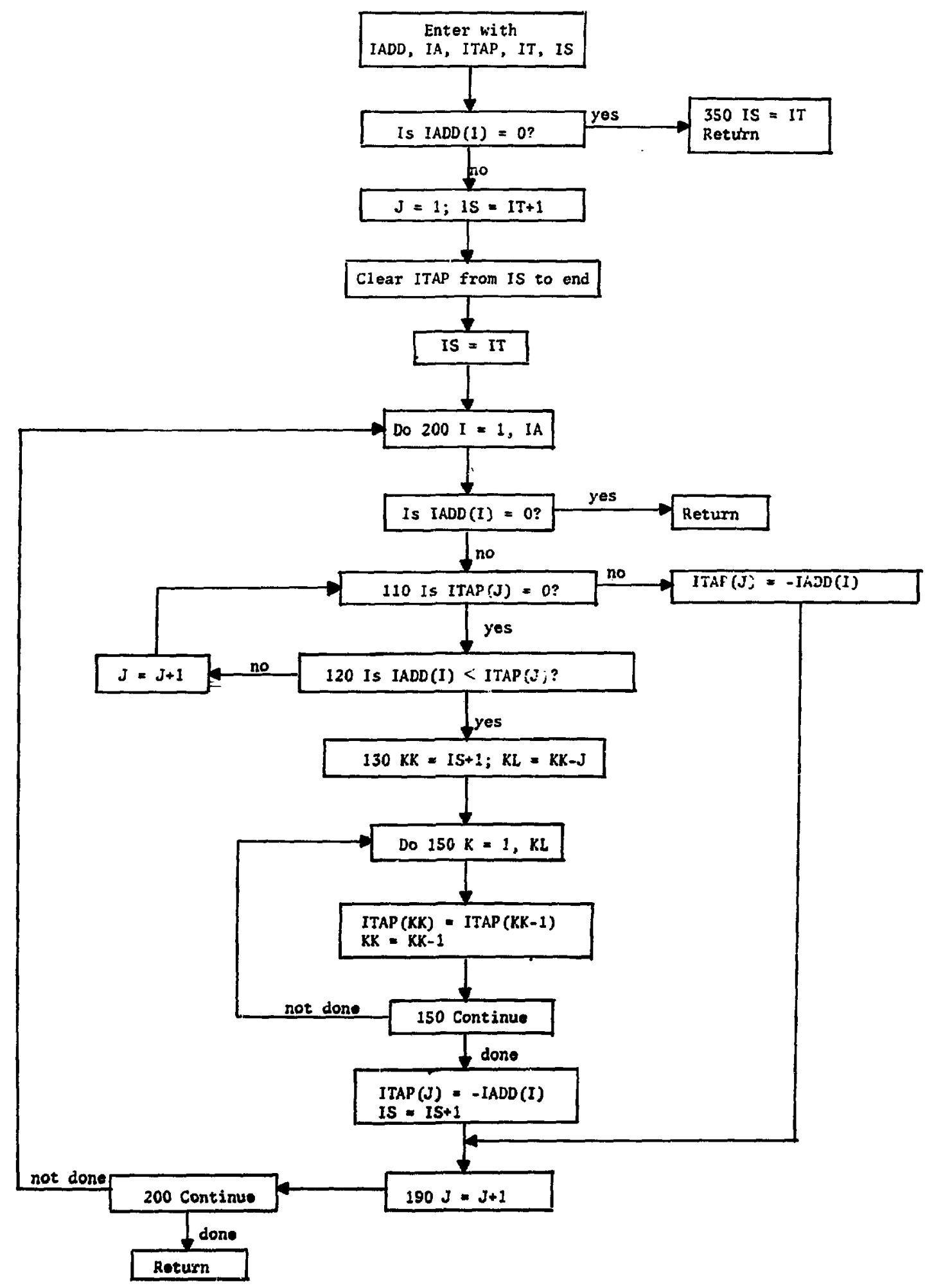




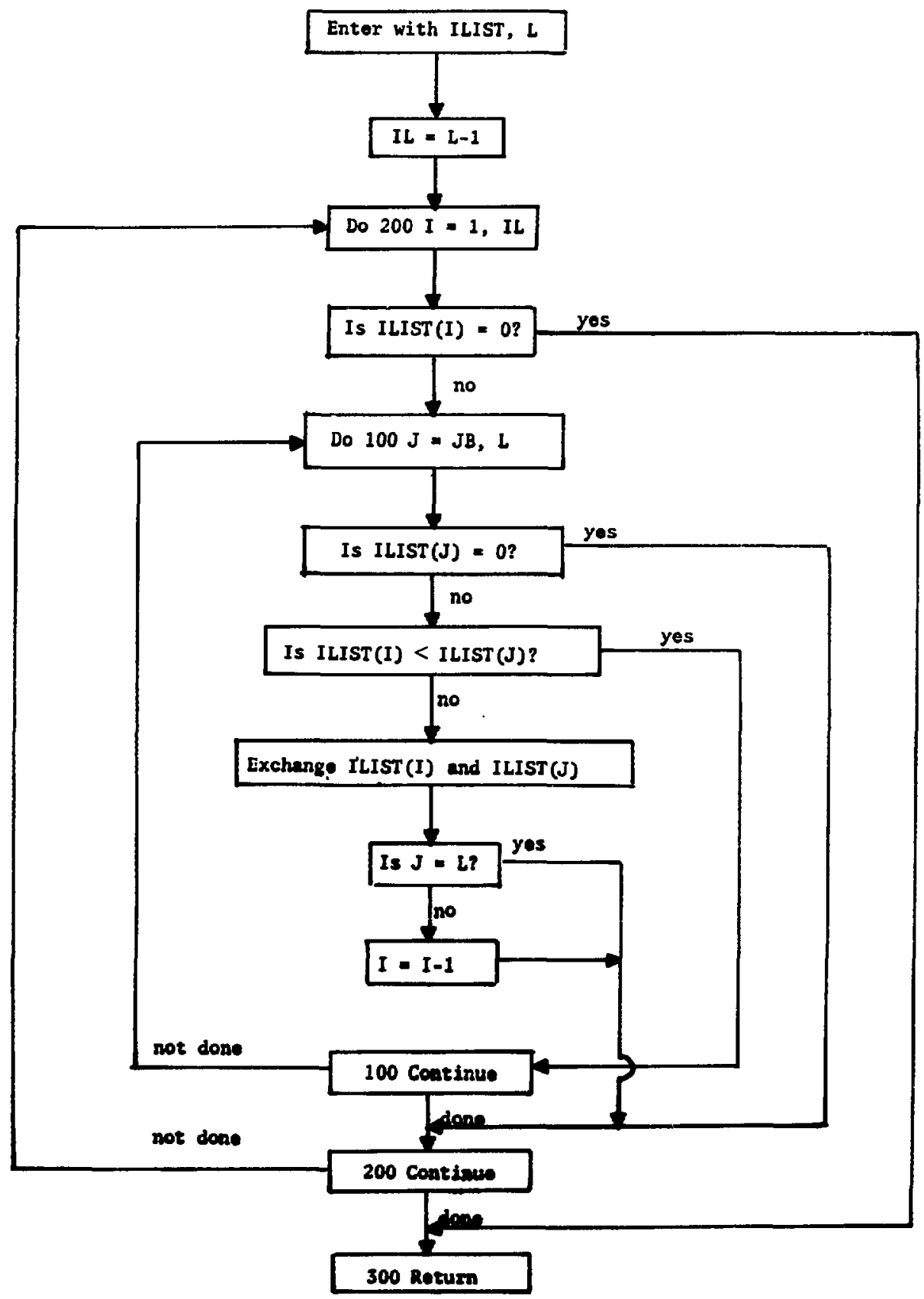




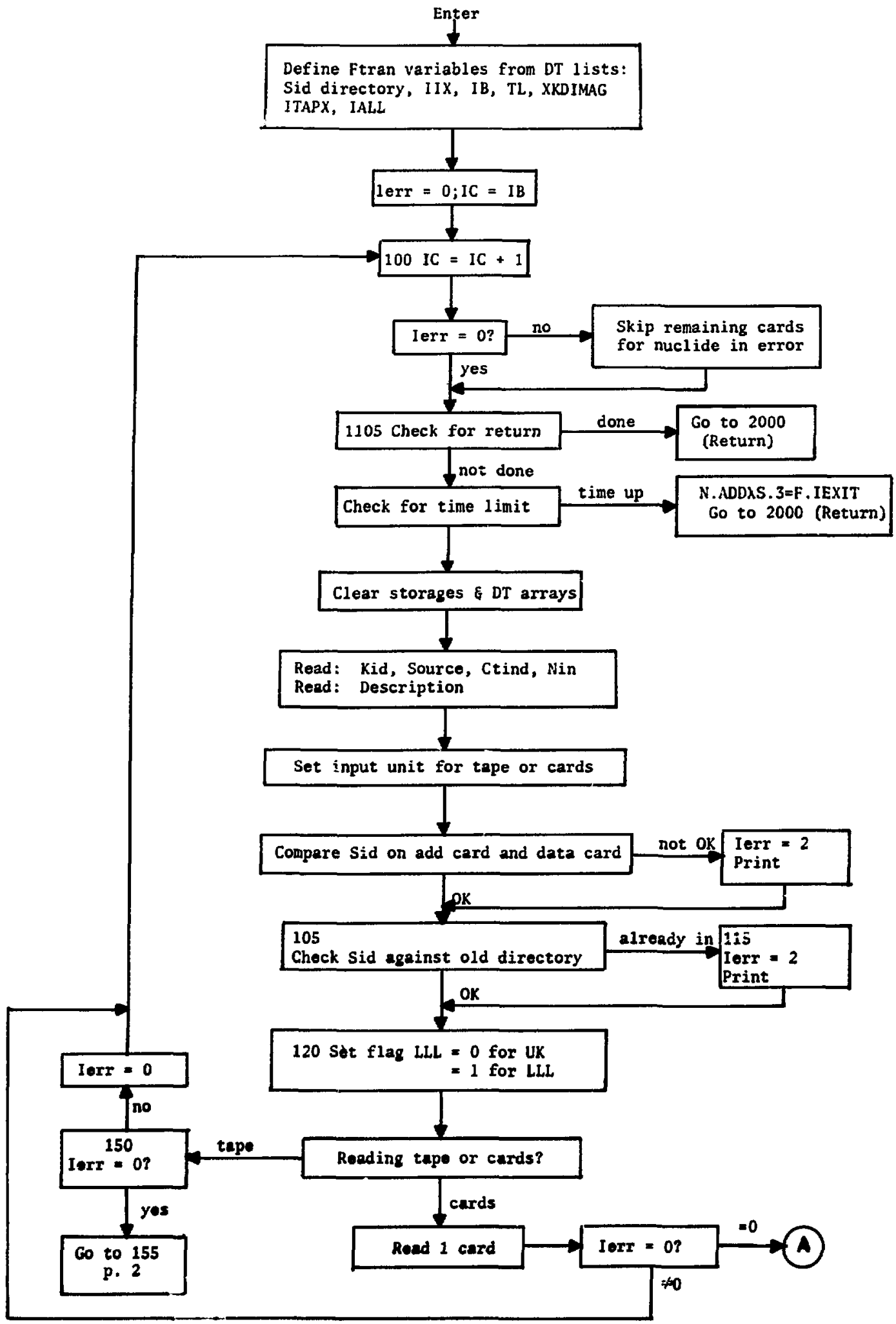




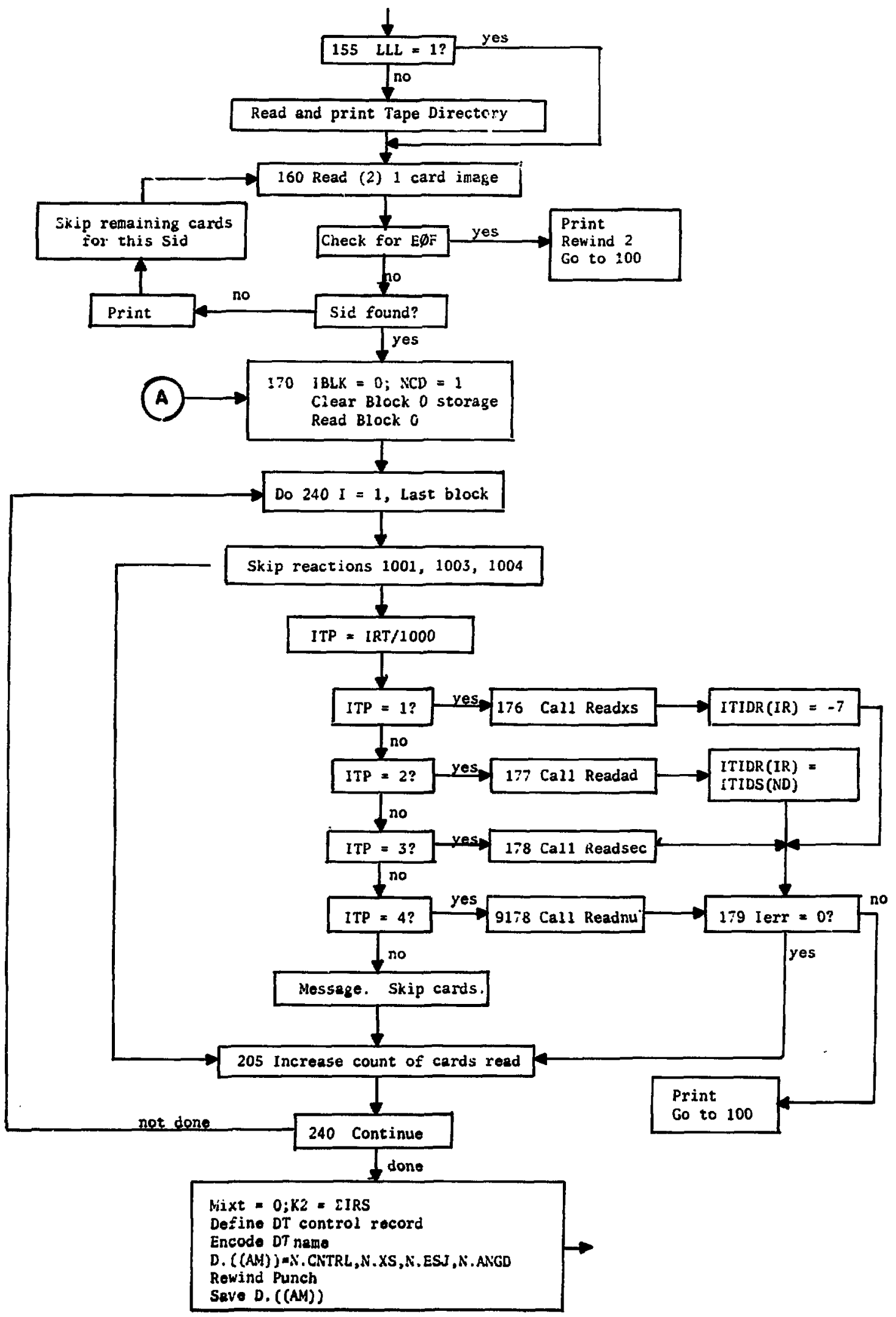




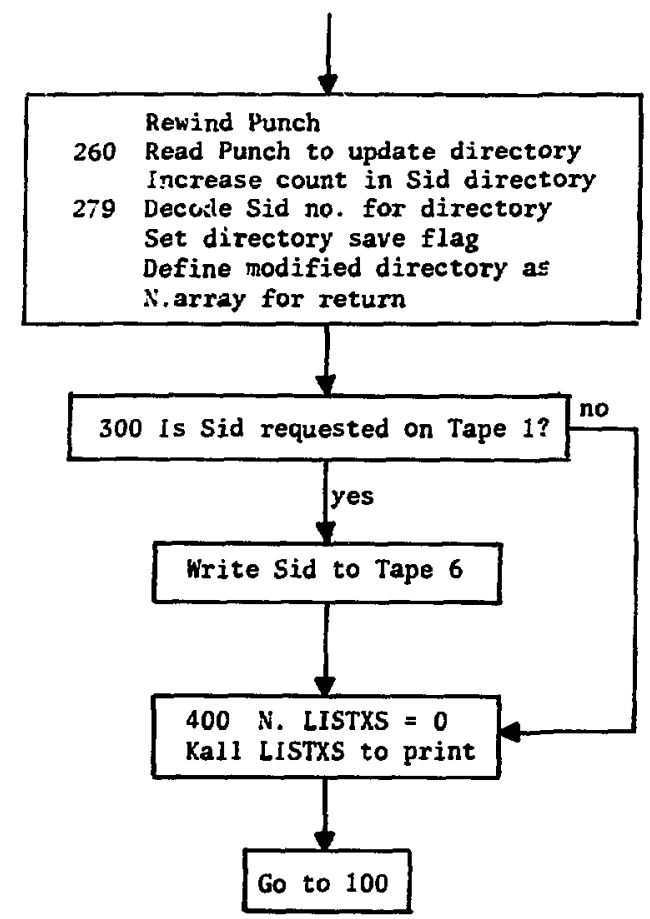

Error Path

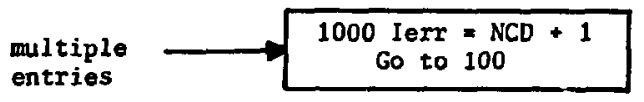

Return

\begin{tabular}{ll|} 
multiple & $2000 \begin{array}{l}\text { Rewind } 2 \\
\text { Define IDIRSV for return to } \\
\text { main code } \\
\text { Return } \\
\text { End }\end{array}$ \\
\hline
\end{tabular}




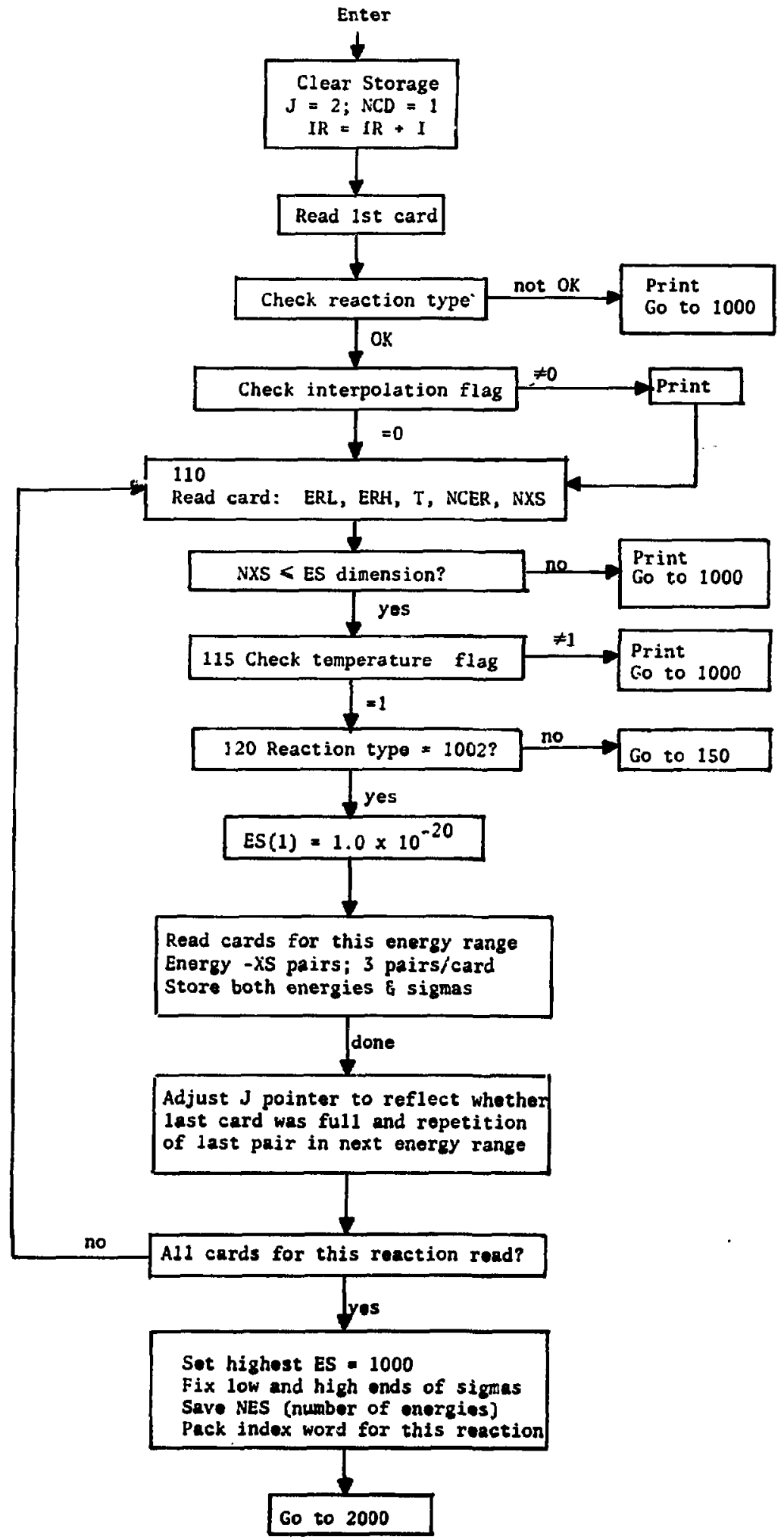




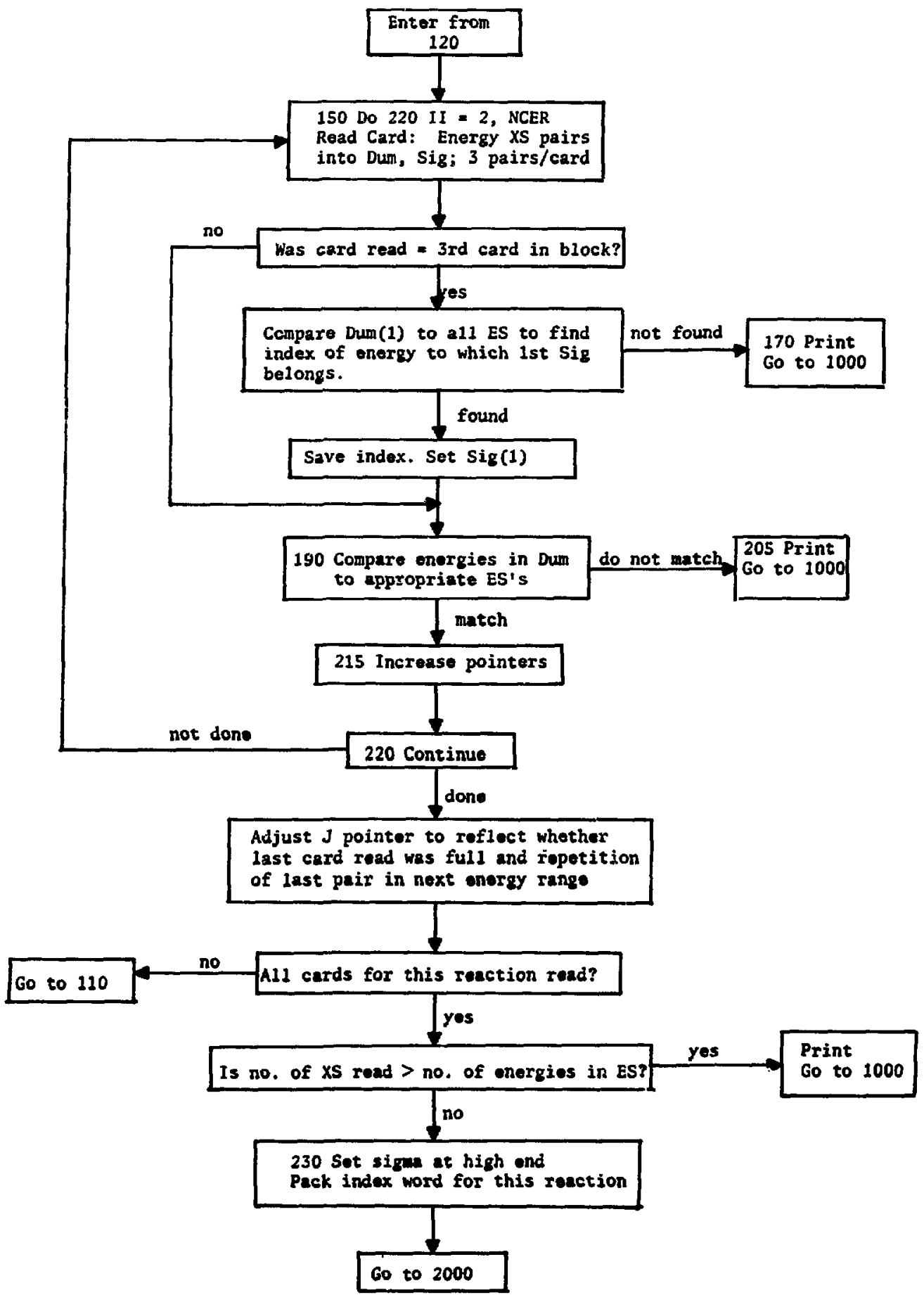




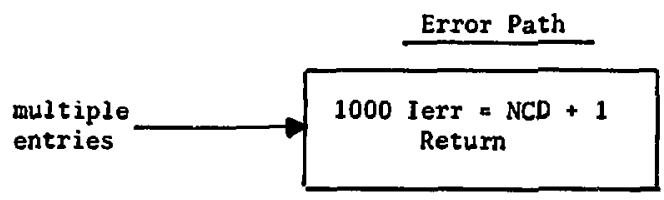

\begin{tabular}{ll|} 
multiple \\
entries
\end{tabular}


SUBROUTINE READAD

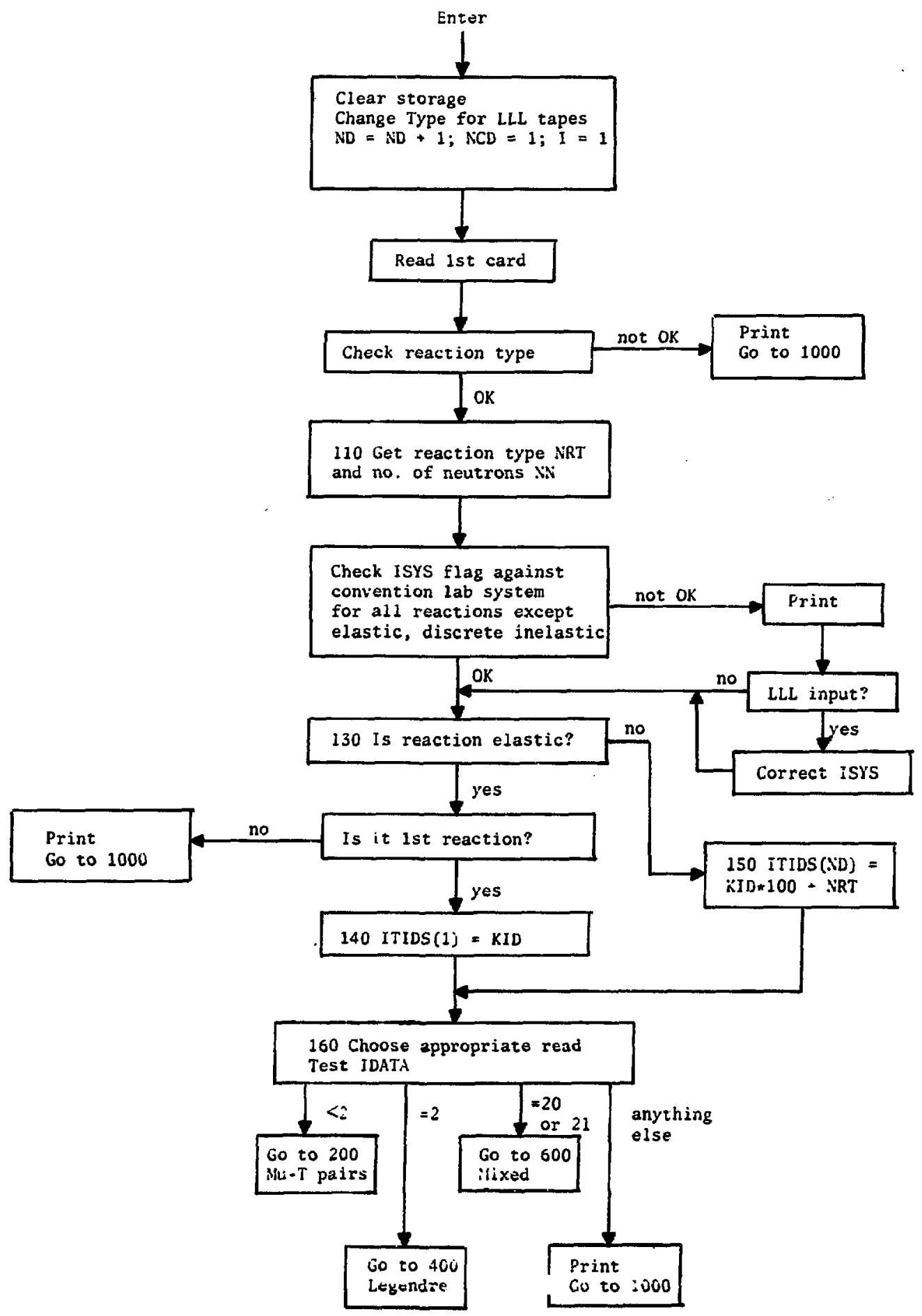




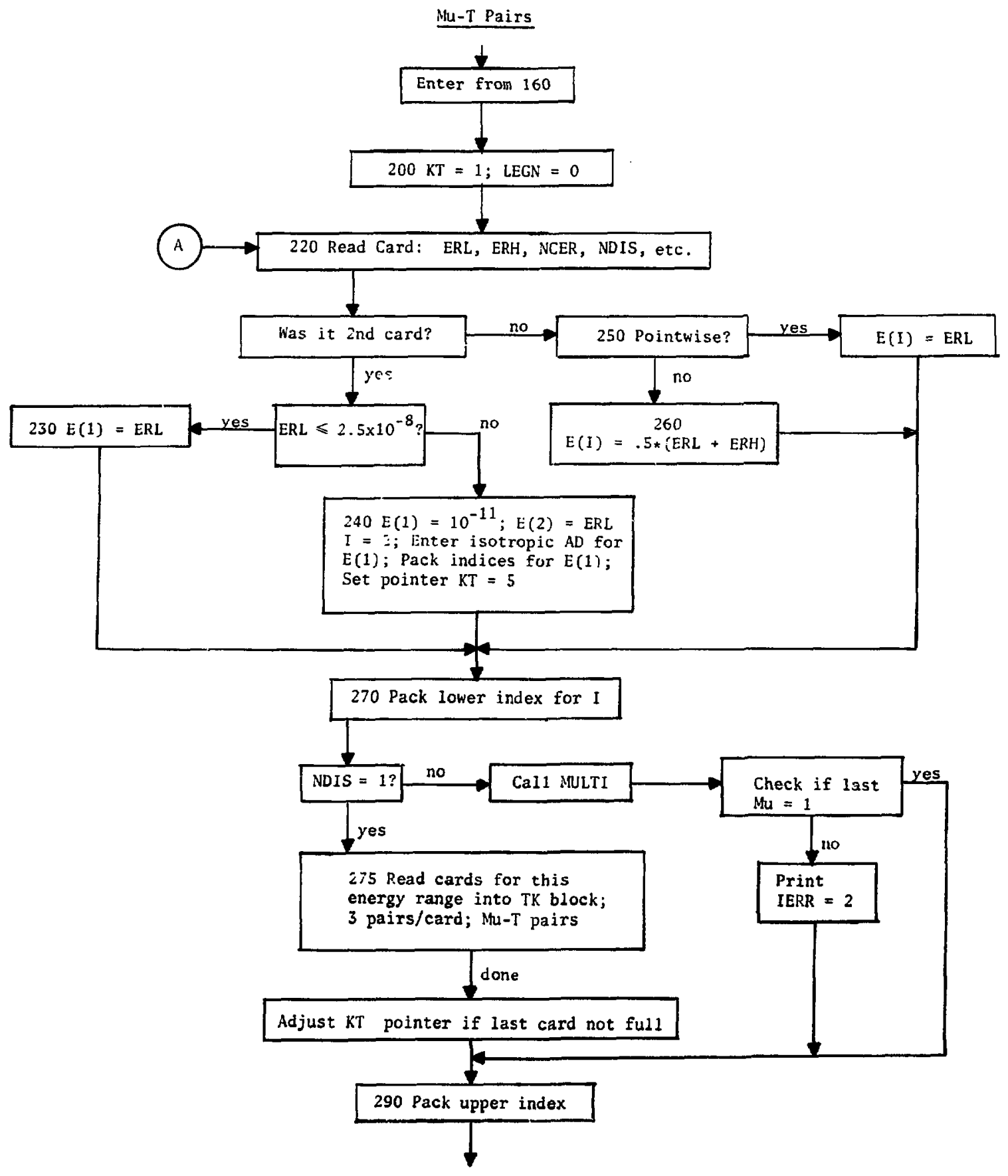




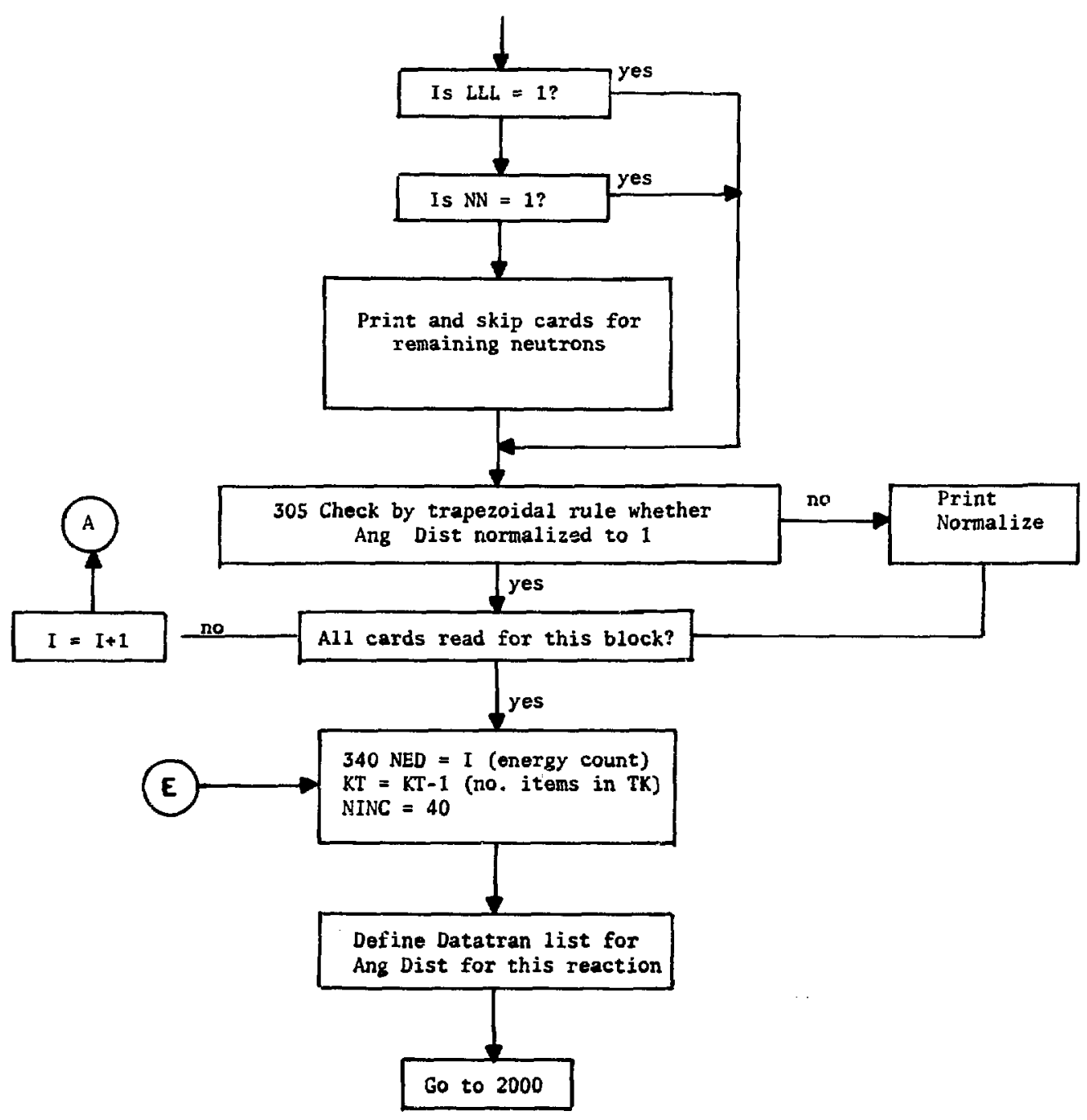


Mixed Legendre and Mu-T

Enter from $160+$
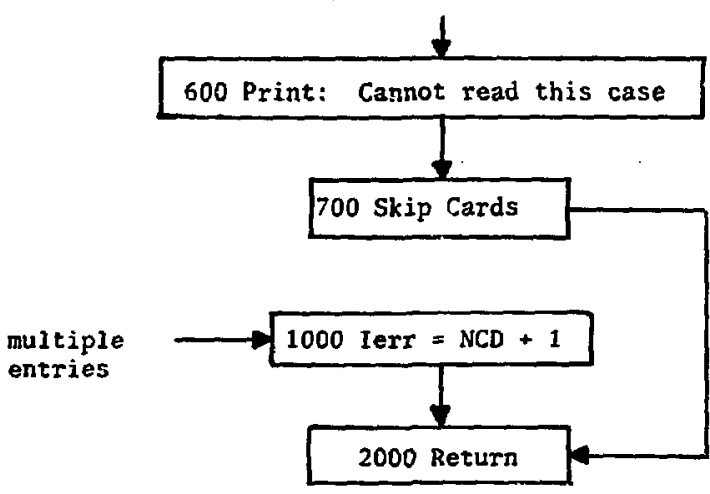

Legendre

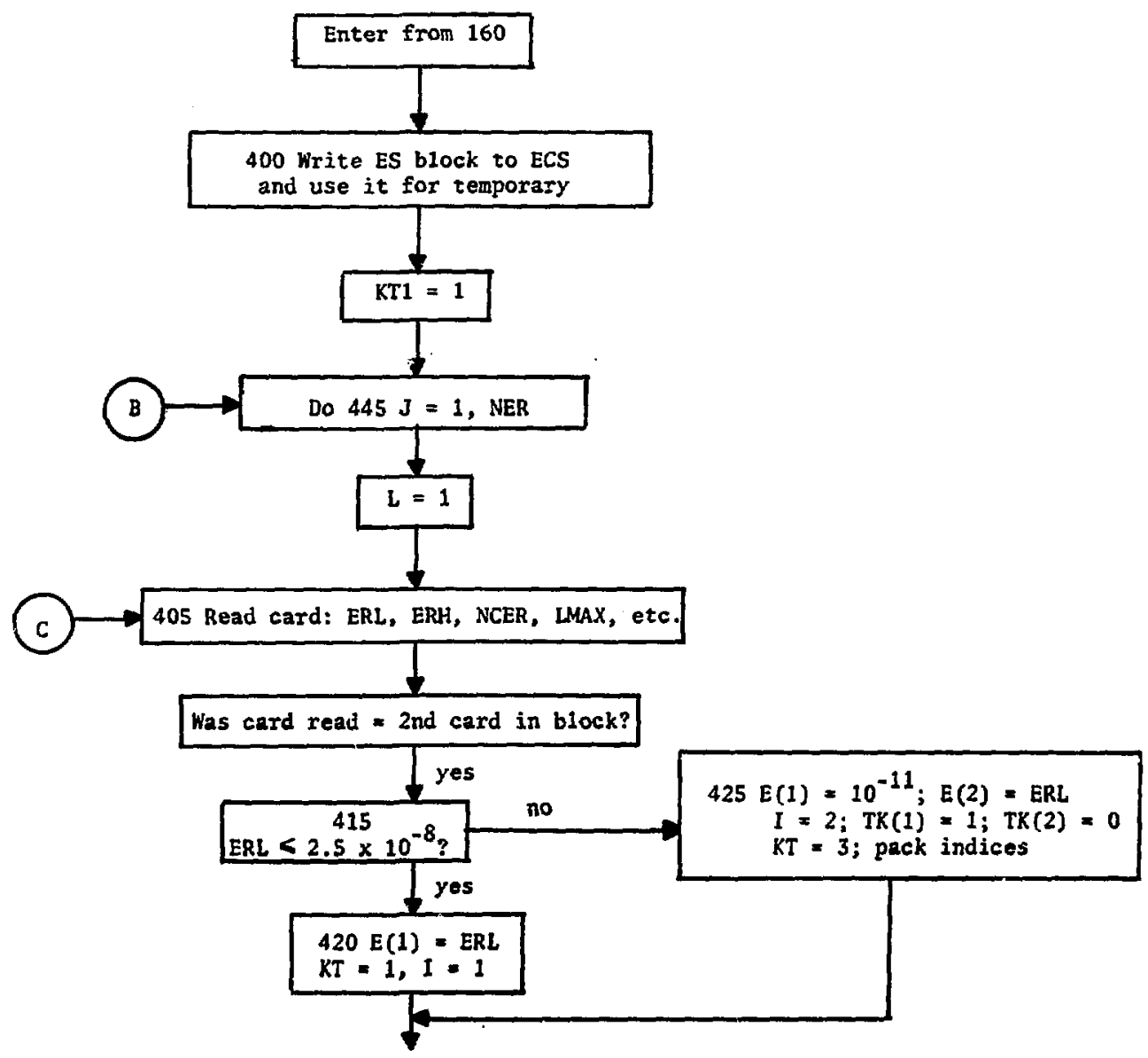




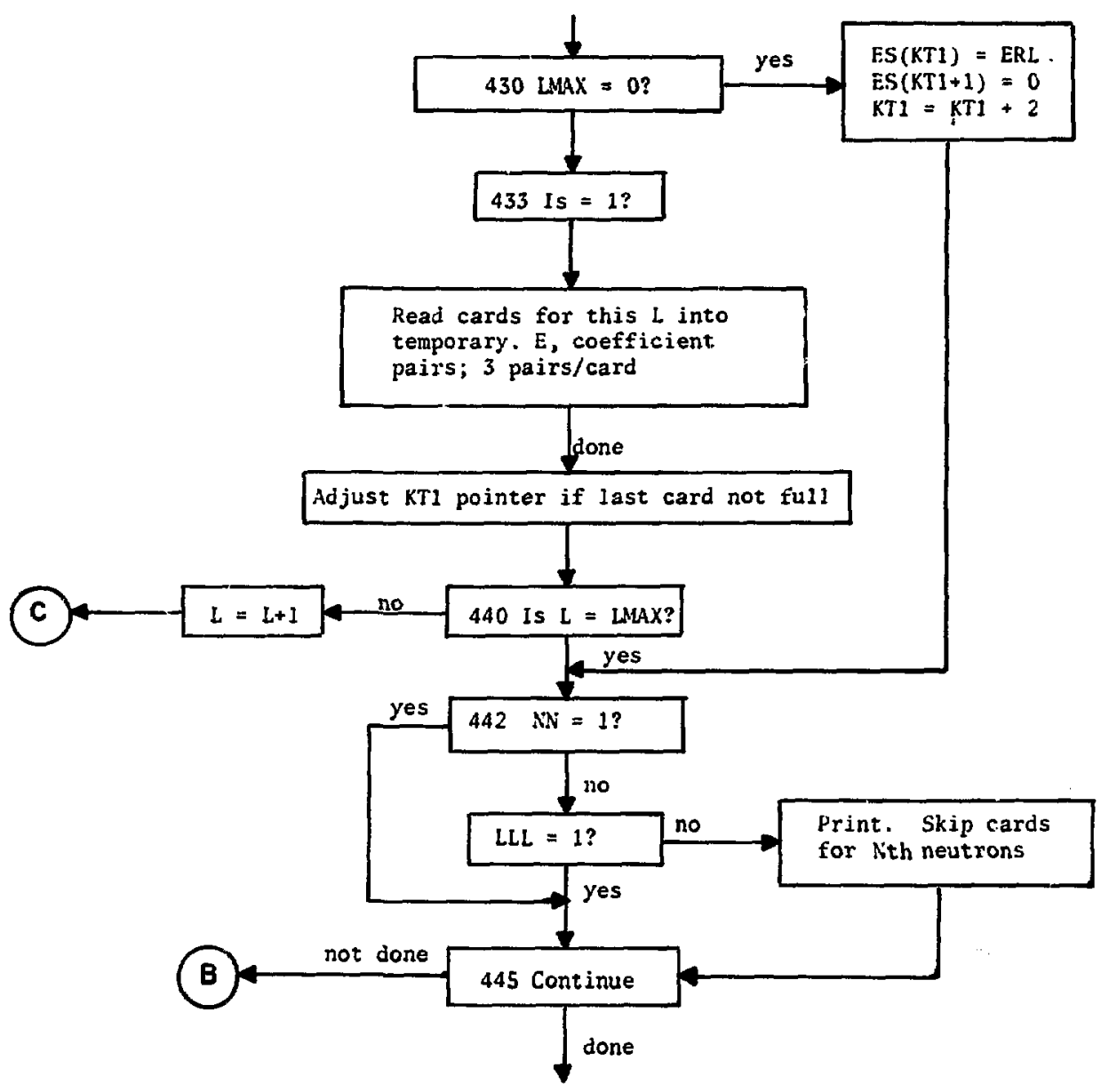




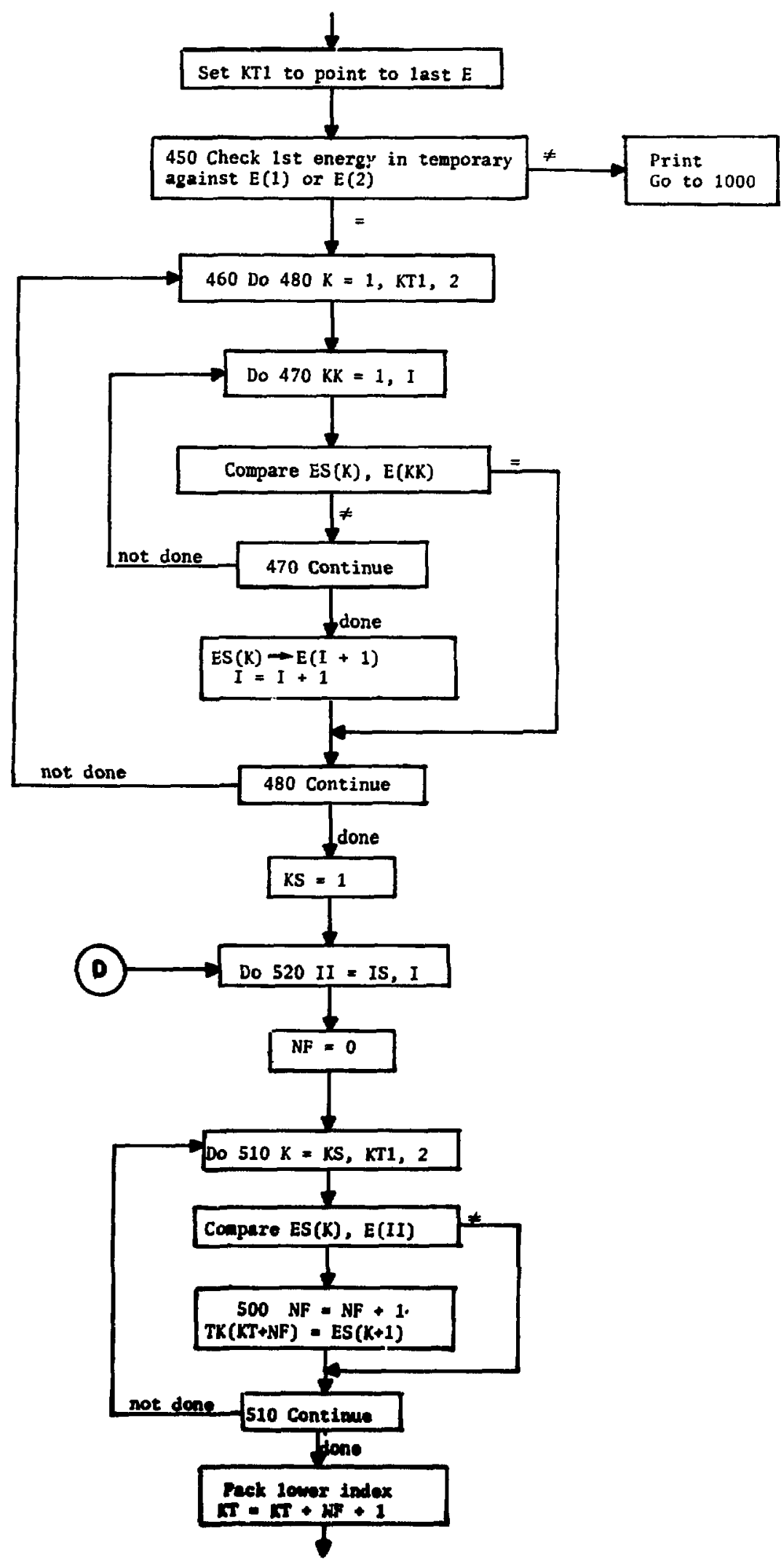




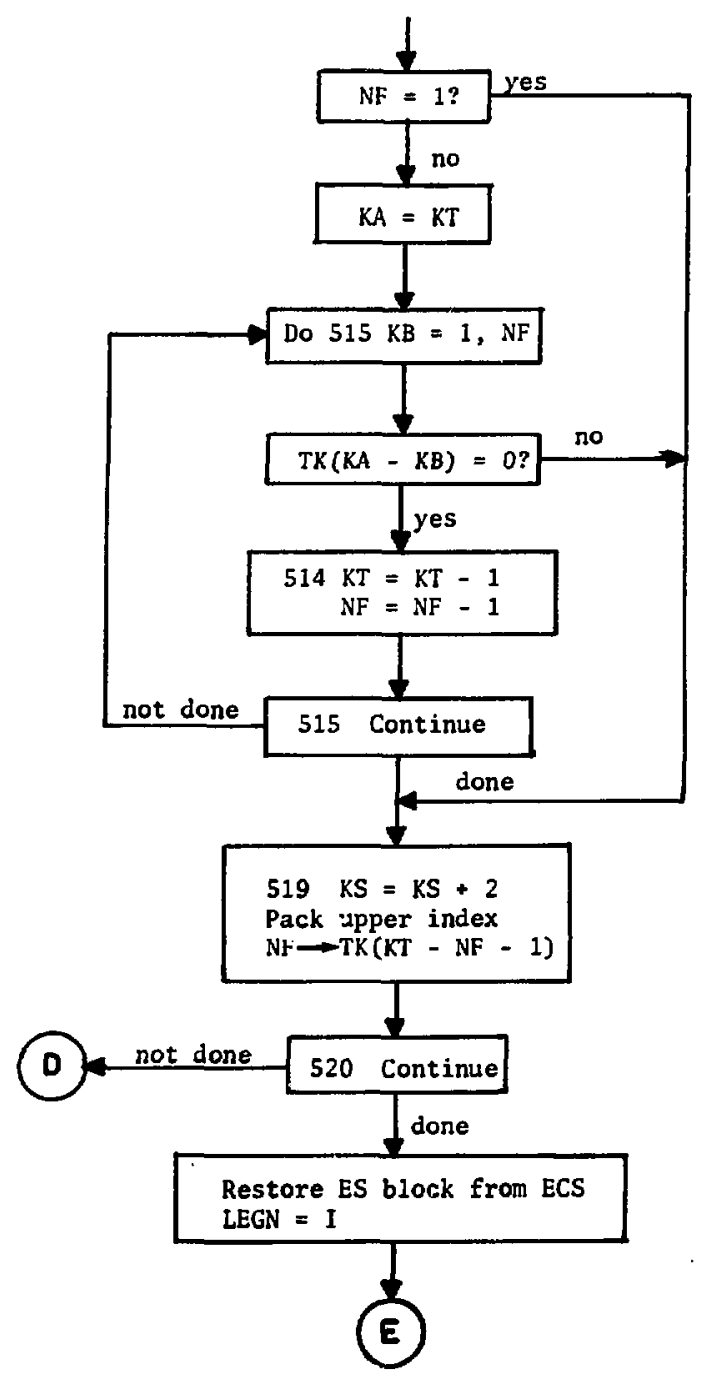




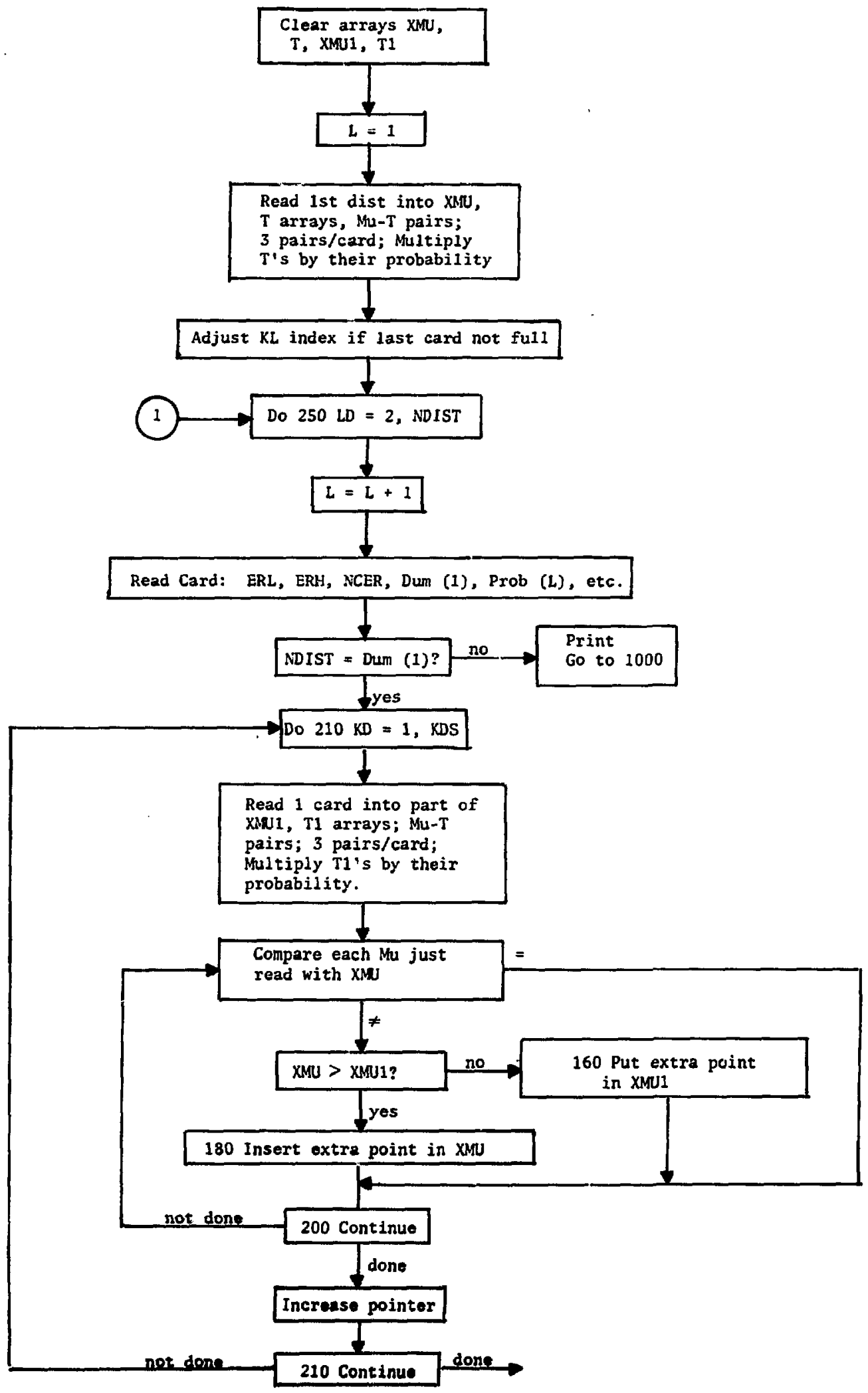




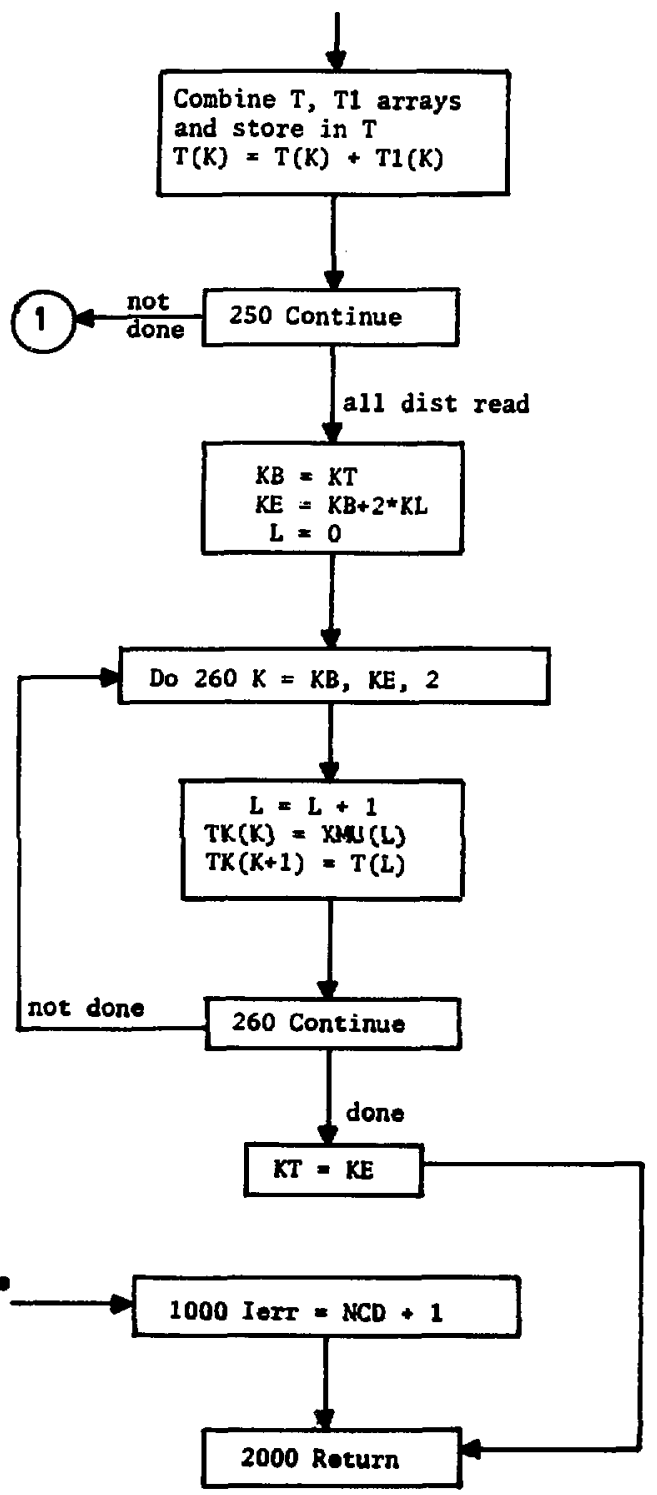




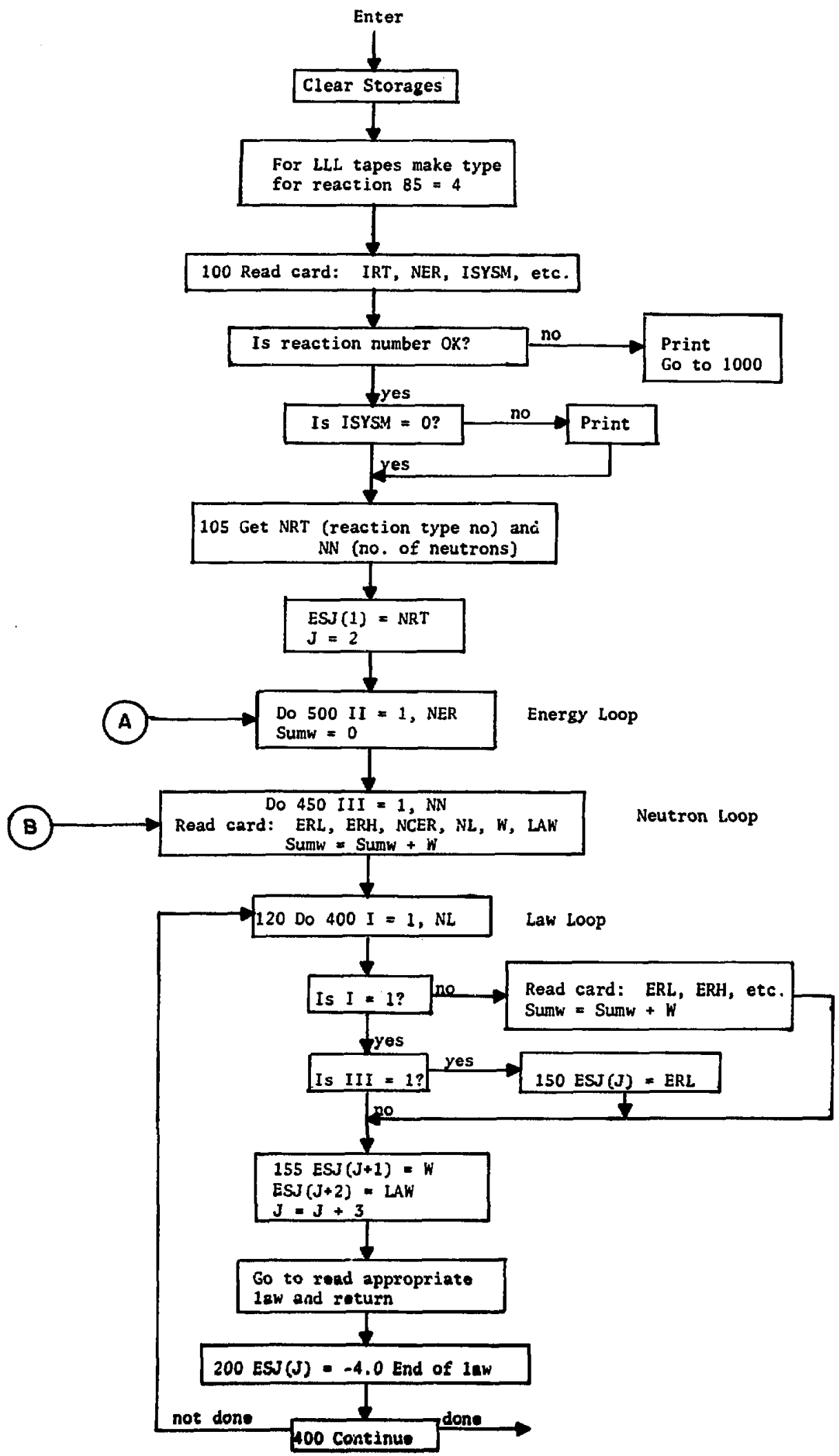




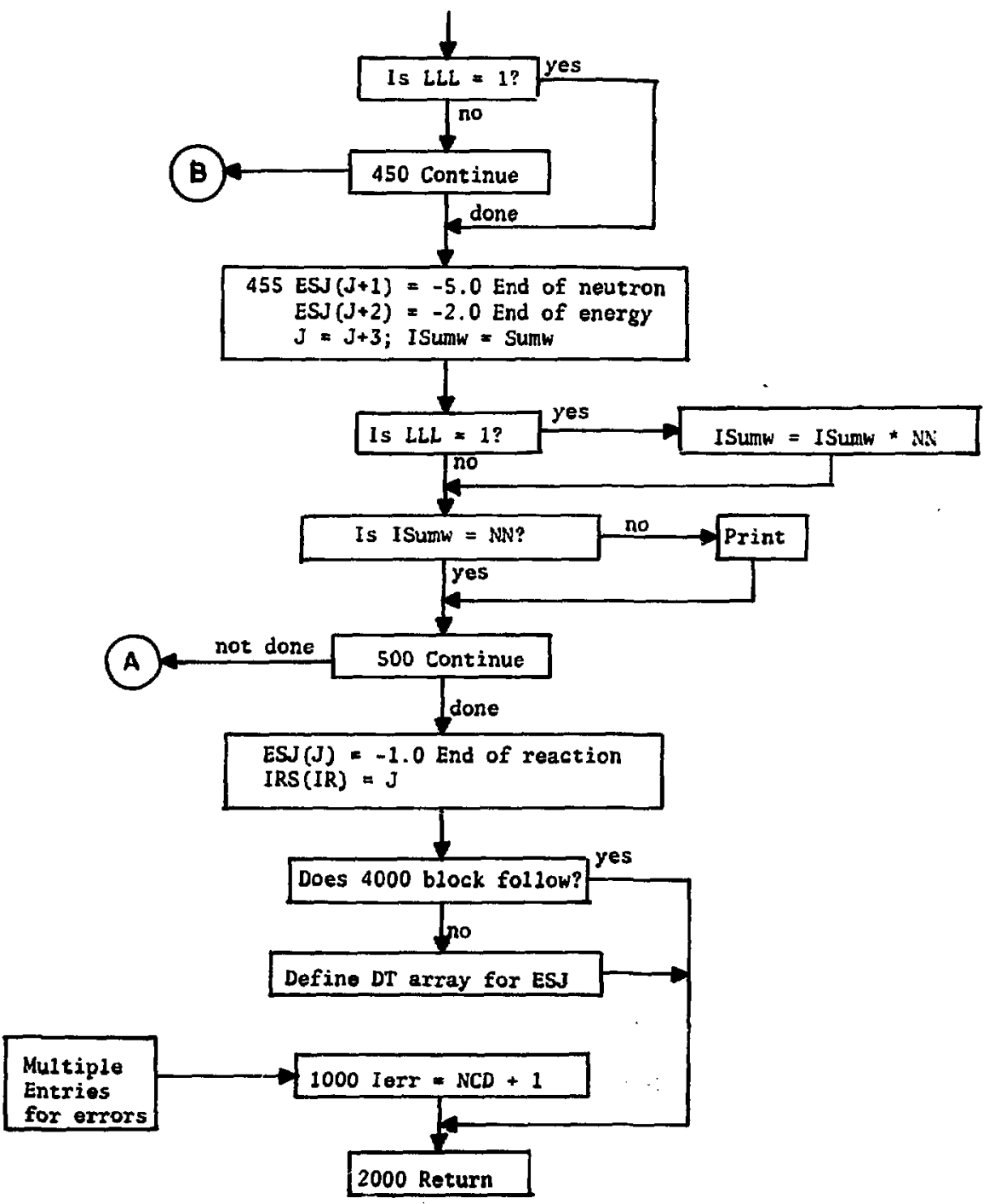


LAWS 1-6

Enter al1 laws with $\mathrm{J}$ pointing to first unused word in ESJ

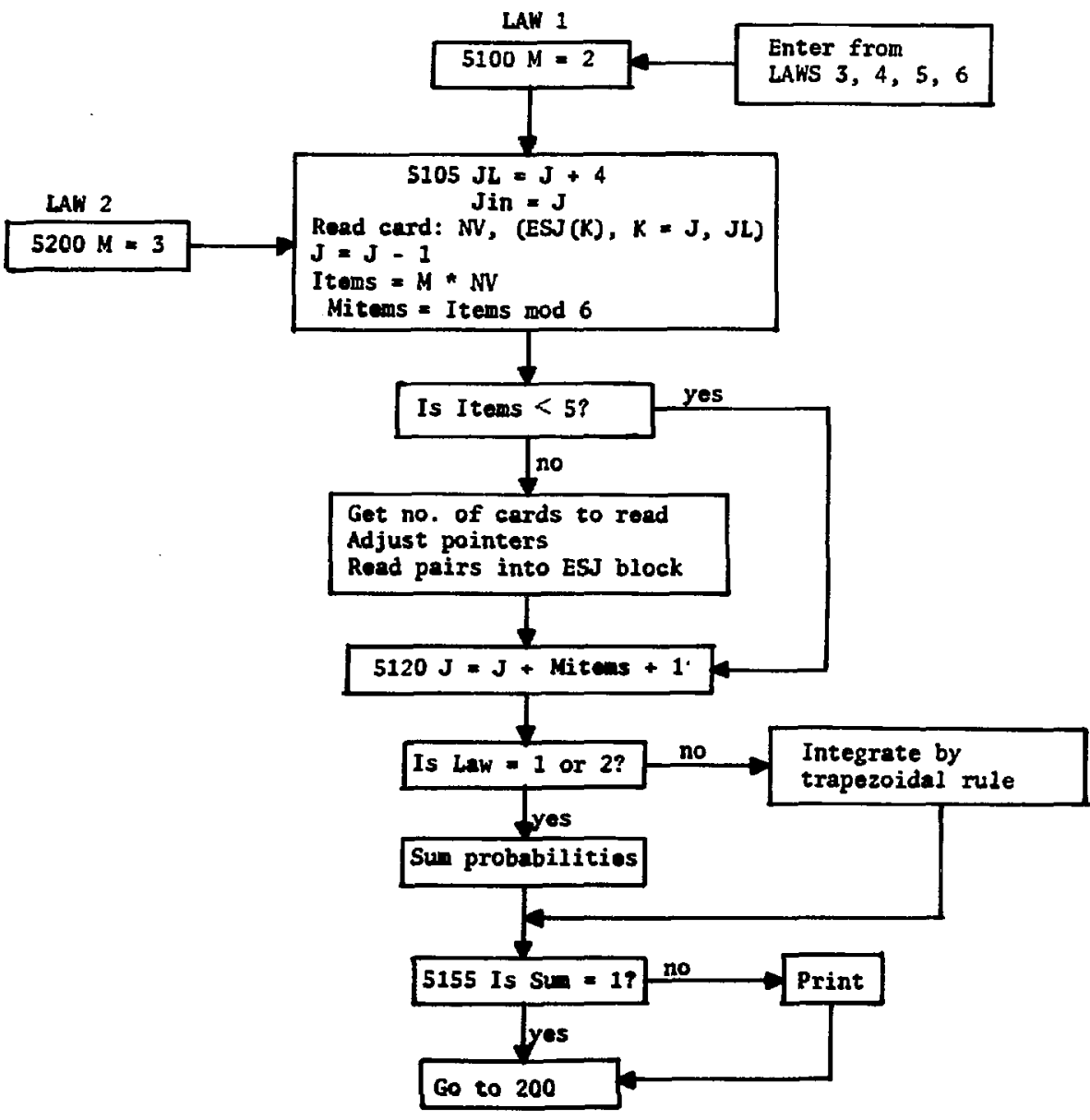

LAW 7

$5700 \mathrm{JL}-\mathrm{J}+3$

Read 4 paranoters into ESJ

$\mathbf{J}=\mathbf{J L}+1$

Co to 200

LAI 10

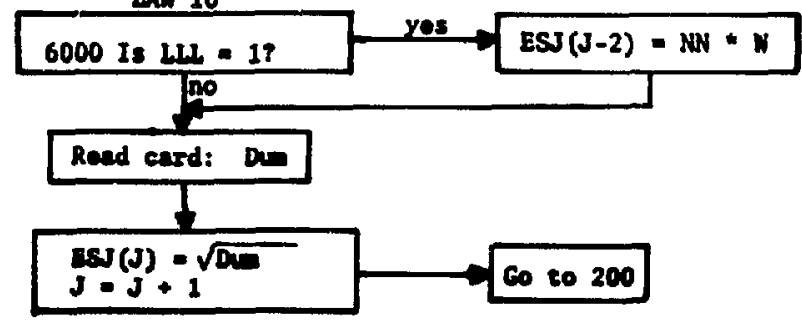




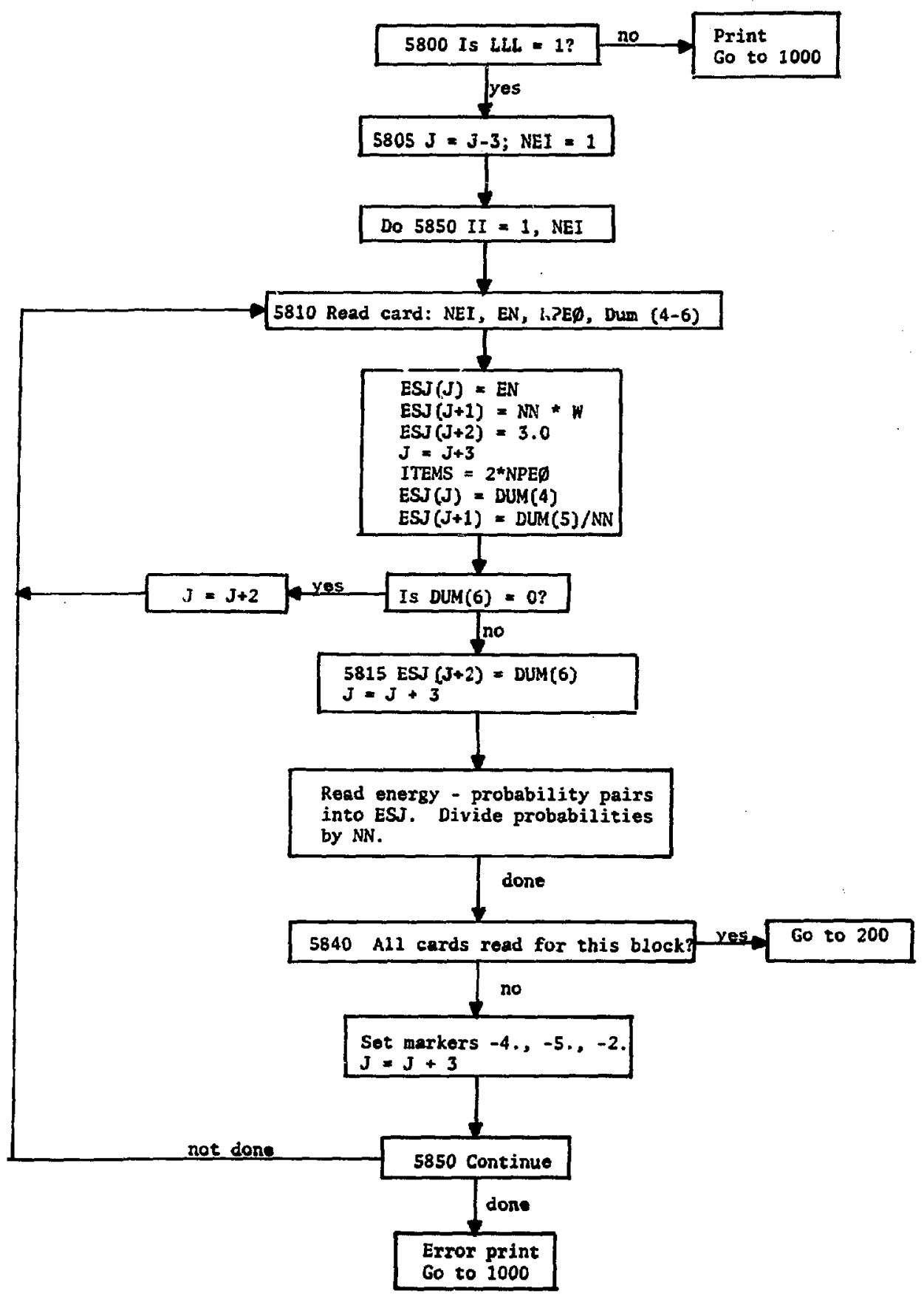




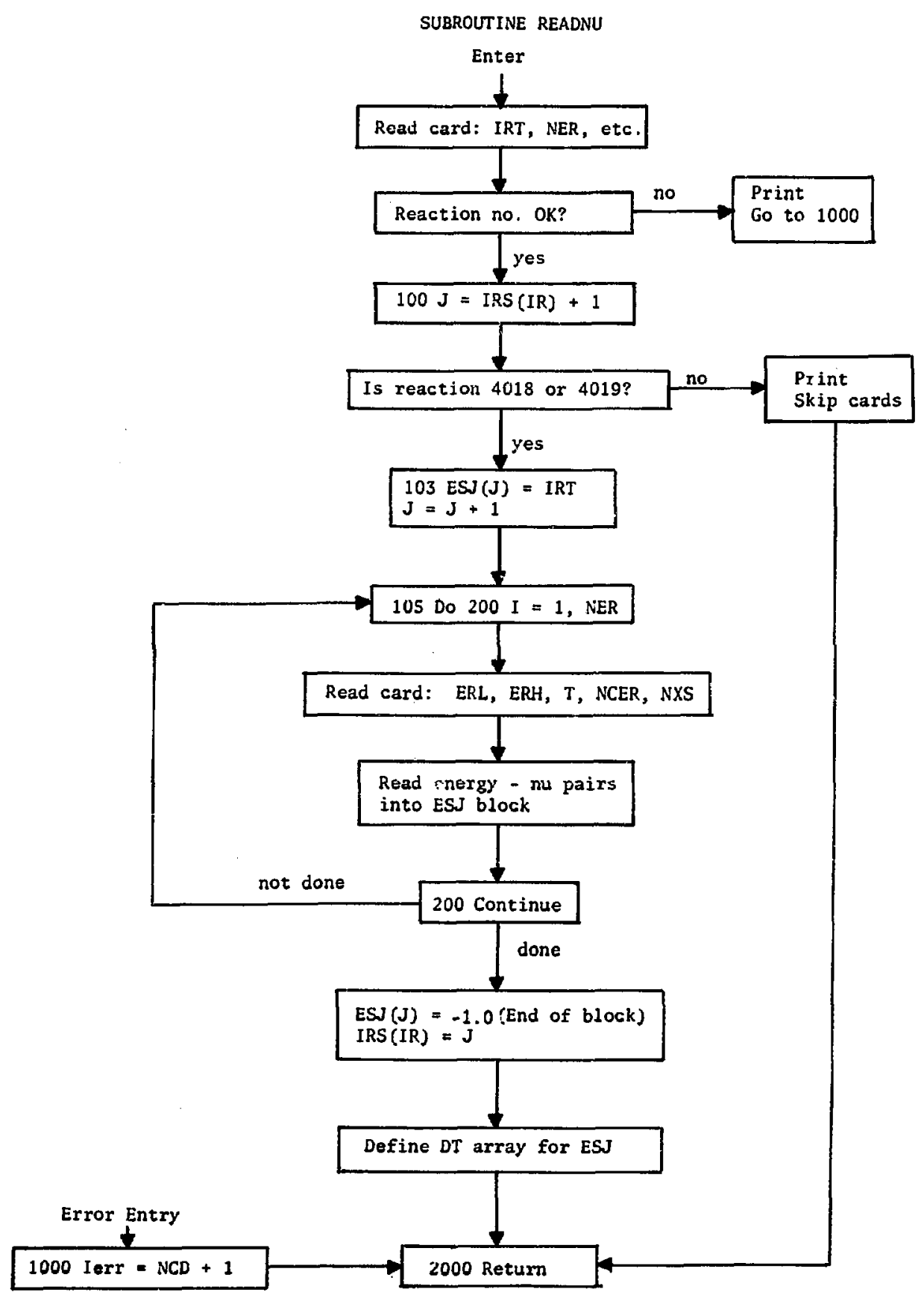


MODULE LISTXS

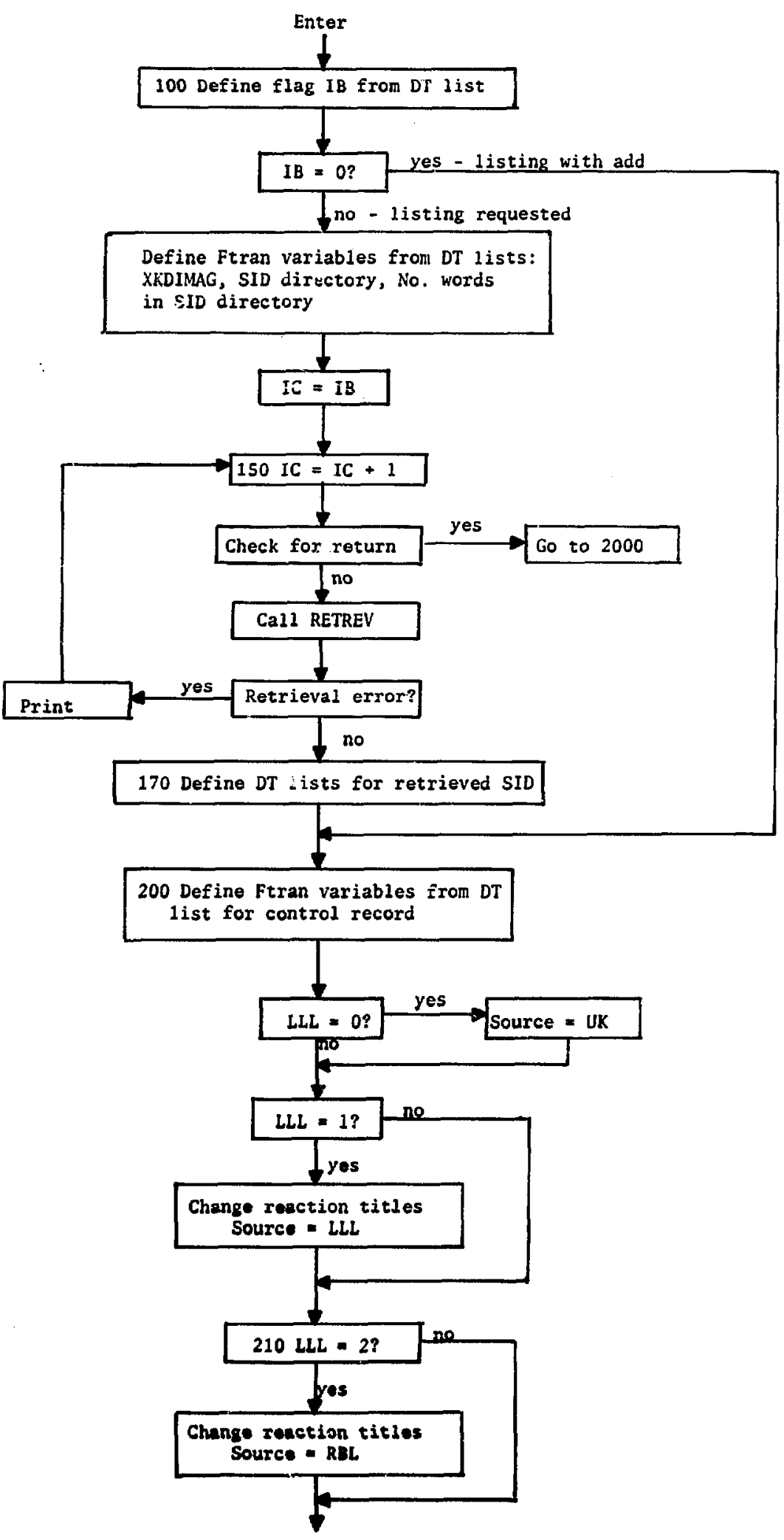




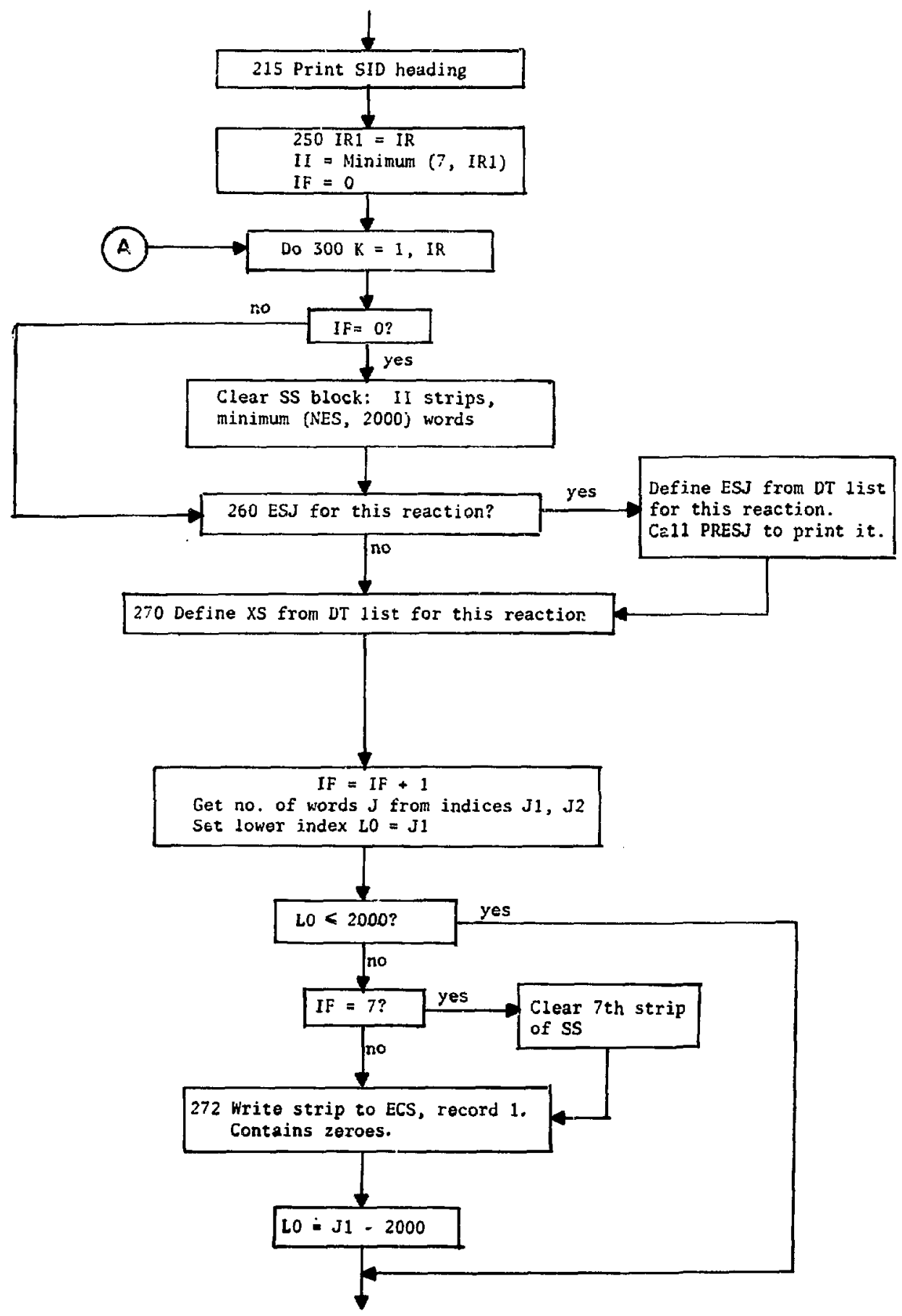




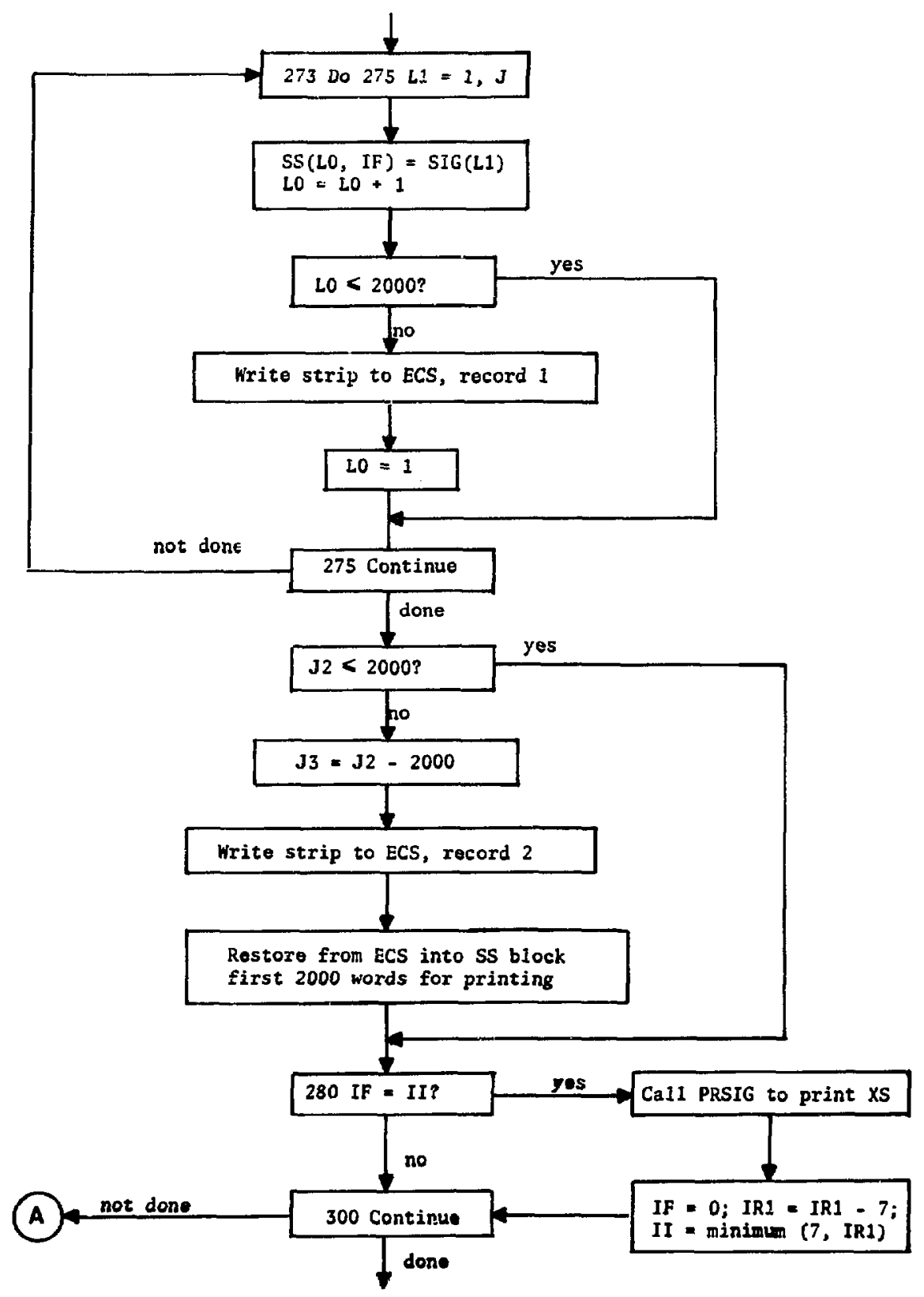




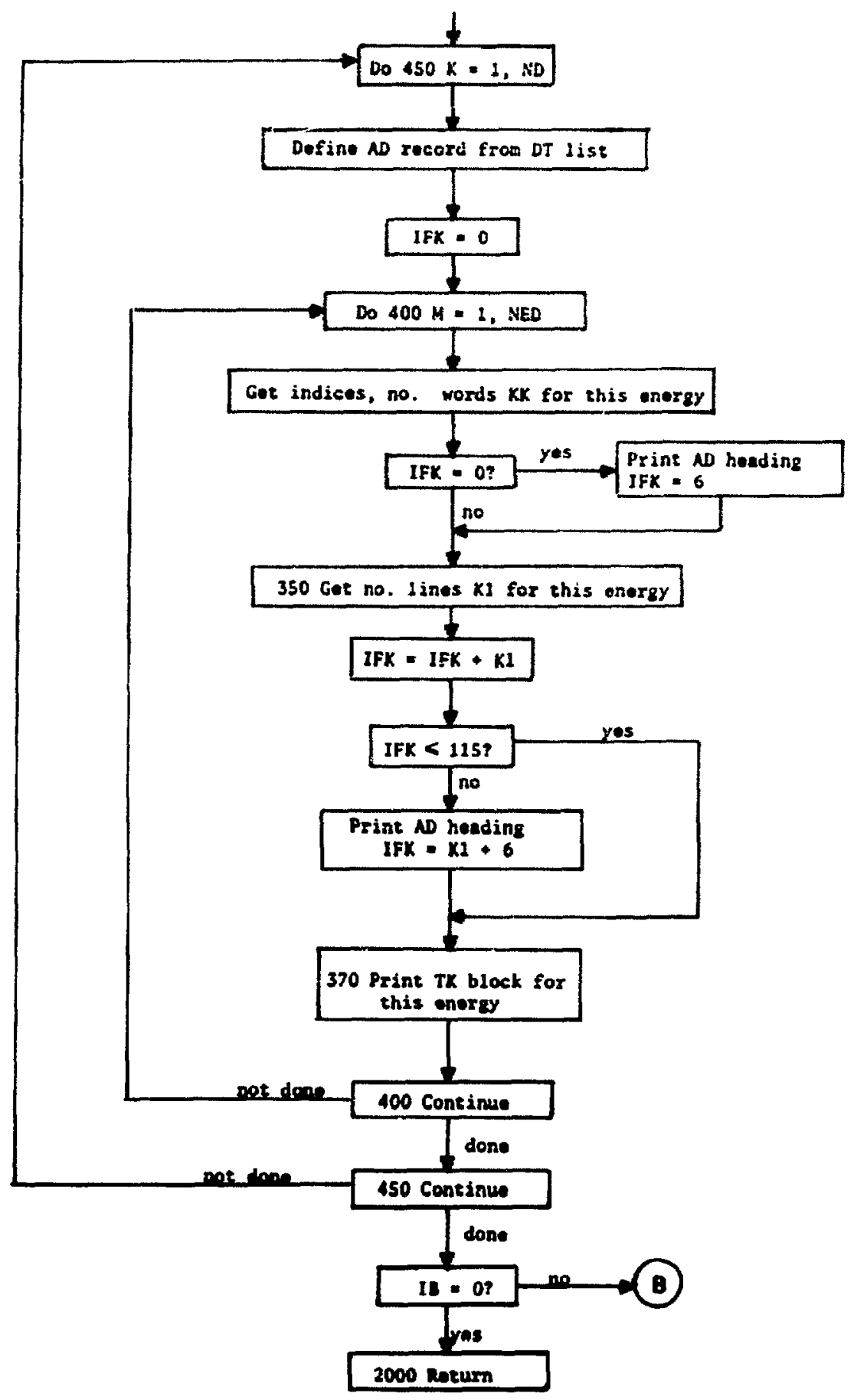




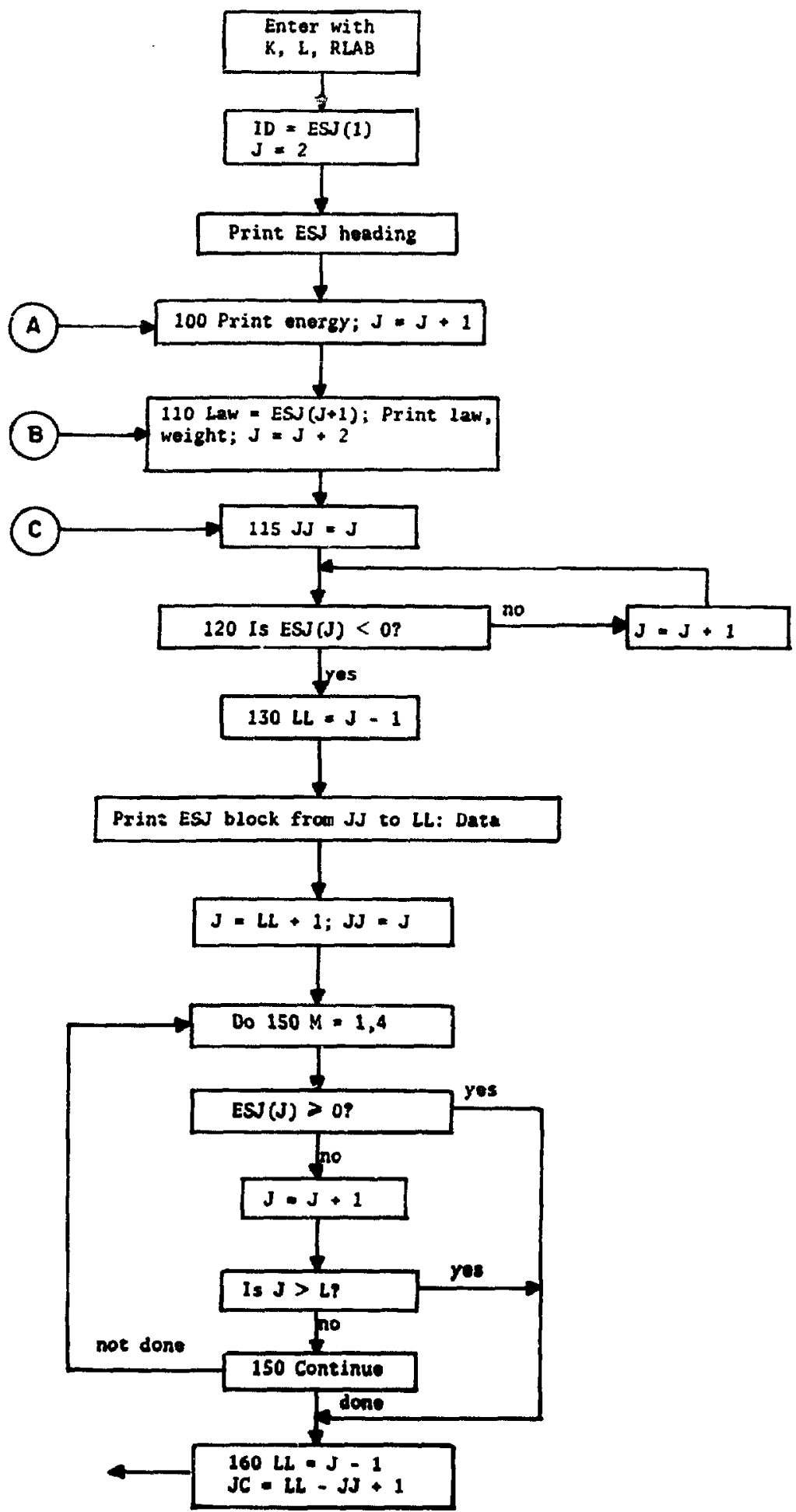




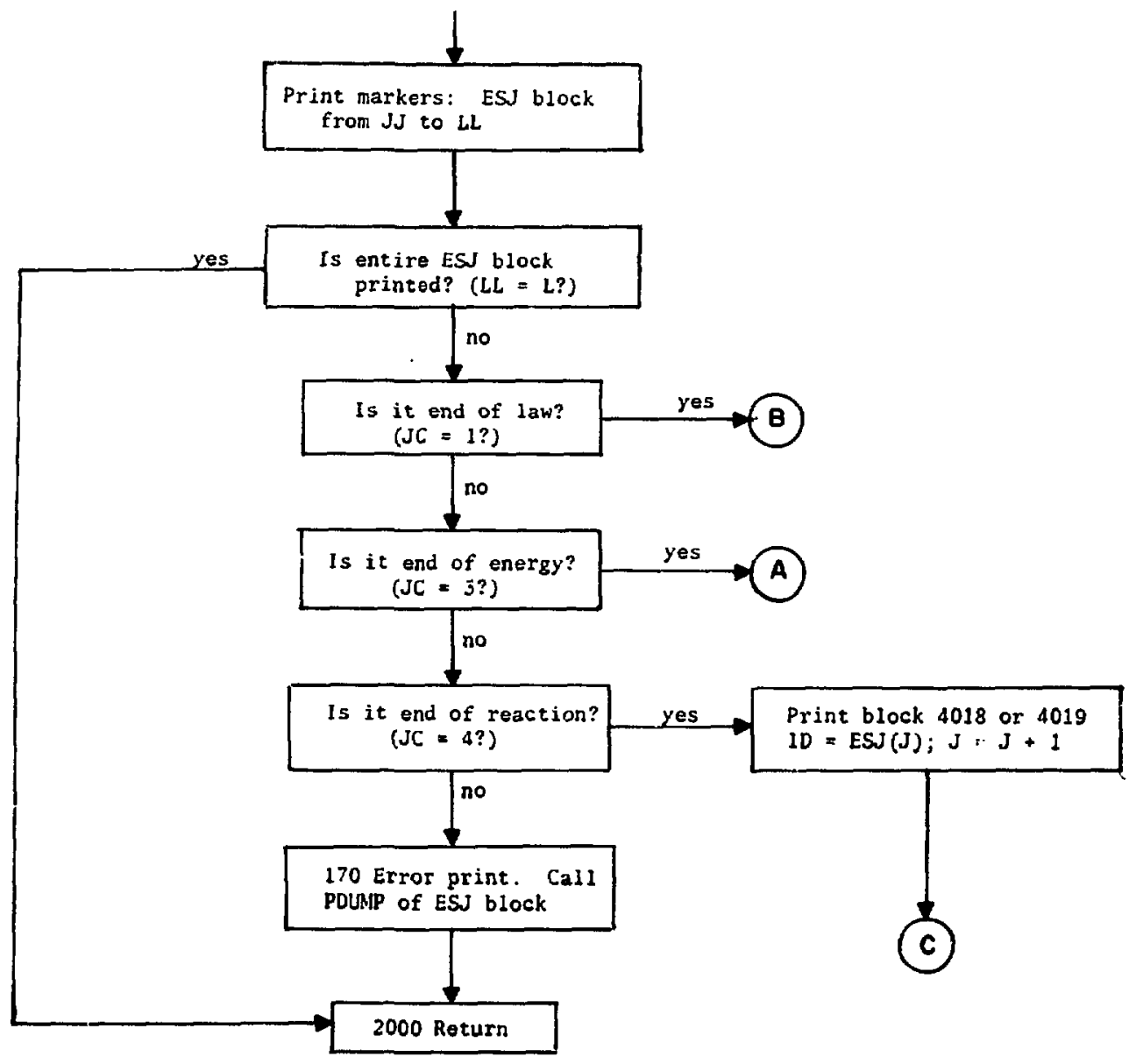




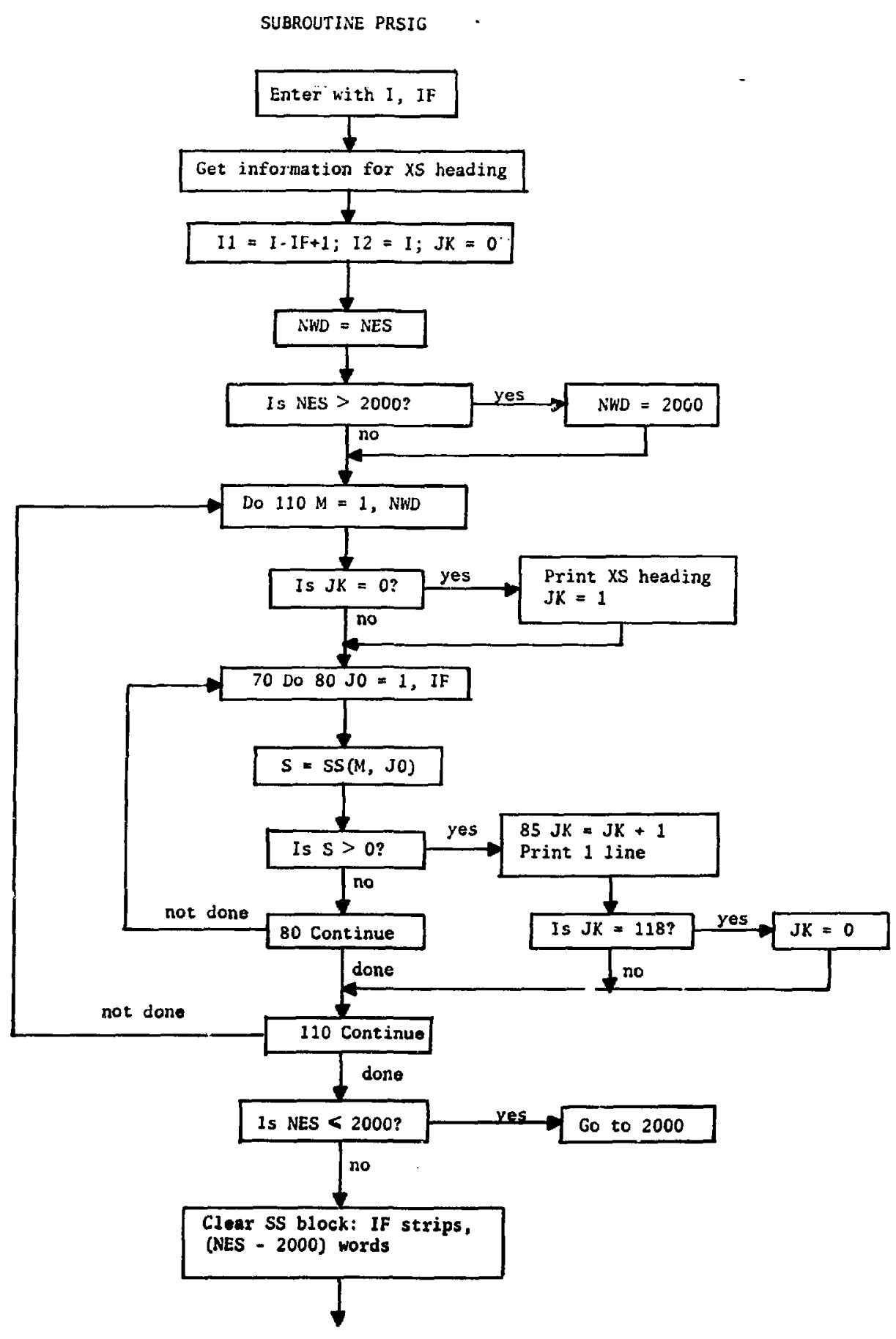




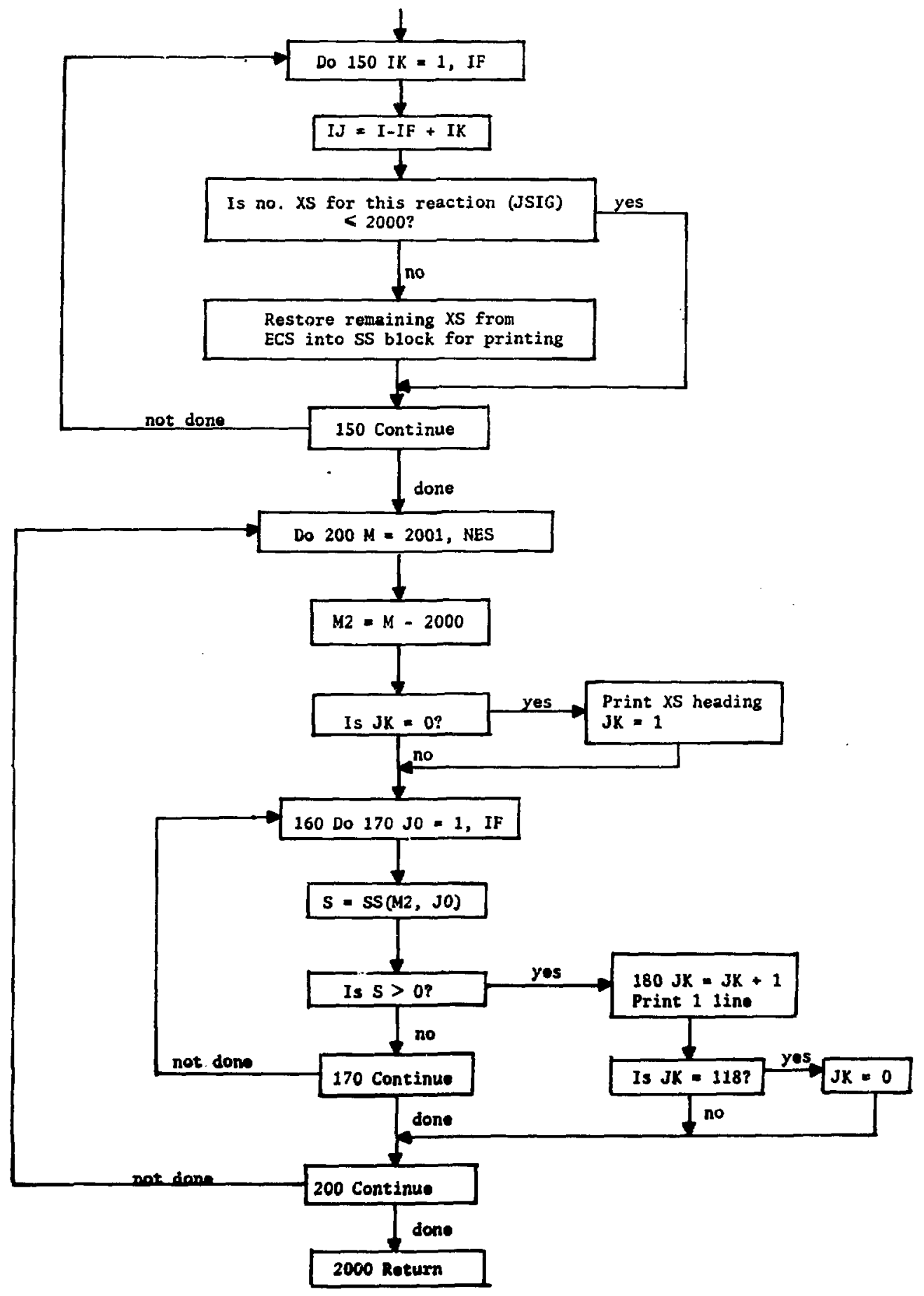




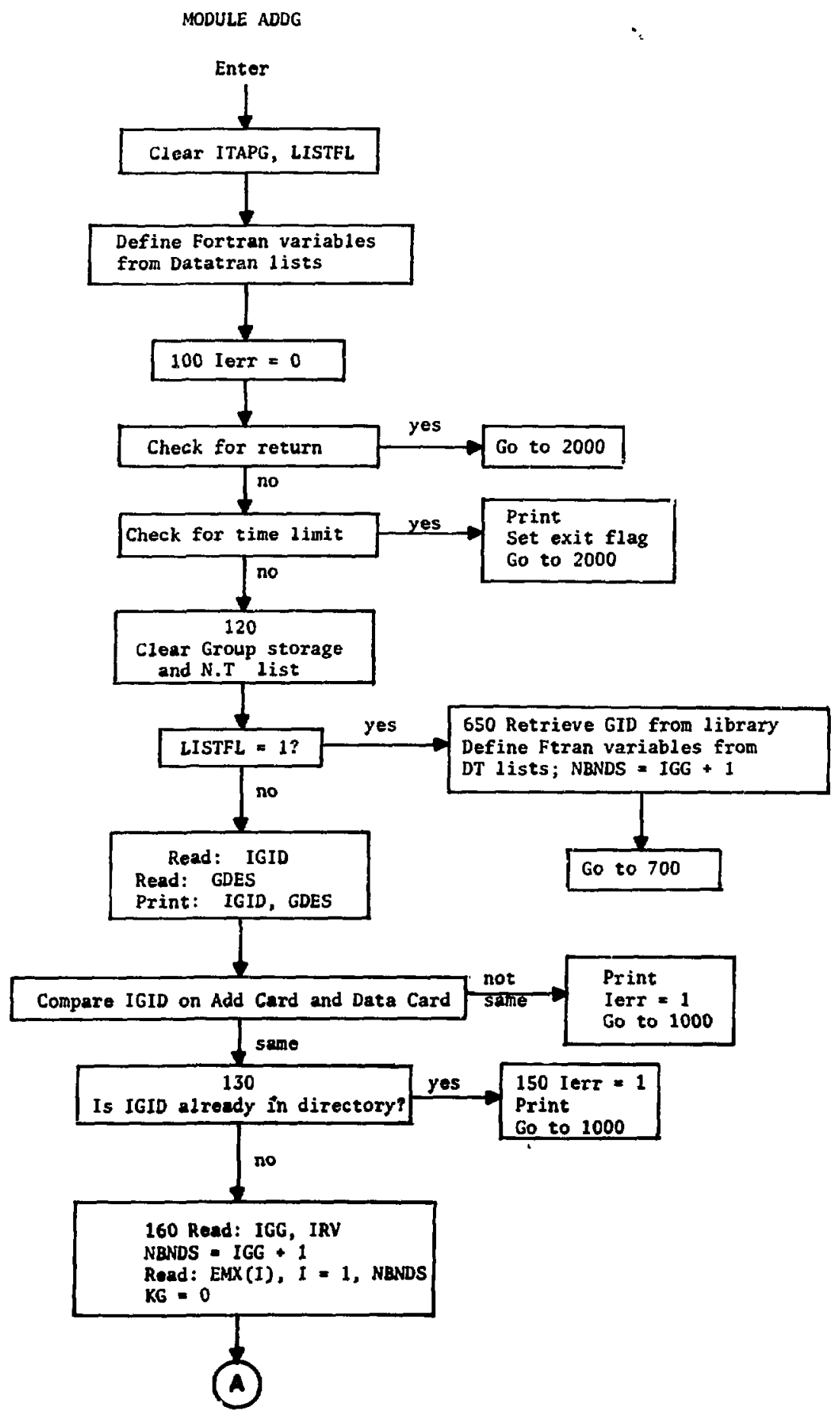




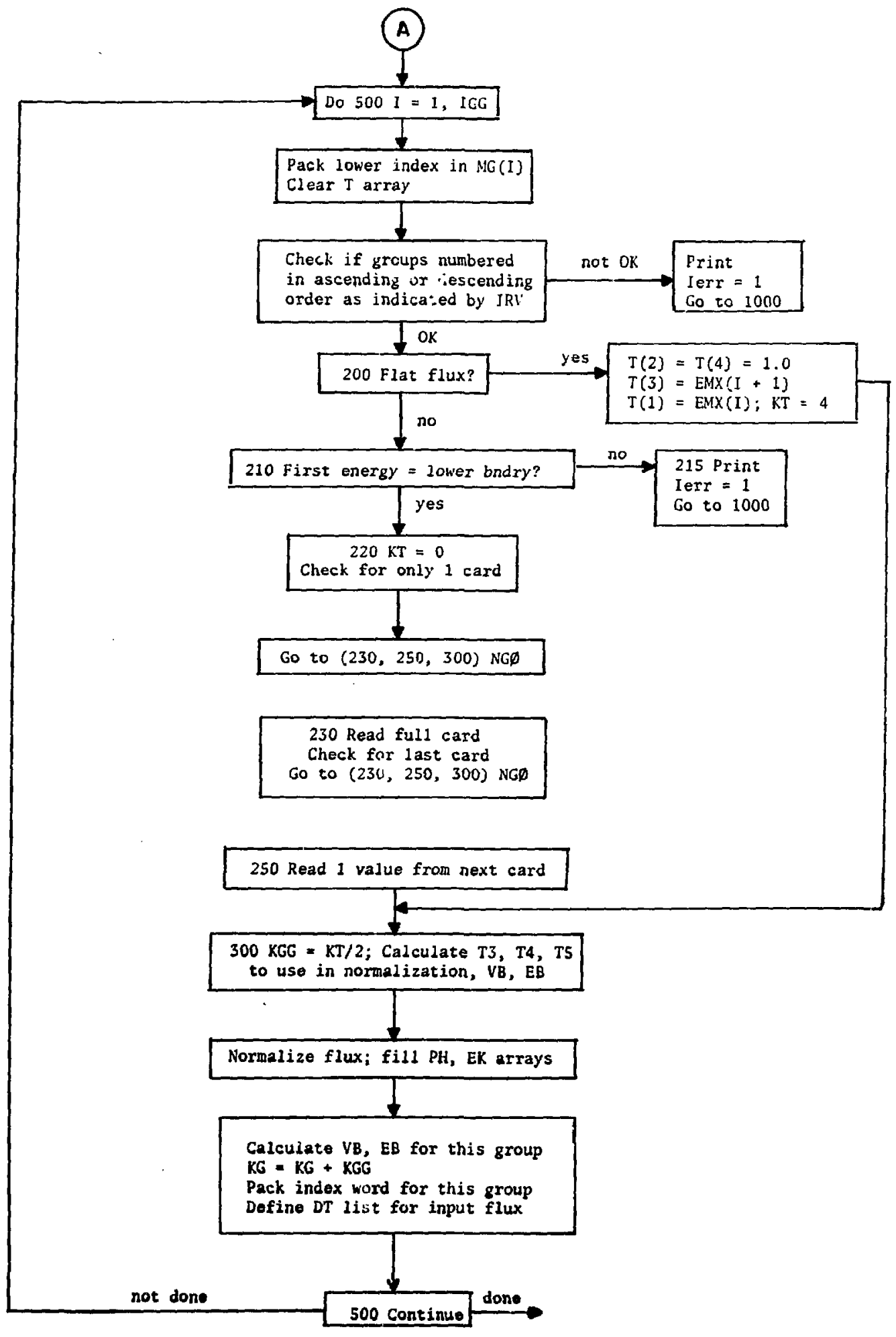




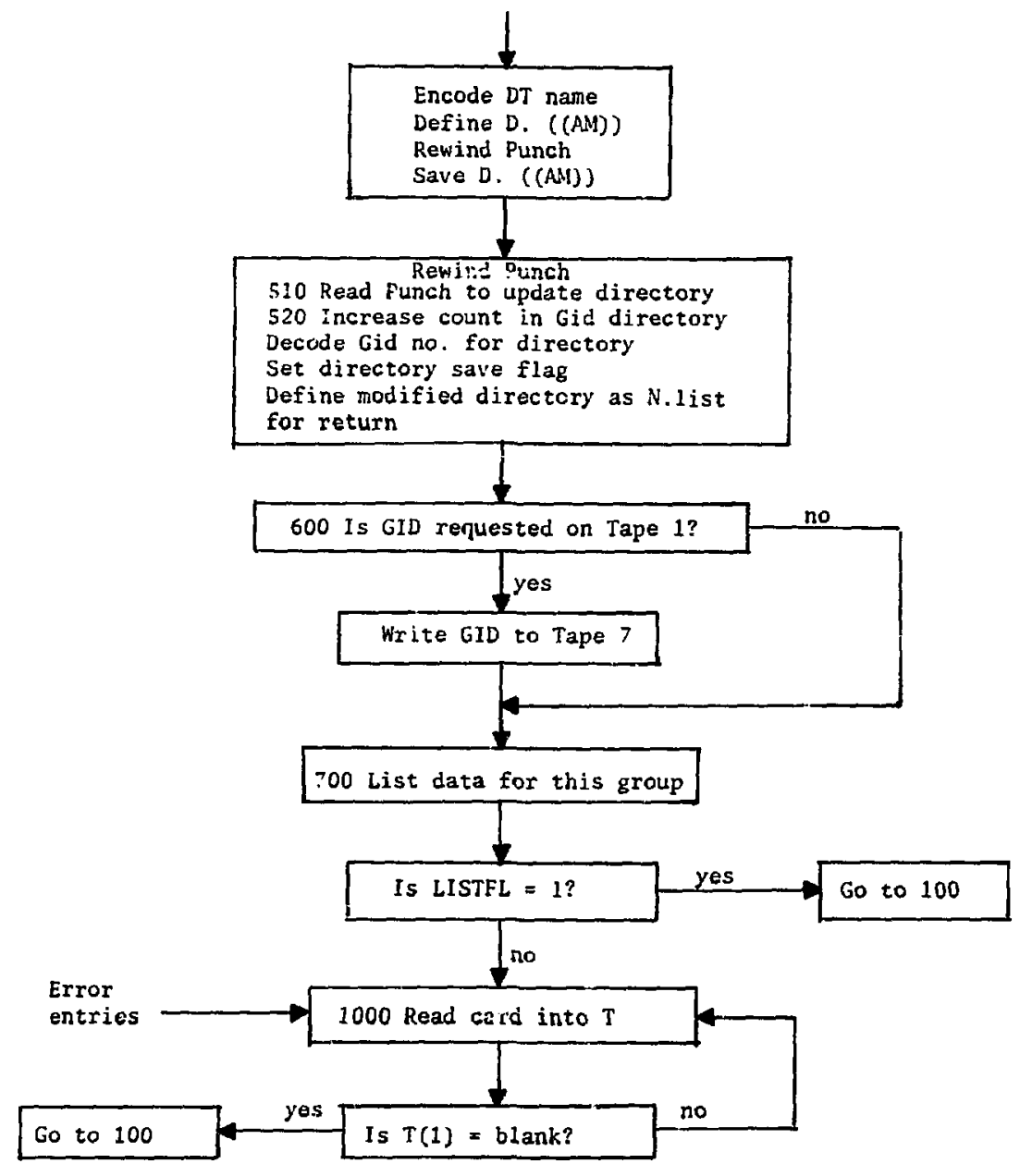

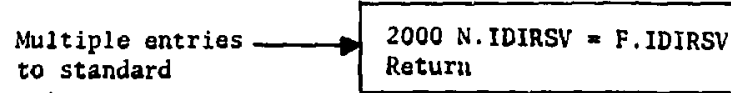

return 


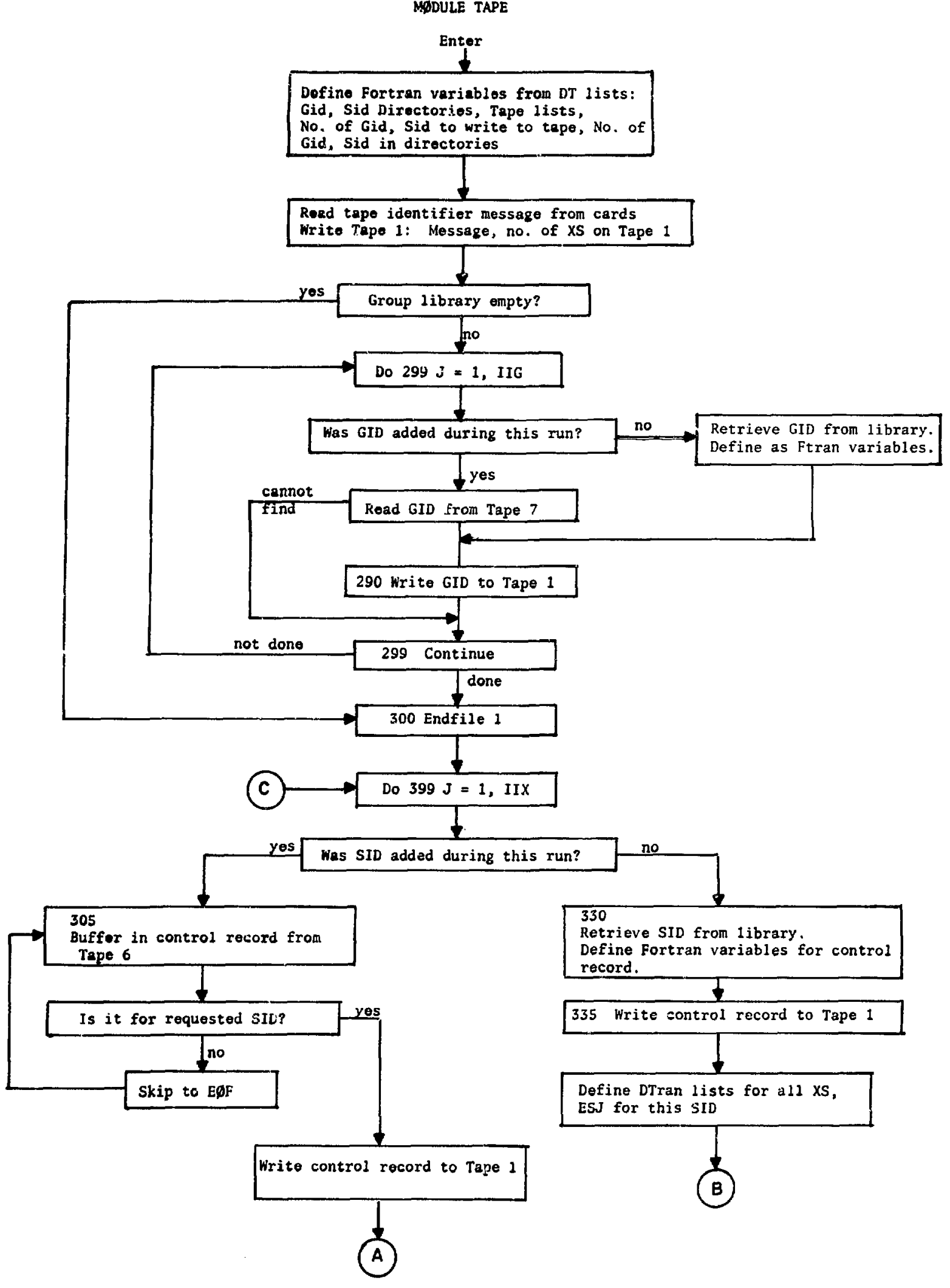




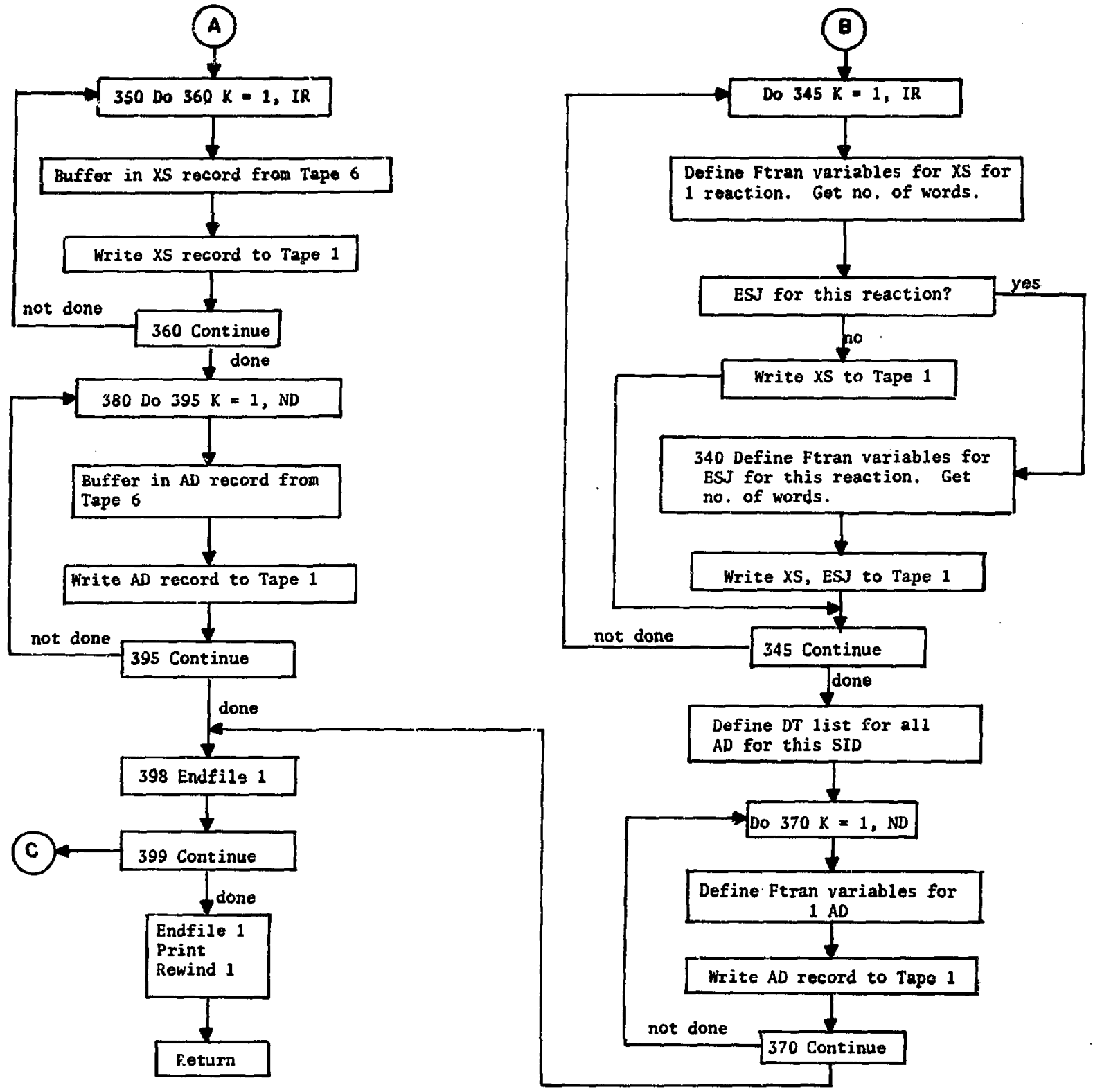


APPENDIX B

CODE LISTING

LASL Identification: LP-0287

JOB MARTY

PROGRAM XSMOD(INPUT,OUTPUT,PUNCH,TAPE1, TAPE2,TAPE18=OUTPUT, TAPE10= PUNCH)

THE DIRECTORY RECALL CARD IS FOR TAPE30 $=$ LB204 RECALL $=67$

PROGRAM XSMOD

THIS PROGRAM WAS WRITTEN FOR THE CDC6600 BY MARTHA S. HOYT AT THE LOS ALAMOS SCIEN'TIFIC LABORATORY, LOS ALAMOS, NEW MEXICO

\section{AUGUST 1973}

TAPE30 DATA TRAN TAPE

TAPE1 FILE TO BE USED FOR EVXS.

TAPE2 UK OR IRLUK INPUT TAPE FOR ADDXS.

\section{KEYWORDS}

ADD ADD A DATASET,MAKE DTRAN TAPE,LIST.

DELETE DELETE A DATASET,MAKE DTRAN TAPE.

EVXS EVXS PROCESSING REQUESTED.

LIST LIST A DATASET.

CONTENTS PRINT GID,SID CURREN: I,Y IN DATATRAN DIRECTORY

TAPE ALL WRITE ALL GID,SID TO TAPE1

TAPE WRITE A DATASET TO TAPE1

LAST LAST INPUT CARD.

COMMON /CDID/IA7, IA8,IA9,IBLNO(100),IDB(100),ICDS(100),DUM(9),LLL

COMMON/DIR/ KGID(300),KSID(300),IDIR,IIG,IIXX,IDIRSV

DIMENSION IDNOG(100),NWDSG(100),IDNOS(100),NWDSS(100)

EQUIVALENCE (KGID(101),IDNOG(1)),(KGID(201),NWDSG(1)),

COMMON /OPTS/ KDIMAG(1100),N(2),IALL,IB

DIMENSION XKDIMAG(1100)

EQUIVALENCE (KDIMAG,XKDIMAG)

DIMENSION M(15),XM(15)

C

EQUIVALENCE $(M, X M)$

DATA (M(I),I=1,15) /10HCHANGE SID, 10HCHANGE GID, 10HEVXS

10HPUNCH GID, 10HADD SID , 10HADD GID, 10HDELETE SID,

10HDELETE GID, 10HLIST SID , 10HLIST GID , 10HCONTENTS ,

C

10HTAPE ALL , 10HTAPE SID , 10HTAPE GID , 10HLAST

IEXIT $=0$

CALL CPAREA(KDIMAG)

ITL=KDIMAG(19) . AND. $77777700000000 \mathrm{~B}$

TL=ITL/100000000B

IC $=$ LOCF(IB) - LOCF(IBLNO(1)) + 1

100

DO $100 \mathrm{I}=1, \mathrm{IC}$

IBLNO $(I)=0$

ITP $=0$

PRINT 8

CROSS SECTION LIBRAKY MODIFICATION CODE + +

$+* / /)$

RECALL N. IMAGES

ERASE IN-1-DAY 21973WRD RMHX1

2

XSMOD

XSMOD

XSMOD

LB204

XSMOD

XSMOD

XSMOD

XSMOD

XSMOD

XSMOD

XSMOD

XSMOD

XSMOD

XSMOD

XSMOD

XS $M$ LOD

XSMOD

XSMOD

XSMOD

XSMOD

XSMOD

XSMOD

XSMOD

XSMOD

XSMOD

XSMOD

XSMOD

XSMOD

XSMOD

XSMOD

XSMOD

CDID

DIR

DIR

DIR

DIR

OPTS

OPTS

OPTS

XSMOD

XSMOD

XSMOD

XSMOD

XSMOD

XSMOD

XSMOD

XSMOD

XSMOD

XSMOD

XSMOD

XSMOD

XSMOD

XSMOD

XSMOD

XSMOD

XSMOD

XSMOD

XSMOD

XSMOD 


\begin{tabular}{|c|c|c|c|}
\hline $\mathbf{C}$ & RECALLS DIRECTORY TO DATATRAN TAPE & XSMOD & 56 \\
\hline C & THIS DIRECTORY RECALL CARD MUST BE CHANGED IF A DIFFERENT TAPE 30 & XSMOD & 57 \\
\hline C & $\begin{array}{l}\text { IS USED. } \\
\text { RECALL D. DIRECT }\end{array}$ & XSMOD & 58 \\
\hline \multirow[t]{10}{*}{ C } & $\begin{array}{l}\text { RECALL D. DIRECT } \\
\text { DEFINE FORTRAN VARIABLES FROM RECALLED DIRECTORY. }\end{array}$ & $\begin{array}{l}\text { LB204 } \\
\text { XSMOD }\end{array}$ & 60 \\
\hline & F. KGID=N. DIRGID. $1 /$ & XSMOD & 61 \\
\hline & F. IDNOG=N. DIRGID. 2/ & XSMOD & 62 \\
\hline & F. NWDSG=N. DIRGID. 3/ & XSMOD & 63 \\
\hline & F. KSID=N. DIRSID. $1 /$ & XSMOD & 64 \\
\hline & F. IDNOS=N. DIRSID. 2 I & XSMOD & 65 \\
\hline & F. NWDSS $=$ N. DIRSID. $\tilde{s}$ / & XSMOD & 66 \\
\hline & F. IIG=WORDS OF N. DIRGID. $1 /$ & XSMOD & 67 \\
\hline & F. IIX=WORDS OF N. DIRSID. 1 I & XSMOD & 68 \\
\hline & F. IDIR=N. IID & XSMOD & 69 \\
\hline \multirow[t]{2}{*}{ C } & INITIALIZE N. IDIRSV & XSMOD & 70 \\
\hline & N. IDIRSV $=0$ & XSMOD & 71 \\
\hline $\mathbf{C}$ & & XSMOD & 72 \\
\hline C & READ IN OPTIONS AND THEIR IDS. & XSMOD & 73 \\
\hline C & & XSMOD & 74 \\
\hline C & PREPARE LISTS FOR MODULE RDJOBS & XSMOD & 75 \\
\hline \multirow[t]{3}{*}{ C } & & XSMOD & 76 \\
\hline & N. RDJOBS=F. XM & XSMOD & 77 \\
\hline & KALL RDJOBS & XSMOD & 78 \\
\hline C & & XSMOD & 79 \\
\hline C & 2ND PASS. PROCESS OPTIONS. & XSMOD & 80 \\
\hline C & & XSMOD & 81 \\
\hline \multirow[t]{3}{*}{ C } & DEFINE FORTRAN VARIABLES FROM RDJOBS OUTPUT LIST & XSMOD & 82 \\
\hline & $\begin{array}{l}\text { F. XKDIMAG=N. RDJOUT. } 1 / \\
\text { F. N=N, RDJOUT. } 2 /\end{array}$ & $\begin{array}{l}\text { XSMOD } \\
\text { XSMOD }\end{array}$ & 83 \\
\hline & F. IALL $=$ N. RDJOUT. $2 / .3$ & $\begin{array}{l}\text { XSMOD } \\
\text { XSMOD }\end{array}$ & $\begin{array}{l}84 \\
85\end{array}$ \\
\hline 199 & $\mathrm{IB}=1$ & XSMOD & 86 \\
\hline \multirow[t]{2}{*}{200} & DO $205 I=1,15$ & XSMOD & 87 \\
\hline & IF(KDLMAG(IB) . EQ. M(I))GO TO 220 & XSMOD & $\mathbf{8 8}$ \\
\hline 205 & CONTINUE & XSMOD & 89 \\
\hline \multirow[t]{3}{*}{210} & $\mathrm{IB}=\mathrm{IB}+11$ & XSMOD & 90 \\
\hline & CALL SECOND(CP) & XSMOD & 91 \\
\hline & IF(TL-CP-5. 0)215,215,200 & XSMOD & 92 \\
\hline \multirow[t]{2}{*}{215} & IEXIT $=1$ & XSMOD & 93 \\
\hline & PRINT 10, TL,CP & XSMOD & 94 \\
\hline \multirow{2}{*}{${ }_{1}^{10}$} & $\begin{array}{l}\text { FORMAT(* LESS THAN } 5 \text { SEC LEFT. EXIT FLAG SET. TL=*F10. 3,5X*CP=* } \\
\text { F10. 3) }\end{array}$ & XSMOD & 95 \\
\hline & Go TO 1000 & $\begin{array}{l}\text { XSMOD } \\
\text { XSMOD }\end{array}$ & $\begin{array}{l}96 \\
97\end{array}$ \\
\hline \multirow{2}{*}{$\begin{array}{r}220 \\
1\end{array}$} & Go TO $(500,550,600,650,700,750,800,850,900,950,960,970,970,970$, & XSMOD & 98 \\
\hline & $1000) I$ & XSMOD & 99 \\
\hline \multirow[t]{2}{*}{500} & CALL CHANGE & XSMOD & 100 \\
\hline & GO TO $21 \mathrm{c}$ & XSMOD & 101 \\
\hline \multirow[t]{2}{*}{550} & CALL CHANGE & XSMOD & 102 \\
\hline & GO TO 210 & XSMOD & 103 \\
\hline \multirow{2}{*}{600} & IEVXS=1 & XSMOD & 104 \\
\hline & GO TO 210 & XSMOD & 105 \\
\hline \multirow[t]{3}{*}{650} & Go TO 210 & XSMOD & 106 \\
\hline & GO TO 210 & XSMOD & 107 \\
\hline & & XSMOD & 108 \\
\hline [ & PREPARE LIST FOR MODULE ADDXS & XSMOD & 109 \\
\hline 700 & N. ADDXS=F, IB,F, TL,F. IEXIT & XSMOD & 110 \\
\hline & CALL SECOND(CP) & XSMOD & 111 \\
\hline & IF(TL- CP- 15. 0)705,705,710 & XSMOD & 112 \\
\hline 705 & IEXIT $=1$ & XSMOD & 113 \\
\hline & PRINT 12, TL, CP & XSMOD & 114 \\
\hline 12 & FORMAT(" LESS THAN 15 SEC LEFT AND NEXT JOB IS ADDXS. EXIT FLAG SET & XSMOD & 115 \\
\hline 1 & $\mathrm{TL}=* \mathrm{~F} i \mathrm{O}, 3,5 \mathrm{X} * \mathrm{CP}=* \mathrm{~F} 10,3)$ & XSMOD & 116 \\
\hline & GO TO 1000 & XSMOD & 117 \\
\hline 710 & KALL ADDXS & XSMOD & 118 \\
\hline & MODIFIED DIRECTORY RETURNED FROM ADDXS & XSMOD & 119 \\
\hline & F. KSID=N. DIRSID. $1 /$ & XSMOD & 120 \\
\hline & F. IDNOS=N. DIRSID. 2I & XSMOD & 121 \\
\hline & F. NWDSS=N. DIRSID. 3i & XSMOD & 122 \\
\hline & F. IIX=WORDS OF N. DIRSID. I/ & XSMOD & 123 \\
\hline & $\begin{array}{l}\text { F. IDIRSV=N, IDIRSV } \\
\text { E IEXIT }=\text { N. ADDXS, } 3\end{array}$ & XSMOD & 124 \\
\hline & IF(IEXIT. EQ I)GO TO 1000 & XSMOD & $\begin{array}{l}120 \\
126\end{array}$ \\
\hline
\end{tabular}




\begin{tabular}{|c|c|c|c|}
\hline & GO TO 210 & XSMOD & 127 \\
\hline $\begin{array}{l}\mathbf{C} \\
\mathbf{C}\end{array}$ & PREPARE LIST FOR MODULE ADDG & XSMOD & $\begin{array}{l}128 \\
129\end{array}$ \\
\hline \multirow[t]{2}{*}{750} & $\begin{array}{l}\text { PREPARE LIST FOR MODULE ADDG } \\
\text { N. ADDG=F. IB,F. TL,F. IEXIT,O }\end{array}$ & $\begin{array}{l}\text { XSMOD } \\
\text { XSMOD }\end{array}$ & $\begin{array}{l}129 \\
130\end{array}$ \\
\hline & CALL SECOND(CP) & XSMOD & \\
\hline 760 & IEXIT $=1$ & XSMOD & 13 \\
\hline \multirow{3}{*}{14} & $\begin{array}{l}\text { PRINT 14, TL,CP } \\
\text { FORMAT(* LESS THAN } 10 \text { SEC LEFT AND NEXT JOB IS ADDG. EXIT FLAG SET }\end{array}$ & XSMOD & 15 \\
\hline & $\begin{array}{l}\text { FORMAT(* LESS THAN } 10 \text { SEC LEFT AND NEXT JOB IS ADDG. EXIT FLAG SET } \\
\left.\text {. TL }={ }^{*} \mathrm{~F} 10.3,5 \mathrm{X}^{*} \mathrm{CP}={ }^{*} \mathrm{~F} 10.3\right)\end{array}$ & XSMOD & 15 \\
\hline & $\begin{array}{l}\text { TL=*F10. 3,5X*CP=*F10. 3) } \\
\text { GO TO } 1000\end{array}$ & $\begin{array}{l}\text { XSMOD } \\
\text { XSMOD }\end{array}$ & \\
\hline \multirow{10}{*}{$c^{770}$} & KALL ADDG & XSMOD & \\
\hline & MODIFIED DIRECTORY RETURNED FROM ADDG & XSMOD & 13 \\
\hline & F. KGID=N. DIRGID. $1 /$ & XSMOD & \\
\hline & F. IDNOG=N. DIRGID. 21 & XSMOD & \\
\hline & F. NWDSG $=$ N. DIRGID. $3 /$ & XSMOD & 14 \\
\hline & F. IIG=WORDS OF N. DIRGID. $1 /$ & XSMOD & 14 \\
\hline & F. IDIRSV =N. IDIRSV & XSMOD & 14 \\
\hline & F. IEXIT $=$ N. ADDG. 3 & XSMOD & \\
\hline & IF(IEXIT . EQ. 1)GO TO 1600 & XSMOD & 14 \\
\hline & Go To 210 & XSMOD & 14 \\
\hline \multirow[t]{2}{*}{$\mathbf{8 0 0}$} & CALL DELETE(KSID,IIX,1) & XSMOD & \\
\hline & Go To 210 & XSMOD & \\
\hline \multirow[t]{2}{*}{850} & CALL DELETE(KG ID,IIG,2) & XSMOD & \\
\hline & GO TO 210 & XSMOD & 15 \\
\hline \multirow{4}{*}{${ }^{C_{900}}$} & PREPARE LIST FOR MODULE LISTXS & XSMOD & 15 \\
\hline & N. LISTXS=F. IB & XSMOD & 15 \\
\hline & KALL LISTXS & XSMOD & \\
\hline & GO TO 210 & XSMOD & 15 \\
\hline C 950 & $\begin{array}{l}\text { PREPARE LIST FOR MODULE ADDG TO LIST A GROUP } \\
\text { LISTFL=1 }\end{array}$ & $\begin{array}{l}\text { XSMOD } \\
\text { XSMOD }\end{array}$ & 15 \\
\hline & N. ADDG=F, IB,F, TL,F. IEXIT,F. LISTFL & XSMOD & 13 \\
\hline & KALL ADDG & XSMOD & \\
\hline & Go To 210 & XSMOD & 16 \\
\hline \multirow[t]{2}{*}{960} & CALL CONTENT & XSMOD & 16 \\
\hline & GO TO 210 & XSMOD & \\
\hline \multirow{3}{*}{$C_{970}$} & SET FLAG FOR MAKING TAPE1 FILE. ENTER TAPE MODULE LAST. & XSMOD & 16 \\
\hline & ITP=1 & XSMOD & 164 \\
\hline & Go TO 210 & XSMOD & 16 \\
\hline \multirow{3}{*}{${ }_{1000}^{C}$} & DEFINE AND SAVE DIRECTORY IF MODIFIED & XSMOD & 16 \\
\hline & $\begin{array}{l}\text { IF(IDIRSV . NE. O)GO TO } 1003 \\
\text { IF(IEXIT . EQ. 1)CALL EXIT }\end{array}$ & $\begin{array}{l}\text { XSMOD } \\
\text { XSMOD }\end{array}$ & 16 \\
\hline & Go TO 1005 & XSMOD & 16 \\
\hline \multirow[t]{4}{*}{1003} & IDIR=IDIRSV + 1 & XSMOD & 170 \\
\hline & N. IID=F. IDIR & XSMOD & 17 \\
\hline & D. DIRECT $=$ N. DIRGID/N. DIRSID/N. IID & XSMOD & 17 \\
\hline & PRINT 16 & XSMOD & 173 \\
\hline \multirow[t]{5}{*}{16} & FORMAT(1H1) & XSMOD & 174 \\
\hline & SAVE D. DIRECT & XSMOD & 175 \\
\hline & N. LIST =DIRECT & XSMOD & 176 \\
\hline & KALL IMAGE & XSMOD & 177 \\
\hline & IF(IEXIT . EQ. 1)CALL ABORT & XSMOD & 178 \\
\hline \multirow[t]{2}{*}{1005} & $\begin{array}{l}\text { IF(ITP NE. 1)GO TO } 1050 \\
\text { KALL TAPE }\end{array}$ & XSMOD & 179 \\
\hline & IF(IEVXS . NE, 1)GO TO 1050 & XSMOD & 181 \\
\hline 2 & FORMAT $\left(/ /^{*}\right.$ ALL OFTIONS PROCESSED. READY TO BEGIN LINKING, DIRECTORY & XSMOD & 182 \\
\hline 1 & RECALL NO. * ${ }^{*}(4)$ & XSMOD & 183 \\
\hline & PRINT 2, IDIR & XSMOD & 184 \\
\hline & ENDFILE 18 & XSMOD & 185 \\
\hline & CALL OVERLAY (4HEVXS,0,0) & XSMOD & 186 \\
\hline & PRINT 4 & XSMOD & 187 \\
\hline 4 & FORMAT( $/ *$ RETURNED FROM EVXS. END JOB. *) & XSMOD & 188 \\
\hline & CALL EXIT & XSMOD & 189 \\
\hline 1050 & PRINT 6, IDIR & XSMOD & 190 \\
\hline 6 & FORMAT(/"* END JOB. NO EVXS PROCESSING REQUESTED. DIRECTORY RECALL $N$ & XSMOD & 191 \\
\hline 1 & o. $-(4)$ & XSMOD & 192 \\
\hline & EXND & XSMOD & 193 \\
\hline & SUBROUTINE CHANGE & XSMOD & 194 \\
\hline & PRINT 2 & XSMOD & 195 \\
\hline 2 & $\begin{array}{l}\text { FORMAT( } / \text { ENTERED SUBROUTINE CHANG } \\
\text { RETURN }\end{array}$ & $\begin{array}{l}\text { XSMOD } \\
\text { XSMOD }\end{array}$ & $\begin{array}{l}196 \\
197\end{array}$ \\
\hline
\end{tabular}


END

SUBROUTINE CONTENT

C PRINT CURRENT CONTENTS OF DIRECTORY

COMMON/DIR/ KGID(300),KSID(300),IDIR,1IG.1IX,IDIRSV

DIMENSION IDNOG(100),NWDSG(100),IDNOS(100), NWDSS(100)

1

EQUIVALENCE (KGID(101),IDNOG(1)),(KGID(201),NWDSG(1)), (KSID(101),IDNOS(1)),(KSID(201),NWDSS(1))

PRINT 2

2 FORMAT $(* 1$ CONTENTS OF DATATRAN TAPE DIRECTORY* $)$

PriNT 4, (KGID(I),1=1,11G)

FORMAT $\left.{ }^{*} \operatorname{GID}^{*} /(12 \mathrm{11} 0)\right)$

PRINT 6, (KSID(I), I=1,IIX)

FORMAT $\left(/ /^{*}\right.$ SID*/(12I10))

PRINT 8, IDIR,IDIRSV

FORMAT $/ / *$ RECALL ID NO. OF DIRECTORY *I3* DIRECTORY SAVE FLAG=

- I4//* IF SAVE FLAG=0 DIRECTORY ID OK. OTHERWISE DIRECTORY IS BEIN

G UPDATED AND ID NO. NOT AVAILABLE UNTIL END OF JOB.")

RETURN

END

SUBROUTINE DELETE(KDIR,IIK,JJ)

C
C
C
C
C
C
C
C

DELETES FROM DIRECTORY SPECIFIED KIDS AND THEIR ASSOCIATED RECALL

NOS. AND NOS. OF WORDS. CLOSES UP DIRECTORY.

PRINTS OUT INFORMATION NEEDED FOR A DTPURGE JOB.

IB INDEX TO KDIMAG

J] $=1$,DELETING SID. $=2$,DELETING GID

KDIR DIRECTORY FROM WHICH DELETE IS BEING MADE.

IIK NO. OF ITEMS IN DIRECTORY.

COMMON /DIR/ KGID(300),KSID(300),IDIR,IIG,IIX,IDIRSV

COMMON /OPTS/ KDIMAG(1100),N(2),IALL,IB

DIMENSION XKDIMAG(1100)

EQUIVALENCE (KDIMAG,XKDIMAG)

C

DIMENSION KDIR(300)

DIMENSION HOL(2)

DATA HOL(1),HOL(2) /3HSID, 3HGID/

C

SET FLAG TO SAVE NEW DIRECTORY=HIGHEST ID NO. IN LIBRARY

IDIRSV=MAXO(KGID(IIG+ 100), KSID(IIX+100),IDIR)

IC=IB

$100 \quad I C=I C+1$

IF(KDIMAG(IC). EQ. O)GO TO 150

IF((KDIMAG(IC) . AND. 77000000000000000000B) . NE. 0)GO TO 150

KID=KDIMAG(IC)

DO $110 \quad I=1$, IIK

IF(KID . NE. KDIR(I))GO TO 110

PRINT 2, HOL(JJ),KDIR(I),KDIR(I+ 100),KDIR(I+ 200)

2

FORMAT(** DELETE FROM LIBRARY *A3,14* WITH RECALL 1D**I4* NWDS="I6 )

$\operatorname{KDIR}(I)=0$

$\operatorname{KDIR}(I+100)=0$

$\operatorname{KDIR}(I+200)=0$

GO TO 100

110 CONTINUE

PRINT 4, HOL(JJ),KID

4 FORMAT( $/ *$ CANNOT FiND *A3,I4* IN DIRECTORY. DELETE WAS REQUESTED*) GO TO 100

C

PRINT RECALL ID NO. OF OLD DIRECTORY FOR DTPURGE JOB.

PRINT 6, IDIR

FORMAT(* RECALL ID NO. OF OLD DIRECTORY IS"I4*, USE FOR DTPURGE JOB

C TO TAKE OLD DIRECTORY OFF LIBRARY TAPE. ")

CLOSE UP DIRECTORY

DO 170 Jal,IIK

IF(KDIR(I) . NE. O)GO TO 170

IIK=IIK- 1

IF(I . GT. IIK)GO TO 170

DO $160 \mathrm{~J}=\mathrm{I}, \mathrm{IIK}$

$\operatorname{KDIR}(J)=\operatorname{KDIR}(J+1)$

XSMOD

XSMOD

XSMOD

XSMOD

DIR

DIR

DIR

DIR

XSMOD

XSMOD

XSMOD

XSMOD

XSMOD

XSMOD

XSMOD

XSMOD

XSMOD

XSMOD

XSMOD

XSMOD

XSMOD

XSMOD

XSMOD

XSMOD

XSMOD

XSMOD

XSMOD

XSMOD

XSMOD

XSMOD

XSMOD

OPTS

OPTS

OPTS

XSMOD

XSMOD

XSMOD

XSMOD

XSMOD

XSMOD

XSMOD

XSMOD

XSMOD

XSMOD

XSMOD

XSMOD

XSMOD

XSMOD

XSMOD

XSMOD

XSMOD

XSMOD

XSMOD

XSMOD

XSMOD

XSMOD

XSMOD

XSMOD

XSMOD

XSMOD

XSMOD

XSMOD

XSMOD

XSMOD

XSMOD

XSMOD

XSMOD

XSMOD

XSMOD

XSMOD

XSMOD 
C.

KDIR(J+ 200)=KDIR(J + 201)

CONTINUE

CHECK SAME LOCATION FOR ANOTHER D.

$1=1$

C

CONTINUE

DEFINE CURRENT GID/SID DIRECTORIES

IF(IIK . EQ. O) IIK $=1$

IF(J) . EQ. 1)IIX $=11 \mathrm{~K}$

IF(J) . EQ. 2)IIG=IIK

IIGZ $=11 G+100$

IIG3=11G+ 200

N. DIRGID=(F. KGID(I),I=1,IIG)/(F. KGID(I),I=10I, $I I G 2) /$

(F. KGID(1), $\mid=201,11 G 3$ )

$11 X 2=11 X+100$

$11 \times 3=11 X+200$

N. DIRSID=(F. KSID(I),I=1,IIXy/F. KSID(I),I=101,IIX2)I

(F. $\operatorname{KSID}(1), 1=201,11 \times 3$ )

RETURN

END

MODULE ADDG

PROGRAM ADDG(INPUT,OUTPUT,PUNCH,TAPEIOEPUNCH,TAPE7)

ADDS GID TO LIBRARY FROM CARDS. USES UNNORMALIZED ENERGY-FLUX PAIRS 612 COLUMN RIGHT JUSTIFIED NUMBERS/CARD. SOME INTEGERS. SOME F FMT.

KT NO. OF ITEMS IN T ARRAY FOR 1 GROUP

KGG NO. OF ENERGY. FLUX PAIRS FOR I GROUP

KG TOTAL ENERGY.FLUX PAIRS FOR ALL GROUPS

IGG NO. OF GROUPS

IRV $=0$ INPUT GROUPS NUMBERED IN ASCENDING ORDER.

O INPUT GROUPS NUMBERED IN DESCENDING ORDER.

COMMON/DIR/ KGID(300),KSID(300),IDIR,IIG,IIX,IDIRSV

DIMENSION IDNOG(100),NWDSG(100), IDNOS(100),NWDSS(100)

EQUIVALENCE (KGID(101),IDNOG(1)),(KGID(201),NWDSG(1)), (KSID(101),JDNOS(1)),(KSID(201),NWDSS(1))

COMMON IOPTSI KDIMAG(1100).N(2),IALL,IB

DIMENSION XKDIMAG(1100)

EQUIVALENCE (KDIMAG,XKDIMAG)

COMMON /GRP/ IGID(1),GDES(8),IGG(1),MG(80),GE(80),KG(1),PH(500),

EK(500), VB(80), EMX(80)

COMMON T(1000)

DIMENSION MASK(2),MBLNK(2),FMT(3),P(3),ITAPG(100)

DATA $124 / 100500000 B$

DATA (F(I),I=1,3) $110 \mathrm{H}\left(^{\circ} \mathrm{GID} \cdot 13\right), 10 \mathrm{H}\left({ }^{\circ} \mathrm{GID} \cdot 12\right), 10 \mathrm{H}\left({ }^{\circ} \mathrm{GID} \cdot 11\right)$ /

DATA (FMT(1), Ia1,3) /10H(5XI1) .1OH(5XI2)

DATA MASK(1),MASK(2) 177770000B, 770000B/

DATA MBLNK(1),MBLNK(2) /55550000B, 550000B/

c

C INITIALIZE STORAGES

DO $90 \quad I=1,100$

90 ITAPG(1)=0

C

LISTFLO

C DEFINE FORTRAN VARIABLES FROM DT LISTS

F. KGID-N. DIRGID. 1/

F. IDNOG=N. DIRGID. 21

F. NWDSG=N. DIRGID. 3/

F. NG=WORDS OF N. DIRGID. I/

F. XKDIMAG $=$ N, KDJOUT. I/

F. ITAPG=N. RDJOUT. 3/

F. IALLEN, RDJOUT. 21. 3

F. IB=N. ADDG.

F. TL-N. ADDG. 2

B. LISTFL LN. ADDG.

F. IDIRSV=N. IDIRSV

C

SAVE REEL MHX!

IC-IB

\begin{tabular}{|c|c|}
\hline XSMOD & 264 \\
\hline XSMOD & 265 \\
\hline XSMOD & 266 \\
\hline XSMOD & 267 \\
\hline XSMOD & 268 \\
\hline XSMOD & 269 \\
\hline XSMOD & 270 \\
\hline XSMOD & 271 \\
\hline XSMOD & 272 \\
\hline XSMOD & 273 \\
\hline XSMOD & 274 \\
\hline XSMOD & 275 \\
\hline XSMOD & 276 \\
\hline XSMOD & 277 \\
\hline XSMOD & 278 \\
\hline XSMOD & 279 \\
\hline XSMOD & 280 \\
\hline XSMOD & 281 \\
\hline XSMOD & 282 \\
\hline XSMOD & 283 \\
\hline XSMOD & 284 \\
\hline XSMOD & 285 \\
\hline XSMOD & 286 \\
\hline XSMOD & 287 \\
\hline XSMOD & 288 \\
\hline XSMOD & 289 \\
\hline XSAOD & 290 \\
\hline XSMOD & 291 \\
\hline XSMOD & 292 \\
\hline XSMOD & 293 \\
\hline XSMOD & 294 \\
\hline XSMOD & 295 \\
\hline XSMOD & 296 \\
\hline XSMOD & 297 \\
\hline DIR & 2 \\
\hline DIR & 3 \\
\hline DIR & 4 \\
\hline DIR & 5 \\
\hline OPTS & 2 \\
\hline oPTs & 3 \\
\hline OPTS & + \\
\hline GRP & 2 \\
\hline GRP & 3 \\
\hline XSMOD & 301 \\
\hline XSMOD & 302 \\
\hline XSMOD & 303 \\
\hline XSMOD & 304 \\
\hline XSMOD & 305 \\
\hline XSMOD & 306 \\
\hline XSMOD & 307 \\
\hline XSAIOD & 308 \\
\hline Xsnton & 309 \\
\hline XSMOD & 310 \\
\hline XSAOD & 311 \\
\hline XSMOD & 312 \\
\hline XSMOD & 313 \\
\hline XSAMOD & 314 \\
\hline XSMOD & 315 \\
\hline XSMOD & 316 \\
\hline XSMOD & 317 \\
\hline XSAHOD & 318 \\
\hline XSAKDD & 319 \\
\hline XSMOD & 320 \\
\hline XSMOD & 321 \\
\hline XSAKOD & 322 \\
\hline XSMOD & 323 \\
\hline XSMDD & 324 \\
\hline XSMOD & 325 \\
\hline XSMOD & 326 \\
\hline XSMOD & 327 \\
\hline XSMOD & 328 \\
\hline
\end{tabular}




\begin{tabular}{|c|c|c|c|}
\hline \multirow[t]{2}{*}{100} & IERR $=0$ & XSMOD & 329 \\
\hline & $I C=I C+1$ & XSMOD & 330 \\
\hline \multirow[t]{3}{*}{$\mathbf{C}$} & CHECK FOR RETURN & XSMOD & 331 \\
\hline & IF(KDIMAG(IC) . EQ. 0)GO TO 2000 & XSMOD & 332 \\
\hline & IF((KDIMAG(IC) . AND. 77000000000000000000B) . NE. 0)GO TO 2000 & XSMOD & 333 \\
\hline \multirow[t]{3}{*}{$\mathbf{C}$} & CHECK FOR TIME LIMIT & XSMOD & 334 \\
\hline & CALL SECOND(CP) & XSMOD & 335 \\
\hline & [F(TL-CP-10, 0)110,110,120 & XSMOD & 336 \\
\hline \multirow{2}{*}{110} & IEXIT $=1$ & XSMOD & 337 \\
\hline & PRINT 2, TL,CP & XSMOD & 338 \\
\hline \multirow{4}{*}{${ }^{2}$} & FORMAT(* ADDG. LESS THAN 10 SEC LEFT. ANOTHER ADD REQUESTED. EXIT FL & XSMOD & 339 \\
\hline & AG SET. TL=* $\left.F 10,3,5 X^{*} \mathrm{CP}={ }^{*} \mathrm{~F} 10,3\right)$ & XSMOD & 340 \\
\hline & N. ADDG. $3=F$. IEXIT & XSMOD & 341 \\
\hline & GO TO 2000 & XSMOD & 342 \\
\hline \multirow{3}{*}{$C_{120}$} & CLEAR STORAGES AND N LIST & XSMOD & $3+3$ \\
\hline & $1=$ LOCF $(\operatorname{EMX}(80))-$ LOCF(IGID)+ 1 & XSMOD & 344 \\
\hline & DO $125 \mathrm{~J}=1, \mathrm{I}$ & XSMOD & 345 \\
\hline \multirow[t]{2}{*}{125} & $\operatorname{IGID}(J)=0$ & XSMOD & 346 \\
\hline & DO $126 \mathrm{~J}=1,1000$ & XSMOD & 347 \\
\hline \multirow[t]{2}{*}{126} & $T(J)=0$ & XSMOD & 348 \\
\hline & N. T=NULL & XSMOD & 349 \\
\hline C & & XSMOD & 350 \\
\hline \multirow[t]{2}{*}{$\mathbf{C}$} & CHECK FOR LISTING A GID ALREADY IN THE LIBRARY. & XSMOD & 351 \\
\hline & IF(LISTTLL . EQ. 1)GO TO 650 & XSMOD & 352 \\
\hline \multirow[t]{3}{*}{$\mathbf{C}$} & & XSMOD & 353 \\
\hline & $\begin{array}{l}\text { READ 5, IGID } \\
\text { READ } 3 \text { GDES }\end{array}$ & XSMOD & 354 \\
\hline & READ 3, GDES & XSMOD & 355 \\
\hline \multirow{2}{*}{3} & $\begin{array}{l}\text { FORMAT(8A10) } \\
\text { PRINT 6, IGID,GDES }\end{array}$ & XSMOD & 356 \\
\hline & PRINT 6, IGID,GDES & XSMOD & 357 \\
\hline \multirow[t]{5}{*}{6} & FORMAT(*1WILL READ GID=*14,5X,8A10) & XSMOD & 358 \\
\hline & COMPARE GID ON ADD CARD AND DATA CARD & XSMOD & 359 \\
\hline & IF(KDIMAG(IC) . EQ. IGID)GO TO 130 & XSMOD & 360 \\
\hline & IERR=1 & XSMOD & 361 \\
\hline & PRINF 4. KDIMIAG(IC),IGID & XSMOD & 362 \\
\hline 4 & F.ORMIAT $\left(/ /^{*}\right.$ INPUT ERROR FOR GID. ADD CARD $=* 14^{*}$ DATA CARD $\left.=* 14\right)$ & XSMOD & 363 \\
\hline & Gn to 1000 & XSMOD & 364 \\
\hline c & CHECK GID AGAINST DIRECTORY. & XSMOD & 365 \\
\hline 130 & DO $140 \quad \mid=1, I I G$ & XSMOD & 366 \\
\hline & IF(KGID(I) . EQ. IGID)GO TO 150 & XSMOD & 367 \\
\hline 140 & CONTINUE & XSMOD & 368 \\
\hline & Go To 160 & XSMOD & 369 \\
\hline 150 & IERR=1 & XSMOD & 370 \\
\hline & PRINT 8, IEID & XSMOD & 371 \\
\hline 8 & FORMAT $\left(1{ }^{*}\right.$ GID*13* IS ALREADY IN THE LIBRARY. $\left.{ }^{*}\right)$ & XSMOD & 372 \\
\hline & Go to 1000 & XSMOD & 373 \\
\hline $\mathrm{C}$ & & XSMOD & 374 \\
\hline C & READ DATA & XSMOD & 375 \\
\hline 160 & READ 5, IGG, IRV & XSMOD & 376 \\
\hline 5 & FORMAT(2112) & XSMOD & 377 \\
\hline & NBNDS $=I G G+I$ & XSMOD & 378 \\
\hline & READ 11, (EMX(1),I=1,NBNDS) & XSMOD & 379 \\
\hline & KG=0 & XSMOD & 380 \\
\hline C & & XSMOD & 381 \\
\hline $\mathbf{C}$ & MAIN LOOP. ITEAD AND PROCESS I GROUP AT A TIME. & XSMOD & 382 \\
\hline & 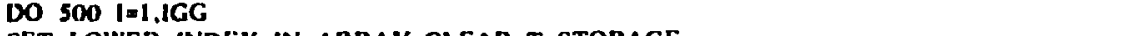 & XSMOD & 383 \\
\hline $\mathbf{C}$ & SET LOWER INDEX IN ARRAY. CLEAR T STORAGE. & XSMOD & 384 \\
\hline & $M G(1)=(K G+1)^{\bullet} 124$ & XSMOD & 385 \\
\hline & DO 170 Jel,1000 & XSMCD & 386 \\
\hline 170 & $T(J)=0$ & XSMOD & 387 \\
\hline & READ 9, KGRP,(T(K),K=1,5) & XSMOD & 388 \\
\hline 9 & FOКмАт(112,5F12) & XSMOD & 389 \\
\hline $\boldsymbol{C}$ & CHECK IF GROUPS IN NORMAL OR REVERSE ORDER AS INDICATED BY IRV & XSMOD & 390 \\
\hline & IF(IRV , EQ. O)GO TO 190 & XSMOD & 391 \\
\hline & IF(NBNDS- KCRP , BQ. I)GO TO 200 & Xsion & 392 \\
\hline 180 & PRINT IO, IRV,KGRP,I & XSMOD & 393 \\
\hline 10 & FORMAT(//" INPUT ERHOR. REVERSE FLAG $={ }^{\bullet} \mid 2^{*}$ GROUP NO. $={ }^{*}\left|3^{\bullet}\right|=\bullet|3|$ & XSMOD & 394 \\
\hline & IERR=1 & XSMOD & 395 \\
\hline & GO TO 1000 & XSMOD & 396 \\
\hline 190 & IF(KGRP . NE. I)GO TO 180 & XSMOD & 397 \\
\hline c & CHECK FOR FLAT FLUX & XSMOD & 398 \\
\hline 200 & $(T 1=T(1)$ & XSMOD & 399 \\
\hline
\end{tabular}




\begin{tabular}{|c|c|c|c|}
\hline \multirow{7}{*}{$\mathbf{C}$} & IF(IT1 _NE. - 1)GO TO 210 & XSMOD & 400 \\
\hline & $\begin{array}{l}\text { FLAT FLUX } \\
\text { T(1)=EMX(I) }\end{array}$ & XSMOD & 401 \\
\hline & $\begin{array}{l}T(1)=\operatorname{EMX}(1) \\
T(2)=T(4)=1.0\end{array}$ & XSMOD & 402 \\
\hline & & XSMOD & 403 \\
\hline & $T(3)=E M X(1+1)$ & XSMOD & 404 \\
\hline & $K T=4$ & XSMOD & 405 \\
\hline & GO TO 300 & XSMOD & 406 \\
\hline C & CHECK LOWEST ENERGY VALUE AGAINST BOUNDARY & XSMOD & 407 \\
\hline 210 & IF(ABS(T(1)- EMX(I))- .001 *EMX(I))220,220,215 & XSMOD & 408 \\
\hline 215 & PRINT 12, T(1),EMX(I),I,IGID & XSMOD & 409 \\
\hline 12 & FORMAT $\left(/ /^{*}\right.$ FIRST ENERGY VALUE NOT EQUAL TO LOWER BNDRY. E="E13.6" & XSMOD & 410 \\
\hline \multirow[t]{3}{*}{1} & BNDRY $=* E 13.6^{*} I=* 13 *$ GID $\left.={ }^{*} I 4\right)$ & XSMOD & 411 \\
\hline & IERR=1 & XSMOD & 412 \\
\hline & Go TO 1000 & XSMOD & 413 \\
\hline C & CHECK FOR ONLY ONE CARD & XSMOD & 414 \\
\hline \multirow[t]{4}{*}{220} & $\mathbf{K T}=\mathbf{0}$ & XSMOD & 415 \\
\hline & CALL LAST $(1,5, \mathrm{KT}$, NGO,IERR,EMX(I+ 1)) & XSMOD & 416 \\
\hline & IF(IERR . NE. O)GO TO 1000 & XSMOD & 417 \\
\hline & GO TO $(230,250,300) N G O$ & XSMOD & 418 \\
\hline C & & XSMOD & 419 \\
\hline $\mathbf{C}$ & READ NEXT CARD & XSMOD & 420 \\
\hline \multirow[t]{2}{*}{230} & $K L=K T+5$ & XSMOD & 421 \\
\hline & READ $11,(T(K), K=K T, K L)$ & XSMOD & 422 \\
\hline \multirow[t]{2}{*}{11} & FORMAT(6F12) & XSMOD & 423 \\
\hline & $\mathrm{KS}=\mathrm{KT}+1$ & XSMOD & 424 \\
\hline \multirow[t]{4}{*}{ C } & CHECK FOR LAST CARD & XSMOD & 425 \\
\hline & CALL LAST(KS,KL.KT,NGO,IERR,EMX(I+1)) & XSMOD & 426 \\
\hline & IF(IERK . NE. O)GO TO 1000 & XSMOD & 427 \\
\hline & GO TO(230,250,300)NGO & XSMOD & 428 \\
\hline C & & XSMOD & 429 \\
\hline c & READ ONE VALUE FROM NEXT CARD & XSMOD & 430 \\
\hline \multirow[t]{3}{*}{250} & READ $11 . T(K T)$ & XSMOD & 431 \\
\hline & & XSMOD & 432 \\
\hline & PROCESS & XSMOD & 433 \\
\hline \multirow{13}{*}{$c^{300}$} & $T 3=T 4=T 5=0$ & XSMOD & 434 \\
\hline & GET NO, OF PAIRS FOR THIS GROUP & XSMOD & 435 \\
\hline & KGG $=K T / 2$ & XSMOD & 436 \\
\hline & DO $310 \mathrm{~J}=3, \mathrm{KT}, 2$ & XSMOD & 437 \\
\hline & $T 3=T 3+A I N T L N(T(J-2), T(J), T(J-1), T(J+1))$ & XSMOD & 438 \\
\hline & $T 2 S=S Q R T(T(J-2))$ & XSMOD & 439 \\
\hline & TS=SQRT(T(J)) & XSMOD & 440 \\
\hline & $F 1=T(J-1) / T 2 S$ & XSMON & 441 \\
\hline & $F 2=T(J+1) / T S$ & XSMOD & 442 \\
\hline & $\mathrm{T} 4=\mathrm{T} 4+\operatorname{AINTLN}(\mathrm{T}(\mathrm{J}-2), \mathrm{T}(\mathrm{J}), \mathrm{F} 1, \mathrm{~F} 2)$ & XSMOD & 443 \\
\hline & $F 3=T(J-1) * T 2 S$ & XSMOD & 444 \\
\hline & $F 4=T(J+1)^{\bullet} T S$ & XSMOD & 445 \\
\hline & T5=T5 + AINTLN(T(J-2),T(J),F 3,F4) & XSMOD & 446 \\
\hline \multirow{2}{*}{$c^{310}$} & CONTINUE & XSMOD & 447 \\
\hline & & XSMOD & $\mathbf{4 4 8}$ \\
\hline \multirow[t]{7}{*}{ C } & NORMALIZE FLUX AND FILL PH AND EK ARRAYS & XSMOD & 449 \\
\hline & $J B=K G+1$ & XSMOD & 450 \\
\hline & $J E=K G+K G G$ & XSMOD & 451 \\
\hline & $J \mathbf{J}=\mathbf{0}$ & XSMOD & 452 \\
\hline & DO $320 \mathrm{~J}=\mathrm{JB}, \mathrm{JE}$ & XSMOD & 453 \\
\hline & $J \int=J j+2$ & XSMOD & 454 \\
\hline & $\operatorname{EK}(\eta)=T(J) \cdot 1)$ & XSMOD & 455 \\
\hline \multirow{2}{*}{320} & $\begin{array}{l}\text { PH(J)=T(J)/T. } \\
\text { CONTINUE }\end{array}$ & XSMOD & 456 \\
\hline & & XSMOD & $\begin{array}{l}457 \\
458\end{array}$ \\
\hline \multirow[t]{3}{*}{ c } & CALCULATE AVERAGE ENERGY AND VELOCITY FOR THIS GROUP & XSMOD & 459 \\
\hline & $V B(i)=13.83^{*} \mathrm{~T} 3 / \mathrm{T} 4$ & XSMOD & $\mathbf{4 6 0}$ \\
\hline & GE(1)=T $5 / T 4$ & XSMOD & 461 \\
\hline C & UPDATE TOTAL PAIRS FOR ALL GROUPS AND PACK INDEX & XSMOD & 462 \\
\hline & $\mathbf{K G}=\mathbf{K G}+\mathbf{K G G}$ & XSMOD & 463 \\
\hline & $M G(I)=M G(i)+\cdot K G$ & XSMOD & 464 \\
\hline $\begin{array}{l}\mathbf{C} \\
\mathbf{C}\end{array}$ & & XSMOD & 465 \\
\hline $\mathbf{C}$ & DEFINE DTRAN ARRAY FOR INPUT FLUX FOR 1 GROUP & XSMOD & 466 \\
\hline & $N, T(I)=(P, T(J), J=2, K T, 2) /$ & XSMOD & 467 \\
\hline$c^{500}$ & CONTINUE & XSMOD & 468 \\
\hline C & $\begin{array}{l}\text { DEFINE AND SAVE DTRAN ARRAYS,UPDATE DIRECTORY } \\
\text { IP(IGID . LT. 1000)GO TO SOS }\end{array}$ & $\begin{array}{l}\text { XSMOD } \\
\text { XSMOD }\end{array}$ & $\begin{array}{l}469 \\
470\end{array}$ \\
\hline
\end{tabular}




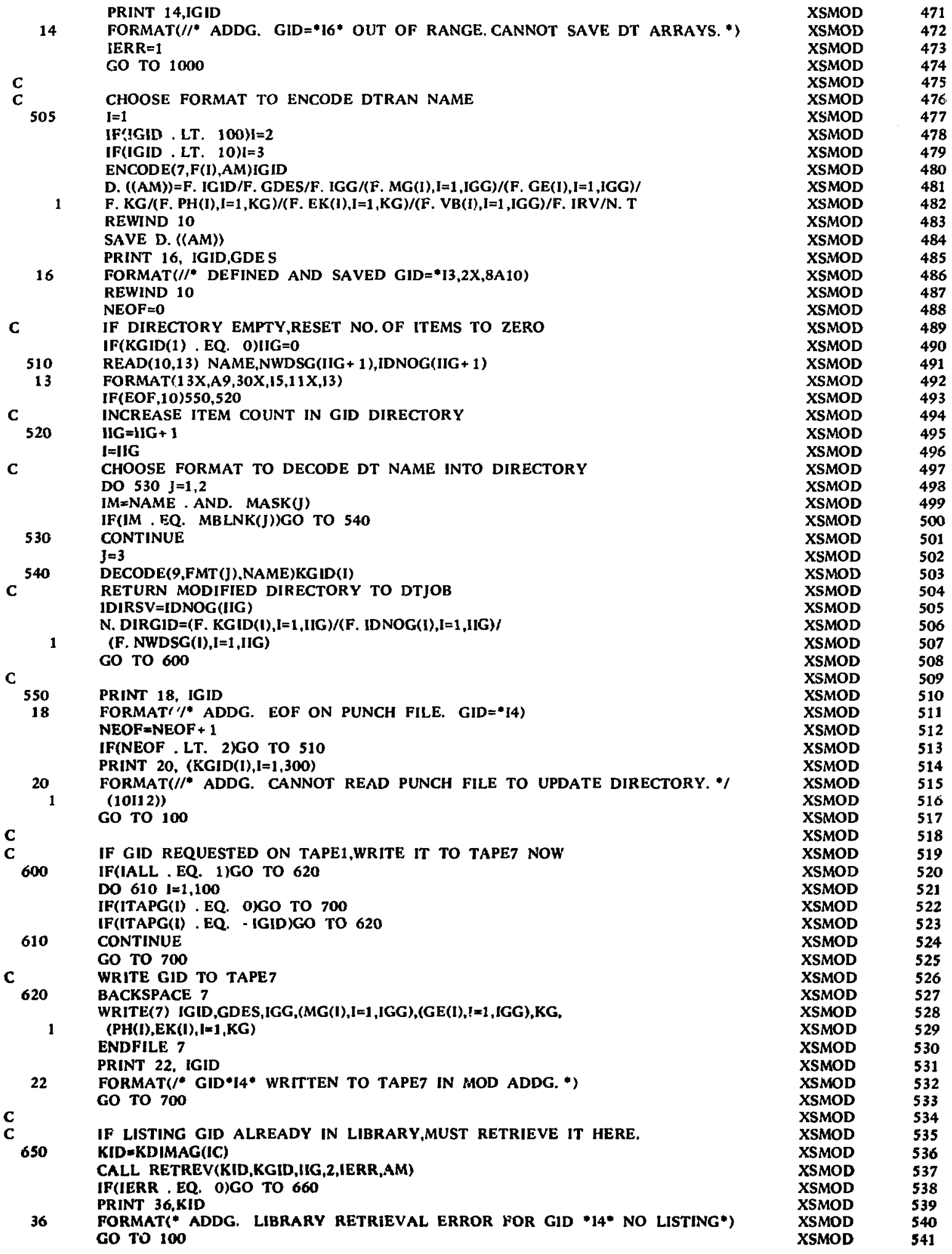


F. IGG=D. ((AM)). 3/

F. $M G=D$. $((A M)) .4$ /

F. $G E=D .((A M)) .5$ /

F. $K G=D .((A M)) .6 /$

F. $\mathrm{PH}=$ D. $((\mathrm{AM})) .7 /$

F. $E K=D .((A M)) .8$ /

F. $V B=D$. $((A M)) .9$,

F. IRV $=$ D. ((AM)) .10 /

C

N. T=D. ((AM)). N. T

NBNDS=IGG +1

C

C LIST DATA HERE

700 PRINT 30,IGID,GDES

30 FORMAT $(* 1$ GID $=* \mid 6,6 \mathrm{X}, 8 \mathrm{~A} 10 /$

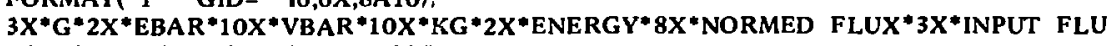

XSMOD

XSMOD

XSMOD

XSMOD

XSMOD

XSMOD

$\begin{array}{ll}1 & 3 X^{*} G^{*} 2 X^{*} \text { EBAR* } 10 X^{*} \text { VBAR } \\ 2 & X^{*} 4 X^{*} \text { FLUX } 10 X^{*}\end{array}$

XSMOD

$\mathrm{K}=1$

$\mathrm{X}=\mathrm{PH}(1)$

DO 950 I=1, IGG

F. $\mathbf{T}=\mathbf{N}$. $\mathbf{T}(\mathrm{l})$

JT=1

$\mathrm{J} 1=\mathrm{MG}(\mathrm{I}) / 124$

$J 2=M G(I)-J 1 \cdot 124$

II =I

IF(IRV . NE. O) II=NBNDS- I

$F L=P H(K) / X$

PRINT 32, II,GE(I), VB(I),K,EK(K),PH(K),T(1),FL,J1,J2

FORMAT(14,1P2E14. 6,I4,1P4E14. 6,2I8)

$\mathrm{J} 1=\mathrm{J} 1+1$

DO $925 \mathrm{~J}=\mathrm{J1}, \mathrm{J} 2$

$\mathrm{JT}=\mathrm{JT}+1$

$F L=P H(J) / X$

PRINT 34, J,EK(J),PH(J),T(JT),FL

34 FORMAT(32X,I4, 1 P4E1 4. 6)

925 CONTINUE

$K=] 2+1$

$\mathrm{X}=\mathrm{X} * \mathrm{PH}(\mathrm{K}) / \mathrm{PH}(\mathrm{J} 2)$

C

CONTINUE

XSMOD

XSMOD

XSMOD

XSMOD

XSMOD

XSMOD

XSMOD

XSMOD

XSMOD

XSMOD

XSMOD

XSMOD

XSMOD

XSMOD

XSMOD

XSMOD

XSMOD

XSMOD

XSMOD

XSMOD

XSMOD

XSMOD

XSMOD

IF LISTING ONLY,CHECK FOR NEXT GID

XSMOD

IF(LISTFL . EQ. 1)GO TO 100

C IF NO ERROR, SKIP BLANK CARD AT END OF GROUP.

C ERROR. SKIP REMAINING DATA CARDS FOR THIS GROUP

XSMOD

XSMOD

XSMOD

XSMOD

XSMOD

XSMOD

XSMOD

IF(T(1) . NE. $10 \mathrm{H}$

)GO TO 1000

GO TO 100

XSMOD

RETURN

END

C

FUNCTION AINTLN(E1,E2,F1,F2)

XSMOD

XSMOD

XSMOD

$\mathrm{X} 1=\mathrm{E} 1 * \mathrm{~F} 1$

$\mathrm{X}_{2}=\mathrm{E} 2 * \mathrm{F2}$

IF(TEST $(X 1, X 2)$. NE. 0)GO TO 200

AINTLN=X1 *ALOG(E2/E1)

C

RETURN

XSMOD

XSMOD

XSMOD

XSMOD

XSMOD

XSMOD

XSMOD

AINTLN $=(X 2-X 1) * A L O G(E 2 / E 1) / A L O G(X 2 / X 1)$

XSMOD

XSMOD

END

c

FUNCTION TEST $(X, Y)$

XSMOD

XSMOD

IF(ABS(X- Y))100,200,100

$100 \quad \mathrm{Z}=(\mathrm{X}-\mathrm{Y}) /(\mathrm{ABS}(\mathrm{X})+\mathrm{ABS}(\mathrm{Y}))$

IF(ABS(Z)- 1. OE- 06)200,200,110

XSMOD

XSMOD

XSMOD

110 TEST $=2$

XSMOD 


\begin{tabular}{|c|c|c|c|}
\hline & RETURN & XSMOD & 613 \\
\hline C & & XSMOD & 614 \\
\hline \multirow[t]{4}{*}{200} & TEST $=0$ & XSMOD & 615 \\
\hline & RETURN & XSMOD & 616 \\
\hline & END & XSMOD & 617 \\
\hline & SUBROUTINE LAST(JS,JE,KT,NGO,IERR,EMX) & XSMOD & 518 \\
\hline C & CHECKS TO SEE IF CARD JUST READ IS LAST ONE FOR TILS GROUP AND & XSMOD & 619 \\
\hline C & CHECKS FOR INCREASING ENERGY WITHIN GROUP. & XSMOD & 620 \\
\hline C & INDEX TO T ARRAY WHERE CHECK WILL START & XSMOD & 621 \\
\hline C & INDEX TO T ARRAY WHERE CHECK WILL END & XSMOD & 622 \\
\hline C & INDEX TO T ARRAY WHICH RETURNS POINTER TO NEXT PLACE IN T & XSMOD & 623 \\
\hline $\mathbf{C}$ & ARRAY IF ANOTHER CARD IS TO BE READ. IF LAST CARD HAS & XSMOD & 624 \\
\hline C & BEEN READ, KT RETURNS NO. OF ITEMS IN T ARRAY. & XSMOD & 625 \\
\hline C & FLAG TO BE RETURNED FOR COMPUTED GO TO & XSMOD & 626 \\
\hline C & $=1$ READ ANOTHER FULL CARD & XSMOD & 627 \\
\hline C & $=2$ READ ONLY 1 VALUE FROM NEXT CARD & XSMOD & 628 \\
\hline C & =3 READING DONE. START PROCESSING. & XSMOD & 629 \\
\hline C & ERROR FLAG. IF=0,EVERYTHING OK. & XSMOD & 630 \\
\hline $\mathbf{C}$ & UPPER ENERGY BOUNDARY. & XSMOD & 631 \\
\hline \multirow[t]{2}{*}{$\mathbf{C}$} & & XSMOD & 632 \\
\hline & COMMON T(1000) & XSMOD & 633 \\
\hline \multirow[t]{3}{*}{ C } & & XSMOD & 634 \\
\hline & DO $160 \mathrm{~J}=\mathrm{JS}, \mathrm{JE}, 2$ & XSMOD & 635 \\
\hline & $1 F(T(J)-E M X) 130,110,100$ & XSMOD & 636 \\
\hline 100 & PRINT 2, T(J),EMX,J,KT & XSMOD & 637 \\
\hline 2 & FORMAT $\left(/ /^{*}\right.$ SUBR LAST. INTERMEDIATE ENERGY GREATER THAN EMAX. T(j)=* & XSMOD & 638 \\
\hline \multirow[t]{2}{*}{1} & E15. 8* EMX $=* E 15.8 * J=*(4 * K T=* 14)$ & XSMOD & 639 \\
\hline & GO TO 1000 & XSMOD & 640 \\
\hline 110 & IF(J . EQ. JE)GO TO 120 & XSMOD & 641 \\
\hline \multirow[t]{4}{*}{ C } & READY TO PROCESS & XSMOD & 642 \\
\hline & $\mathrm{KT}=\mathrm{J}+1$ & XSMOD & 643 \\
\hline & NGO=3 & XSMOD & 644 \\
\hline & GO TO 2000 & XSMOD & 645 \\
\hline C & READ ONE MORE VALUE & XSMOD & 646 \\
\hline \multirow[t]{3}{*}{120} & $\mathrm{KT} \approx \mathrm{j}+1$ & XSMOD & 647 \\
\hline & NGO $=2$ & XSMOD & 648 \\
\hline & GO TO 2000 & XSMOD & 649 \\
\hline C & & XSMOD & 650 \\
\hline 130 & IF(I. EQ. 1)GO TO 160 & XSMOD & 651 \\
\hline \multirow[t]{2}{*}{ C } & CHECK FOR INCREASING ENERGY & XSMOD & 652 \\
\hline & I $F(T(J)-T(J-2)) 140,140,160$ & XSMOD & 653 \\
\hline 140 & PRINT 4, J,KT,T(J),T(J-2),EMX & XSMOD & 654 \\
\hline 4 & FORMAT $\left(/{ }^{*}\right.$ SUBR LAST. ENERGIES NOT INCREASING. J=*14* KT=*I4/ & XSMOD & 655 \\
\hline \multirow[t]{2}{*}{1} & $\left.* T(J)={ }^{*} E 15.8^{*} T(J-2)=* E 15 . B^{*} \quad E M X=* E 15.8\right)$ & XSMOD & 656 \\
\hline & GO TO 1000 & XSMOD & 657 \\
\hline \multirow[t]{4}{*}{160} & CONTINUE & XSMOD & 658 \\
\hline & $K T=K T+6$ & XSMOD & 659 \\
\hline & $\mathrm{NGO}=1$ & XSMOD & 660 \\
\hline & GO TO 2000 & XSMOD & 661 \\
\hline 1000 & IERR=1 & XSMOD & 662 \\
\hline \multirow[t]{3}{*}{2000} & RETURN & XSMOD & 663 \\
\hline & END & XSMOD & 664 \\
\hline & SUBROUTINE RETREV(KID,KGID,IIK,DUM,IERR,AM) & XSMOD & 665 \\
\hline C & RETRIEVES SELECTED GID FROM DTRAN TAPE & XSMOD & 666 \\
\hline c & KID GID NO. IN LIBRARY & XSMOD & 667 \\
\hline C & KGID DTRAN DIRECTORY TO GID & XSMOD & 668 \\
\hline C & NO. OF GID IN DIRECTORY & XSMOD & 669 \\
\hline C & DUMMY & XSMOD & 670 \\
\hline C & ERROR FLAG. O IF OK. & XSMOD & 671 \\
\hline C & AM DTRAN NAME FOR THIS GID & XSMOD & 672 \\
\hline \multirow[t]{3}{*}{$\mathbf{C}$} & & XSMOD & 673 \\
\hline & DIMENSION KGID $(300), M(3)$ & XSMOD & 674 \\
\hline & DATA $(M(1), I=1,3) / 10 \mathrm{H}\left({ }^{\circ} \mathrm{GID} * \mathrm{I}\right), 10 \mathrm{H}\left({ }^{\circ} \mathrm{GID} \mathrm{ID}^{*} \mathrm{I}\right), 10 \mathrm{H}\left({ }^{\circ} \mathrm{GID} \mathrm{D}^{*} \mathrm{I1}\right) /$ & XSMOD & 675 \\
\hline \multirow[t]{4}{*}{ C } & & XSMOD & 676 \\
\hline & IERR $=0$ & XSMOD & 677 \\
\hline & DO $110 \mathrm{I}=1, \mathrm{IIK}$ & XSMOD & 678 \\
\hline & IF(KID . EQ. KGID(I))GO TO 120 & XSMOD & 679 \\
\hline 110 & CONTINUE & XSMOD & 680 \\
\hline & PRINT 2, KID & XSMOD & 681 \\
\hline 2 & FORMAT1* ADDG,RETREV. CANNOT FIND GID *I3* ON DTRAN TAPE. ") & XSMOD & 682 \\
\hline & ( & XSMOD & 683 \\
\hline
\end{tabular}


GET RECALl NO. ASSOCIATED WITH THIS GID

|F(KID . LT. 100) I=2

XSMOD

IF(KID. LT. 10) I=3

ENCODE (7,M(I),AM)KID

C

DO RETRIEVE

D. $((A M 1))=D$. DT00010 *MHX1* F. K

RETURN

END

END MODULE

MODULE ADDXS

PROGRAM ADDXS(INPUT,OUTPUT,PUNCH,TAPE2,TAPE6,TAPE3 $=$ INPUT,

XSMOD

XSMOD

XSMOD

XSMOD

XSMOD

XSMOD

XSMOD

XSMOD

XSMOD

XSMOD TAPE10=PUNCH)

ADDS SID TO LIBRARY FROM CARDS OR TAPE IN UK OR LLL FORMAT.

CARLS OR TAPE, LLL OR UK ARE SPECIFIED ON IST DATA CARD READ.

SENSE 4 ON TO PRINT UKTAPE DIRECTORY.

TAPE2 UK OR LLL TAPE. ORIGINAL LLL TAPES MUST BE PRE-PROCESSED

XSMOD

XSMOD

XSMOD

XSMOD

XSMOD

XSMOD

XSMOD BY MCGIRT S LRLUK CODE.

N INPUT UNIT. 3=CARDS. 2=TAPE

SOURCE LLL OR UK DATA

IB INDEX TO KDIMAG

CTIND CARDS OR TAPE INDICATOR

NIN NUCLIDE ID NO. TO SEARCH FOR ON TAPE OR CHECK ON CARDS

KID SID NO. IN LIBRARY

ISID NUCLIDE ID NO. READ FROM TAPE OR CARDS

COMMON /CNTRL/ ISID(1),KID,ND,ITIDS(25),SDES(8),IR,ITIDR(50),NES, $\operatorname{ES}(4000), \operatorname{IDR}(50), \mathrm{ME}(50), \mathrm{IRS}(50), \mathrm{QR}(50)$, IZ,MIXT, K2

COMMON $/ \mathrm{X} / \mathrm{X}(\mathbf{4 8 5 0})$

DIMENSION ITID(1),TDES(8), E(400),TK(4000),MD(400),PROB(10), NMU(10)

EQUIVALENCE (ITID(1), $\dddot{X}(1)),(\operatorname{TDES}(1), X(2)),($ NED,X(10)), (E(1),X(11)), (ISYS,X(411)), (A,X(412)), (LEGN,X $\mathbf{X}(413))$,

(KT,X(414)), (TK(1),X(415)), (MD(1),X(4415)), (NINC,X(4815)), (PROB(1),X(4816)), (NMU(1),X(4826))

DIMENSION ESJ(3000)

EQUIVALENCE (ESJ(1),ES(1))

COMMON /CDID/IA7,IA8,IA9,IBLNO(100),IDB(100), ICDS(100), DUM(9), LLL

COMMON/DIR/ KGID(300),KSID(300),IDIR,IIG,IIX,IDIRSV

DIMENSION IDNOG(100),NWDSG(100),IDNOS(100), NWDSS(100)

EQUIVALENCE (KGID(101),IDNOG(1)),(KGID(201),NWDSG(1)), (KSID(101),IDNOS(1)),(KSID(201),NWDSS(1))

COMMON /OPTS/ KDIMAG(1100),N(2),IALL,IB

IIMENSION XKDIMAG(1100)

E:ZUIVALENCE (KDIMAG,XKDIMAG)

C

DIMENSION HOL(4)

DIMENSION MASK(3),MBLNK(3),FMT(4),F(3)

DIMENSION NUK.ID(200),NCARDS(200),P(200),DES(200)

DIMENSION TIAPX(100)

DATA HOL(1),HOL(2),HOL(3) /1HX,5H TAPE,6H CARDS/

DATA SOURCE $/ 6 \mathrm{H}$ UK

DATA (FMT(1),I=1,4) /10H(5XI1) ,10H(5XI2) ,10H(5XI3) $10 \mathrm{H}(5 \mathrm{XI} 4)$,

DATA (MASK(I),l=1,3) /000000000000077777700,000000000000000777700

, O00000000000000007700/

DATA (MBLNK(I),I=1,3)/000000000000055555500

00000000000000555500 , $000000000000000005500 /$

DATA $124 / 10000000 B /$

DATA (F(I),I=1,3) /10H("SID*I4),10H("SID*I3),10H("SID*I2) /

XSMOD

XSMOD

XSMOD

XSMOD

XSMOD

XSMOD

XSMOD

XSMOD

XSMOD

CNTRL

CNTRL

$\mathrm{X}$

ANGD

ANGD

ANGD

ANGD

ANGD

ANGD

ANGD

XS

XS

XS

XSMOD

XSMOD

CDID

DIR

DIR

DIR

DIR

OPTS

OPTS

OPTS

XSMOD

XSMOD

XSMOD

XSMOD

XSMOD

XSMOD

XSMOD

XSMOD

XSMOD

XSMOD

XSMOD

XSMOD

XSMOD

XSMOD

XSMOD

XSMOD

XSMOD 


\begin{tabular}{|c|c|c|c|}
\hline \multirow[b]{2}{*}{90} & DO $90 I=1,100$ & XSMOU & 741 \\
\hline & ITAPX $(I)=0$ & XSMOD & 742 \\
\hline C & & XSMOD & 743 \\
\hline \multirow{11}{*}{ C } & DEFINE FORTRAN VARIABLES TRANSMITTED BY DT LISTS. & XSMOD & 744 \\
\hline & F. KSID=N. DIRSID. 1/ & XSMOD & 745 \\
\hline & F. IDNOS=N. DIRSID. 2 I & XSMOD & 746 \\
\hline & F. NWDSS=N. DIRSID. 3/ & XSMOD & 747 \\
\hline & F. IIX=WORDS OF N. DIRSID. 1/ & XSMOD & 748 \\
\hline & F. IB=N. ADDXS. 1 & XSMOD & 749 \\
\hline & F. TL=N. ADDXS. 2 & XSMOD & 750 \\
\hline & F. XKDIMAG=N. RDjOUT. 1 / & XSMOD & 751 \\
\hline & F. ITAPX=N. RDJOUT. 4/ & XSMOD & 752 \\
\hline & F. IALL=N. RDJOUT. $2 / .3$ & XSMOD & 753 \\
\hline & F. IDIRSV=N. IDIRSV & XSMOD & 754 \\
\hline \multirow[t]{4}{*}{ C } & & XSMOD & 755 \\
\hline & SAVE REEL MHXI & XSMOD & 756 \\
\hline & IERR $=0$ & XSMOD & 757 \\
\hline & $\mathrm{IC}=\mathrm{IB}$ & XSMOD & 758 \\
\hline \multirow{2}{*}{100} & $I C=I C+1$ & XSMOD & 759 \\
\hline & IF(IERR . EQ. 0)GO TO 1105 & XSMOD & 760 \\
\hline C & IF ERROR DETECTED BEFORE ALL CARDS READ,MUST SKIP REMAINING CARDS & XSMOD & 761 \\
\hline \multirow[t]{3}{*}{ C } & FOR NUCLIDE IN ERROR. & XSMOD & 762 \\
\hline & KTOTCDS=KTOTCDS+ IERR & XSMOD & 763 \\
\hline & DO 1100 I=KTOTCDS,NTOTCDS & XSMOD & 764 \\
\hline 1100 & $\operatorname{READ}(N, 11)$ & XSMOD & 765 \\
\hline C & CHECK FOR RETURN TO MAIN CODE. & XSMOD & 766 \\
\hline \multirow[t]{2}{*}{1105} & IF(KDIMAG(IC) . EQ. 0)GO TO 2000 & XSMOD & 767 \\
\hline & IF((KDIMAG(IC) . AND. 77000000000000000000B) . NE. 0)GO TO 2000 & XSMOD & 768 \\
\hline \multirow[t]{3}{*}{$\mathbf{C}$} & CHECK FOR TIME LIMIT & XSMOD & 769 \\
\hline & CALL SECOND(CP) & XSMOD & 770 \\
\hline & IF(TL-CP-15. 0)1110,1110,1115 & XSMOD & 771 \\
\hline \multirow[t]{2}{*}{1110} & IEXIT $=1$ & XSMOD & 772 \\
\hline & PRINT 28, TL,CP & XSMOD & 773 \\
\hline \multirow{4}{*}{$\begin{array}{r}28 \\
1\end{array}$} & FORMAT(* ADDXS. LESS THAN 15 SEC LEFT. ANOTHER ADD REQUESTED. EXIT & XSMOD & 774 \\
\hline & FLAG SET. TL=*F10. 3,5X*CP=*F10. 3) & XSMOD & 775 \\
\hline & N. ADDXS. 3=F. IEXIT & XSMOD & 776 \\
\hline & GO TO 2000 & XSMOD & 777 \\
\hline 1115 & CONTINUE & XSMOD & 778 \\
\hline \multirow[t]{3}{*}{ C } & CLEAR STORAGLS AND DT ARRAYS & XSMOD & 779 \\
\hline & $I=L O C F(K 2)-L O C F(I S I D)+1$ & XSMOD & 780 \\
\hline & DO $101 \mathrm{~J}=1, \mathrm{I}$ & XSMOD & 781 \\
\hline \multirow[t]{3}{*}{101} & $\operatorname{ISID}(J)=0$ & XSMOD & 782 \\
\hline & $\mathrm{I}=\operatorname{LOCF}(\mathrm{DUM}(9))-\operatorname{LOCF}(\mathrm{IBLNO}(1))+1$ & XSMOD & 783 \\
\hline & DO $102 \mathrm{~J}=1, \mathrm{I}$ & XSMOD & 784 \\
\hline \multirow[t]{7}{*}{102} & $\operatorname{IBLNO}(\mathrm{J})=0$ & XSMOD & 785 \\
\hline & IERR $=0$ & XSMOD & 786 \\
\hline & KTOTCDS $=0$ & XSMOD & 787 \\
\hline & N. CNTRL=NULL & XSMOD & 788 \\
\hline & N. ANGD=NULL & XSMOD & 789 \\
\hline & N. XS=NULL & XSMOD & 790 \\
\hline & N. ES J $=$ NULL & XSMOD & 791 \\
\hline C & READ INPUT STREAM & XSMOD & 792 \\
\hline & READ 1,KID,SOURCE,CTIND,NIN & XSMOD & 793 \\
\hline 1 & FORMAT(I6,2A6,16) & XSMOD & 794 \\
\hline & READ 15 , SDES & XSMOD & 795 \\
\hline 15 & FORMAT(8A10) & XSMOD & 796 \\
\hline & $\mathbf{N}=\mathbf{2}$ & XSMOD & 797 \\
\hline & IF(CTIND . EQ 6H CARDS) N=3 & XSMOD & 798 \\
\hline & PRINT 2, KID,HOL(N),SDES & XSMOD & 799 \\
\hline 2 & FORMAT("1SID*I5" WILL BE READ FROM *A5/1X,8A10) & XSMOD & 800 \\
\hline C & COMPARE SID ON ADD CARD AND DATA CARD. & XSMOD & 801 \\
\hline & IF(KDIMAG(IC) . EQ. KID)GO TO 105 & XSMOD & 802 \\
\hline & IERR=2 & XSMOD & 803 \\
\hline & PRINT 4, KDIMAG(IC),KID & XSMOD & 804 \\
\hline 4 & FORMAT("DINPUT ERROR FOR SID. ADD CARD= "I4" DATA CARD= "I4) & XSMOD & 805 \\
\hline C & & XSMOD & 806 \\
\hline C & CHECK SID AGAINST OLD DIRECTORY. & XSMOD & 807 \\
\hline 105 & DO $110 \quad l=1$, IIX & XSMOD & 808 \\
\hline & IF(KSID(I) . EQ. KID)GO TO 115 & XSMOD & 809 \\
\hline 110 & CONTINUE & XSMOD & 810 \\
\hline & GO TO 120 & XSMOD & 811 \\
\hline
\end{tabular}




\begin{tabular}{|c|c|c|c|}
\hline \multirow[t]{2}{*}{115} & IERR=2 & XSMOD & 812 \\
\hline & PRINT 6, KID & XSMOD & 813 \\
\hline 6 & FORMA'T $1 /{ }^{*}$ SID*I4* IS ALREADY IN THE LIBRARY. *) & XSMOD & 814 \\
\hline C & & XSMOD & 815 \\
\hline C & CHECK FOR LLL OR UK & XSMOD & 816 \\
\hline \multirow[t]{2}{*}{120} & $L L L=0$ & XSMOD & 817 \\
\hline & IF(SOURCE . EQ. 6H LLL)LLL=1 & XSMOD & 818 \\
\hline C & & XSMOD & 819 \\
\hline \multirow[t]{2}{*}{ C } & CHECK FOR READING TAPE OR CARDS & XSMOD & 820 \\
\hline & $\mathrm{IF}(\mathrm{N} . \mathrm{EQ} .2) \mathrm{GO}$ TO 150 & XSMOD & 821 \\
\hline \multirow[t]{4}{*}{$\mathrm{C}$} & SKIP CARDS IF ERROR FLAG SET & XSMOD & 822 \\
\hline & READ (3,7) ISID, NTOTCDS,ICDSO,IZ,A, LBLNO,IA7,IA8, IA9 & XSMOD & 823 \\
\hline & IF(IERR . EQ. 0)GO TO 170 & XSMOD & 824 \\
\hline & Go TO 100 & XSMOD & 825 \\
\hline C & & XSIMOD & 826 \\
\hline C & READ DATA & XSMOD & 827 \\
\hline \multirow[t]{3}{*}{150} & IF(IERR . EQ. 0)GO TO 155 & XSMOD & 828 \\
\hline & IERR =0 & XSMOD & 829 \\
\hline & GO TO 100 & XSMOD & 830 \\
\hline \multirow{2}{*}{155} & IF(LLL . EQ. 1)GO TO 160 & XSMOD & 831 \\
\hline & IF(JSWFL . EQ. 2)GO TO 160 & XSMOD & 832 \\
\hline C & READ TAPE DIRECTORY & XSMOD & 833 \\
\hline \multirow[t]{3}{*}{5} & FORMAT(111,1X,111) & XSMOD & 834 \\
\hline & READ(2,5) NFILES & XSMOD & 835 \\
\hline & READ $(2,13)$ (P(I),NUKID(1),NCARDS(1),DES(I),I=1,NFILES $)$ & XSMOD & 836 \\
\hline \multirow[t]{6}{*}{13} & FORMAT(A1,110,1 X,I1 1,2X,A10) & XSMOD & 837 \\
\hline & CALL SSWTCH $(4, J S W)$ & XSMOD & 838 \\
\hline & IFUJSW.EQ. 2)GO TO 160 & XSMOD & 839 \\
\hline & IF(JSWFL . EQ. 2)GO TO 160 & XSMOD & 840 \\
\hline & $J S W F L=2$ & XSMOD & 841 \\
\hline & PRINT 14 , NFILES,(P(1),NUKID( (), NCARDS(l),DES(l), l=1,NFILES) & XSMOD & 842 \\
\hline 14 & FORMAT $(/ / *$ DIRECTORY TO UKTAPE. NO. OF FILES $=* 15 / /$ & XSMOD & 843 \\
\hline 1 & * NUCLIDE ID NO. NO. OF CARDS AND DESCRIPTION FOLLOW. * & XSMOD & 844 \\
\hline \multirow[t]{2}{*}{2} & $/ /(3(1 \times, A 1,1 \times, 15,16,2 X, A 10,15 X)))$ & XSMOD & 845 \\
\hline & SEARCH FOR REQUESTED SID & XSMOD & 846 \\
\hline 160 & READ $(N, 7)$ ISID,NTOTCDS,ICDS0,IZ,A,LBLNO,IA 7,IA 8,IA9 & XSMOD & 847 \\
\hline \multirow[t]{2}{*}{7} & FORMAT(1X,I10,1X,3([11,1X),F $11.6,1 X,[11,1 X, 13,12,13)$ & XSMOD & 848 \\
\hline & IF(EOF,2)161,162 & XSMOD & 849 \\
\hline 161 & PRINT 16, NIN, KID & XSMOD & 850 \\
\hline \multirow[t]{3}{*}{16} & FORMAT $\left(* D\right.$ CANNOT FIND NIN $=* 14^{*}$ ON TAPE. SID $\left.=* 14\right)$ & XSMOD & 851 \\
\hline & REWIND 2 & XSMOD & 852 \\
\hline & Go TO 100 & XSMOD & 853 \\
\hline 162 & CONTINUE & XSMOD & 854 \\
\hline & IF(ISID , EQ. NIN)GO TO 170 & XSMOD & 855 \\
\hline & PRINT 18, ISID & XSMOD & 856 \\
\hline 18 & FORMAT(* NIN=*14* ENCOUNTERED. *) & XSMOD & 857 \\
\hline & DO $165[=2$, NTOTCDS & XSMOD & 858 \\
\hline & $\operatorname{READ}(2,11)$ & XSMOD & 859 \\
\hline 11 & FORMAT(IX) & XSMOD & 860 \\
\hline 165 & CONTINUE & XSMOD & 861 \\
\hline & GO TO 160 & XSMOD & 862 \\
\hline C & FOUND SID. CLEAK AND READ BLOCK 0 & XSMOD & 863 \\
\hline 170 & IB LK $=0$ & XSMOD & 864 \\
\hline & $\mathrm{NCD}=1$ & XSMOD & 865 \\
\hline & ICHK $=P R C T(1$, IBLK,ISID) & XSMOD & 866 \\
\hline & IF(ICHK . NE. O)GO TO 1000 & XSMOD & 867 \\
\hline & DO $172 \quad[=1,300$ & XSMOD & 868 \\
\hline 172 & $\operatorname{IBLNO}(\mathrm{I})=0$ & XSMOD & 869 \\
\hline & PRINT 26,ISID,SOURCE,HOL(N),KID & XSMOD & 870 \\
\hline 26 & FORMAT $\left(/ *\right.$ READING NIN $=* 15^{*}$ FROM*A6,A6* TO GO INTO LIBRARY AS SID* & XSMOD & 871 \\
\hline I & I5) & XSMOD & 872 \\
\hline & $I E=I C D S 0-1$ & XSMOD & 873 \\
\hline & $J=-1$ & XSMOD & 874 \\
\hline & DO 174 I=1,IE & XSMOD & 875 \\
\hline & $J=J+2$ & XSMOD & 876 \\
\hline & $\operatorname{READ}(\mathrm{N}, \mathfrak{g})$ IBI.NO(J),IDB(J),ICDS $(\mathrm{J}), \operatorname{IBLNO}(\mathrm{J}+1), \operatorname{IDB}(\mathrm{J}+1)$, & XSMOD & 877 \\
\hline 1 & ICDS $(J+1), I A 7, I A 8, I A 9$ & XSMOD & 878 \\
\hline 9 & FORMAT $(6(111,1 X), 33,12,13)$ & XSMOD & 879 \\
\hline & $\mathrm{NCD}=1+1$ & XSMOD & 880 \\
\hline & ICHIK=PRCT(I+1,0,ISID $)$ & XSMOD & 881 \\
\hline & IF(ICHK . NE. O)GO TO 1000 & XSMOD & 882 \\
\hline 174 & CONTINUE & XSMOD & 883 \\
\hline
\end{tabular}


KTOTCDS=ICDSO

READ CROSS SECTIONS,ANG DISTRS AND SECONDARY ENERGIES,

DO 240 I=1, LBLNO

IRT $=$ IDB(I)

C DO NOT SAVE REACTIONS 1001,1003,1004

IF(IRT . NE. 1001 . AND. IRT . NE. 1003 , AND. IRT . NE. 1004)GOTO 1174

IL $=\operatorname{ICDS}(1)$

DO $2174 \mathrm{~J}=1, \mathrm{IL}$

2174 READ(N,11)

GO TO 205

1174 ITP $=$ IRT $/ 1000$

IF(ITP .EQ. 1)GO TO 176

IF(ITP . EQ. 2)GO TO 177

IF(ITP . EQ. 3)GO TO 178

IF(ITP . EQ. 4)GO TO 9178

175 PRINT 20, IRT,I,LBLNO,IA7

20 FORMAT $(/ *$ ADDXS. CANNOT READ IN THIS CLASSIFICATION. WILL SKIP. $\%$

* REACTION TYPE $=* 15 *$ BLOCK NO="13* LAST BLOCK="13* NIN="15)

$J E=I C D S(I)$

DO $1176 \mathrm{~J}=1, \mathrm{JE}$

$1176 \operatorname{READ}(\mathrm{N}, 11)$

GO TO 205

176 CALL READXS(KID,I,N,IERR)

$\operatorname{ITIDR}(\mathbf{R})=-7$

GO TO 179

177 CALL. READAD(KID,I,N,IERR)

ITIDR(IR) $\approx \operatorname{ITIDS(ND)}$

GO TO 179

178 CALL READSEC(KID,I,N,IERR)

GO TO 179

9178 CALL READNU(KID,I,N,IERR)

179 IF(IERR . EQ. O)GO TO 205

PRINT 22, KID, HOL(N)

22 FORMAT $\left(/{ }^{*}\right.$ COULD NOT ADD SID*14* TO LIBRARY FROM *A7)

C.U TO 100

C

INCREASE COUNT OF CARDS READ

205 KTOTCDS=KTOTCDS + ICDS(I)

240

CONTINUE

C

ALL DATA FOR ONE NUCLIDE READ

MIXT $=0$

$\mathrm{K} 2=0$

DO $207 \mathrm{~J}=1, \mathrm{IR}$

C

$207 \quad K 2=K 2+I R S(J)$

C DEFINE XS CONTROL FILE.

N. CNTRL=F. KID/F. ND/(F. ITIDS(J),J=1,ND)/F. SDES/F. IR/(F. ITIDR(j), $J=1, I R) / F . N E S /(F . E S(J), J=1, N E S) /(F .,(D R(J), J=1, I R) /(F . M E(J)$.

$\mathrm{J}=1, \mathrm{IR}) /(\mathrm{F} . \operatorname{IRS}(\mathrm{J}), \mathrm{J}=\mathrm{I}, \mathrm{IR}) /(\mathrm{F} . \mathrm{QR}(\mathrm{J}), \mathrm{J}=1, \mathrm{IR}) / \mathrm{F} . \mathrm{IZ} / \mathrm{F} . \mathrm{MIXT} / F, \mathrm{K2} /$ F. LLL/

FORMAT(* ADDXS. CANNOT SAVE DT ARRAYS. KID OUT OF RANGE. 'I6)

IF(KID . LT. 10000. AND. KID . GE. 10)GO TO 210

PRINT 24,KID

GO TO 100

C

CHOOSE FORMAT FOR ENCODING DTRAN NAME

IF(KID . LT. 10000) K=1

IF(KID . LT. 1000$) \mathrm{K}=2$

IF(KID , LT, 100$) K=3$

ENCODE(7,F(K),AM)KID

D. ((AM))=N. CNTRL,N. XS,N. ESJ,N. ANGD

REWIND 10

SAVE D. ((AM))

C
C

ALL DATA FOR ONE NUCLIDE SAVED ON DT TAPE.

UPDATE DIRECTORY

REWIND 10

NEOF $=0$

C

IF SID DIRECTORY EMPTY,RESET NO. OF ITEMS TO ZERO

IF(XSID(1) . EQ. O)IIX $=0$

260 READ(10,3) NAME,NWDSS(IIX+ 1), IDNOS(IIX+1)

3 FORMAT(1 3X,A9, 30X,15,11X,13)

XSMOD

XSMOD

XSMOD

XSMOD

XSMOD

XSMOD

XSMOD

XSMOD

XSMOD

XSMOD

XSMOD

XSMOD

XSMOD

XSMOD

XSMOD

XSMOD

XSMOD

XSMOD

XSMOD

XSMOD

XSMOD

XSMOD

XSMOD

XSMOD

XSMOD

XSMOD

XSMOD

XSMOD

XSMOD

XSMOD

XSMOD

XSMOD

XSMOD

XSMOD

XSMOD

XSMOD

XSMLD

XSMOD

XSMOD

XSMOD

XSASOD

XSMOD

XSMOD

XSMOD

XSMOD

XSMOD

XSMOD

XSMOD

XSMOD

XSMOD

XSMOD

XSMOD

XSMOD

XSMOD

XSMOD

XSMOD

XSMOD

XSAOD

XSMOD

XSMOD

XSMOD

XSMOD

XSMOD

XSAOD

XSMOD

XSAKD

XSMOD

XSMOD

XSMOD

XSAOD

XSMYD 


\begin{tabular}{|c|c|c|c|}
\hline & $\operatorname{IE}(E O F, 10) 2 \mathrm{BO}, 270$ & XSMOD & 955 \\
\hline 270 & CONTINUE & XSMOD & 956 \\
\hline \multirow[t]{3}{*}{ c. } & INCKBASE ITBM COUNT IN SID DIRECTOKY & XSMOD & 957 \\
\hline & $I t X-t t X+1$ & XSMOD & 958 \\
\hline & follx & XSMOD & 959 \\
\hline \multirow[t]{4}{*}{ C } & CHDOSE FORMAT TO DECODE DT NAMIE INTO DIIECTORY & XSMOD & 960 \\
\hline & $\begin{array}{l}\text { Do } 275 \mathrm{~J}=1.3 \\
\text { MINAME . AND. MASK }(\mathrm{N})\end{array}$ & XSMOD & 961 \\
\hline & $\begin{array}{l}\text { MIDNAME . AND. MASK(J) } \\
\text { IF(MI. BO. MBLNR(J)GO ro } 277\end{array}$ & XSMOD & 962 \\
\hline & If(IM ER. MBLNRIJ)GO TO 277 & XSMOD & 963 \\
\hline \multirow[t]{2}{*}{275} & CONTINUE & XSMOD & 964 \\
\hline & $J=4$ & KSMOD & 965 \\
\hline 277 & IFMT $=\mathbf{J}$ & XSMOD & 966 \\
\hline 279 & DECODE(9.FMT(IFMT).NAMEKSID(1) & XSMOD & 967 \\
\hline \multirow[t]{2}{*}{ C } & RETURN MODIFtlE DIRECTORY TO DTJOB & XSMOD & 968 \\
\hline & IDIKSVaIDNOS(IIX) & XSMOD & 969 \\
\hline \multirow[t]{2}{*}{ C } & SET DERECTORY SAVE HAAGOHIGEHST RECALL ID & XSMOD & 970 \\
\hline & N. DIRSID=(F. KSID(1),1=2.11X)/(F. IDNOS(1), $1=1,11 x)\}$ & XSMOD & 971 \\
\hline \multirow[t]{2}{*}{$\mathbf{I}$} & (f. NWDSS(1),1=1,11X) & XSMOD & 972 \\
\hline & Go To 300 & XSMOD & 973 \\
\hline 280 & PHINT 10 & XSMOD & 974 \\
\hline \multirow[t]{4}{*}{10} & 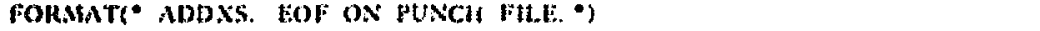 & XSMOD & 975 \\
\hline & NEOEMNEOF+ I & XSMOD & 976 \\
\hline & IF(NEOE - IT. 2$)(0010260$ & XSMOD & 977 \\
\hline & PRINT 12, (KSTD(1).101.300) & XSMIOD & 978 \\
\hline \multirow{4}{*}{12} & PORMAT" ADDXS. CANAOT HEAD PUNCE FIEE TO UPDATE DIRECTORY. & XSMIOD & 979 \\
\hline & $(10112))$ & XSMOD & 980 \\
\hline & EEKRDO & XSMOD & 981 \\
\hline & Go To 100 & XSMOD & 982 \\
\hline \multirow{3}{*}{$C_{300}$} & & XSAIOD & 983 \\
\hline & EF STD KEQUESTED ON TAPEL, WRTE IT TO TAPEO NOW & XSAIOD & 984 \\
\hline & 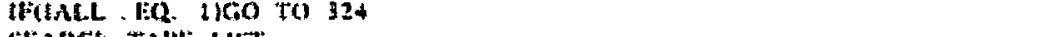 & XSMOD & 985 \\
\hline \multirow[t]{4}{*}{$\boldsymbol{C}$} & StiARCt TAIE I.IST & XSMOD & 986 \\
\hline & Do sas $1=1,100$ & XSMOD & 987 \\
\hline & 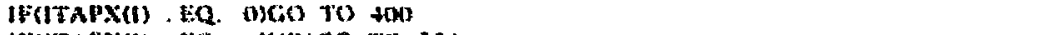 & XSMOI & 988 \\
\hline & F(tTAPX(1) . HQ . KID)CO TO 324 & XSMOD & 989 \\
\hline \multirow[t]{2}{*}{305} & GONTANUI: & XSMOD & 990 \\
\hline & coto too & XSMOD & 991 \\
\hline C & What: SID TO TAPLG & XSMOD & 992 \\
\hline 324 & BACKSPACE 6 & XSMOD & 993 \\
\hline 325 & 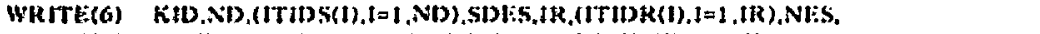 & XSMIOD & 994 \\
\hline 1 & 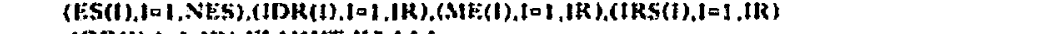 & XSMOD & 995 \\
\hline 2 & $.(Q R(1) . \pm=1.14) .1 \% . M I X T, K 2 . L L L$ & XSMOD & 996 \\
\hline c & ONIY ONE REACTION AT A THME IN CORL & XSMOD & 997 \\
\hline & $1003+0 \mathrm{~K}=1,1 \mathrm{k}$ & XSMOD & 998 \\
\hline & $F, S I G=N, X S(K)$ & XSMOD & 999 \\
\hline & 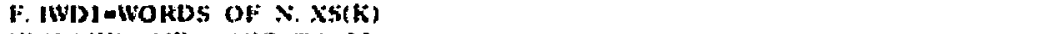 & XSMOD & 1000 \\
\hline & If(tks(K) .NE. (O)t:O TO 330 & XSMOD & 1001 \\
\hline & WhITL(6)(SIC(1).1-1.1W(1)1) & XSMOD & 1002 \\
\hline & Go To $3 * 0$ & XSMOD & 1003 \\
\hline 330 & F. LESJ $=$ N. $155 f(k)$ & XSMOD & 1004 \\
\hline & 1F. IWD2-WOHDS Ot: N. ISSJ(k) & XSMOD & 1005 \\
\hline & WHITE(G) (5TC,(1).t-1.1WDIS.(ES)(1).1=1.1WD2) & XSMOD & 1006 \\
\hline $3+0$ & CONTINUE & XSMOD & 1007 \\
\hline C: & ONLY ONE A.D AT A TIMIE IN COHL & XS:MOD & 1008 \\
\hline & DO $350 \mathrm{~K}=1, \mathrm{ND}$ & XSMOD & 1009 \\
\hline & F. ITID=N. ANCBD(K). II & XSMOD & 1010 \\
\hline & 1. TDESSN ANGIX(K). 2I & XSMOD & 1011 \\
\hline & F. NED $N$ N. ANGD(K). 3/ & XSMOD & 1012 \\
\hline & F. E-N, ANGD(K), +1 & XSMOD & 1013 \\
\hline & F. ISYSIN N. ANCiD(K). SI & XSMOD & 1014 \\
\hline & [. AFN. ANCD(K) $G)$ & XSMOD & 1015 \\
\hline & 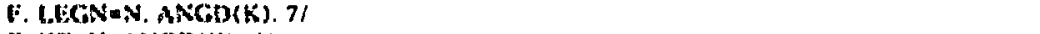 & XSMOD & 1016 \\
\hline & F. $K T=N . A N C D(K), K /$ & XSMIOI & 1017 \\
\hline & F. TKaK. ANCiDCKi. 9I & XSMOD & 1018 \\
\hline & F. MUDN. ANGD(K). 10/ & XSMOD & 1019 \\
\hline & I. NINC & XSMOD & 1020 \\
\hline & 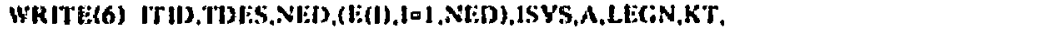 & XSMOD & 1021 \\
\hline & $(\mathrm{K} K(1),\{=1, K T),(Y)(1), \mid=1, N E D), N \mid N C$ & XSMOD & 1022 \\
\hline 350 & CONTINUI: & XSMOD & 1023 \\
\hline & ENDEILE 6 & XSMOD & 1024 \\
\hline & ENDFILE: 6 & XSMOD & 1025 \\
\hline & PRINT 3SI,KID & XSMOD & 1026 \\
\hline
\end{tabular}




\begin{tabular}{|c|c|c|c|}
\hline$c^{351}$ & FORMAT(* SID*I5* WRITTEN TO TAPE6 IN MOD ADDXS*) & $\begin{array}{l}\text { XSMOD } \\
\text { XSMOD }\end{array}$ & 1027 \\
\hline C & LIST DATA IN S- 4 FORMAT HERE & XSMOD & 1029 \\
\hline C & PREPARE LIST FOR MODULE LISTXS & XSMOD & 1030 \\
\hline \multirow[t]{2}{*}{400} & $\begin{array}{l}\text { N. LISTXS }=0 \\
\text { KALL LISTXS }\end{array}$ & XSMOD & $\begin{array}{l}1031 \\
1032\end{array}$ \\
\hline & GO TO 100 & XSMOD & 1033 \\
\hline C & ERROR ENTRY. SET IERR TO SKIP REMAINING CARDS & XSMOD & 1034 \\
\hline \multirow[t]{2}{*}{1000} & IERR $=N C D+1$ & XSMOD & 1035 \\
\hline & GO TO 100 & XSMOD & 1036 \\
\hline C & STANDARD RETURN & XSMOD & 1037 \\
\hline \multirow[t]{6}{*}{2000} & REWIND 2 & XSMOD & 1038 \\
\hline & N. IDIRSV $=$ F. IDIRSV & XSMOD & 1039 \\
\hline & RETURN & XSMOD & 1040 \\
\hline & END & XSMOD & 1041 \\
\hline & FUNCTION MOD(N,L) & XSMOD & 1042 \\
\hline & IF(N , LT. L)GO TO 10 & XSMOD & 1043 \\
\hline \multirow[t]{2}{*}{1} & $\mathrm{~N}=\mathrm{N}-\mathrm{L}$ & XSMOD & 1044 \\
\hline & IF(N, GE, L)GO TO 1 & XSMOD & 1045 \\
\hline \multirow[t]{11}{*}{10} & $M O D=N$ & XSMOD & 1046 \\
\hline & $\begin{array}{l}\text { KETUKN } \\
\text { END }\end{array}$ & XSMOD & $\begin{array}{l}1047 \\
1048\end{array}$ \\
\hline & PRCT(I,IB, NIN) & XSMOD & 1049 \\
\hline & COMMON /CDID/IA7,IA8,IA9,IBLNO(100),IDB(100),ICDS(100),DUM(9),LLL & CDID & 2 \\
\hline & IERR $=0$ & XSMOD & 1051 \\
\hline & $\mathrm{IM}=\mathrm{MOD}(\mathrm{I}, \mathbf{1 0 0 0})$ & XSMOD & 1052 \\
\hline & IF(IA9 . NE. IM)IERR=1 & XSMOD & 1053 \\
\hline & IF(IAB . NE. IB)IERR=2 & XSMOD & 1054 \\
\hline & IF(IA7 . NE. NIN)IERR=3 & XSMOD & 1055 \\
\hline & IF(IERR . EQ . O)GO TO 100 & XSMOD & 1056 \\
\hline & PRINT 2, IA7,IA8,IA9,NIN,IB,I & XSMOD & 1057 \\
\hline \multirow{6}{*}{$\begin{array}{c}2 \\
100^{1}\end{array}$} & FORMAT $\left(/ /^{*}\right.$ ID FIELD ERROR ON DATA CARD. A7,8,9= $316^{*}$ NIN,BLK,CDNO & XSMOD & 1058 \\
\hline & $=3(6)$ & XSMOD & 1059 \\
\hline & PRCT $=$ IERR & XSMOD & 1060 \\
\hline & RETURN & XSMOD & 1061 \\
\hline & END & XSMOD & 1062 \\
\hline & SUBROUTINE MULTI(KID,IBLK,N,IERR,NCD,NDIST) & XSMOD & 1063 \\
\hline \multirow{7}{*}{$\begin{array}{l}\text { C } \\
\text { C }\end{array}$} & READS MULTIPLE ANG DISTRS FOR FIRST NEUTRON AND COMBINES THEM INTO & XSMOD & 1064 \\
\hline & ONE A-D FOR LIBRARY. & XSMOD & 1065 \\
\hline & SID NO. IN LIBRARY & XSMOD & 1066 \\
\hline & IBLK BLOCK NO. & XSMOD & 1067 \\
\hline & ERROR FLAG. NO ERROR=0. & XSMOD & 1068 \\
\hline & INPUT UNIT. $3=$ CARDS. $2=$ TAPE & XSMOD & 1069 \\
\hline & & XSMOD & 1070 \\
\hline \multirow{2}{*}{$\mathbf{C}$} & COMMON $/ \mathrm{X} / \mathrm{X}(\mathbf{4 8 5 0})$ & $\mathbf{x}$ & \\
\hline & DIMENSION ITID(1),TRES(8), E(400), TK(4000),MD(400), PROB (10), & ANGD & 2 \\
\hline \multirow[t]{5}{*}{1} & NMU(10) & ANCD & 3 \\
\hline & EQUIVALENCE (ITID $(1), X(1)),(\operatorname{TDES}(1), X(2)),(N E D, X(10))$, & ANGD & 4 \\
\hline & $(E(1), X(11)),($ ISYS,$X(411)),(A, X(412)),($ LEGN,X(413)), & ANGD & 5 \\
\hline & $(K T, X(414)),(T K(1), X(415)),(\operatorname{MD}(1), X(4415)),(N I N C, X(4815))$, & ANGD & 6 \\
\hline & $(\mathrm{PROB}(1), \mathrm{X}(4816)),(\mathrm{NMU}(1), \mathrm{X}(4826))$ & ANGD & 7 \\
\hline \multirow[b]{4}{*}{ C } & COMMON /CDID & ANGD & 8 \\
\hline & 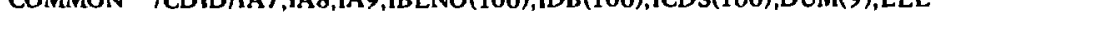 & XSMOD & 1074 \\
\hline & DIMENSION XMU(100),T(100),XMU1(100),T1(100) & XSMOD & 1075 \\
\hline & & XSMOD & 1076 \\
\hline \multirow[t]{6}{*}{ C } & READ IN FIRST DISTRIBUTION INTO RESIDUAL & XSMOD & 1077 \\
\hline & DO $100 I=1,100$ & XSMOD & 1078 \\
\hline & $X M U(I)=0$ & XSMOD & 1079 \\
\hline & $T(1)=0$ & XSMOD & 1080 \\
\hline & $\mathrm{XMU1}(\mathrm{l})=0$ & XSMOD & 1081 \\
\hline & $T 1(I)=0$ & XSMOD & 1082 \\
\hline \multirow[t]{9}{*}{100} & CONTINUE & XSMOD & 1083 \\
\hline & $L=1$ & XSMOD & 1084 \\
\hline & $\mathrm{KDS}=\mathrm{NMU} / 3$ & XSMOD & 1085 \\
\hline & NMUR $=M O D(N M U, 3)$ & XSMOD & 1086 \\
\hline & IF(NMUR ，NE， 0)KDS=KDS + 1 & XSMOD & 1087 \\
\hline & $K 1=1$ & XSMOD & 1088 \\
\hline & DO $130 \mathrm{KD}=1$, KDS & XSMOD & 1089 \\
\hline & $K L=K 1+2$ & XSMOD & 1090 \\
\hline & READ(N,1) (XMU(K),T(K),K=K1,KL),IA7,IA8,IA9 & XSMOD & 1091 \\
\hline 1 & FORMAT $(6(F 11,6,1 X), 13,12,13)$ & XSMOD & 1092 \\
\hline
\end{tabular}




\begin{tabular}{|c|c|c|c|}
\hline & $N C D=N C D+1$ & XSMOD & $10 \% 3$ \\
\hline & ICHK=PRCT(NCD.1BLK,ISID) & KSAIOD & 3094 \\
\hline & IF(ICIIK , NE. O)GO TO tOOO & XSMO & 1025 \\
\hline & DO $120 K=K I, K L$ & XSNON & 1096 \\
\hline \multirow[t]{2}{*}{120} & $T(K)=P R O B{ }^{*} T(K)$ & XSMOD & 1097 \\
\hline & $K 1=K 1+3$ & XSAIOD & $209 \mathrm{H}$ \\
\hline \multirow[t]{3}{*}{130} & CONTINUL & XSAIOD & $109 \%$ \\
\hline & KLADJ $=3-$ NMIUR & XS.MOD & IItK) \\
\hline & $K L=K L \cdot K L A D]$ & XSMWU] & 1101 \\
\hline C & & Xsinom & 1102 \\
\hline \multirow{3}{*}{ C } & READ IN REAAINING DISTKBNS AND COABINE WITU RESIDUAL ONE AT A TIME & Xssion & 1163 \\
\hline & $\begin{array}{l}00250 L D=2, \text { NDIST } \\
L=L+1\end{array}$ & $\begin{array}{l}\text { Xsilot } \\
\text { Xsion }\end{array}$ & 1104 \\
\hline & READ(N,3) LRL,ERU,NCTER,DUM(1),PROU(L),N.IU(L),IA7,1A8,1A9 & XSMON & 1lak \\
\hline \multirow[t]{6}{*}{3} & FORMIAT(2(F11, 6,1X),2(111,1X1,F11, $6,1 \times, 111,1 \times, 13,12,13)$ & XSAMGD & 1107 \\
\hline & $\mathrm{NCD}=\mathrm{NCD}+1$ & $X S .100$ & $110 \mathrm{H}$ \\
\hline & ICHK=PRCT(NCD,IRLK,ISID) & XSMOD & 1100 \\
\hline & IF(ICIIK . NE. O)GO TO 1000 & XSNOD & 1110 \\
\hline & IF(NDIST EQ DUM(I))GO TO It) & XSMOD & 1111 \\
\hline & PRINT 2, NDIST,DUM(1),IRT,LIULK,ISID & XS.MOD & 1112 \\
\hline 2 & FORMAT" MULTI. DISCREPLNCY IN NO. OF DISTRS FOR A GIVEN NLUTRON. N & XSNIOD & 1113 \\
\hline \multirow[t]{2}{*}{1} & 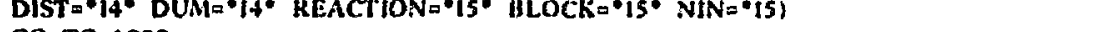 & XSMIOD & $111+$ \\
\hline & GO TO 1000 & XSMIOD & 1115 \\
\hline \multirow[t]{11}{*}{140} & KDS $=N M U(L) / 3$ & XSAIOD & 1116 \\
\hline & NAUR=MOD(NMU(L),3) & Xsmion & 1117 \\
\hline & IF(NMIUR . NE. O)KDS=KDS+ I & XSMOD & 1118 \\
\hline & $\mathbf{K} \mathbf{I}=\mathbf{A} \mathbf{I}=\mathbf{1}$ & XSMON & 1119 \\
\hline & $\mathrm{DO} 210 \mathrm{KD}=1, \mathrm{KDS}$ & XSMOL & 1120 \\
\hline & $K L \mathbf{l}=\mathbf{k} I+2$ & XS.MTOD & 1121 \\
\hline & READ(N,1) (XMU1(K),T1(K),K=K1,KL),1A7,1AB,1A9 & XSMOND & 1122 \\
\hline & $N C D=N C D+1$ & XSMOD & 1123 \\
\hline & ICHK=PRCT(NCD,IHLK,ISID) & XS.MOD & 1124 \\
\hline & IF(ICHK . NE. O)GO TO IOK & XSMOU & 1125 \\
\hline & DO $150 \mathrm{~K}=\mathrm{KI}, \mathrm{KLI}$ & XSMIOD & 1126 \\
\hline \multirow{2}{*}{$c^{150}$} & $T I(K)=1+R O B(L) \bullet T Y(K)$ & XSMOD & 1127 \\
\hline & & XSMIOD & 1128 \\
\hline \multirow[t]{4}{*}{ C } & FOR I CARD CHECK MU*S AGAINST RESIDUAL & Xsston & 1129 \\
\hline & DO $200 \mathrm{~K} \times \mathrm{K} 1 . \mathrm{KLI}$ & XSAIOD & 1130 \\
\hline & IF(ABS(XMU(M)-XMUI(K)), LEE. 1.OE:OS)GO TO 195 & XSMOD & 1131 \\
\hline & IF(XMU(A) , GT. X,MUI(K))GO TO IRO & XSATOD & 1132 \\
\hline \multirow{5}{*}{$c^{160}$} & $J J=K L I$ & XSMON & 1133 \\
\hline & DUT EXTRA POINT IN TENT & Xsiliou & 1134 \\
\hline & DO 170 KK=K.KLI & XSMMOD & 1135 \\
\hline & $T(J)+1)=T 1(J))$ & XSAIOD & 1136 \\
\hline & $\mathrm{XMUI}(J)+1)=X . M U 1(J))$ & XSMMOD & 1137 \\
\hline \multirow[t]{3}{*}{170} & J了=J-1 & XSiNtoD & 1138 \\
\hline & $X M U I(K)=X M U(M)$ & XSMOD & 1139 \\
\hline & $T 1(K)=T 1(K-1)+(X M U(A))-X M U 1(K-1))(X M) U I(K)-X M U 1(K-1 b)$ & XSMONOD & $11+10$ \\
\hline \multirow[t]{4}{*}{$\mathbf{J}$} & •(T1(K)- TI(K-1)) & XSMIOD & $11+1$ \\
\hline & $\mathbf{K} \mathbf{1}=\mathbf{K} \mathbf{1}+\mathbf{I}$ & XSMLOD & $11+2$ \\
\hline & $K L I=K L 1+1$ & XSMOD & $11+3$ \\
\hline & Co TO 195 & XSNOD & 1144 \\
\hline \multirow{2}{*}{$c^{180}$} & $J\}=K L$ & XsMOD & $11+5$ \\
\hline & PUT EXTRA POINT IN RESIDUAL & XSMOD & $11+6$ \\
\hline & DO :90 KK=M.KL. & XSMOD & 1147 \\
\hline & $T(J J+1)=T(J))$ & XSASOD & $11+8$ \\
\hline & $X M U(J J+1)=X M U(J))$ & XSMOD & $11+9$ \\
\hline 290 & $\int \mathrm{J}=\mathrm{J} \mathrm{J}-\mathrm{I}$ & XSMOD & 1150 \\
\hline & XMU $(M)=X M U 1(K)$ & XSMOD & 1151 \\
\hline & $T(M)=T(M-2)+(X M U 1(K)-X M U(M-1)) /(X M I U(M)+1)-X M U(M-1))$ & XSMOD & 1152 \\
\hline 1 & ${ }^{*}(T(M+1) \cdot T(M-1))$ & XSMDD & 1153 \\
\hline & $K L=K L+1$ & XSMOD & 1154 \\
\hline 195 & $\mathbf{M} \subset \mathbf{M}+\mathbf{1}$ & XSMOO & 1155 \\
\hline 200 & CONTINUE & XSMOD & 1156 \\
\hline & $\mathbf{K} \mathbf{1}=\mathbf{K} \mathbf{1}+3$ & Xsiton & 1157 \\
\hline 220 & CONTINUE & XSMTOD & 1158 \\
\hline C & COMBINE TENI' AND RESIDUAL T ARRAYS. & XSMOD & II5y \\
\hline & DO $220 \mathrm{~K}=1, \mathrm{KL}$ & XSMOD & 1101 \\
\hline 220 & $T(K)=T(K)+T 1(K)$ & XSMOD & 1161 \\
\hline 250 & CONTINUE & XSMOD & 1162 \\
\hline C & $\begin{array}{l}\text { ALL DSTRBNS READ IN AND COMBINED. } \\
\text { KB=KT }\end{array}$ & $\begin{array}{l}\text { XSMOD } \\
\text { XSMOD }\end{array}$ & 163 \\
\hline
\end{tabular}




\begin{tabular}{|c|c|c|c|}
\hline & $K E=K B+2 \cdot K L$ & XSMOD & 1165 \\
\hline & $L=0$ & XSMOD & 1166 \\
\hline \multirow[t]{4}{*}{ C } & PUT RESIDUAL. INTO PERMANENT ANG DISTR ARRAY & XSMOD & 1167 \\
\hline & DO $260 K=K B, K E, 2$ & XSMOD & 1168 \\
\hline & $L=L+1$ & XSMOD & 1169 \\
\hline & $\begin{array}{l}\operatorname{TK}(K)=X M U(L) \\
T K(K+1)=T(L)\end{array}$ & XSMOD & 1170 \\
\hline \multirow{3}{*}{260} & CONTINUE & $\begin{array}{l}\text { XSMOD } \\
\text { XSMOD }\end{array}$ & $\begin{array}{l}1171 \\
1172\end{array}$ \\
\hline & $K T=K E$ & XSMOD & 1173 \\
\hline & Go To 2000 & XSMOD & 1174 \\
\hline 1000 & IERR $=N C D+1$ & XSMOD & 1175 \\
\hline \multirow{3}{*}{2000} & RETURN & XSMOD & 1176 \\
\hline & END & XSMOD & 1177 \\
\hline & SUBROUTINE READAD(KID,IBLK,N,IERR) & XSMOD & 1178 \\
\hline C & RLADS ANGUI,AR DISTRIBUTION DATA FROM UK FORMAT TAPE OR CARDS & XSMOD & 1179 \\
\hline C & KID SID NO. IN LIBRARY & XSMOD & 1180 \\
\hline C & IBLK BLOCK NO. & XSMOD & 1181 \\
\hline C & ERROR FLAG. NO ERROR=0. & XSMOD & 1182 \\
\hline C & INPUT UNIT. 3=CARDS. 2=TAPE & XSMOD & 1183 \\
\hline C & ISID NUCLIDE ID NO. READ FROM TAPE OR CARDS & XSMOD & 1184 \\
\hline \multirow[t]{3}{*}{ C } & & XSMOD & 1185 \\
\hline & COMMON $/ X / X(4850)$ & $\mathbf{X}$ & \\
\hline & COMMON /CNTRL/ ISID(1),KID,ND,ITIDS(25),SDES(8),IR,ITIDR(50),NES, & CNTRL & \\
\hline \multirow[t]{2}{*}{1} & ES(4000),IDR(50),ME(50),IRS(50),QR(50),IZ,MIXT,K2 & CNTRL & \\
\hline & DIMENSION ITID(I),TDES(8),E(400),TK(4000),MD(400),PROB(10), & ANGD & \\
\hline \multirow{5}{*}{$\begin{array}{l}1 \\
1 \\
2 \\
3\end{array}$} & NMU(10) & ANGD & \\
\hline & EQUIVALENCE (ITID(1), X(1)), (TDES(1),X(2)), (NED,X(10)), & ANGD & \\
\hline & $(E(1), X(11)),($ ISYS,$X(4 \mid 1)),(A, X(412)),(\operatorname{LEGN}, X(413))$ & ANGD & 2 \\
\hline & $(K T, X(414)),(T K(1), X(415)),(M D(1), X(4415)),(N I N C, X(4815))$ & ANGD & 6 \\
\hline & $(P R O B(1), X(4816)),\{N M U(1), X(4826))$ & ANGD & 7 \\
\hline C & & ANGD & \\
\hline C & COMMON /CDID/IA7,IA8,IA9,IBLNO(100),IDB(100),ICDS(100),DUM(9),LLL & CDID & $\begin{array}{r}2 \\
1190\end{array}$ \\
\hline \multirow[t]{3}{*}{ C } & & $\begin{array}{l}\text { XSMOD } \\
\text { XSMOD }\end{array}$ & 1190 \\
\hline & COMMON TTYPE/ ITYPER(150) & TYPE & 2 \\
\hline & DATAITYPER $/ 15^{*} 1,2,3,0,0,1,2,1,1,2,3,2,0,1,1,2,55^{*} 1,65^{*} 0 /$ & TYPE & \\
\hline \multirow{2}{*}{ c } & & TYPE & \\
\hline & DATA $124 / 100000000 B /$ & XSMOD & 1193 \\
\hline \multirow{2}{*}{ C } & & XSMOD & 1194 \\
\hline & CLEAR STORAGES & XSMOD & 1195 \\
\hline \multirow{4}{*}{80} & $\begin{array}{l}\text { DO } 80 \quad 1=1,4850 \\
X(1)=0\end{array}$ & XSMOD & 1196 \\
\hline & $x(1)=0$ & $\begin{array}{l}\text { XSMOD } \\
\text { XSMOD }\end{array}$ & $\begin{array}{l}1197 \\
1198\end{array}$ \\
\hline & ITYPER DATA STATEMENT GIVES UK-LLL TYPES. LLL8S IS NN,4N & XSMOD & 1199 \\
\hline & IF(LLL . EQ. 1)ITYPER(85)=4 & XSMOD & 1200 \\
\hline C & & XSMOD & 1201 \\
\hline \multirow[t]{3}{*}{100} & $N D=N D+1$ & XSMOD & 1202 \\
\hline & $N C D=I=1$ & XSMOD & 1203 \\
\hline & READ(N,I) IAT,NER,A,ISYS,IDATA,NE L,IA7,IA8,IA9 & XSMOD & 1204 \\
\hline \multirow[t]{5}{*}{1} & FORMAT(2(111,1X),F11. 6,1X,3(111,1X),13,12,13) & XSMOD & 1205 \\
\hline & ICHK=PRCT(1.IBLK,ISID) & XSMOD & 1206 \\
\hline & IF(ICHK . NE. O)GO TO 1000 & XSMOD & 1207 \\
\hline & IF(IRT . EQ. IDB(IBLK))GO TO 110 & XSMOD & 1208 \\
\hline & PRINT 6, IDB(IBLK),IRT,IBLK,ISID & XSMOD & 1209 \\
\hline $\mathbf{6}$ & FORMAT $\left(/ /^{\bullet}\right.$ READAD. REACTION TYPE DOES NOT MATCH THAT IN BLOCKO. IDB= & XSMOD & 1210 \\
\hline 1 & $* 14^{*} 1 \mathrm{RT}={ }^{* 14^{*}}$ BLOCK=*14* N(N=*15) & XSMOD & 1211 \\
\hline & Go To 1000 & XSMOD & 1212 \\
\hline C & GET TWO-DIGIT REACTION NUMBER AND NO. OF NEUTRONS & XSMOD & 1213 \\
\hline 110 & NRT $=$ MOD $($ IRT,1000) & XSMOD & 1214 \\
\hline & $N N=$ ITYPER(NRT) & XSMOD & 1215 \\
\hline C & CHECK ISYS FLAG AGAINST CONVENTION. FOR LLL CHANGE IF INCORRECT & XSMOD & 1216 \\
\hline & IF(NRT . EQ. 2)GO TO 115 & XSMOD & 1217 \\
\hline & IF(NRT . GE. 5 . AND. NRT . LE. 14)GO TO 115 & XSMOD & 1218 \\
\hline & 1F(LLL. EQ. 1 . AND. NRT . GE. 31 . AND. NRT . LE, 79)GO TO 115 & XSMOD & 1219 \\
\hline & IF(ISYS . EQ. 2)GO TO 130 & XSMOD & 1220 \\
\hline & PRINT 1 t, ISYS,NRT,IBLK,ISID,LLL & XSMOD & 1221 \\
\hline 14 & FORMAT $\left(/{ }^{*}\right.$ READAD. ISYS DISCREPANCY. ISYS="12" REACTION="I3" BLOCK=" & XSMOD & 1222 \\
\hline 1 & $15^{\circ} N\left(N=* 15^{*} \quad L L L=* 12\right)$ & XSMOD & 1223 \\
\hline & IF(LLL . EQ, I)ISYS=2 & XSMOD & 1224 \\
\hline & PRINT 22. ISYS & XSMOD & 1225 \\
\hline 22 & FORMAT(* ISYS CHANGED TO *I2) & XSMOD & 1226 \\
\hline
\end{tabular}




\begin{tabular}{|c|c|c|c|}
\hline \multirow{4}{*}{115} & GO TO 130 & XSMOD & 1227 \\
\hline & IF(ISYS EQ. 1)GO TO 130 & XSMOD & 1228 \\
\hline & PRINT 14, ISYS,NRT,IBLK,ISID,LLL & XSMOD & 1229 \\
\hline & IF(LLL . EQ. 1)ISYS=1 & XSMIOD & 1230 \\
\hline & PRINT 22, ISYS & XSMOD & 1231 \\
\hline \multirow[t]{3}{*}{130} & IF(NRT . NE, 2)GO TO 150 & XSMOD & 1232 \\
\hline & IF(ND . EQ. 1)GO TO 140 & XSMOD & 1233 \\
\hline & PRINT 2,IRT,IBLK,ISID & XSMOD & 1234 \\
\hline 2 & FORMAT $\left(/ /^{*}\right.$ READAD, IST ANG D NOT FOR ELASTIC. REACTION=*I5, BLOCK $=*$ & XSMOD & 1235 \\
\hline \multirow[t]{2}{*}{1} & $15, * N \mid N=* 15\}$ & XSMOD & 1236 \\
\hline & Go To 1000 & XSMOD & 1237 \\
\hline C & FORM TID & XSMOD & 1238 \\
\hline \multirow{2}{*}{140} & $\operatorname{ITIDS}(1)=I T I D=K I D$ & XSMOD & 1239 \\
\hline & GO TO 160 & XSMOD & 1240 \\
\hline \multirow{2}{*}{$c^{150}$} & $\operatorname{ITIDS}(\mathrm{ND})=K I D * 100+\mathrm{NRT}$ & XSMOD & 1241 \\
\hline & & XSMOD & 1242 \\
\hline C & CHOOSE APPROPRIATE READ & XSMOD & 1243 \\
\hline \multirow[t]{4}{*}{160} & IF(IDATA . LT. 2)GO TO 200 & XSMOD & 1244 \\
\hline & IF(IDATA . EQ. 2)GO TO 400 & XSMOD & 1245 \\
\hline & IF(IDATA . EQ. 20 . OR. IDATA , EQ. 21)GO TO 600 & XSMOD & 1246 \\
\hline & PRINT 4, IDATA,IRT,IBLK,NIN & XSMOD & 1247 \\
\hline \multirow{3}{*}{4} & FORMAT $/ / /^{*}$ READAD. ERROR IN AD TYPE SPEC. IDATA=*15* REACTION=*15, & XSMOD & 1248 \\
\hline & BLOCK $=* 15 * \mathrm{NIN}=* 15)$ & XSMOD & 1249 \\
\hline & GO TO 1000 & XSMOD & 1250 \\
\hline $\begin{array}{l}C \\
C\end{array}$ & & XSMOD & 1251 \\
\hline C & READ MU,T PAIRS & XSMOD & 1252 \\
\hline \multirow[t]{2}{*}{200} & $K T=1$ & XSMOD & 1253 \\
\hline & LEGN=0 & XSMOD & 1254 \\
\hline \multirow{7}{*}{$\begin{array}{r}220 \\
3\end{array}$} & READ(N,3) ERL,ERH,NCER,NDIS,PROB(1),NMU(1),IA7,IA8,IA9 & XSMOD & 1255 \\
\hline & FORMAT(2(F11 $6,1 \mathrm{X}), 2(111,1 \mathrm{X}), \mathrm{F} 11.6,1 \mathrm{X}, \mathrm{I1} 1,1 \mathrm{X}, 13,12,13)$ & XSMOD & 1256 \\
\hline & KCER $=1$ & XSMOD & 1257 \\
\hline & $\mathrm{NCD}=\mathrm{NCD}+1$ & XSMOD & 1258 \\
\hline & ICHK=PRCT(NCD,IBLK, ISID) & XSMOD & 1259 \\
\hline & IF(ICHK . NE. O)GO TO 1000 & XSMOD & 1260 \\
\hline & 1F(NCD. NE. 2)GO TO 250 & XSMOD & 1261 \\
\hline \multirow[t]{2}{*}{ C } & CHECK IF NEED TO ADD LOWEST ENERGY & XSMOD & 1262 \\
\hline & IF(ERL- 2. 5E-08)230,230,240 & XSMOD & 1263 \\
\hline 230 & $E(1)=E R L$ & XSMOD & 1264 \\
\hline & Go To 270 & XSMOD & 1265 \\
\hline 240 & $E(1)=1.0 E-11$ & XSMOD & 1266 \\
\hline & $E(2)=E R L$ & XSMOD & 1267 \\
\hline & $\mathbf{I}=\mathbf{2}$ & XSMOD & 1268 \\
\hline C & PACK LOWER INDEX. ENTER ISOTROPIC DISTR FOR LOWEST ENERGY & XSMOD & 1269 \\
\hline & $M D(1)=K T^{*} I 24$ & XSMOD & 1270 \\
\hline & $\operatorname{TK}(1)=-1.0$ & XSMOD & 1271 \\
\hline & $T K(2)=T K(4)=0.5$ & XSMOD & 1272 \\
\hline & $\operatorname{TK}(3)=1.0$ & XSMOD & 1273 \\
\hline & $\mathbf{K T}=4$ & XSMOD & 1274 \\
\hline c & PACK UPPER INDEX AND INCREASE KT POINTER & XSMOD & 1275 \\
\hline & $M D(1)=M D(1)+K T$ & XSMOD & 1276 \\
\hline & $K T=5$ & XSMOD & 1277 \\
\hline & Go To 270 & XSMOD & 1278 \\
\hline c & & XSMOD & 1279 \\
\hline C & AVERAGE ENERGY IF RANGE GIVEN & XSMOD & 1280 \\
\hline 250 & IF(ERH . NE. O)GO TO 260 & XSMOD & 1281 \\
\hline & $E(I)=E R L$ & XSMOD & 1282 \\
\hline & Go To 270 & XSMOD & 1283 \\
\hline 260 & $E(I)=0.5^{\star}(E R L+E R H)$ & XSMOD & 1284 \\
\hline C & PACK LOWER INDEX AND CHECK FOR MULTIPLE DISTRIBUTIONS & XSMOD & 1285 \\
\hline 270 & $M D(1)=K T^{*} I 24$ & XSMOD & 1286 \\
\hline & IF(NDIS . EQ. 1)GO TO 275 & XSMOD & 1287 \\
\hline & CALL MULTI(KID,IBLK,N,IERR,NCD,NDIS) & XSMOD & 1288 \\
\hline & IF(TK(KT- 2) . EQ. 1)Go TO 290 & XSMUD & 1289 \\
\hline & PRINT 8, TK(KT- 2),KT,IRT,IBLK,ISID,NDIS & XSMOD & 1290 \\
\hline 8 & FORMAT(" READAD. AFTER MULTI LAST MU NOT $=1$, MU="E12. 5* KT $=5^{*} 5^{*}$ REAC & XSMOD & 1291 \\
\hline 1 & T1ON=*I5* BLOCK $=* 14 *$ N1N $=* 15 *$ NDIS $=* 12)$ & XSMOD & 1292 \\
\hline & IERR $=2$ & XSMOD & 1293 \\
\hline & Go To 290 & XSMOD & 1294 \\
\hline C & READ MU,T PAIRS INTO TK BLOCK & XSMOD & 1295 \\
\hline 275 & $K D S=N M U / 3$ & XSMOD & 1296 \\
\hline & NMUR=MOD(NMU,3) & XSMOD & 1297 \\
\hline
\end{tabular}


IF(NMUR . NE. O) KDS=KDS+ 1

XSMOD

DO 280$\rfloor=I, K D S$

$K L=K T+5$

READ(N,S) (TK(K),K=KT,KL),LA7,LAB,IA9

XSMOD

XSMOD

XSMOD

FORMAT $(6(F 11,6,1 X), 13,12,13)$

KCER $=K C E R+1$

$\mathrm{NCD}=\mathbf{N C D}+1$

ICHK=PRCT(NCD,IBLK,JSIV)

IF(ICHK . NE. O)GO TO 1000

280 CONTINUE

$K T=K T+6$

IF(NMUR . EQ. D)GO TO 290

C ADJUST POINTER IF LAST CARD NOT FULL AND PACK UPPER INDEX

KTADJ $=2$ "(3- NMUR)

KT $=K T-K T A D]$

C

$290 \quad M D(I)=M D(I)+K T=1$

C

ON LLL TAPE AD GIVEN FOR IST NEUTRON ONLY, ON UK SKIP AD GIVEN FOR 2ND AND 3RD NEUTRONS

IF(LLL . EQ. 1)GO TO 305

IF(NN, EQ. I)GO TO 305

PRINT 12,IRT,IBLK,ISID,NN

12 FORMAT(* READAD. SKIPPING AD FOR NTH NEUTRONS. REACTION=*I5* BLOCK=*

XSMOD

XSMOD

XSMOD

XSMOD

XSMOD

XSMOD

XSMOD

XSMOD

XSMOD

XSMOD

XSMOD

XSMOD

XSMOD

XSMOD

XSMOD

XSMOD

XSMOD

XSMOD

XSMOD

XSMOD

$14^{*} \mathrm{NIN}=* 15^{*}$ TYPE $=* 12$ )

KEAD(N, 3) ERL,ERH,NCER,DUM(1),DUM(2),DUM(3),IA7,IA8,IA9

XSMOD

$K C E R=K C E R+1$

$\mathrm{NCD}=\mathrm{NCD}+1$

ICHK=PRCT(NCD,IBLK,ISID)

IF(ICHK . NE. O)GO TO 1000

$K C E R=K C E R+1$

DO 295 J=KCER,NCER

$\mathrm{NCD}=\mathrm{NCD}+1$

295 READ(N,7)

C NORMALIZE ANG DISTR

FORMAT(1X)

$J B=M D(I) / 124$

JE $=M D(L) \cdot \int B * 1243$

$S=0$

DO $310 \mathrm{~J} 1=\mathrm{JB}, \mathrm{JE}, 2$

$S=0.5^{*}(T K(J 1+1)+T K(J 1+3))^{*}(T K(J 1+2)-T K(J 1))+S$

310 CONTINUE

IF(ABS(S- 1.0) . LT. . 02)GO TO 320

PRINT 10, E(I),S,IRT, IBLK,ISID

10 FORMAT( ${ }^{*}$ NORMALIZING ANG DISTR FOR $E={ }^{*} E 12.5^{*}$ NORM FACTOR=*E12.5* $R$

EACTION $=* 15 *$ BLOCK $=* 14 *$ NIN $=*(5)$

$320 \quad \mathrm{JB}=\mathrm{JB}+1$

$\mathrm{JE}=\mathbf{j E}+3$

DO $330 \mathrm{J1}=\mathrm{JB}, \mathrm{JE}, 2$

$\operatorname{TK}(J 1)=\operatorname{TK}(J 1) / S$

330 CONTINUE

IF(NCD . EQ. ICDS(IBLK))GO TO 340

$1=I+1$

C

GO TO 220

C

ENTER HERE FROM BOTH LEGENDRE AND MU,T PAIRS TO WRAP UP ANG DIST

NED $=1$

KT $=$ KT -1

NINC $=40$

C

C DEFINE DT ARRAY FOR ANGULAR DISTRIBUTION

N. ANGD(ND)=F. ITIDS(ND)/F. SDES/F. NED/(F, E(J), J=1,NED)/F. ISYS/F, A/

F. LEGN/F. KT/(F. TK(J),J=1,KT)/(F. MD(J),J=1,NED)/F. NINC/ GO TO 2000

C

READ LEGENDRE REPRESENTATION HERE.

READ IN ENTIRE BLOCK USING ES BLOCK AS TEMPORARY STORAGE.

ON INPUT TAPE ENERGIES AND CORRESPONDING COEFFS ARE GIVEN FOR EACH

L. REARRANGE IN LIBRARY SO THAT COEFFS CORRESPONDING TO $L=1, L=2$,

XSMOD

XSMOD

XSMOD

XSMOD

XSMOD

XSMOD

XSMOD

XSMOD

XSMOD

XSMOD

XSMOD

XSMOD

XSMOD

XSMOD

XSMOD

XSMOD

XSMOD

XSMOD

XSMOD

XSMOD

XSMOD

XSMOD

XSMOD

XSMOD

XSMOD

XSMOD

XSMOD

XSMOD

XSMOD

XSMOD

XSMOD

XSMOD

XSMOD

XSMOD

XSMOD

XSMOD

XSMOD

XSMOD

XSMOD

XSMOD

XSMOD

XSMOD

XSMOD

XSMOD

XSMOD

XSMOD

C 


\begin{tabular}{|c|c|c|c|}
\hline $\begin{array}{l}\mathbf{C} \\
\mathbf{C}\end{array}$ & ETC. ARE GIVEN FOR EACH E. & $\begin{array}{l}\text { XSMOD } \\
\text { XSMOD }\end{array}$ & $\begin{array}{l}1370 \\
1371\end{array}$ \\
\hline \multirow{4}{*}{400} & N. ES=F. ES & XSMOD & 1372 \\
\hline & $\mathrm{KT} 1=1$ & XSMOD & 1373 \\
\hline & DO $445 \mathrm{~J}=1, \mathrm{NER}$ & XSMOD & 1374 \\
\hline & La1 & XSMOD & 1375 \\
\hline \multirow{8}{*}{$\begin{array}{r}405 \\
9\end{array}$} & READ(N,9)ERL,ERH,NCER,LMAX,INT,NE,IA7,IA8,1A9 & XSMOD & 1376 \\
\hline & FORMAT $(2(F 11.6,1 X), 4(111,1 X), 13,12,13)$ & XSMOD & 1377 \\
\hline & $K C E R=1$ & XSMOD & 1378 \\
\hline & $\mathrm{NCD}=\mathrm{NCD}+1$ & XSMOD & 1379 \\
\hline & ICHK=PRCT(NCD,IBLK,ISID) & XSMOD & 1380 \\
\hline & IF(ICHK . NE. O)GO TO 1000 & XSMOD & 1381 \\
\hline & IF(NCD . EQ. 2)Gr TO 415 & XSMOD & 1382 \\
\hline & GO TO 430 & XSMOD & 1383 \\
\hline C & CHECK IF NEED TO ADD LOWEST ENERGY. & XSMOD & 1384 \\
\hline 415 & IF(ERL- 2. 5E- 08)420,420,425 & XSMOD & 1385 \\
\hline \multirow{4}{*}{420} & $E(1)=E R L$ & XSMOD & 1386 \\
\hline & $\mathbf{K T}=1$ & XSMOD & 1387 \\
\hline & $\begin{array}{l}\text { I=1 } \\
\text { GO }\end{array}$ & XSMOD & 1388 \\
\hline & $\begin{array}{l}\text { GO TO } 430 \\
E(1)=1,0 \mathrm{E}-11\end{array}$ & XSMOD & 1389 \\
\hline \multirow{7}{*}{425} & & XSMOD & 1390 \\
\hline & $\begin{array}{l}E(2)=E R L \\
I=2\end{array}$ & XSMOD & 1391 \\
\hline & $\mathbf{I = 2}$ & XSMOD & 1392 \\
\hline & TK(I)=1 & XSMOD & 1393 \\
\hline & $T K(2)=0$ & XSMOD & 1394 \\
\hline & $\mathbf{K T}=3$ & XSMOD & 1395 \\
\hline & $M D(1)=00000000000100000002 B$ & XSMOD & $1 ? 96$ \\
\hline \multirow{6}{*}{$c^{430}$} & IF (LMAX . NE. O)GO TO 433 & XSMOD & 1.97 \\
\hline & IF LMAX $=0$ DSTRBN IS ISOTROPIC & XSMOD & 1398 \\
\hline & ES(KT1)=ERL & XSMOD & 1399 \\
\hline & $\mathrm{ES}(\mathrm{KT} 1+1)=0$ & XSMOD & 1400 \\
\hline & $K T 1=K T 1+2$ & XSMOD & 1401 \\
\hline & GO TO 442 & XSMOD & 1402 \\
\hline \multirow{6}{*}{$c^{435}$} & IS $=\mathbf{I}$ & XSMOD & 1403 \\
\hline & $\begin{array}{l}\text { NE IS NO. OF ENERGIES FOR WHICH COEFFS ARE GIVEN FOR THIS L. } \\
\text { KDS }=\text { NE/3 }\end{array}$ & $\begin{array}{l}\text { XSMOD } \\
\text { XSMOD }\end{array}$ & $\begin{array}{l}1404 \\
1405\end{array}$ \\
\hline & NNER $=\mathrm{MCD}(\mathrm{NE}, 3)$ & XSMOD & 1406 \\
\hline & IF(NNER , NE. $\quad 0) K D S=K D S+1$ & XSMOD & 1407 \\
\hline & DO $435 \mathrm{~K}=1, \mathrm{KDS}$ & XSMOD & 1408 \\
\hline & $\mathrm{JL}=\mathrm{KT} 1+5$ & XSMOD & 1409 \\
\hline \multirow[t]{7}{*}{ c } & READ IN ENERGY-COEFF PAIRS & XSMOD & 1410 \\
\hline & READ(N,5) (ES(J),J=KT1,JL),IA 7,IA8, IA9 & XSMOD & 1411 \\
\hline & KCER=KCER + 1 & XSMOD & 1412 \\
\hline & $\mathrm{NCD}=\mathrm{NCD}+1$ & XSMOD & 1413 \\
\hline & ICHK=PRCT(NCD,IBLK,ISID) & XSMOD & 1414 \\
\hline & IF(ICHK . NE. O)GO TO 1000 & XSMOD & 1415 \\
\hline & $\mathrm{KT} 1=\mathrm{KT} 1+6$ & XSMOD & 1416 \\
\hline \multirow[t]{2}{*}{435} & CONTINUE & XSMOD & 1417 \\
\hline & IF(NNER , EQ O)GO TO 440 & XSMOD & 1418 \\
\hline \multirow[t]{3}{*}{ c } & ADJUST POINTER IF LAST CARD WAS NOT FULL & XSMUD & 1419 \\
\hline & KTAD J $=2 *(3-N N E F)$ & XSMOD & 1420 \\
\hline & KT1=KT1-KTA J J & XSMOD & 1421 \\
\hline \multirow[t]{2}{*}{440} & IF(L . EQ LMAX)GO TO 442 & XSMOD & 1422 \\
\hline & $L=L+1$ & XSMOD & 1423 \\
\hline \multirow[t]{3}{*}{$\mathbf{C}$} & GO BACK AND READ FOR NEXT L. & XSMOD & 1424 \\
\hline & GO TO 405 & XSMOD & 1425 \\
\hline & HAVE READ FOR ALL $L$. & XSMOD & 1426 \\
\hline 442 & IF(NN . EQ. 1)GO TO 445 & XSMOD & 1427 \\
\hline & IF(LLL . EQ. 1)GO TO 445 & XSMOD & 1428 \\
\hline & PRINT 18, IRT,IBLK,NIN,NN & XSMOD & 1429 \\
\hline 18 & FORMAT(* READAD. SKIP LEGENDRE AD FOR NTH NEUTRONS. REACTION=*I5* BL & XSMOD & 1430 \\
\hline 1 & $O C K=* 14 *$ NIN $=* 15 *$ TYPE $=* 12)$ & XSMOD & 1431 \\
\hline & READ(N,3) ERL,ERH,NCER,DUM(1),DUM(2),DUM(3),IA7,IA8,IA9 & XSMOD & 1432 \\
\hline & KCER-KCER+ 1 & XSMOD & 1433 \\
\hline & $N C D=N C D+1$ & XSMOD & 1434 \\
\hline & ICHK=PRCT(NCD,IB LK,ISID) & XSMOD & 1435 \\
\hline & IF(ICHK . NE. O)GO TO 1000 & XSMOD & 1436 \\
\hline & KCER=KCER+ 1 . & XSMOD & 1437 \\
\hline & DO $443 J J=K C E R, N C E R$ & XSMOD & 1438 \\
\hline & $N C D=N C D+1$ & XSMOD & 1439 \\
\hline 443 & READ(N,7) & XSMOD & 1440 \\
\hline 445 & CONTINUE & XSMOD & 1441 \\
\hline
\end{tabular}




\begin{tabular}{|c|c|c|c|}
\hline $\mathbf{C}$ & $\begin{array}{l}\text { SET KT1 TO POINT TO LAST E } \\
\text { KT1 }=\text { KT } 1-2\end{array}$ & $\begin{array}{l}\text { XSMOD } \\
\text { XSMOD }\end{array}$ & $\begin{array}{l}1442 \\
1443\end{array}$ \\
\hline C & & XSMOD & 1444 \\
\hline C & FILL E BLOCK & XSMOD & 1445 \\
\hline $\mathbf{C}$ & & XSMOD & 1446 \\
\hline 450 & IF(ABS(ES(1)-E(I))-.0000 $I) 460,460,455$ & XSMOD & 1447 \\
\hline 455 & PRINT 16, ES(1),E(1),IRT,1BLK,N1N & XSMOD & 1448 \\
\hline 16 & FORMAT $(*$ READAD. POSSIBLE INDEX OR INPUT ERROR. ES1="E12.5* E=*E12. 5 & XSMOD & 1449 \\
\hline & - I=*15, REACTION=*I5* BLOCK=*15* NIN=*15) & XSMOD & 1450 \\
\hline & GO TO 1000 & XSMOD & 1451 \\
\hline $\mathbf{C}$ & CHECK EACH ENERGY IN TEMPORARY ES BLOCK AGAINST THOSE ALREADY & XSMOD & 1452 \\
\hline $\mathbf{C}$ & TABULATED IN E BLOCK. IF NOT IN E BLOCK, PUT IT IN AND INCREASE I. & XSMOD & 1453 \\
\hline 460 & DO $480 \mathrm{~K}=1, \mathrm{KT} 1,2$ & XSMOD & 1454 \\
\hline & DO $470 \mathrm{KK}=1$, I & XSMOD & 1455 \\
\hline & IF(ABS(ES(K)- E(KK))- . 00001)480,480,470 & XSMOD & 1456 \\
\hline 470 & CONTINUE & XSMOD & 1457 \\
\hline & $E(I+1)=E S(K)$ & XSMOD & 1458 \\
\hline & $I=I+1$ & XSMOD & 1459 \\
\hline 480 & CONTINUE & XSMOD & 1460 \\
\hline C & & XSMOD & 1461 \\
\hline C & FILL TK BLOCK & XSMOD & 1462 \\
\hline $\mathbf{C}$ & & XSMOD & 1463 \\
\hline & $\mathrm{KS}=1$ & XSMOD & 1464 \\
\hline C & $\begin{array}{l}\text { KEEP COUNT NF. } \\
\text { DO } 520 \text { II=IS,I }\end{array}$ & XSMOD & $\begin{array}{l}1466 \\
1467\end{array}$ \\
\hline & $\mathrm{NF}=0$ & XSMOD & 1468 \\
\hline & DO $510 \mathrm{~K}=\mathrm{KS}, \mathrm{KT} 1,2$ & XSMOD & 1469 \\
\hline & $\operatorname{IF}(A B S(E S(K)-E(I I))-.00001) 500,500,510$ & XSMOD & 1470 \\
\hline 500 & $N F=N F+1$ & XSMOD & 1471 \\
\hline & $T K(K T+N F)=E S(K+1)$ & XSMOD & 1472 \\
\hline 510 & CONTINUE & XSMOD & 1473 \\
\hline $\mathbf{C}$ & HAVE FOUND ALL COEFFS FOR 1 E. PACK LOWER INDEX AND INCREASE KT. & XSMOD & 1474 \\
\hline & $M D(I I)=K T^{*} I 24$ & XSMOD & 1475 \\
\hline & $\begin{array}{l}\mathrm{KT}=\mathrm{KT}+\mathrm{NF}+1 \\
\text { IF(NF EQ } 1 \text { ) GO TO } 519\end{array}$ & XSMOD & 1476 \\
\hline $\mathbf{C}$ & $\begin{array}{l}\text { IF(NF . EQ 1)GO TO } 519 \\
\text { REMOVE ZERO COEFFS AT HIGHEST L }\end{array}$ & XSMOD & 1477 \\
\hline & $\begin{array}{l}\text { REMOVE ZERO COEFFS AT HIGHEST L } \\
\text { KA=KT }\end{array}$ & XSMOD & 1478 \\
\hline & & XSMOD & 1479 \\
\hline & IF(TK(KA-KB)) 519,514,519 & XSMOD & 1480 \\
\hline 514 & KT $=$ KT -1 & XSMOD & 1481 \\
\hline & $N F=N F-1$ & $\begin{array}{l}\text { XSMOD } \\
\text { XSMOD }\end{array}$ & $\begin{array}{l}1482 \\
1483\end{array}$ \\
\hline 515 & CONTINUE & XSMOD & 1484 \\
\hline 519 & $\mathrm{KS}=\mathrm{KS}+2$ & XSMOD & 1485 \\
\hline C & PACK UPPER INDEX AND STORE NO. OF COEFFS & XSMOD & 1486 \\
\hline & $\mathrm{MD}(\mathrm{II})=\mathrm{MD}(\mathrm{II})+\mathrm{KT}-1$ & XSMOD & 1487 \\
\hline & TK(KT-NF-1)=NF & XSMOD & 1488 \\
\hline 520 & CONTINUE & XSMOD & 1489 \\
\hline C & & XSMOD & 1490 \\
\hline C & RESTORE ES BLOCK & XSMOD & 1491 \\
\hline & F. ES=N. ES & XSMOD & 1492 \\
\hline & LEGN $=I$ & XSMOD & 1493 \\
\hline 600 & $\begin{array}{l}\text { GO TO } 340 \\
\text { PRINT } 601\end{array}$ & XSMOD & 1494 \\
\hline 601 & $\begin{array}{l}\text { PKINT OOI } \\
\text { FORMAT } * \text { CANNOT READ MIYED REPRESENTATION YET *) }\end{array}$ & XSMOD & 1495 \\
\hline 700 & NCDS=ICDS(IBLK) & XSMOD & 1496 \\
\hline & DO $800 \quad I=2, N C D S$ & XSMOD & 1497 \\
\hline 800 & $\operatorname{READ}(\mathbf{N}, \mathbf{8 0 1})$ & XSMOD & 1499 \\
\hline 801 & FORMAT(1X) & XSMOD & 1500 \\
\hline & GO TO 2000 & XSMOD & 1501 \\
\hline C & ERROR RETURN. SET TO SKIP REMAINING CARDS. & XSMOD & 1502 \\
\hline 1000 & IERR $=$ NCD + 1 & XSMOD & 1503 \\
\hline C & STANDARD RETURN & XSMOD & 1504 \\
\hline 2000 & RETURN & XSMOD & 1505 \\
\hline & END & XSMOD & 1506 \\
\hline & SUBROUTINE READNU(KID,IBLK,N,IERR) & XSMOD & 1507 \\
\hline C & READS ENERGY-NU PAIRS FOR FISSION REACTIONS & XSMOD & 1508 \\
\hline C & SID NO. IN LIBRARY & XSMOD & 1509 \\
\hline C. & BLOCK NO. & XSMOD & 1510 \\
\hline- & ERROR FLAG. NO ERROR $=0$. & XSMOD & 1511 \\
\hline $\mathbf{C}$ & INPUT UNIT, 3=CARDS. 2-TAPE & XSMOD & 1512 \\
\hline C & NUCLIDE ID NO. READ FROM TAPE OR CARDS & XSMOD & 1513 \\
\hline
\end{tabular}


C 1

C

1

C 100 4019. WILL SKIP REACTION=*I5* BLOCK $=* 14^{*}$ NIN=*15)

$\mathrm{IL}=I \mathrm{CDS}(1 \mathrm{BLK})$

DO $102[=2.1 \mathrm{~L}$

$102 \operatorname{READ}(\mathrm{N} .7)$

7 FORMAT'(1X)

C

Go TO 2000

STORE REACTION IDENTIFIER IN ESJ.

$103 \quad$ ESJ $(J)=I R T$

$\mathrm{J}=\mathrm{J}+1$

105 DO $200 \quad I=1$, NER

READ(N, 3) ERL, ERH,T,NCER,NXS, IA6,IA7,1A8, IA9

FORMAT $3(\mathrm{~F} 11,6,1 \mathrm{X}), 3(111,1 \mathrm{X}), 13,12,13)$

$\mathrm{NCD}=\mathrm{NCD}+1$

ICHK $=$ PRCTT(NCD, IBLK,ISID)

IF(ICHK . NE. O)GO TO 1000

DO $150 \quad 11=2$, NCER

$J i=J+5$

C

C

C

c

$1000 \quad$ IERR $=\mathrm{NCD}+1$

2000 RETURN

END

SUBROUTINE READSEC(KID,IBLK,N,IERR)

C
C
C

$\operatorname{READ}(\mathrm{N}, 5)(\mathrm{ESJ}(\mathrm{J} 1), \mathrm{J} 1=\mathrm{J}, \mathrm{JL}), \mathrm{IA} 7, \mathrm{IAB}, \mathrm{IA} 9$

促

=PRCT(NCD.IBLK,ISID)

FíICHK . NE. O)GO TO 1000

$J=\int \mathbf{L}+\mathbf{1}$

MTEMS $=$ MOD(ITEMS 6$)$

IF(MITEMS . EQ. O)GO TO 200

$\mathrm{J}=\mathrm{J}-6+\mathrm{MITEMS}$

NTINUE

$\operatorname{ESJ}(J)=-1.0$

IRS(IR) $=$ J

DEFINE DT ARRAY FOR ES

N. $\operatorname{ESJ}(I R)=(F, \operatorname{ESJ}(J 1), J I=1, J)$ )

GO TO 2000

READS SECONDARY ENERGIES FROM UK FORMAT TAPE OR CARDS

KID SID NO. IN LIBRARY

IBLK BLOCK NO.

IERR ERROR FLAG. NO ERROR=0.

N INPUT UNIT. 3=CARDS. 2=TAPE

ISID NUCLIDE ID NO. READ FROM TAPE OR CARDS

COMMON /CDID/IA7,IA8,IA9,IBLNO(100),IDB(100),ICDS(100),DUM(9), LLL

XSMOD

CDID

CNTRL.

CNTRL

$\mathrm{X}$

ES J

ESJ

XSMOD

XSMOD

XSMOD

XSMOD

XSMOD

XSMOD

$X S M O D$

XSMOD

XSMOD

XSMOD

XSMOD

XSMOD

XSMOD

XSMOD

XSMOD

XSMOD

XSMOD

XSMOD

XSMOD

XSMOD

XSMOD

XSMOD

XSMOD

XSMOD

XSMOD

XSMOD

XSMOD

XSMOD

XSMOD

XSMOD

XSMOD

XSMOD

XSMIOD

XSMOD

XSMOD

XSMOD

XSMOD

XSMOD

XSMOD

XSMOD

XSMOD

XSMOD

XSMOD

XSMOD

XSMOD

XSMOD

XSMOD

XSMOD

XSMOD

XSMOD

XSMOD

XSMOD

XSMOD

XSMOD

XSMOD

XSMOD

XSMOD

XSMOD

XSMOD

XSMOD

XSMOD

XSMOD

XSMOD

XSMOD

XSMOD

CDID 
COMMON /CNTRL/ ISID(1),KID,ND,ITIDS(25),SDES(8),IR,ITIDR(50),NES, ES(4000), IDR(50), ME(50), IRS(50),QR(50),IZ,MIXT,K2

COMMON $/ \mathrm{X} / \mathrm{X}(\mathbf{4 8 5 0})$

DIMENSION ESJ(3000)

EQUIVALENCE (ESJ(1),X(1))

COMMON /TYPE/ ITYPER(150)

DATA ITYPER $/ 15^{*} 1,2,3,0,0,1,2,1,1,2,3,2,0.1,1,2,55^{*} 1,65^{*} 0$ /

C

C CLEAR STORAGE

DO $80 \quad I=1,4850$

$80 \quad X(1)=0$

C FOR LLL TAPES CHANGE TYPE FOR REACTION 85

IF(LLL , EQ . 1)ITYPER(85)=4

100 READ(N,1) IRT,NER,ISYSM,DUM(4),DUM(5),DUM(6), IA7,IA 8, IA9

1 FORMAT $6(111,1 X), 13,12, I 3)$

ICHK=PRCT (NCD, IBLK,ISID)

IF(ICHK . NE. O)GO TO 1000

IF(IRT . EQ. IDB(IBLK))GO TO 103

PRINT 10,IDB(IBLK),IRT,IB LK, ISID

10 FORMAT(//* READSEC. REACTION TYPE DOES NOT MATCH THAT IN BLOCKO. IDB $=* 15 *$ IRT $=* 15 *$ BLOCK=*I4* NIN $=* 15)$

GO TO 1000

103 IFISYSM.EQ O)GO TO 105

PRINT 2, IRT,IBLK.ISID

2 FORMAT $/^{*}$ SECONDARY ENERGY AND SCATTERING ANGLE GIVEN IN CENTER OF

MASS SYSTEM. REACTION $=* 15 *$ BLOCK $=* 14 * N 1 N=* 14)$

C

GET REACTION NO. AND NO. OF NEUTRONS

105 NRT $=$ MOD $($ IRT,1000)

NN=MAXO(ITYPER(NRT),1)

$\operatorname{ESJ}(1)=N R T$

$J=2$

C LOOP FOR ENERGY RANGES

DO 500 II $=1$,NER

SUMW $=0,0$

C LOOP FOR NEUTRONS

DO 450 III $=1$, NN

READ(N, 3) ERI,ERH,NCER,NL,W,LAW,IA 7,IA8,IA9

(

$\mathrm{NCD}=\mathrm{NCD}+1$

ICHK $=$ PRCT (NCD, IB LK, ISID)

IF (ICHK . NE. 0)GO TO 1000

SUMW $=S U M W+W$

C

LOOP FOR LAWS

120 DO $400 \quad I=1, N L$

IF(I . EQ. 1. AND. III . EQ. 1)GO TO 150

IF(I . EQ. 1)GO TO 155

READ(N,3) ERL,ERH,NCER,NL,W,LAW,IA7,IA8,IA9

$\mathrm{NCD}=\mathrm{NCD}+\mathrm{I}$

ICHK=PRCT (NCD, IB LK,ISID)

IF(ICHK . NE. O)GO TO 1000

SUMW $=S U M W+W$

$\operatorname{ESJ}(\mathrm{J})=\mathrm{ERL}$

$\operatorname{ESJ}(J+1)=W$

$\operatorname{ESJ}(J+2)=\mathrm{LAW}$

$\mathrm{J}=\mathrm{J}+3$

C GO TO READ INDICATED LAW. RETURN TO 200.

GO TO(5100,5200,5300,5400,5500,5600,5700,5800,5900,6000)LAW

C

END OF LAW

$200 \quad \operatorname{ESJ}(J)=-4.0$

400 CONTINUE

IF(LLL . EQ. 1)GO TO 455

450 CONTINUE
END OF NEUTRON

$455 \quad$ ES] $(J+1)=-5.0$

C END OF ENERGY

$\operatorname{ESJ}(J+2)=-2.0$

$J=\mathrm{J}+3$

ISUMW=SUMW

IF(LLL . EQ. 1)ISUMW=ISUMW"NN

CNTRL

CNTRL

ESJ

ES]

TYPE

TYPE

TYPE

XSMOD

XSMOD

XSMOD

XSMOD

XSMOD

XSMOD

XSMOD

XSMOD

XSMOD

XSMOD

XSMOD

XSMOD

XSMOD

XSMOD

XSMOD

XSMOD

XSMOD

XSMOD

XSMOD

XSMOD

XSMOD

XSMOD

XSMOD

XSMOD

XSMOD

XSMOD

XSMOD

XSMOD

XSMOD

XSMOD

XSMOD

XSMOD

XSMOD

XSMOD

XSMOD

XSMOD

XSMOD

XSMOD

XSMOD

XSMOD

XSMOD

XSMOD

XSMOD

XSMOD

XSMOD

XSMOD

XSMOD

XSMOD

XSMOD

XSMOD

XSMOD

XSMOD

XSMOD

XSMOD

XSMOD

XSMOD

XSMOD

XSMOD

XSMOD

XSMOD

XSMOD

XSMOD

XSMOD

2
2 


\begin{tabular}{|c|c|c|c|}
\hline & IF(ISUMW . EQ. NN)GO TO 500 & XSMOD & 1652 \\
\hline & PRINT 4, IRT,IBLK,ISID,NN,ISUMW & XSMOD & 1653 \\
\hline 4 & FORMAT $/ /^{*}$ READSEC. SUM OF WEIGHTS NOT EQUAL NO. NEUTRONS OUT. REACT & XSMOD & 1654 \\
\hline 1 & ION=*15* BLOCK=*I4* NIN=*I5* NN=*I2* ISUMW=*I2) & XSMOD & 1655 \\
\hline 500 & CONTINUE & XSMOD & 1656 \\
\hline $\mathbf{C}$ & & XSMOD & 1657 \\
\hline C & END OF REACTION & XSMOD & 1658 \\
\hline & $\operatorname{ES}](J)=-1.0$ & XSMOD & 1659 \\
\hline C & STORE NO. OF ITEMS IN ESJ BLOCK. & XSMOD & 1660 \\
\hline & IRS(IR)=J & XSMOD & 1661 \\
\hline C & & XSMOD & 1662 \\
\hline $\mathrm{C}$ & DEFINE DT ARRAY FOR ESJ IF NO 4000 BLOCK FOLLOWING. & XSMOD & 1663 \\
\hline & INEXT =IDB (IBLK+ 1) & XSMOD & 1664 \\
\hline & IF(INEXT . EQ. 4018 . OR. INEXT . EQ. 4019)GO TO 2000 & XSMOD & 1665 \\
\hline & N. ESJ(IR)=(F. ESJ $(J 1), J 1=1, J) /$ & XSMOD & 1666 \\
\hline & Go TO 2000 & XSMOD & 1667 \\
\hline 1000 & IERR $=N C D+I$ & XSMOD & 1668 \\
\hline 2000 & RETURN & XSMOD & 1669 \\
\hline c & & XSMOD & 1670 \\
\hline C & LAW 1 & XSMOD & 1671 \\
\hline 5100 & $M=2$ & XSMOD & 1672 \\
\hline 5105 & $J L=J+4$ & XSMOD & 1673 \\
\hline & $\mathrm{JIN}=\mathrm{J}$ & XSMOD & 1674 \\
\hline & READ (N,9) NV,(ESJ(K),K=J,JL),IA7, IA 8, IA9 & XSMOD & 1675 \\
\hline 9 & FORMAT(I11,1X,5(F11. 6,1X),I3,12,I3) & XSMOD & 1670 \\
\hline & $\mathrm{NCD}=\mathrm{NCD}+1$ & XSMOD & 1677 \\
\hline & ICHK=PRCT (NCD,IBLK,ISID) & XSMOD & 1678 \\
\hline & IF(ICHK . NE. O)GO TO 1000 & XSMOD & 1679 \\
\hline & $\mathrm{J}=\mathrm{J}-1$ & XSMOD & 1680 \\
\hline & ITEMS $=M * N V$ & XSMOD & 1681 \\
\hline & MITEMS $=$ MOD $($ ITEMS,6) & XSMOD & 1682 \\
\hline & IF(ITEMS . LT. 5)GO TO 5120 & XSMOD & 1683 \\
\hline & KDS $=$ IT EMS $/ 6$ & XSMOD & 1684 \\
\hline & DO $5110 \mathrm{~K}=1$, KDS & XSMOD & 1685 \\
\hline & $\mathrm{J}=\mathrm{J}+6$ & XSMOD & 1686 \\
\hline & $\mathrm{JL}=\mathrm{J}+5$ & XSMOD & 1687 \\
\hline & $\operatorname{READ}(\mathrm{N}, 11)(\operatorname{ESJ}(\mathrm{J} 1), \mathrm{J} 1=\mathrm{J}, \mathrm{J} \mathrm{L}), \mathrm{IA7}, \mathrm{IA} 8, \mathrm{IA} 9$ & XSMOD & 1688 \\
\hline 11 & FORMAT(6(F11. $6,1 X),[3,12,13)$ & XSMOD & 1689 \\
\hline & $N C D=N C D+1$ & XSMOD & 1690 \\
\hline & ICHK=PRCT(NCD,IBLK,ISID) & XSMOD & 1691 \\
\hline & IF(ICHK . NE. 0)GO TO 1000 & XSMOD & 1692 \\
\hline 5110 & CONTINUE & XSMOD & 1693 \\
\hline 5120 & $\mathrm{~J}=\mathrm{J}+\mathrm{MITEMS}+1$ & XSMOD & 1694 \\
\hline C & FOR LAWS 1,2 ONLY CHECK FOR SUM OF PROBABILITIES=1. & XSMOD & 1695 \\
\hline & IF(LAW . NE. 1 . AND. LAW . NE. 2)GO TO 5150 & XSMOD & 1696 \\
\hline & $\mathbf{J B}=\mathbf{J I N}+\mathbf{M} \cdot \mathbf{1}$ & XSMOD & 1697 \\
\hline & SUM $=0.0$ & XSMOD & 1698 \\
\hline & DO $5130 \mathrm{~K}=\mathrm{JB}, \mathrm{J}, \mathrm{M}$ & XSMOD & 1699 \\
\hline 5130 & $S U M=S U M+E S J(K)$ & XSMOD & 1700 \\
\hline & GO TO 5155 & XSMOD & 1701 \\
\hline C & FOR LAWS 3,4,5,6 CHECK BY TRAPEZOIDAL RULE WHETHER INTEGRAL=1. & XSMOD & 1702 \\
\hline 5150 & SUM=0. 0 & XSMOD & 1703 \\
\hline & SUM $=0.0$ & XSMOD & 1704 \\
\hline & $J E=J-3$ & XSMOD & 1705 \\
\hline & DO $5151 \mathrm{~K}=\mathrm{JIN}, \mathrm{JE}, 2$ & XSMOD & 1706 \\
\hline 5151 & $\operatorname{SUM}=S U M+0.5^{*}(\operatorname{ESJ}(K+3)+\operatorname{ESJ}(K+1))^{*}(\operatorname{ESJ}(K+2)-\operatorname{ESJ}(K))$ & XSMOD & 1707 \\
\hline 5155 & IF(ABS(1.0-SUM)- . 001)200,200,5160 & XSMOD & 1708 \\
\hline 5160 & PRINT 14, SUM,LAW,ERL,1RT,IBLK,IS1D & XSMOD & 1709 \\
\hline 14 & FORMAT $\left(/ /^{*}\right.$ READSEC. SUM=*E12. 5* FOR LAW*12* ENERGY=*E12. 5* REACTION & XSMOD & 1710 \\
\hline 1 & $=* 15 * B L O C K=* 14 * N I N=* I 4 / /)$ & XSMOD & 1711 \\
\hline & GO TO 200 & XSMOD & 1712 \\
\hline C & & XSMOD & 1713 \\
\hline C & LAW 2 & XSMOD & 1714 \\
\hline 5200 & $M=3$ & XSMOD & 1715 \\
\hline & GO TO 5105 & XSMOD & 1716 \\
\hline C & LAW 3 & XSMOD & 1717 \\
\hline 5300 & IF(NN. EQ. 1)GO TO 5305 & XSMOD & 1718 \\
\hline & PRINT 12, IRT,NN & XSMOD & 1719 \\
\hline 12 & FORMAT $\left(/ /^{*}\right.$ USING TRUE LAW3 FOR REACTION *14* WITH *I1* NEUTRONS OU & XSMOD & 1720 \\
\hline 1 & T. WRITE- UPS NOT CLEAR ON WHETHER TO MULTIPLY WEIGHT BY NN. *//) & XSMOD & 1721 \\
\hline 5305 & GO TO 5100 & XSMOD & 1722 \\
\hline C & LAW 4 & XSMOD & 1723 \\
\hline
\end{tabular}




\begin{tabular}{|c|c|c|c|}
\hline 5400 & Go TO 5100 & XSMOD & 1724 \\
\hline C & LAW 5 & XSMOD & 1725 \\
\hline 5500 & GO TO 5100 & XSMOD & 1726 \\
\hline C & LAW 6 & XSMOD & 1727 \\
\hline 5600 & GO TO 5100 & XSMOD & 1728 \\
\hline & LAW 7 & XSMOD & 1729 \\
\hline \multirow[t]{2}{*}{5700} & $J \mathbf{L}=\mathbf{J}+3$ & XSMOD & 1730 \\
\hline & $\operatorname{READ}(\mathrm{N}, 13)(\operatorname{ESJ}(\mathrm{J} 1), \mathrm{J} 1=\mathrm{J}, \mathrm{J} L), I A 7,1 A 8,1 A 9$ & XSMOD & 1731 \\
\hline \multirow{6}{*}{13} & FORMAT(4(F11. $6,1 \times), 24 X, 13,12,13)$ & XSMOD & 1732 \\
\hline & $\mathrm{NCD}=\mathrm{NCD}+1$ & XSMOD & 1733 \\
\hline & IClHK=PRCT(NCD,IBLK,ISID) & XSMOD & 2734 \\
\hline & IF(ICHK , NE. O)GO TO 1000 & XSMOD & 17.35 \\
\hline & $J=J L+1$ & XSMOD & 1736 \\
\hline & GO TO 200 & XSMOD & 1737 \\
\hline C & & XSMOD & 1738 \\
\hline C & LAW 8 & XSMOD & 1739 \\
\hline \multirow[t]{2}{*}{5800} & IF(LLL , EQ. 1)GO TO 5805 & XSMOD & 1740 \\
\hline & PRINT 8, IBLK,ISID & XSMOD & 1741 \\
\hline \multirow[t]{2}{*}{8} & FORMAT $\left(/ /^{*}\right.$ NO LAW 8 FOR UKDATA. BLOCK $=* 14^{*}$ NIN $\left.=* 15\right)$ & XSMOD & 1742 \\
\hline & Go TO 1000 & XSMOD & 1743 \\
\hline C & & XSMOD & 1744 \\
\hline C & CHANGE LAW NUMBER TO 3 AS IN S4. & XSMOD & 1745 \\
\hline C & BREAK UP LAW 8 FORMAT INTO SEVEKAL LAW 3S. & XSMOD & 1746 \\
\hline C & & XSMOD & 1747 \\
\hline 5805 & $\mathrm{~J}=\mathrm{J}-\mathbf{3}$ & XSMOD & 1748 \\
\hline \multirow[t]{3}{*}{ C } & SET NEl=1 TO GET STARTED. SET TO ITS REAL VALUE WHEN CARD IS READ. & XSMOD & 1749 \\
\hline & $\begin{array}{l}\text { NEI }=1 \\
\text { DO } 5850 \quad I I=1, N E I\end{array}$ & XSMOD & 175 \\
\hline & DO 5850 II $=1$, NEI & XSMOD & 1751 \\
\hline 5810 & READ(N,17) NEI,EN.NPEO,DUM(4),DUM(5),DUM(6),IA7,IA8,IA9 & XSMOD & 1752 \\
\hline \multirow[t]{14}{*}{17} & FORMAT(11 1,1X,F11, 6,1X,111,1X,3(F11. 6,1X), $13,12,13)$ & XSMOD & 1753 \\
\hline & $\mathrm{NCD}=\mathrm{NCD}+1$ & XSMOD & 1754 \\
\hline & ICHK=PRCT(NCD,IBLK,ISID) & XSMOD & 1755 \\
\hline & IF(ICHK . NE. 0)GO TO 1000 & XSMOD & 1756 \\
\hline & $\operatorname{ESJ}(J)=E N$ & XSMOD & 1757 \\
\hline & $\operatorname{ESJ}(J+1)=N N * W$ & XSMOD & 1758 \\
\hline & $\operatorname{ESJ}(J+2)=3.0$ & XSMOD & 1759 \\
\hline & $J=J+3$ & XSMOD & 1760 \\
\hline & ITEMS $=2 *$ NPEO & XSMOD & 1761 \\
\hline & $\operatorname{ESJ}(J)=\operatorname{DUM}(4)$ & XSMOD & 1762 \\
\hline & $\operatorname{ESJ}(\mathrm{J}+1)=\operatorname{DUM}(5) / \mathrm{NN}$ & XSMOD & 1763 \\
\hline & IF(DUM(6) . NE. O)GO TO 5815 & XSMOD & 1764 \\
\hline & $\mathrm{J}=\mathrm{J}+2$ & XSMOD & 1765 \\
\hline & GO TO 5810 & XSMOD & 1766 \\
\hline \multirow[t]{12}{*}{5815} & $\operatorname{ESJ}(J+2)=\operatorname{DUM}(6)$ & XSMOD & 1767 \\
\hline & $\mathrm{J}=\mathbf{J}+\mathbf{3}$ & XSMOD & 1768 \\
\hline & IT 3=ITEMS+ 3 & XSMOD & 1769 \\
\hline & KDS $=\mathrm{IT} 3 / 6$ & XSMOD & 1770 \\
\hline & DO $5830 \mathrm{KK}=1, \mathrm{KDS}$ & XSMOD & 1771 \\
\hline & $\mathrm{JL}=\mathrm{J}+5$ & XSMOD & 1772 \\
\hline & $\operatorname{READ}(\mathrm{N}, 11)(\mathrm{ESJ}(\mathrm{J} 1), J 1=\mathrm{J}, \mathrm{JL})$, IA 7,IA8,IA9 & XSMOD & 1773 \\
\hline & $\mathrm{NCD}=\mathrm{NCD}+1$ & XSMOD & 1774 \\
\hline & ICHK=PRCT(NCD, IBLK,ISID) & XSMOD & 1775 \\
\hline & IF(ICHK . NE. 0)GO TO 1000 & XSMOD & 1776 \\
\hline & IF(NN, EQ. I)GO TO 5825 & XSMOD & 1777 \\
\hline & DO $5820 \mathrm{~J} 1=\mathrm{J}, \mathrm{JL}, 2$ & XSMOD & 1778 \\
\hline \multirow[t]{2}{*}{ C } & MUST DIVIDE PROBS BY NN SINCE DATA IS COMPOSITE FOR ALI. NEUTRONS. & XSMOD & 1779 \\
\hline & $\operatorname{ESJ}(J 1)=\operatorname{ESJ}(J 1) / N N$ & XSMOD & 1780 \\
\hline$\$ 820$ & CONTINUE & XSMOD & 1781 \\
\hline 5825 & $J=J L+1$ & XSMOD & 1782 \\
\hline 5830 & CONTINUE & XSMOD & 1783 \\
\hline \multirow[t]{4}{*}{ C } & ADJUST J POINTER & XSMOD & 1784 \\
\hline & MIT $3=\operatorname{MOD}(1 \mathrm{~T} 3,6)$ & XSMOD & 1785 \\
\hline & IF(IT3 . EQ. O)GO TO 5840 & XSMOD & 1786 \\
\hline & $J=J-6+M 1 / \Gamma 3$ & XSMOD & 1787 \\
\hline $\mathbf{5 8 4 0}$ & IF(NCD . EQ. ICDS(IBLK))GO TO 200 & XSMOD & 1788 \\
\hline \multirow[t]{5}{*}{ C } & IF ALL CARDS IN BLOCK NOT READ,PUT IN MARKERS AND READ NEXT ENERGY & XSMOD & 1789 \\
\hline & $\operatorname{ES} J(J)=-4.0$ & XSMOD & 1790 \\
\hline & $\operatorname{ESJ}(J+1)=-5.0$ & XSMOD & 1791 \\
\hline & $\operatorname{ESJ}(J+2)=-2.0$ & XSMOD & 1792 \\
\hline & $J=J+3$ & XSMOD & 1793 \\
\hline 5850 & CONTINUE & XSMOD & 1794 \\
\hline
\end{tabular}


DRINT 16, NCD.ICDS(IILK),IBL.K,ISID

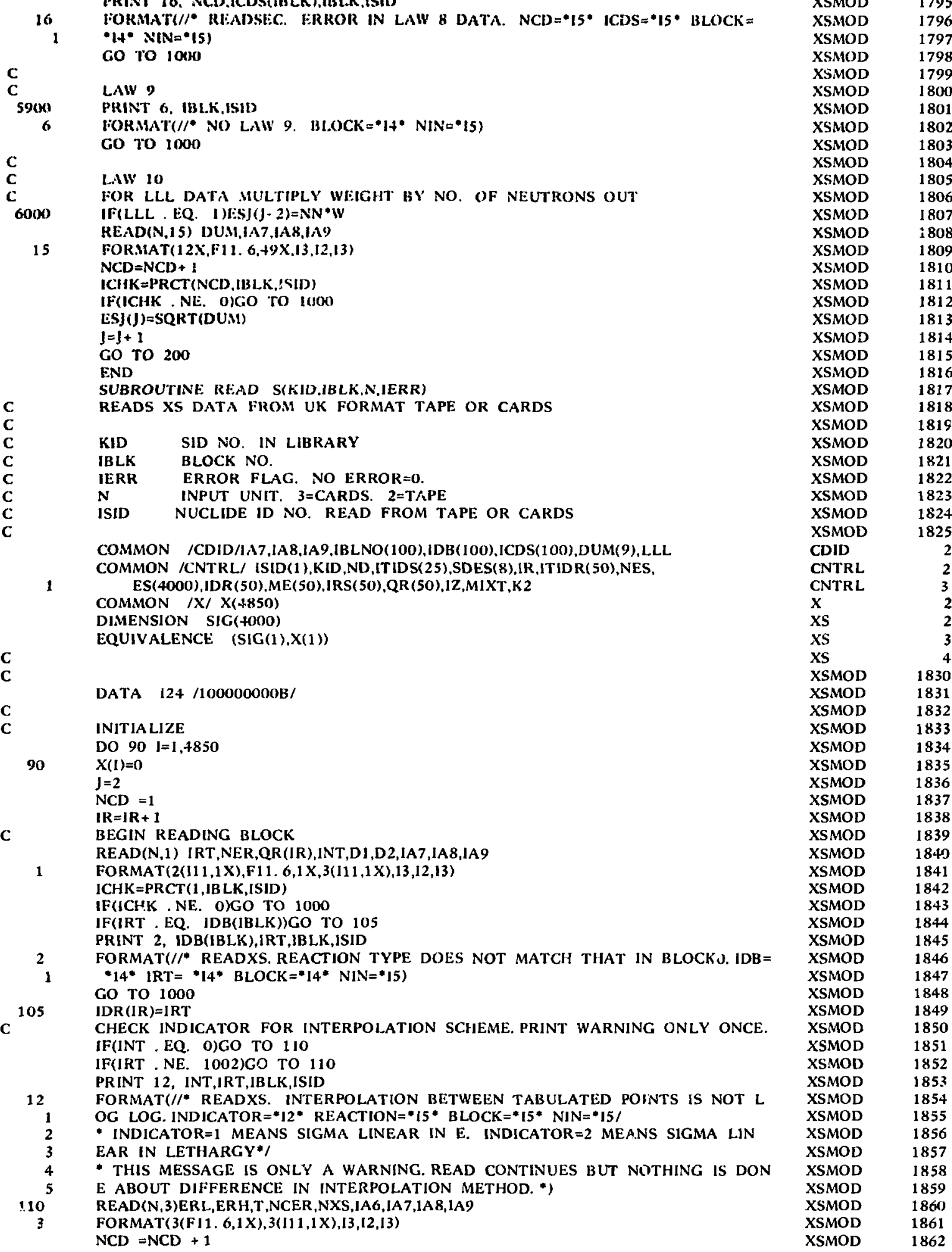


ICHK=PRCT(NCD,IB LK, ISID)

XSMOD

IF(ICHK . NE. O)GO TO 1000

IF(NXS . LE. 4000)GO TO 115

PRIN'I 14, NXS, IBLK, ISID

14

FORMAT $\left(/{ }^{*}\right.$ READXS. NO. OF XS GREATER THAN ES DIMENSION. NXS $=* I 5 *$ BL $O C K=* I 4 * N I N=* 15)$

GO TO 1000

115 IF(IA6 . EQ. 1)GO TO 120

PRINT 4, IA6,IRT,IBLK,ISID

4 FORMAT $/ / /^{*}$ READXS. IA6 $=* 15 *$ CANNOT HANDLE TEMPERATURE DEPENDENCE.

$1 \quad$ REACTION $=* 15 *$ BLOCK $=* 14 * N I N=* 15)$

GO TO 1000

C SET UP ENERGY MESH FROM ELASTIC BLOCK.

120 IF(IRT . GT. 1002)GO TO 150

C SET LOWEST ENERGY

ES $(1)=1.0 E-20$

DO $130 \quad I l=2$, NCER

$\mathrm{NCD}=\mathrm{NCD}+1$

$\operatorname{READ}(\mathrm{N}, 5) \operatorname{ES}(\mathrm{J}), \operatorname{SIG}(\mathrm{J}), \operatorname{ES}(\mathrm{J}+1), \operatorname{SIG}(\mathrm{J}+1), \operatorname{ES}(\mathrm{J}+2), \mathrm{SIG}(\mathrm{J}+2), \mathrm{IA} 7, \mathrm{IA} 8$, IA9

5 FORMAT (6) F11, 6,1X), I3, I2,I3)

ICHK=PRCT(NCD, IB LK, ISID)

IF(ICHK . NE. O)GO TO 1000

$\mathrm{J}=\mathrm{J}+3$

C

C

C

C

C

C

C

C

\section{CONTINUE}

ENERGY RANGE REPEATS HIGHEST F FROM RANGE JUST FINISHED

$\mathrm{L}=$ MOD $(\mathrm{NXS}, 3)$

$J A D J=3-L+1$

$\mathrm{IF}(\mathrm{L}, \mathrm{EQ}, \quad 0) \mathrm{JADJ}=1$

J=J- JADJ

CHECK FOR ALL CARDS READ FOR THIS BLOCK

IF(NCD . NE. ICDS(1))GO TO 110

SET HIGHEST E VALUE AND SIGMAS AT BOTH ENDS

$\mathrm{J}=\mathrm{J}+1$

$\operatorname{ES}(\mathrm{J})=1.0 \mathrm{E} 03$

$\operatorname{SIG}(1)=\operatorname{SIG}(2)$

$\operatorname{SIG}(\mathrm{J})=\operatorname{SIG}(\mathrm{J}-1)$

NES $=\mathrm{J}$

PACK LOWER AND UPPER INDICES FOR THIS REACTION

IS $=1$

$M E(I R)=I S * I 24+N E S$

GO TO 2000

FOR REACTIONS OTHER THAN ELASTIC

DO 220 II $=2, N C E R$

$\mathrm{NCD}=\mathrm{NCD}+1$

READ(N,5) DUM(1),SIG(J),DUM(2),SIG(J + 1),DUM(3),SIG(J+2),IA7,IA8, IA9

ICHK=PRCT $(N C D$, IBLK,ISID)

IF(ICHK . NE. O)GO TO 1000

COMPARE WITH MASTER ENERGY MESH TO FIND INDEX OF STARTING ENERGY IF(IA9 . NE. 3)GO TO 190

DO $160 \quad 1=2$,NES

IF(DUM(1)- ES(1))170,180,160

CONTINUE

PRINT 6, DUM(1),ES(I),I,IRT, IBLK, ISID

FORMAT $(/ / *$ READXS. FIRST ENERGY NOT IN MESH. ENERGY=*E11.6* ES(I)=* E11.6* I=*15* REACTION=*I5* BLOCK="I5* NIN=*15)

Go To 1000

ASSIGN A SIGMA TO ENERGY PRECEDING STARTING ENERGY

IS $=$ ISX $=I-1$

$\operatorname{SIG}(1)=\operatorname{SIG}(2)$

IF(IS . NE. 1)SIG(1)=1. OE- 20

CHECK ENERGIES READ AGAINST MASTER MESH

DO $210 \quad I=1,3$

IF(DUM(I)- ES(ISX+1)) 200,210,200

IF(DUM(I))205,215,205

PRINT 8, IRT, IBLK, ISID, IS, ISX,(ES(ISX+ 1), I=1,3),(DUM(I), ]=1,3)

FORMAT $(/ / *$ READXS. ENERGIES DONT MATCH MESH. REACTION="I5* BLOCK=* 15* NIN $=* 15 *$ IS $=$ *I5* ISX $=* I 5 / *$ MESH ENERGIES $=* 3($ E15.6) * ENERG $E S=* 3(E 15.6))$
XSMOD

XSMOD

XSMOD

XSMOD

XSMOD

XSMOD

XSMOD

XSMOD

XSMOD

XSMOD

XSMOD

XSMOD

XSMOD

XSMOD

XSMOD

XSMOD

XSMOD

XSMOD

XSMOD

XSMOD

XSMOD

XSMOD

XSMOD

XSMOD

XSMOD

XSMOD

XSMOD

XSMOD

XSMOD

XSMOD

XSMOD

XSMOD

XSMOD

XSMOD

XSMOD

XSMOD

XSMOD

XSMOD

XSMOD

XSMOD

XSMOD

XSMOD

XSMOD

XSMOD

XSMOD

XSMOD

XSMOD

XSMOD

XSMOD

XSMOD

XSMOD

XSMOD

XSMOD

XSMOD

XSMOD

XSMOD

XSMOD

XSMOD

XSMOD

XSMOD

XSMOD

XSMOD

XSMOD

XSMOD

XSMOD

XSMOD

XSMOD

XSMOD

XSMOD

XSMOD 


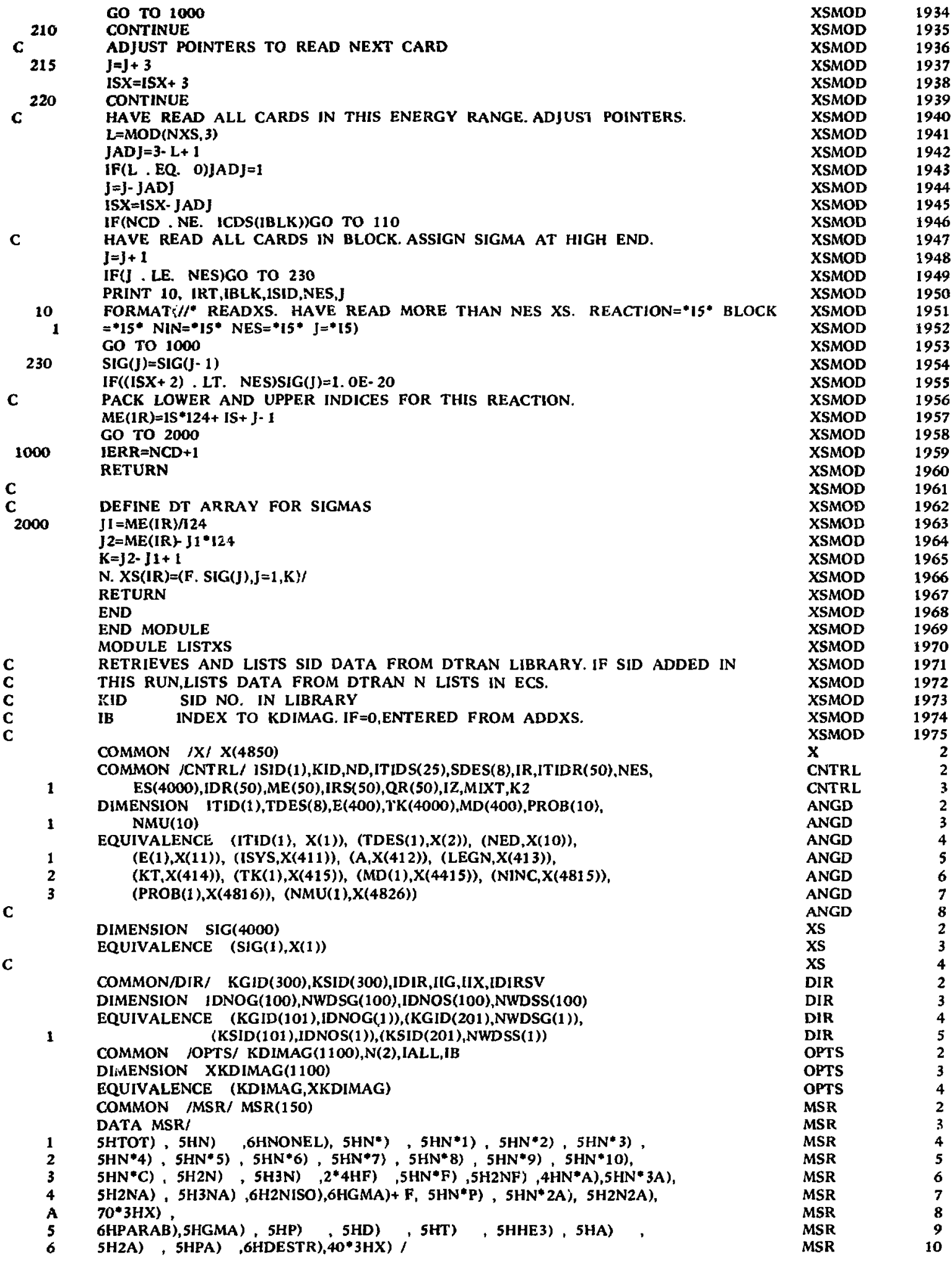


COMMON SS(2000,7)

DIMENSION DUM(2000)

EQUIVALENCE (DUM(1),SS(1,7))

DIMENSION ESJ(3000)

EQUIVALENCE (ESJ(1),X(1))

C

DATA $124 / 10000000 \mathrm{~B} /$

C

F. IB $=N$, LISTXS

IF(IB . EQ. O)GO TO 200

c

LISTING REQUESTED ON OPTION CARD. DEFINE FTRAN VARIABLES FROM DT.

XSMOD

XSMOD

XSMOD

XSMOD

XSMOD

XSMOD

XSMOD

XSMOD

XSMOD

XSMOD

XSMOD

XSMOD

XSMOD

XSMOD

XSMOD

XSMOD

XSMOD

XSMOD

XSMOD

XSMOD

XSMOD

XSMOD

XSMOD

XSMOD

XSMOD

XSMOD

XSMOD

XSMOD

XSMOD

XSMOD

XSMUD

XSMOD

XSMOD

XSMOD

XSMOD

XSMOD

XSMOD

XSMOD

XSMOD

XSMOD

XSMOD

XSMOD

XSMOD

XSMOD

XSMOD

XSMOD

XSMOD

XSMOD

XSMOD

XSMOD

XSMOD

XSMOD

XSMOD

XSMOD

XSMOD

XSMOD

XSMOD

XSMOD

XSMOD

XSMO'

XSMOD

XSMOD

XSMOD

XSMOD

XSMOD

XSMOD

XSMOD

XSMOD

XSMOD

XSMOD

XSMOD

XSMOD
2001

2002

2003

2004

2005

2006

2007

2008

2009

2010

2011

2012

2013

2014

2015

2016

2017

2018

2019

2020

2021

2022

2023

2024

2025

2026

2027

2028

2029

2030

2031

2032

2033

2034

2035

2036

2037

2038

2039

2040

2041

2042

2043

2044

2045

2046

2047

2048

2049

2050

2051

2052

2053

2054

$\operatorname{MSR}(101)=5 H X$

$\operatorname{MSR}(110)=5 \mathrm{HX})$ 


\begin{tabular}{|c|c|c|c|}
\hline & SOURCE $=3$ HLLL & XSMOD & \\
\hline C & & XSMOD & 2056 \\
\hline $\mathbf{C}$ & CHANGE REACTION TITLES FOR RBL. TYPE NOT USED. & XSMOD & 2057 \\
\hline 210 & IF(LLL . NE. 2)GO TO 215 & XSMOD & 2058 \\
\hline & $\left.\operatorname{MSR}(27)=S H N^{*} \mathrm{P}\right)$ & XSMOD & 2059 \\
\hline & $\operatorname{MSR}(28)=6 \mathrm{HN} * \mathrm{GMA})$ & XSMOD & 2060 \\
\hline & $\left.\operatorname{MSK}(29)=5 H^{*}{ }^{*} D\right)$ & XSMOD & 2061 \\
\hline & $\operatorname{MSR}(30)=6 \mathrm{HN} * \mathrm{HE} 3)$ & XSMOD & 2062 \\
\hline & $\left.\operatorname{MSR}(31)=5 H^{*} T\right)$ & XSMOD & 2063 \\
\hline & $\operatorname{MSR}(109)=5 \mathrm{HX})$ & XSMOD & 2064 \\
\hline & $\operatorname{MSR}(110)=5 H X)$ & XSMOD & 2065 \\
\hline & SOURCE $=3 \mathrm{HRBL}$ & XSMOD & 2066 \\
\hline C & PRINT HEADING & XSMOD & 2067 \\
\hline 215 & PRINT 4, KID,SDES,ND,IR,NES,SOURCE & XSMOD & 2068 \\
\hline 4 & FORMAT(22H1 * * CROSS SECTION,16,6X,8A10//25X,"NO. OF ANG. DIST. & XSMOD & 2069 \\
\hline 1 & ${ }^{*} 16,6 \mathrm{X},{ }^{*}$ NO. OF REACT. ${ }^{*} \mathrm{I6,6X},{ }^{*}$ NO. OF ENERG. ${ }^{*} 16,6 \mathrm{X},{ }^{*}$ SOURCE $\left.={ }^{*} \mathrm{~A} 3\right)$ & XSMOD & 2070 \\
\hline & PRINT 6, IZ,K2,(ITIDS(I),I=1,ND) & XSMOD & 2071 \\
\hline 6 & FORMAT $\left(32 \mathrm{HO} *\right.$ ANG. IDS * TIDS(ND) * $* 20 \mathrm{X},{ }^{*} \mathrm{Z}={ }^{*} 16,4 \mathrm{X},{ }^{*} \mathrm{~K} 2={ }^{*} 16 / \mathrm{f}$ & XSMOD & 2072 \\
\hline 1 & $(1218))$ & XSMOD & 2073 \\
\hline & PRINT 8 & XSMOD & 2074 \\
\hline 8 & FORMAT $\left(28 H O *\right.$ DATA FOR EACH REACTION $/ /^{*}$ REACT. ID ANG.DIST. & XSMOD & 2075 \\
\hline 1 & INDICES(ES) $\quad$ ENERGY REL(Q) REACTION LENGTH(ESJ)* $/$ ) & XSMOD & 2076 \\
\hline c & PRINT SUMMARY FOR EACH REACTION. UNPACK INDICES. & XSMOD & 2077 \\
\hline & DO $220 \mathrm{I}=1, \mathrm{IR}$ & XSMOD & 2078 \\
\hline & $J 1=M E(I) / 124$ & XSMOD & 2079 \\
\hline & $\mathrm{J} 2=\mathrm{ME}(\mathrm{I})-\mathrm{J1} \cdot 124$ & XSMOD & 2080 \\
\hline & ID=IDR(I) & XSMOD & 2081 \\
\hline & $1 D=M O D(I D, 1000)$ & XSMOD & 2082 \\
\hline & PRINT 10, I,ID,ITIDR(I),J1,J2,QR(I),MSR(ID),IRS(I) & XSMOD & 2083 \\
\hline 10 & FORMAT $\left(216,18,3 \mathrm{X}, 217,1\right.$ PE19. 8,5X, $\left(\mathrm{N},{ }^{*} \mathrm{Aó}, 4 \mathrm{X}, 17\right)$ & XSMOD & 2084 \\
\hline 220 & CONTINUE & XSMOD & 2085 \\
\hline 250 & $\mathbf{I R} 1=1 \mathrm{R}$ & XSMOD & 2086 \\
\hline C & CAN PRINT CROSS SECTIONS FOR ONLY 7 REACTIONS ACROSS PAGE & XSMOD & 2087 \\
\hline & $I I=M I N O(7, I R I)$ & XSMOD & 2088 \\
\hline & {$[F=0$} & XSMOD & 2089 \\
\hline & DO $300 \mathrm{~K}=1, I R$ & XSMOD & 2090 \\
\hline & IF(IF . NE. O) GO TO 260 & XSMOD & 2091 \\
\hline C & CLEAR SS BLOCK II*NES WORDS & XSMOD & 2092 \\
\hline & NWD $=$ NFS & XSMOD & 2093 \\
\hline & IF(NES . GT. 2000)NWD $=2000$ & XSMOD & 2094 \\
\hline & DO $255 \mathrm{~J}=1, \mathrm{HI}$ & XSMOD & 2095 \\
\hline & DO $254 \quad L, L=1, N W D$ & XSMOD & 2096 \\
\hline & $\operatorname{SS}(L L, J J)=0.0$ & XSMOD & 2097 \\
\hline 254 & CONTINUE & XSMOD & 2098 \\
\hline 255 & CONTINUE & XSMOD & 2099 \\
\hline & & XSMOD & 2100 \\
\hline $\mathrm{c}$ & IF ESJ FOR THIS REACTION, DEFINE FROM DT LIST AND PRINT & XSMOD & 2101 \\
\hline 260 & $L=I R S(K)$ & XSMOD & 2102 \\
\hline & IF(L. EQ. O)GO TO 270 & XSMOD & 2103 \\
\hline & F. ESJ $=$ N. ESJ(K) & XSMOD & 2104 \\
\hline & ID = IDR(K) & XSMOD & 2105 \\
\hline & $I D=M O D(I D, 1000)$ & XSMOD & 2106 \\
\hline & MSG $=$ MSR(ID) & XSMOD & 2107 \\
\hline & CALL PRESJ(K,L,MSG) & XSMOD & 2108 \\
\hline & & XSMOD & 2109 \\
\hline & DEFINE SIGMAS FROM DT LIST & XSMOD & 2110 \\
\hline 270 & F. $S I G=N . X S(K)$ & XSMOD & 2111 \\
\hline 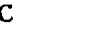 & FILL PART OF SS BLOCK WITII SIGMAS FOR THIS REACTION & XSMOD & $21 \mathrm{i} 2$ \\
\hline & SS BLOCK IS 7 STRIPS OF 2000 WDS. IF IS COUNT OF STRIPS FILLED. & XSMCD & 2113 \\
\hline & $I F=1 F+1$ & XSMOD & 2114 \\
\hline & GET NO. OF WORDS FROM INDICES & XSMOD & 2115 \\
\hline & $\mathrm{J} 1=\mathrm{ME}(\mathrm{K}) / \mathbf{1 2 4}$ & XSMOD & 2116 \\
\hline & $J 2=M E(K)-J 1 * 124$ & XSMOD & 2117 \\
\hline & $J=J 2-J 1+1$ & XSMOD & 2118 \\
\hline 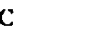 & SET LOWER INDEX & XSMOD & 2119 \\
\hline & $L O=\rfloor 1$ & XSMOD & 2120 \\
\hline 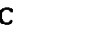 & IF LOWER INDEX GT 2000, MUST SAVE ZEROES & XSMOD & 2121 \\
\hline & IF(LO . L.E. 2000)GO TO 273 & XSMOD & 2122 \\
\hline : & IF NEED TO USE PART OF SS THAT IS DUM,MUST CLEAR IT FIRST & XSMOD & 2123 \\
\hline & IF(IF . NE. 7)GO TO 272 & XSMOD & 2124 \\
\hline & DO $271 \mathrm{M}=1,2000$ & XSMOD & 2125 \\
\hline & $\operatorname{SS}(M, 7)=0.0$ & XSMOD & 2126 \\
\hline
\end{tabular}




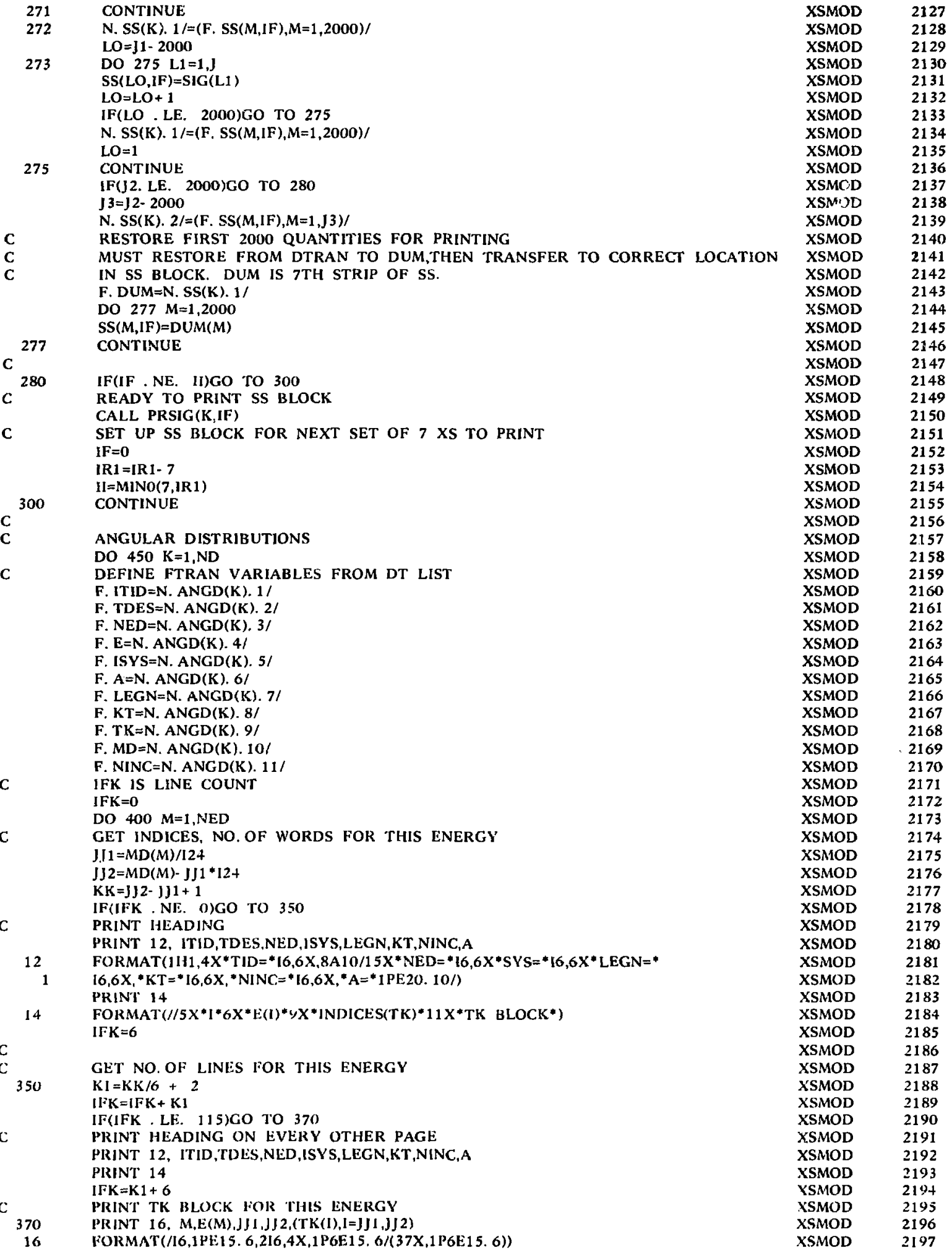




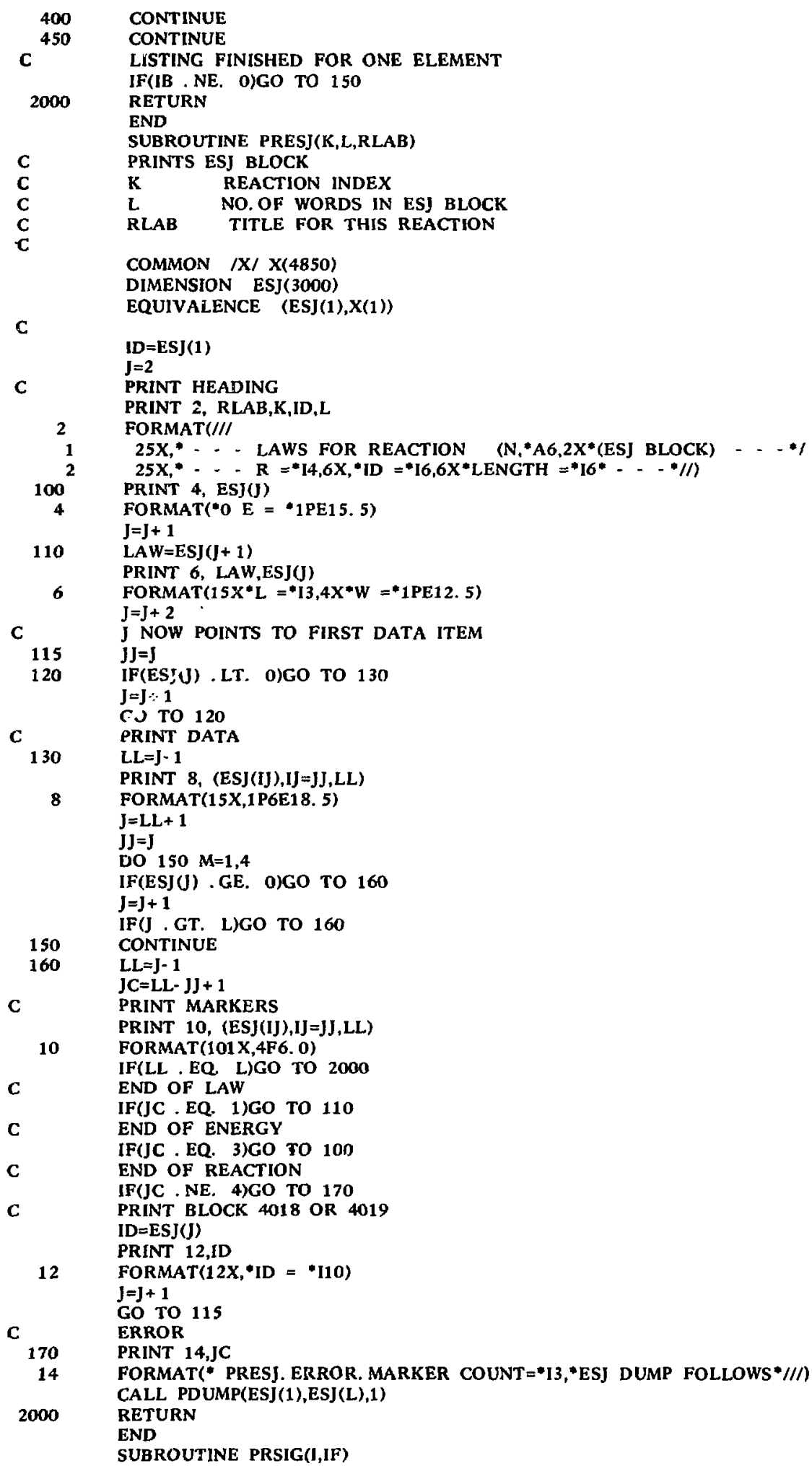

XSMOD

XSMOD 
PRINTS SIGMAS

XSMOD $\quad 2269$

I REACTION INDEX

IF NO.OF REACTIONS FOR WHICH SIGMAS WILL BE PRINTED

JK LINE COUNT

COMMON /CNTRL/ ISID(i),KID,ND,ITIDS(25),SDES(8),IR,ITIDR(50),NES,

$\operatorname{ES}(4000), \operatorname{IDR}(50), \mathrm{ME}(50), \mathrm{IRS}(50), \mathrm{QR}(50), \mathrm{IZ}, \mathrm{MIXT}, \mathrm{K} 2$

COMMON /TYPE/ ITYPER(150)

COMMON /MSR/ MSR(150)

COMMON SS(2000,7)

DIMENSION DUM(2000)

EQUIVALENCE (DUM(1),SS(1,7))

DIMENSION KHEAD(10)

DATA HOL /4H (N,/

C

GET INFORMATION FOR HEADING AND PRINT IT

DO 100 IK=1,IF

IJ $=\mathbf{I}-\mathbf{I F}+\mathbf{I K}$

ID=IDR(1)

ID $=$ MOD (ID, 1000)

KHEAD(IK)=MSR(ID)

100 CONTINUE

I $1=\mathrm{I}-\mathrm{IF}+1$

$12=1$

C

$\mathrm{JK}=\mathbf{0}$

NWD $=\mathrm{NES}$

IF(NES . GT. 2000) NWD $=\mathbf{2 0 0 0}$

DO $110 \mathrm{M}=1, \mathrm{NWD}$

IF(JK . NE. O)GO TO 70

PRINT 2, I1, 12,(HOL, KHEAD(IK), IK=1,IF)

$\begin{array}{cl}2 & \text { FORMAT }\left(1 \mathrm{H} 1,25 \mathrm{X}, * *-\mathrm{SIG} \text { FOR ALL REACTIONS - - R }={ }^{*} \mathrm{I} 2^{*},{ }^{*} \mathrm{I} 2\right. \\ 1 & \left.*--{ }^{*} / / 4 \mathrm{X}^{*} \mathrm{I}^{*} 6 \mathrm{X}{ }^{*} \mathrm{ES}(\mathrm{I}) * 6 \mathrm{X}, 7(\mathrm{~A} 4, \mathrm{~A} 6,4 \mathrm{X})\right)\end{array}$

$\mathrm{J}=1$

C

IF ALL SIGMAS FOR AN ENERGY ARE ZERO,DO NOT PRINT

70 DO $80 \mathrm{JO}=1, \mathrm{IF}$

$\mathrm{S}=\mathrm{SS}(\mathrm{M}, \mathrm{JO})$

IF(S . GT. 0)GO TO 85

80 CONTINUE

GO TO 110

$85 \quad \mathrm{JK}=\mathrm{JK}+1$

PRINT 4, M,ES(M), (SS $(M, J), J=1, I F)$

4 FORMAT(15,1 P8E14. 5)

$110 \quad[F(J K . E Q .118)] K=0$

C CONTINUE

IF MORE THAN 2000 ENERGIES MUST GET REMAINING DATA FROM ECS

IF(NES . LE. 2000)GO TO 2000

C CLEAR SS BLOCK 1 F $^{*}$ (NES- 2000) WORDS

$J L=N E S-2000$

DO $130 \quad \mathrm{~J}=1, \mathrm{IF}$

DO $120 \mathrm{~L}=1, \mathrm{JL}$

$\operatorname{SS}(L, J)=0.0$

CONTINUE

130 CONTINUE

C

FILL SS BLOCK

DO $150 \quad$ IK $=1, \mathrm{IF}$

IJ $=\mathrm{I}-\mathrm{IF}+\mathrm{IK}$

C FIND OUT IF THIS REACTION HAS MORE THAN 2000 SIGMAS

JSIG=ME(IJ) . AND. $77777777 B$

IF(JSIG . LE, 2000)CO TO 150

C FOR THIS REACTION GET SIGMAS FROM ECS

C MUST RESTORE FROM DTRAN TO DUM,THEN TRANSFER TO CORRECT LOCATION

IN SS BLOCK. DUM IS 7TH STRIP OF SS. CLEAR IT WHEN IF=7

J3 =JSIG- 2000

IF(IF . NE. 7)GO TO 140

DO $135 M=1,2000$

$\operatorname{DUM}(M)=0.0$

CONTINUE

$140 \quad$ F. DUM=N. SS(IJ). 21

DO $145 M=1, J 3$

$S S(M, I K)=\operatorname{DUM}(M)$

XSMOD 2270

XSMOD $\quad 2272$

CNTRL

CNTRL

XSMOD 2274

XSMOD 2275

XSMOD $\quad 2276$

XSMOD $\quad 2277$

XSMOD 2278

XSMOD 2279

XSMOD 2280

XSMOD 2281

XSMOD 2282

XSMOD 2283

XSMOD 2284

XSMOD $\quad 2285$

XSMOD $\quad 2286$

XSMOD 2287

XSMOD $\quad 2288$

XSMOD $\quad 2289$

XSMOD 2290

XSMOD 229]

XSMOD 2292

XSMOD 2293

XSMOD 2294

XSMOD 2295

XSMOD 2296

XSMOD 2297

XSMOD 2298

XSMOD 2299

XSMOD $\quad 2300$

XSMOD 2301

XSMOD 2302

XSMOD 2303

XSMOD 2304

XSMOD $\quad 2305$

XSMOD 2306

XSMOD $\quad 2307$

XSMOD 2308

XSMOD 2309

XSMOD $\quad 2310$

XSMOD 2311

XSMOD $\quad 2312$

XSMOD 2313

XSMOD $\quad 2314$

XSMOD $\quad 2315$

XSMOD $\quad 2316$

XSMOD $\quad 2317$

XSMOD $\quad 2318$

XSMOD $\quad 2319$

XSMOD $\quad 2320$

XSMOD $\quad 2321$

XSMOD 2322

XSMOD $\quad 2323$

XSMOD $\quad 2324$

XSMOD $\quad 2325$

XSMOD 2326

XSMOD $\quad 2327$

XSMOD $\quad 2328$

XSMOD $\quad 2329$

XSMOD $\quad 2330$

XSMOD 2331

XSMOD $\quad 2332$

XSMOD 2333

XSMOD $\quad 2334$

XSMOD 2335

XSMOD $\quad 2336$

XSMOD 2337

XSMOD 2338 


\begin{tabular}{|c|c|c|c|}
\hline 145 & CONTINUE. & XSMOD & 2339 \\
\hline 150 & CONTINUE & XSMOD & 2340 \\
\hline C & & XSMOD & 2341 \\
\hline \multirow[t]{6}{*}{ c } & SS BLOCK FILLED. KEADY TO PRINT & XGMOD & 2342 \\
\hline & DO $200 M=2001$, NES & XSMOD & 2343 \\
\hline & $M 2=M \cdot 2000$ & XSMOD & 2344 \\
\hline & IF(JK . NE. O)GO TO 160 & XSMOD & 2345 \\
\hline & PRINT $2, \quad[1,12,(H O L, K H E A D(I K), I K=1, I F)$ & XSMOD & 2346 \\
\hline & $J K=1$ & XSMOD & 2347 \\
\hline \multirow{3}{*}{160} & DO $170 \mathrm{JO}=1, \mathrm{IF}$ & XSMOD & 2348 \\
\hline & $\mathrm{S}=\mathrm{SS}(\mathrm{M} 2 \mathrm{JO})$ & XSMOD & $23+9$ \\
\hline & IF(S . GT. O)GO TO 180 & XSMOD & 2350 \\
\hline \multirow[t]{2}{*}{170} & CONTINUE & XSMOD & 2351 \\
\hline & GO TO 200 & XSMOD & 2352 \\
\hline \multirow[t]{3}{*}{180} & $\mathbf{J K}=\mathrm{JK}+1$ & XSIMOD & 2353 \\
\hline & PRINT 4, M,ES(M),(SS(M2,J),J=1,IF) & XSMOD & 2354 \\
\hline & {$[F(J K . E Q . \quad 118) J K=0$} & XSMOD & 2355 \\
\hline 200 & CONTINUE & XSMOD & 2356 \\
\hline \multirow[t]{3}{*}{2000} & RETURN & XSMOD & 2357 \\
\hline & ENND & XSMOD & 2358 \\
\hline & SUBROUTINE RETREV(KID,KSID,IIK,DUM,IERR,AM) & XSMOD & 2359 \\
\hline C & RETRIEVES SELECTED SID FROM DTRAN TAPE & XSMOD & 2360 \\
\hline C & KID SID NO. IN LIBRARY & XSMOD & 2361 \\
\hline C & KSID DTRAN DIRECTORY TO SID & XSMOD & 2362 \\
\hline C & IIK NO. OF SID IN DIRECTORY & XSMOD & 2363 \\
\hline C & DUM DUMMY & XSMOD & 2364 \\
\hline C & IERR ERROR FLAG. O IF OK. & XSMOD & 2365 \\
\hline C & AM DTRAN NAME FOR THIS SID & XSMOD & 2366 \\
\hline \multirow[t]{3}{*}{ C } & & XSMOD & 2367 \\
\hline & DIMENSION KSID $(j 00), M(3)$ & XSMOD & 2368 \\
\hline & 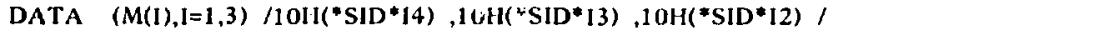 & XSMOD & 2369 \\
\hline \multirow[t]{2}{*}{ C } & & XSMOD & 2370 \\
\hline & IERR $=0$ & XSMOD & 2371 \\
\hline C & SEARCH DIRECTORY FOIR THIS SID & XSMOD & 2372 \\
\hline \multirow[t]{3}{*}{$\dot{c}$} & SEARCH FOR SID IN DIRECTORY & XSMOD & 2373 \\
\hline & DO $110 \quad I=1, \mathrm{IIK}$ & XSMOD & 2374 \\
\hline & IF(KID . EQ. KSID(l))GO To 120 & XSMOD & 2375 \\
\hline \multirow[t]{2}{*}{110} & CONTINUE & XSMOD & 2376 \\
\hline & PRINT 2, KID & XSMOD & 2377 \\
\hline \multirow[t]{3}{*}{2} & FORMAT(" LISTXS,RETREV. CANNOT FIND SID *I4* ON DTRAN TAPE. *) & XSMOD & 2378 \\
\hline & IEIRR=I & XSMOD & 2379 \\
\hline & RETURN & XSIMOD & 2380 \\
\hline C & & XSMOD & 2381 \\
\hline C & GET RECALL NO. ASSOCIATID WITH THIS SID & XSMOD & 2382 \\
\hline 120 & $K=K S I D(1+100)$ & XSMOD & 2383 \\
\hline \multirow[t]{5}{*}{ C } & SELECT FORMAT FOR IENCODING DTRAN NAME & XSMOD & 2384 \\
\hline & IF(KID , LT, $10000,1=1$ & XSMOD & 2385 \\
\hline & IF(KID . LT. 1000)]=2 & XSMOD & 2386 \\
\hline & IF(KID . LT. 100)I=3 & XSMOD & 2387 \\
\hline & I:NCODE $(7, M(I), A M) K I D$ & XSMOD & 2388 \\
\hline \multirow[t]{7}{*}{ C } & DO RETRIEVE & XSMOD & 2389 \\
\hline & D. $((A M)\}=D$. DTOOO10 *MHX1* $* K$ & XSMOD & 2390 \\
\hline & RETURN & XSMOD & 2391 \\
\hline & END & XSMOD & 2392 \\
\hline & END MODULE & XSMOD & 2393 \\
\hline & MODULE RDJOI3S & XSMOD & 2394 \\
\hline & PROGRAM RDJOBS(INPUT,OUTPUT) & XSMOD & 2395 \\
\hline $\mathbf{C}$ & RLADS OPTION CARDS. MAKES LISTS OF ALL GID,SID TO BE RECALLED FROM & XSMOD & 2396 \\
\hline $\mathbf{C}$ & LIBRARY AND ALL GID,SID TO IBE WRITTEN TO TAPE. SETS UP DT LISTS & XSMOD & 2397 \\
\hline $\mathbf{C}$ & AND CALLS MODULE RECLIB. & XSMOD & 2398 \\
\hline & COMMON/DIR/ KGID(300),KSID(300),IDIR,IIG,IHX,IDIRSV & DIR & 2 \\
\hline & DIMENSION IDNOG(100),NWDSG(100),1DNOS $(100), N W D S S(100)$ & DIR & 3 \\
\hline & EQUIVALENCE (KGID(10!),IDNOG(1)),(KGID(201),NWDSG(1)). & DIR & 4 \\
\hline 1 & $($ KSID(101),IDNOS(1)),(KSID(201),NWDSS $(1))$ & DIR & 5 \\
\hline & COMMON /OPIS/ KDIMAG(1100),N(2),IALL,IB & OPTS & 2 \\
\hline & DIMENSION XKDIMAG( 1100$)$ & OPTS & 3 \\
\hline & SQUIVALENCE (KDIMAG,XKDIMAG) & OPTS & 4 \\
\hline & COMMON /TEMP/ ITEMPX(200),ITEMPG(200),IADDX(100), IADDG(100), & TEMP & 2 \\
\hline 1 & ITAPX(100),JTAPG(100),M(15) & TEMP & 3 \\
\hline & DIMENSION XM(15) & TEMP & 4 \\
\hline & EQUIVALENCE $(M, X M)$ & TEMP & 5 \\
\hline
\end{tabular}


F. KGID $=$ N. DIRGID. $1 /$

F. IDNOG=N. DIRGID. $2 /$

F. NWDSG $=$ N. DIRGID, 3/

F. KSID=N. DIRSID. $1 /$

F. IDNOS $=$ N. DIRSID. 2 /

F. NIWDSS=N. DIRSID. $3 /$

F. IIG=WORDS OF N. DIRGID. 1/

F. IIX=WORDS OF N. DIRSID. 1/

C

F. $X M=N$. RDJOBS

XSMOD

XSMOD

240 .

XSMOD

XSMOD 2407

XSMOD 2408

XSMOD 2409

XSMOD 2410

XSMOD 2411

XSMOD 2412

XSMOD 2413

XSMOD 2414

XSMOD 2415

CLEAR STORAGES

IC=LOCF (ITAPG (100)) - LOCF (ITEMPX(1))+ 1

XSMOD 2416

DO $100 \quad \mathrm{l}=1$, IC

$100 \quad$ ITEMPX $(\mathrm{I})=0$

$I C=\operatorname{LOCF}(N(2))-\operatorname{LOCF}(\operatorname{KDIMAG}(1))+1$

DO $101 \quad 1=1,1 \mathrm{C}$

$101 \quad$ KDIMAG $(l)=0$

DO $105 \quad i=1,150$

$\operatorname{INGID}(l)=0$

$105 \quad \operatorname{INSID}(1)=0$

C

READ IN OPTIONS AND THEIR IDS.

C RETURNS IX NO. SID,IG=NO. GID TO WRITE TO TAPE1 CALL READOPT(IX,IG)

IF(IALL . EQ. 1)GO TO 107

C CHECK FOR NO SIDS TO BE RECALLED.

IF(N(1) . EQ. 0)GO TO 106

C MAKE LIST OF SIDS TO BE RECALLED.

CALL USELST(ITEMPX,INSID, 1, KSID, IIX)

C CHECK FOR NO GIDS TO BE RECALLED.

106 IF(N(2) . EQ. 0)GO TO 108

C

MAKE LIST OF GIDS TO BE RECALLED.

CALL USELST(ITEMPG,INGID, 2,KGID,IIG)

GO TO 108

C ENT1RE LIBRARY TO BE RECALLED.

107 CALL USEALL(ITEMPX,INSID,1,KSID,IIX)

CALL USEALL(ITEMPG,INGID, 2,KGID,IIG)

C

C PREPARE LISTS FOR MODULE RECALL.

108 N. REEL $=*$ MHXI *

IF(KGID(1) . EQ. 0 . AND, KSID(1) . EQ. 0)GO TO 125

XSMOD

XSMOD

XSMOD

XSMOD

XSMOD

XSMOD

XSMOD

XSMOD

XSMOD

XSMOD

XSMOD

XSMOD

XSMOD

XSMOD

XSMOD

XSMOD

XSMOD

XSMOD

XSMOD

XSMOD

XSMOD

XSMOD

XSMOD

XSMOD

XSMOD

XSMOD

XSMOD

XSMOD

XSMOD

XSMOD

IF(KGID(1) . EQ. 0)GO TO 1109

IF(KSID(1) . EQ. 0)GO TO 1108

N. RECLID $=(F, I D N O G(I), F, N W D S G(I), I=1, I I G),(F$. IDNOS(I),F. NWDSS(I),I=

XSMOD

XSMOD

XSMOD

XSMOD

Go TO 109

1108

N. RECLID=(F. IDNOG(I),F. NWDSG(I),1=1,11G)

GO TO 109

XSMOD

XSMOD

XSMOD

XSMOD

$\operatorname{IXE}=\mathrm{N}(1)$

$I G E=N(2)$

IF(IXE . EQ. O . AND. IGE . EQ. 0)GO TO 125

XSMOD

XSMOD

XSMOD

IF(IXE . EQ. O)GO TO 110

XSMOD

N. USE $=($ F. ITEMPG $(I), l=1, I G E),(F$. ITEMPX $X(I), I=1, I X E)$

XSMOD

GO TO 120

$110 \quad N$, USE $=(F . \operatorname{ITEMPG}(1), I=1$, IGE $)$

Go TO 120

$115 \quad \mathrm{~N}, U S E=(F, I T E M P X(I), I=1, I X E)$

120 CONTINUE

K.ALL, RECLIB

C

PREPARE DT LIST FOR RETURN TO MAIN CODE

XSMOD

XSMOD

XSMOD

XSMOD

XSMOD

XSMOD

XSMOD

$1 F(I X$. EQ. 0$) I X=1$

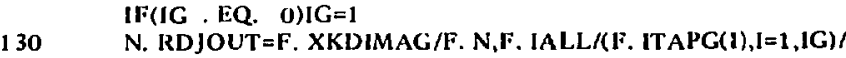

RLTURN

(F. ITAPX(I), l=1,IX)/

XSMOD

XSMOD

XSMOD

XSMOD

Y.MOD

END

XSMOD

2417

2418

2419

2420

2421

2422

2423

2424

2425

2426

2427

2428

2429

2430

2431

2432

2433

2434

2435

2436

2437

2438

2439

2440

2441

2442

2443

2444

2445

2446

2447

2448

2449

2450

2451

2452

2453

2454

2455

2456

2457

2458

2459

2460

2461

2462

2463

2464

2465

2466

2467

2468

2469

2470

2471

2472 


\begin{tabular}{|c|c|c|c|}
\hline & SUBROUTINE READOPT(IX,IG) & XSMOD & 2473 \\
\hline C & READS OPTIONS AND THEIR IDS,SETS UP COMPLETE LISTS OF SID,GID. & XSMOD & 2474 \\
\hline C & MAKES ADD LISTS AND TAPE LISTS. FLAGS ADDS IN TAPE LIST & XSMOD & 2475 \\
\hline C & RETURNS IX,IG=NO. OF SID,NO. OF GID TO WRITE TO TAPEI & XSMOD & 2476 \\
\hline C & & XSMOD & 2477 \\
\hline & COMMON/DIR/ KGID(300),KSID(300),IDIR,IIG,IIX,IDIRSV & DIR & \\
\hline & DIMENSION IDNOG(100),NWDSG(100),IDNOS(100),NWDSS(100) & DIR & \\
\hline & EQUIVALENCE （KGID(101),IDNOG(1)),(KGID(201),NWDSG(1)), & DIR & 4 \\
\hline \multirow[t]{5}{*}{1} & $($ KSID(101), IDNOS(1)),(KSID( 201),NWDSS(1)) & DIR & \\
\hline & COMMON /OPTS/ KDIMAG(1100),N(2),IALL,IB & OPTS & \\
\hline & DIMENSION XKDIMAG(1100) & OPTS & \\
\hline & EQUIVALENCE (KDIMAG,XKDIMAG) & OPTS & \\
\hline & COMMON /TEMP/ ITEMPX(200),ITEMPG(200),IADDX(100),IADDG(100), & TEMP & \\
\hline \multirow[t]{3}{*}{1} & ITAPX(100), ITAPG(100),M(15) & TEMP & \\
\hline & DIMENSION XM(15) & TEMP & \\
\hline & EQUIVALENCE $(M, X M)$ & TEMP & \\
\hline C & & XSMOD & 2481 \\
\hline \multirow[t]{8}{*}{ C } & INITIALIZE INDICES,FLAGS,COUNTERS. READ OPTION CARDS INTO KDIMAG. & XSMOD & 2482 \\
\hline & IALL $=0$ & XSMOD & 2483 \\
\hline & $\mathrm{IB}=1$ & XSMOD & 2484 \\
\hline & $\mid E=11$ & XSMOD & 2485 \\
\hline & $J G=1$ & XSMOD & 2486 \\
\hline & $\mathrm{J} X=1$ & XSMOD & 2487 \\
\hline & $K G=1$ & XSMOD & 2488 \\
\hline & $K X=1$ & XSMOD & 2489 \\
\hline 105 & READ 1,(KDIMAG(I),I=[B,IE) & XSMOD & 2490 \\
\hline \multirow[t]{2}{*}{1} & FORMAT(A10,2X,1016) & XSMOD & 2491 \\
\hline & PRINT 2,(KDIMAG(I),I=IB,IE) & XSMOD & 2492 \\
\hline \multirow[t]{4}{*}{2} & FORMAT(1 X,A10,2X,1016) & XSMOD & 2493 \\
\hline & DETERMINE WHICH OPTION REQUESTED AND GO TO APPROPRIATE SETUP. & XSMOD & 2494 \\
\hline & DO $110 \quad 1=1,15$ & XSMOD & 2495 \\
\hline & IF(KDIMAG(IB) , EQ. M(I))GO TO 120 & XSMOD & 2496 \\
\hline \multirow[t]{2}{*}{110} & CONTINUE & XSMOD & 2497 \\
\hline & PRINT 4, (KDIMAG(I),I=IB,IE) & XSMOD & 2498 \\
\hline \multirow[t]{2}{*}{4} & FORMAT $\left(/ /{ }^{*}\right.$ INPUT ERROR. *A10,2X,10I6,//) & XSMOD & 2499 \\
\hline & Gu TO 150 & XSMOD & 2500 \\
\hline 120 & C.J $\operatorname{TO}(130,140,150,150,125,122,150,150,130,140,150,145,160,155$, & XSMOD & 2501 \\
\hline \multirow[t]{2}{*}{1} & 170)! & XSMOD & 2502 \\
\hline & MAKE ADD LISTS & XSMOD & 2503 \\
\hline \multirow[t]{3}{*}{122} & $\begin{array}{l}J B=[B+1 \\
D O 123]=[B] E\end{array}$ & XSMOD & 2504 \\
\hline & $\begin{array}{l}\text { DO } 123 \mathrm{~J}=\mathrm{JB}, \mathrm{IE} \\
\text { IF(KDIMAG(J). EQ. 0)GO TO } 150\end{array}$ & XSMOD & 2505 \\
\hline & $\begin{array}{l}\text { IF(KDIMAG(J) . EQ. 0)GO TO } 150 \\
\text { IADDG }(J G)=K D I M A G(J)\end{array}$ & XSMOD & 2506 \\
\hline \multirow[t]{2}{*}{123} & & $\begin{array}{l}\text { XSMOD } \\
\text { XSMOD }\end{array}$ & $\begin{array}{l}2507 \\
2508\end{array}$ \\
\hline & GO TO 150 & XSMOD & 2509 \\
\hline \multirow[t]{4}{*}{125} & $\mathrm{JB}=\mathrm{IB}+1$ & XSMOD & 2510 \\
\hline & DO $127 \mathrm{~J}=\mathrm{JB}, \mathrm{IE}$ & XSMOD & $25 ! 1$ \\
\hline & IF(KDIMAG(J)，EQ. 0)GO TO 150 & XSMOD & 2512 \\
\hline & $\operatorname{IADDX}(\mathrm{J} X)=\mathrm{KDIMAG}(\mathrm{J})$ & XSMOD & 2513 \\
\hline 127 & $J X=J X+1$ & XSMOD & 2514 \\
\hline & GO TO 150 & XSMOD & 2515 \\
\hline C & MAKE RECALL LISTS & XSMOD & 2516 \\
\hline 130 & CALL TEMPLST(ITEMPX,1,IB,IE) & XSMOD & 2517 \\
\hline & GO TO 150 & XSMOD & 2518 \\
\hline 140 & CALL TEMPLST(ITEMPG, 2,IB,IE) & XSMOD & 2519 \\
\hline & Go TO 150 & XSMOD & 2520 \\
\hline 145 & IALL=1 & XSMOD & 2521 \\
\hline C & GET NEXT OPTION CARD & XSMOD & 2522 \\
\hline 150 & $I B=1 E+1$ & XSMOD & 2523 \\
\hline & $I E=1 B+10$ & XSMOD & 2524 \\
\hline & GO TO 105 & XSMOD & 2525 \\
\hline C & MAKE TAPE L1STS & XSMOD & 2526 \\
\hline 155 & $J B=1 B+1$ & XSMOD & 2527 \\
\hline & DO $157 \mathrm{~J}=\mathrm{JB}, 1 \mathrm{E}$ & XSMOD & 2528 \\
\hline & IF (KDIMAG(J) . EQ. 0)GO TO 140 & XSMOD & 2529 \\
\hline & $\operatorname{ITAPG}(K G)=K D I M A G(j)$ & XSMOD & 2530 \\
\hline 157 & $K G=K G+1$ & XSMOD & 2531 \\
\hline & GO TO 140 & XSMOD & 2532 \\
\hline 160 & $\mathrm{JB}=\mathrm{IB}+1$ & XSMOD & 2533 \\
\hline & DO $162 \mathrm{~J}=\mathrm{JB}, 1 \mathrm{E}$ & XSMOD & 2534 \\
\hline & IF (KDIMAG(J) . EQ. 0)GO TO 130 & XSMOD & 2535 \\
\hline
\end{tabular}




\begin{tabular}{|c|c|c|c|}
\hline \multirow{3}{*}{162} & $\operatorname{ITAPX}(K X)=K D I M A G(J)$ & XSMOD & 2536 \\
\hline & $\mathrm{KX}=\mathrm{KX}+\mathrm{I}$ & XSMOD . & 2537 \\
\hline & GO TO 130 & XSMOD & 2538 \\
\hline 170 & PRINT 6 & XSMOD & 2539 \\
\hline 6 & FORMATU $/ /^{*}$ LAST CARD ENCOUNTERED. READY TO MAKE RECALL LIST. *) & XSMOD & 2540 \\
\hline \multirow[t]{2}{*}{ c } & & XSMOD & 2541 \\
\hline & IF(IALL. EQ. 1)GO TO 250 & XSMOD & 2542 \\
\hline \multirow[t]{5}{*}{ C } & PUT TAPE LISTS IN ASCENDING NUMERICAL ORDER. & XSMOD & 2543 \\
\hline & $I G=K G-1$ & XSMOD & 2544 \\
\hline & $\mathbf{I X}=\mathbf{K X}-1$ & XSMOD & 2545 \\
\hline & CALL ORDER(ITAPG,IG) & XSMOD & 2546 \\
\hline & CALL ORDER(ITAPX,IX) & XSMOD & 2547 \\
\hline \multirow[t]{8}{*}{ C } & FLAG ADDS IN TAPE REQUEST LIST & XSMOD & 2548 \\
\hline & DO $190 \mathrm{~J}=1,100$ & XSMOD & 2549 \\
\hline & IF(ITAPG(I) . EQ. O)GO TO 200 & XSMOD & 2550 \\
\hline & DO $180 \mathrm{~J}=1,100$ & XSMOD & 2551 \\
\hline & IF(IADDG(J). EQ. 0)GO TO 190 & XSMOD & 2552 \\
\hline & IF(ITAPG(I) . NE. IADDG(J))GO TO 180 & XSMOD & 2553 \\
\hline & $\operatorname{ITAPG}(1)=-1 \mathrm{TAPG}(1)$ & XSMOD & 2554 \\
\hline & GO TO 190 & XSMOD & 2555 \\
\hline 180 & CONTINUE & XSMOD & 2556 \\
\hline 190 & CONTINUE & XSMOD & 2557 \\
\hline \multirow[t]{7}{*}{200} & DO $220 \quad 1=1,100$ & XSMOD & 2558 \\
\hline & IF(ITAPX(1) . EQ. O)GO TO 230 & XSMOD & 2559 \\
\hline & DO $210 \mathrm{~J}=1,100$ & XSMOD & 2560 \\
\hline & IF(IADDX $(J)$. EQ. O)GO TO 220 & XSMOD & 2561 \\
\hline & IF(ITAPX(I) . NE. IADDX(J))GO TO 210 & XSMOD & 2562 \\
\hline & ITAPX(I)=- ITAPX(I) & XSMOD & 2563 \\
\hline & GO TO 220 & XSMOD & 2564 \\
\hline 210 & CONTINUE & XSMOD & 2565 \\
\hline 220 & CONTINUE & XSMOD & 2566 \\
\hline 230 & RETURN & XSMOD & 2567 \\
\hline C & FOR TAPEALL MERGE ADD AND TAPE LISTS,FLAG ADDS & XSMOD & 2568 \\
\hline C & PUT ADD AND TAPE LISTS IN ASCENDING NUMERICAL ORDER. & XSMOD & 2569 \\
\hline \multirow[t]{5}{*}{250} & $J G=J G * 1$ & XSMOD & 2570 \\
\hline & $\mathbf{J} \mathbf{X}=\mathbf{J} \mathbf{X}-1$ & XSMOD & 2571 \\
\hline & CALL ORDER(IADDG,JG) & XSMOD & 2572 \\
\hline & CALL ORDER(JADDX,JX) & XSMOD & 2573 \\
\hline & DO $255 I=1, I I G$ & XSMOD & 2574 \\
\hline \multirow[t]{3}{*}{255} & ITAPG $(I)=K G I D(I)$ & XSMOD & 2575 \\
\hline & CALL ORDER(ITAPG,IIG) & XSMOD & 2576 \\
\hline & DO $260 \mathrm{I}=1, \mathrm{IIX}$ & XSMOD & 2577 \\
\hline \multirow[t]{4}{*}{260} & ITAPX(l)=KSID(l) & XSMOD & 2578 \\
\hline & CALL ORDER(ITAPX.IIX) & XSMOD & 2579 \\
\hline & CALL MERGE(1ADDG,JG,ITAPG,IIG,IG) & XSMOD & 2580 \\
\hline & CALL MERGE(IADDX,JX,ITAPX,IIX,IX) & XSMOD & 2581 \\
\hline \multirow[t]{3}{*}{270} & RETURN & XSMOD & 2582 \\
\hline & END & XSMOD & 2583 \\
\hline & SUBROUTINE ORDER(ILIST,L) & XSMOD & 2584 \\
\hline C & PUTS LIST OF INTEGERS IN ASCENDING ORDER & XSMOD & 2585 \\
\hline C & ILIST LIST TO BE ORDERED & XSMOD & 2586 \\
\hline C & L $\quad$ NO OF ITEMS IN LIST & XSMOD & 2587 \\
\hline \multirow[t]{15}{*}{ C } & & XSMOD & 2588 \\
\hline & DIMENSION ILIST(100) & XSMOD & $258 \%$ \\
\hline & $I L=L \cdot I$ & XSMOD & 2590 \\
\hline & DO $200 \mathrm{I}=1, \mathrm{IL}$ & XSMOD & 2591 \\
\hline & IF(ILIST(I) . EQ. O)GO TO 300 & XSMOD & 2592 \\
\hline & $J B=I+1$ & XSMOD & 2593 \\
\hline & DO $100 \mathrm{~J}=\mathrm{JB}, \mathrm{L}$ & XSMOD & 2594 \\
\hline & IF(ILIST(J) . EQ. O)GO TO 200 & XSMOD & 2595 \\
\hline & IF(ILIST(I) . LT. ILIST(J))GO TO 100 & XSMOD & 2596 \\
\hline & IDUM=ILIST(I) & XSMOD & 2597 \\
\hline & ILIST(I)=ILIST(J) & XSMOD & 2598 \\
\hline & ILIST (\}$)=$ IDUM & XSMOD & 2599 \\
\hline & IF(J . EQ. LIGO TO 200 & XSMOD & 2600 \\
\hline & I=I- 1 & XSMOD & 2601 \\
\hline & GO TO 200 & XSMOD & 2602 \\
\hline 100 & CONT INUE & XSMOD & 2603 \\
\hline 200 & CONTINUE & XSMOD & 2604 \\
\hline \multirow[t]{2}{*}{300} & RETURN & XSMOD & 2605 \\
\hline & END & XSMOD & 2606 \\
\hline
\end{tabular}


SUBROUTINE MERGE(IADD,IA,ITAP,IT,IS)

MERGES ADD AND TAPE LISTS WITH IDS IN ASCENDING ORDER. ADDS ARE

FLAGGED WITH MINUS

IA NO OF ID IN ADD LIST

IT NO OF ID IN DIRECTORY AND IN TAPE LIST

IS TOTAL NO OF ID TO BE WRITTEN TO TAPE AFTER MEIRGE

DIMENSION IADD(100),ITAP(100)

C

C

100

C

C

C 130

150

190

200

350

C

C

C

$107 \quad \mathrm{II}=\mathrm{II}+1$

110 $\quad N(J j)=I I$

IX(II)=KDIMAG(I)

RETURN

END

SUBROUTINE USELST(IIN,IOUT,JJ,KDIR,IIK)

C MAKES COMPLETE SID/GID LIST WITH NO DUPLICATIONS

C SEARCHES DIRECTORY FOR SID/GID NAME AND STORES CORRESPONDING

RECALL ID NO. FOR N. USE LIST,PUTS THIS LIST IN ORDER.

ENTERS WITH IIN CONTAINING SID/GID LIST WITH POSSIBLE DUPLICATIONS

RETURN WITH IIN CONTAINING RECALL IDS IN ORDER.
XSMOD

XSMOD

XSMOD 2611

XSMOD $\quad 2612$

XSMOD 2613

XSMOD $\quad 2614$

XSMOD $\quad 2615$

XSMOD $\quad 2616$

XSMOD $261 \%$

XSMOD $\quad 2618$

XSMOD $\quad 2619$

XSMOD $\quad 2620$

XSMOD 2621

XSMOD 2622

XSMOD 2623

XSMOD 2624

XSMOD 2625

XSMOD 2626

XSMOD 2627

XSMOD $\quad 2628$

XSMOD 2629

XSMOD 2630

XSMOD

XSMOD 2632

XSMOD 2633

XSMOD 2634

$X S M O D \quad 2635$

$X S M O D \quad 2636$

XSMOD 2637

XSMOD 2638

XSMOD 2639

XSMOD $\quad 2640$

XSMOD 2641

XSMOD 2642

XSMOD 2643

XSMOD 2644

XSMOD $\quad 2645$

XSMOD 2646

XSMOD $26+7$

XSMOD $\quad 2648$

XSMOD $\quad 2649$

XSMOD 2650

XSMOD 2651

OPTS

OPTS

OPTS 4

XSMOD 2653

XSMOD 2654

XSMOD 2655

XSMOD 2656

XSMOD $\quad 2657$

XSMOD 2658

XSMOD $\quad 2659$

XSMOD 2660

XSMOD 2661

XSMOD 2662

XSMOD 2663

XSMOD 2664

XSMOD $\quad 2665$

XSMOD $\quad 2666$

XSMOD 2667

XSMOD $\quad 2668$

XSMOD $\quad 2669$

XSMOD $\quad 2670$

XSMOD 2671

XSMOD $\quad 2672$

XSMOD 2673

XSMOD $\quad 2674$ 
c

COMMON /OPTS/ KDIMAG(1100),N(2),IALL,IB

DIMENSION XKDIMAG(1100)

EQUIVALENCE (KDIMAG,XKDIMAG)

DIMENSION IIN(200), IOUT(1 50), KDIR(300), HOL(2)

C

DATA HOL(1), HOL(2) /3HSID, 3HGID/

XSMOD

CHECK LIST FOR DUPLICATIONS

IOUT(1) $=\operatorname{IIN}(1)$

IE $=\mathbf{N}(\mathrm{J} J)$

$\mathrm{JE}=1$

IF(IE . EQ . 1)GO TO 125

DO $120 \quad I=2, I E$

DO $110 \mathrm{~J}=1, \mathrm{JE}$

IF(INN(I) . EQ. IOUT(J))GO TO 115

110 CONTINUE

$\mathrm{JE}=\mathrm{JE}+1$

$\operatorname{IOUT}(\mathrm{JE})=[\mathrm{IN}(\mathrm{I})$

GO TO 120

115 PRINT 10, HOL(JJ),IIN(I)

10 FORMAT(/* DUPLICATION IN *A3* LIST. *I4)

120 CONTINUE

125 DO $130 \quad I=1,200$

$130 \quad \operatorname{IIN}(\mathrm{I})=0$

C

SEARCH SID/GID LIST AND GET RECALL ID NO.

$K=0$

DO $150 \mathrm{I}=1, \mathrm{JE}$

DO $140 \mathrm{~J}=1, \mathrm{IIK}$

IF(IOUT(1) . EQ KDIR(J))GO TO 145

140 CONTINUE

PRINT 4, HOL(JJ),IOUT(I) 4 FORMAT(/* SUBR USELST. CANNOT FIND *A3,15* IN DTRAN TAPE DIRECTORY.

GO TO 150

$145 \quad \mathrm{~K}=\mathrm{K}+1$

$\operatorname{IIN}(K)=K D I R(J+100)$

150 CONTINUE

C PUT RECALL IDS IN ORDER

$\mathrm{IE}=\mathrm{K}-1$

DO $180 \mathrm{I}=1$, IE

$\mathrm{JB}=\mathrm{I}+1$

DO $170 \mathrm{~J}=\mathrm{JB}, \mathrm{K}$

IF(IIN(I). LT. IIN(J))GO TO 170

$\operatorname{DUM}=\operatorname{IIN}(\mathrm{I})$

$\operatorname{IIN}(1)=\operatorname{IIN}(\mathrm{J})$

IIN $(J)=D U M$

IF(J . EQ. K)GO TO 180

I $=$ I- 1

GO TO 180

170 CONTINUE

180 CONTINUE

$190 \quad \mathrm{~N}(\mathrm{~J} J)=\mathrm{K}$

RETURN

C

ENTRY USEALL

C MAKES LIST OF ALL RECALL IDS IN DIRECTORY FOR SID OR GID

C

IF(KDIR(1) . EQ. 0) RETURN

$\mathrm{N}(\mathrm{JJ})=\mathrm{IIK}$

DO $200 \quad I=1,1] K$

$200 \quad \operatorname{IIN}(I)=\operatorname{KDIR}(\mathrm{I}+100)$

RETURN

END

END MODULE

MODULE TAPE

PROGRAM TAPE(INPUT, OUTPUT,TAPE1,TAPE6,TAPE7)

C WRITES A FILE TAPE1 TO BE USED BY EVXS. TAPE OPTION IS PROCESSED
C LAST. GID/SID ALREADY IN I.IBRARY ARE RETRIEVED. THOSE ADDED DURING LAST. GID/SID ALREADY IN IIBRARY
THIS RUN ARE READ FROM TAPE7/6.

OPTS

XSMOD

XSMOD

XSMOD

XSMOD

XSMOD

XSMOD

XSMOD

XSMOD

XSMOD

XSMOD

XSMOD

YSMOD

XSMOD

XSMOD

XSMOD

XSMOD

XSMOD

XSMOD

XSMOD

XSMOD

XSMOD

XSMOD

XSMOD

XSMOD

XSMOD

XSMOD

XSMOD

XSMOD

XSMOD

XSMOD

XSMOD

XSMOD

XSMOD

XSMOD

XSMOD

XSMIOD

XSMOD

XSMOD

XSMOD

XSMOD

XSMOD

XSMOD

XSMOD

XSMOD

XSMOD

XSMOD

XSMOD

XSMOD

XSMOD

XSMOD

XSMOD

XSMOD

XSMOD

XSMOD

XSMOD

XSMOD

XSMOD

XSMOD

XSMOD

XSMOD

XSMOD

XSMOD

XSMOD

XSMOD

XSMOD

XSMOD

XSMOD 
COMMON $/ \mathrm{X} / \mathrm{X}(\mathbf{4 8 5 0})$

DIMENSION ITID(1),TDES(8),E(400),TK(4000),MD(400), PROB(10), NMU(10)

EQUIVALENCE (ITID(1), X(1)), (TDES(1),X(2)), (NED,X(10)), $(E(1), X(11))$, (ISYS, $X(411)),(A, X(412)),\left(L_{E G N} X(413)\right)$, (KT,X(414)), (TK(1),X(415)), (MD(1),X(4415)), (NINC,X(4815)), (PROB(1),X(4816)), (NMU(1),X(4826))

C

C

C

C

C 100

C 105

COMMON/DIR/ KGID(300),KSID(300),IDIR,IIG,IIX,IDIRSV

DIMENSION IDNOG(100),NWDSG(i00), IDNOS(100),NWDSS(100)

EQUIVALENCE (KGID(101),IDNOG(1)),(KGID(201),NWDSG(1)), $(\mathrm{KSID}(101), \operatorname{IDNOS}(1)),(\mathrm{KSID}(201), N W D S S(1))$

COMMON /GRP/IGID(1),GDES(8),IGG(1),MG(80),GE(80),KG(1),PH(500),

$\operatorname{EK}(500), \operatorname{VB}(80), \operatorname{EMX}(80)$

COMMON /OPTS/ KDIMAG(1 100),N(2),IALL,IB

DIMENSION XKDIMAG(1100)

EQUIVALENCE (KDIMAG,XKDIMAG)

COMMON /CNTRL/ ISID(1),KID,ND,ITIDS(25),SDES(8),IR,ITIDR(50),NES, $\operatorname{ES}(4000), \operatorname{IDR}(50), \operatorname{ME}(50), \operatorname{IRS}(50), \mathrm{QR}(50), \mathrm{IZ}, \mathrm{MIXT}, \mathrm{K} 2$

DIMENSION SIG(4000)

EQUIVALENCE (SIG(1),X(1))

DIMENSION ESJ(3000)

EQUIVALENCE (ESJ(1),ES(1))

DIMENSION ITAPX(100),ITAPG(100)

DIMENSION TAD(100)

DIMENSION IX(40)

EQUIVALENCE $(X(1), I X(1))$

DEFINE FORTRAN VARIABLES TRANSMITTED BY DT LISTS

F. KGID=N. DIRGID. $1 /$

F. IDNOG $=$ N. DIRGID. $2 /$

F. NWDSG $=$. DIRGID. 3/

F. KSID=N. DIRSID. $1 /$

F, IDNOS=N. DIRSID. 2/

F. NWDSS=N. DIRSID. 3/

F. ITAPG $=$ N. RDJOUT. 31

F. ITAPX $=$ N. RDJOUT. 4 !

P. IIG=WORDS OF N. RD JOUT. 3/

F. IIX=WORDS OF N. RDJOUT, 4/

F. NGID=WORDS OF N. DIRGID. 1/

F. NSID=WORDS OF N. DIRSID, $1 /$

REWIND 1

REWIND 6

REWIND 7

READ IN TAPE IDENTIFIER MESSAGE FROM INPUT CARDS.

\section{DO $100 \mathrm{l}=1,100$}

$\mathrm{TAD}(1)=0$

DO $105 \mathrm{JB}=1,100,8$

$\mathrm{JE}=\mathrm{JB}+7$

READ 1, (TAD(J),J=JB,JE)

IF(TAD(JB) . EQ. 10H JGO TO 110

CONTINUE

FORMAT(8A10)

PRINT 2, (TAD(I),I=1,JB)

FORMAT(1H1 *TAPE OPTION IS BEING PROCESSED. TAPE DESCRIPTION FOLLOWS - $/(/(5 \times 13 A 10))$

WRITE TAPE DESCRIPTION AND NO. OF CROSS- SECTIONS ON TAPE1 WRITE(1) TAD,IIX

PRINT 6

XSMOD

$\mathrm{X}$

ANGD

ANGD

ANGD

ANGD

ANGD

ANGD

ANGD 
DO $299 \mathrm{~J}=1, \mathrm{JIG}$

IF(ITAPG(J) , GT, 0)GO TO 230

C GID WILL BE READ FROM TAPE7

$\mathrm{NEOF}=0$ (PH(I), EK(1), I=1,KG)

IF(EOF,7) 210,220

210 REWIND ?

$\mathrm{NEOF}=\mathrm{NEOF}+1$

IF(NEOF . LT. 2)GO TO 205

PRINT 16, ITAPG(J)

16 FORMAT(* TAPE, EOF ON TAPE7. CANNOT READ GID=*16)

GO TO 299

C

220 IF(IGID . EQ. - ITAPG(J))GO TO 290

C GO TO 205 GID WILL BE RETRIEVED FROM LIBRARY.

$230 \quad K I D=I T A P G(J)$

CALL RETREV(KID,KGID,NGID, 2,IERR,AM)

IF(IERR . EQ. O)GO TO 250

PRINT 4,KID

4 FORMAT(* GROUP LIBRARY RETRIEVAL. ERROR FOK GID=*I5)

GO TO 299

$250 \quad$ F. IGID $=D .((A M)) .11$

F. GDES=D. $((A M)), 2 /$

F. IGG=D. ((AMi)). 3/

F. $M G=D .((A M)) .4 /$

F. GE $=$ D. ((AM)). 5 i

F. $K G=D .((A M)) .6$

F. $P H=D .((A M)) .7 /$

F. $L K=D .((A M)) .8 /$

WRITE(1) IGID,GDES,IGG,(MG(I),I=1,IGG),(GE(I),I=1,IGG),KG, (PHI(I),EK(I), I=I,KG)

PIRINT 18, IGID

18 FORMAT( GID*15* WRITTEN TO TAPE1*)

299 CONTINUE

C

ENDFILE 1

C

WRITE CROSS SECTION AND ANGULAR DISTRIBUTION LIBRARIES.

IIX IS NO. OF SIDS TO WRITE TO TAPE1

DO $399 \mathrm{~J}=1,11 \mathrm{X}$

IF(ITAPX(\}). GT. O)GO TO 330

C

SID WILL BE READ FKOM TAPEG

NG $=0$

$N E O F=0$

BUFFER IN $(6,1)(X(1), X(4850))$

IF(UNIT.6) 306.320.310

$\mathrm{NEOF}=\mathrm{NEOF}+1$

IF(NEOF . EQ. 2)GO TO 312

GO TO 305

312 IF(N6 . LE. 2)GO TO 315

PRINT 8, ITAPX(J)

年

315

GO TO 399

$\mathrm{N} 6=\mathrm{N} 6+1$

REWIND 6

GO TO 303

$320 \quad \mathrm{NEOF}=0$

$\mathrm{ND}=\operatorname{IX}(2)$

$I R=I X(N D+11)$

L=LENGTH(6)

$K I D=I X(1)$

IF(- KID . NE. ITAPX(J))GO TO 322

WRITE(1) (X(1), l=1,L)

GO TO 338

BUFFER IN $(6,1)(X(1), X(+850))$

IF(UNIT,6)323,322,325

$\mathrm{NEOF}=1$

GO TO 305

C 330

RETRIEVE SID FROM LIBRARY

$K 1 D=I T A P X(])$

XSMOD

XSMOD

XSMOD

XSMOD

XSMOD

XSMOD

XSMOD

XSMOD

XSMOD

XSMOD

XSMOD

XSMOD

XSMOD

XSMOD

XSMOD

XSMOD

XSMOD

XSMOD

XSMOD

XSMOD

XSMOD

XSMOD

XSMOD

XSMOD

XSMOD

XSMOD

XSMOD

XSMOD

XSMOD

XSMOD

$X S M O D$

XSMOD

XSMOD

XSMOD

XSMOD

XSMOD

XSMOD

XSMOD

XSMOD

XSMOD

XSMOD

XSMOD

XSMOD

XSMOD

XSMOD

XSMOD

XSMOD

XSMOD

XSMOD

XSMOD

XSMOD

XSMOD

XSMOD

XSMOD

XSMOD

XSAOD

XSMOD

XSMOD

XSMOD

XSMOD

XSMOD

XSMOD

XSMOD

XSMOD

XSMOD

XSMOD

XSMOD

XSMOD

XSMOD

XSMOD

XSMOD
2802

2803

2804

2805

2806

2807

2808

2809

2810

2811

281

2813

2814

2815

2816

2817

2818

2819

2820

2821

2822

2823

2824

2825

2826

2827

2828

2829

2830

2831

2832

2833

2834

2835

2836

2837

2838

2839

2840

2841

2842

2843

2844

$28+5$

$28+6$

2847

2848

2849

2850

2851

2852

2853

2854

2855

2856

2857

2858

2859

2860

2861

2862

2863

2864

2865

2866

2867

2868

2869

2870

2871

2872 
CALL RETREV(KID,KSID,NSID, 1,IERR,AM)

XSMOD IF(IERR . EQ. O)GO TO 333

PRINT 20, KID

FORMAT( XS LIBRARY RETRIEVAL ERROR FOR SID "I5)

C

C

335

C

C

c

360 GO TO 399

DEFINE FTRAN VARIABLES FROM DT LISTS

N. CNTRL=D. ((AM)). N. CNTRL

F. KID =N, CNTRL, 1/

F. ND=N. CNTRL. 21

F. ITIDS $=$ N. CNTRL. 3/

F. SDES=N. CNTRE. 4 /

F. IR=N. CNTRL. 5/

F. ITIDR $=$ N. CNTRL. $6 /$

F. NES=N. CNTRL. 7!

F. ES=N. CNTRL. 81

F. IDR=N. CNTRL. 9/

F. ME $=$ N. CNTRL. 10/

F. IRS $=$ N. CNTRL. $11 /$

F. $Q R=N$. CNTRL. 121

F. IZ=N. CNTRL. $13 /$

F. MIXT=N. CNTRL. 14/

F. $\mathrm{K} 2=\mathrm{N}$. CNTRL. 15/

F. $L L L=N$. CNTRI. $16 /$

WRITE CONTROL RECORD TO TAPEI

WRITE(1) KID,ND, (ITIDS(I),I=1,ND),SDES,IR,(ITIDR(I),I=1,IR), NES, $(\operatorname{ES}(I), I=1, N E S),(I D R(I), I=1, I R),(M E(I), I=1, I R),(I R S(I), I=1, I R)$ , $(\mathrm{QR}(\mathrm{I}), \mathrm{I}=1, \mathrm{IR}), \mathrm{IZ}, \mathrm{MIXT}, \mathrm{K} 2, \mathrm{LLL}$

CROSS SECTION RECORDS

IF(ITAPX(J) . LT, O)GO TO 350

N. $X S=D .((A M)) . N . X S$

N. $E S J=D .((A M))$. N. ESJ

DO $345 \mathrm{~K}=1, \mathrm{IR}$

F. $S I G=N . X S(K)$

F. IWD 1 =WORDS OF N. XS(K)

IF(IRS(K) . NE. O)GO TO 340

WRITE(1) (SIG(I),I=1, IWD1)

GO TO 345

F. ESJ $=$ N. ESJ(K)

F. IWD2 =WORDS OF N. ESJ $(\mathrm{K})$

WR ITE (1) (SIG(I), I=1,IWD1),(ESJ(I),I=1,IWD2)

CONTINUE

GO TO 365

CROSS-SECTION RECORDS FROM TAPE6

DO $360 \mathrm{~K}=1, \mathrm{IR}$

BUFFER IN $(6,1)(X(1), X(4850))$

IF(UNIT,6) 352,356,354

PRINT 22, KID,K,IR

FORMAT(* EOF IN XS RECORDS FOR SID $=$ *I5* RECORD= *I3* OF *13*.

SID ON TAPE1 PROBABLY NO GOOD. *)

GO TO 360

L=LENGTH(6)

WRITE(1) $(X(I), I=1, L)$

CONTINUE

ANGULAR DISTRIBUTION RECORDS

IF(ITAPX(J) . LT. O)GO TO 380

N. ANGD $=D$. $((A M))$. N. ANGD

DO $370 K=1$, ND

F. ITID $=$ N. ANGD(K). $1 /$

F. TDES $=$ N. $\operatorname{ANGD(K)}, 21$

F. NED $=N$. ANGD(K), 3/

F. $E=N$. ANGD(K). 4/

F. ISYS $=N$. ANGD(K). 5 /

F. $A=N . \operatorname{ANGD}(K) .6$

F. $L E G N=N$. ANGD(K). 7 /

F. $K T=N$. $A N G D(K), 8 /$

F. TK=N. ANGD(K). $9 /$

F. $M D=N$. $A N G D(K), 10 /$

F. NINC=N, ANGD(K). 11/

WR ITE(1) ITID,TDES,NED, (E(I),I=1,NED), ISYS,A,LEGN,KT,(TK(I),I=1,KT ),(MD(I),I=1,NED),NINC

XSMOD

XSMOD 2875

XSMOD $\quad 2876$

XSMOD 2877

XSMOD 2878

XSMOD 2879

XSMOD 2880

XSMOD $\quad 2881$

XSMOD 2882

XSMOD 2883

XSMOD 2884

XSMOD 2885

XSMOD 2886

XSMOD 2887

XSMOD $\quad 2888$

XSMOD $\quad 2889$

XSMOD 2890

XSMOD $\quad 2891$

XSMOD 2892

XSMOD 2893

XSMOD 2894

XSMOD 2895

$X$ SMOD 2896

XS MOD 2897

XSMIOD $\quad 2898$

XSMOD 2899

XSMOD 2900

XSMOD 2901

XSMOD 2902

XSMOD 2903

XSMOD 2904

XSMOD 2905

XSMOD 2906

XSMOD 2907

XSMOD 2908

XSMOD 2909

XSMOD 2910

XSMOD 2911

XSMOD 2912

XSMOD 2913

XSMOD 2914

XSMOD 2915

XSMOD 2916

XSMOD 2917

XSMOD 2918

XSMOD 2919

XSMOD $\quad 2920$

XSMOD 2921

XSMOD 2922

XSMOD 2923

XSMOD 2924

XSMOD 2925

XSMOD 2926

XSMOD 2927

XSMOD 2928

XSMOD 2929

XSMOD 2930

XSMOD 2931

XSMOD 2932

XSMOD 2933

XSMOD 2934

XSMOD 2935

XSMOD 2936

XSMOD 2937

XSMOD $\quad 2938$

XSMOD 2939

XSMOD $\quad 2940$

XSMOD 2941

XSMOD 2942

XSMOD 2943 


\begin{tabular}{|c|c|c|c|}
\hline \multirow[t]{2}{*}{370} & CONTINUE & XSMOD & 2944 \\
\hline & GO TO 398 & XSMOD & 2945 \\
\hline C & ANG DISTR RECORDS FROM TAPE6 & XSMOD & 2946 \\
\hline \multirow[t]{2}{*}{380} & DO $395 \mathrm{~K}=1$,ND & XSMOD & 2947 \\
\hline & BUFFER IN(6,1) $(X(1), X(4850))$ & XSMOD & 2948 \\
\hline 382 & IF(UNIT,6)382,386,384 & XSMOD & 2949 \\
\hline 384 & PRINT 24, KID,K,ND & XSMOD & 2950 \\
\hline 24 & FORMAT(* EOF IN AD RECORDS FOR SID $=* 15^{*}$ RECORD $={ }^{*} 13^{*}$ OF *13*. & XSMOD & 2951 \\
\hline \multirow[t]{2}{*}{1} & SID ON TAPE1 PROBABLY NO GOOD. *) & XSMOD & 2952 \\
\hline & GO TO 395 & XSMOD & 2953 \\
\hline \multirow[t]{2}{*}{386} & $L=$ LENGTH $(6)$ & XSMOD & 2954 \\
\hline & WRITE(1) $(X(1), I=1, L)$ & XSMOD & 2955 \\
\hline 395 & CONTINUE & XSMOD & 2956 \\
\hline \multirow[t]{2}{*}{398} & ENDFILE 1 & XSMOD & 2957 \\
\hline & PRINT 14, KID & XSMOD & 2958 \\
\hline 14 & FORMAT ${ }^{*}$ SID*I5* WRITTEN TO TAPE $\left.1 *\right)$ & XSMOD & $2 \overline{5} 59$ \\
\hline \multirow[t]{3}{*}{399} & CONTINUE & XSMOD & 2960 \\
\hline & ENDFILE 1 & XSMGD & 2961 \\
\hline & PRINT 12 & XSAIOD & 2962 \\
\hline \multirow[t]{5}{*}{12} & FORMAT(* TAPE1 FOR EVXS HAS BEEN WRITTEN. DOUBLE EOF AT TAPE END. *) & XSMOD & 2963 \\
\hline & REWIND 1 & XSMIOD & 2964 \\
\hline & RETURN & XSMOD & 2965 \\
\hline & END & XSMOD & 2966 \\
\hline & SUBROUTINE RETREV(KID,KDIR,IIK,JJ,IERR,AM) & XSMODD & 2967 \\
\hline C & RETRIEVES SELECTED SID/GID FROM DTRAN TAPE & XSMOD & 2968 \\
\hline \multirow[t]{4}{*}{$\mathbf{C}$} & & XSMOD & 2969 \\
\hline & DIMENSION KDIR(300), HOL(2),M(6) & XSMOD & 2970 \\
\hline & DATA HOL(1),HOL(2) /3HSID,3HGID/ & XSMOD & 2971 \\
\hline & DATA $(M(I), I=1,6) / 10 H\left({ }^{*} G I D * 13\right), 10 H(* G I D * I 2), 10 H\left({ }^{*} G I D^{*} I 1\right)$ & XSMOD & 2972 \\
\hline 1 & $10 \mathrm{H}\left(* \operatorname{SID}{ }^{*} \mathrm{I} 4\right), 10 \mathrm{H}\left(* \mathrm{SID}^{*} \mathrm{I} 3\right), 10 \mathrm{H}\left({ }^{*} \mathrm{SID} * \mathrm{I}\right) /$ & XSMOD & 2973 \\
\hline \multirow[t]{2}{*}{$\mathbf{C}$} & & XSMOD & 2974 \\
\hline & IERR $=0$ & XSMOD & 2975 \\
\hline \multirow[t]{3}{*}{$\mathbf{c}$} & SEARCH FOR GID/SID IN DIRECTORY & XSMOD & 2976 \\
\hline & DO $110 \mathrm{I}=1, \mathrm{IIK}$ & XSMOD & 2977 \\
\hline & IF(KID . EQ. KDIR(I))GO TO 120 & XSMOD & 2978 \\
\hline \multirow[t]{2}{*}{110} & CONTINUE & XSMOD & 2979 \\
\hline & PRINT 2, HOL $(\mathrm{JJ}), \mathrm{KID}$ & XSMOD & 2980 \\
\hline \multirow[t]{3}{*}{2} & FORMAT ${ }^{*}$ CANNOT FIND *A3,14* ON DTRAN TAPE. *) & XSMOD & 2981 \\
\hline & IERR=1 & XSMOD & 2982 \\
\hline & RETURN & XSMOD & 2983 \\
\hline C & GET ASSOCIATED RECALL ID NO. & XSMOD & 2984 \\
\hline 120 & $K=K D I R(1+100)$ & XSMOD & 2985 \\
\hline & [:7(JJ EQ. EQ. 2)GO TO 130 & XSMOD & 2986 \\
\hline $\mathbf{C}$ & CHOOSE FORMAT FOR ENCODING DT NAME & XSMOD & 2987 \\
\hline & $|F(K I D, L T, \quad 10000)|=4$ & XSMOD & 2988 \\
\hline & IF(KID . LT. 1000$) 1=5$ & XSMOD & 2989 \\
\hline & IF(KID . LT. 100) I=6 & XSMOD & 2990 \\
\hline & GO TO 140 & XSMOD & 2991 \\
\hline 130 & IF(KIII . LT. 1000$) I=1$ & XSMOD & 2992 \\
\hline & $1 F(K I D, L T . \quad 100) 1=2$ & XSMOD & 2993 \\
\hline & IF(KID . LT. 10)I=3 & XSMOD & 2994 \\
\hline 140 & $\operatorname{ENCODE}(7, M(I), A M) K I D$ & XSMOD & 2995 \\
\hline $\mathbf{C}$ & RECONSTRUCTED RECALL CARD & XSMOD & 2996 \\
\hline & D. $((A M))=$ D. DT00010*MHX1* F. K & XSMOD & 2997 \\
\hline & PRINT 4, AM & XSMOD & 2998 \\
\hline 4 & FORMAT(1X,A10* HAS BEEN RETRIEVED. *) & XSMOD & 2999 \\
\hline & RETURN & XSMOD & 3000 \\
\hline & END & XSMOD & 3001 \\
\hline & END MODULE & XSMOD & 3002 \\
\hline & MODULE RECLIB & XSMOD & 2003 \\
\hline C & MODULE RECLIB CAME FROM KAPL & XSMOD & 3004 \\
\hline & DIMENSION IRP $(200,3)$ & XSMOD & 3005 \\
\hline & COMMON /TAPE40/ ISTATUS,IREEL,IRP & XSMOD & 3006 \\
\hline & COMMON /RECALL/ RECALL $(2,1000), \operatorname{USE}(200)$ & XSMOD & 3007 \\
\hline & EQUIVALENCE (IREEL,REEL) & XSMOD & 3008 \\
\hline & DATA IRP $1600^{\circ} 0 /$ & XSMOD & 3009 \\
\hline C & N. REEL = PHYSICAL REEL NO. OF LIBRARY TAPE & XSMOD & 3010 \\
\hline C & N. RECLID = (RECALL ID, NO. OF WORDS, $1=1$, NO OF IDS ON TAPE) & XSMOD & 3011 \\
\hline C & N. USE = ID NUMBERS TO BE RETRIEVED FOR THIS JOB & XSMOD & 3012 \\
\hline & F. NX = WORDS OF N. RECLID & XSMOD & 3013 \\
\hline 1 & $\mathrm{NO}=\mathrm{NX} / 2$ & XSMOD & 3014 \\
\hline
\end{tabular}


ITEST $=2 * \mathrm{NO} \cdot \mathrm{NX}$

IF (ITEST . EQ. 0) GO TO 2

PRINT 102

02 FORMAT(1H0,10(1 H*), POSSIBLE ERROR IN N. RECLID - JOB WILL CONTINUE

BUT RESULT IS RISKY*,10(1 $\left.\left.\mathrm{H}^{*}\right), / /\right)$

101 FORMAT(1HO,10(1 H*), N. RECLID CARD IN ERROR OR MISSING - JOB TERMIN

ATED*,10(1 $\left.\left.\mathrm{H}^{*}\right), / /\right)$

2 IF (NO . LE. 1000) GO TO 3

PRINT 102

3 F. RECALL $=$ N. RECLID

F. REEL = N, REEL

ISTATUS $=1$

F. NUSE = WORDS OF N. USE

IF (NUSE . LE. 200) GO TO 4

PRINT 103

103 FORMAT(1HO,1O(1 H*), *USER REQUESTING MORE THAN 200 RECALLS - গOB TE

1 RMINATED*,10(1 $\left.\left.\mathrm{H}^{*}\right), / /\right)$

STOP

$4 \quad$ F. USE $=$ N. USE

DO $5 \mathrm{I}=1$, NUSE

DO $6 \mathrm{~J}=1$,NO

6 CONTINUE

PRINT 104, USE(I)

IST - SKIPPED - RECALL ID $\left.=* I 5,5 \mathrm{X}, 10\left(1 \mathrm{H}^{*}\right), / /\right)$

GO TO 5

$7 \quad$ IRP(I,1) = IREEL

$\operatorname{IRP}(1,2)=\operatorname{RECALL}(1, \mathrm{~J})$

$\operatorname{IRP}(I, 3)=\operatorname{RECALL}(2, J)$

5 CONTINUE

C SAVE RFL + 3

IADD $=3+1-\operatorname{LOCF}(\operatorname{USE}(1))$

RETAIN3 = USE(IADD)

CALL TAPE40(IERROR)

IF (IERROR . NE. 1) GO TO 8

PRINT 105

FORMAT $\left(1 \mathrm{HO}, 10\left(1 \mathrm{H}^{*}\right),{ }^{*}\right.$ ERROR IN TAPE40 - JOB TERMINATED $\left.{ }^{*}, 10\left(1 \mathrm{H}^{*}\right), / /\right)$

STOP

8 CONTINUE

CALL OVERLAY(7HRECALL,0,0)

CALL READ40

C

RESTORE RFL + 3

USE $($ IADD $)=$ RETAIN3

RETURN

END

SUBROUTINE TAPE4O(IERROR)

C
C
C
C
C
C
C
C
C
C
C
C
C
C
C
C
C
C
C
C
C

THIS SUBROUTINE PREPARES A FILE CALLED TAPE40 WHICH CONTAINS ALL

THE NECESSARY INFORMATION FOR RECALLING DATA WITH IN A JOB.

TAPE40 IS READ BY PROGRAM RECALL CALLED FROM MODULE RECALL. ALL INPUT TO TAPE4O IS VIA A COMMON BLOCK OF THE STRUCTURE

COMMON /TAPE40/ ISTATUS,IREEL,IRP(200,3)

WHERE ISTATUS IS SET AS FOLLOWS

ISTATUS $=0$, NO SAVE OR RECALL

ISTATUS $=1$, JUST RECALL

ISTATUS $=2$, JUST SAVE

ISTATUS $=3$, BOTH SAVE AND RECALL.

IREEL CONTAINS THE REEL NO. ON WHICH ALL SAVES ARE TO BE MADE.

IREEL CONTAINS THE REEL NO. ON WHICH ALL SAVES ARE TO BE MADE.

FOR EACH RECALL CARD ENCOUNTERED IRP IS FILLED OUT AS FOLLOWS $\operatorname{IRP}(!, 1)=$ TAPE NO.

$\operatorname{IRP}(I, 2)=I D$ )

$\operatorname{IRP}(I, 3)=$ NO. OF WORDS,

IF ANY ERROR OCCURES DURING THE EXECUTION OF TAPE40 A MESSAGE IS ISSUED, IERROR IS SET $=1$, AND A RETURN EXECUTED. IERROR IS SET $=0$ AFTER SUCCESSFUL COMPLETION OF SUBROUTINE TAPE40. INTEGER ORDER,CONVERT,TAPE,STAPE,SHIFTL,SHIFTR DIMENSION IRP(200,3),ITA.PE(10),BUF(83),IRPX(200,2),

XSMOD

XSMOD

XSMOD

XSMOD

XSMOD

XSMOD

XSMOD

XSMOD

XSMOD

XSMOD

XSMOD

XSMOD

XSMOD

XSMOD

XSMOD

XSMOD

XSMOD

XSMOD

XSMOD

XSMOD

XSMOD

XSMOD

XSMOD

XSMOD

XSMOD

XSMOD

XSMOD

XSMOD

XSMOD

XSMOD

XSMOD

XSMOD

XSMOD

XSMOD

XSMOD

XSMOD

XSMOD

XSMOD

XSMOD

XSMOD

XSMOD

XSMOD

XSMOD

XSMOD

XSMOD

XSMOD

XSMOD

XSMOD

XSMOD

XSMOD

XSMOD

XSMOD

XSMOD

XSMOD

XSMOD

XSMOD

XSMOD

XSMOD

XSMOD

XSMOD

XSMOD

XSMOD

XSMOD

XSMOD

XSMOD

XSMOD

XSMOD

XSMOD

XSMOD

XSMOD

XSMOD 
COMMON /TAPE40/ ISTATUS,IREEL,IRP

EQUIVALENCE (IRP(1),IRPX(1)),(IRP(401), ORDER(1))

XSMOD

COMMON /CHECKX/IBUF

DATA ITAPE $/ 10^{*} 0 /$

IERROR $=0$

NOTAPE $=0$

13 CALL SETPARM(3,6HTAPE40,BUF,83)

REWIND 40

$\operatorname{IBUF}(1)=-1$

$\operatorname{IBUF}(2)=0$

1 DO $2 I=1,200$

TAPE $=\operatorname{IRP}(1,1)$

IF (TAPE . EQ. 0) GO TO 3

CALL LSHIFT(IRP(I,2))

$\mathrm{NOB}=\operatorname{IRP}(\mathrm{I}, 3) / 511$

CALL PACKR(NOB,IRP(I,2))

DO $4 J=1$, NOTAPE

IF (TAPE . EQ. ITAPE $(J)$ ) GO TO 2

4 CONTINUE

NOTAPE $=$ NOTAPE +1

IF (NOTAPE) . LE. 10) GO TO 6

PRINT 100

100 FORMAT $(/ / / / / / / / / 5 X, 84 \mathrm{HTOO}$ MANY TAPES SPECIFIED ON RECALL CARDS.

1 TEN IS THE MAXIMUM NO. ALLOWED IN ONE JOB $/ / / / /$ )

IERROR = 1

RETURN

ITAPE(NOTAPE) $=$ TAPE

CONTINUE

DO $51=1$, NOTAPE

IF (ITAPE(I) . NE. IREEL) GO TO 5

STAPE $=$ ITAPE $(\mathrm{I})$

ITAPE $(\mathrm{I})=6 \mathrm{H} 999999$

GO TO 8

5 CONTINUE

IF (ISTATUS . EQ. 1) GO TO 8

C SAVE AND RECALL BUT NO RECALLS OFF SAVE TAPE

NOTAPE $=$ NOTAPE $\div 1$

ITAPE $($ NOTAPE $)=6.1999999$

XSMOD

3086

XSMOD

XSMOD $\quad 3089$

XSMOD

XSMOD $\quad 3091$

XSMOD $\quad 3092$

XSMOD 3093

XSMOD $\quad 3094$

XSMOD 3095

XSMOD $\quad 3096$

XSMOD $\quad 3097$

XSMOD $\quad 3098$

XSMOD $\quad 3099$

XSMOD $\quad 3100$

XSMOD $\quad 3101$

XSMOD $\quad 3102$

XSMOD $\quad 3103$

XSMOD $\quad 3104$

XSMOD $\quad 3105$

XSMOD $\quad 3106$

XSMOD $\quad \mathbf{3 1 0 7}$

XSMOD $\quad 3108$

XSMOD $\quad 3109$

XSMOD $\quad 3110$

XSMOD $\quad 3111$

XSMOD $\quad 3112$

XSMOD $\quad 3113$

XSMOD $\quad 3114$

XSMOD $\quad 3115$

XSMOD $\quad 3116$

XSMOD $\quad 3117$

XSMOD $\quad 3118$

XSMOD $\quad 3119$

XSMOD $\quad 3120$

XSMOD $\quad 3121$

XSMOD $\quad 3122$

XSMOD $\quad 3123$

STAPE = IREEL

XSMOD

ISTATUS $=-3$

$\mathrm{C}$

SHIFT RIGHT WITH O FILL SO ORDER WILL ALWAYS BE ON AGSOLUTE VALUE

XSMOD

XSMOD

XSMOD

XSMOD

XSMOD

XSMOD

XSMOD

CALL ARRANGE(ITAPE, NOTAPE)

C SHIFT BACK AND RESTORE BLANK

DO $151=1$, NOTAPE

15 ITAPE(I) $=$ SHIFTL $($ ITAPE $(I), 6)+55 B$

IF(ITAPE(NOTAPE). EQ. 6H999999) ITAPE(NOTAPE) = STAPE

DO $7 I=1$, NOTAPE

$7 \quad \operatorname{IBUF}(2+1)=\operatorname{ITAPE}(\mathrm{I})$

$\operatorname{IBUF}(2)=$ NOTAPE

LIB $=2+$ NOTAPE

IF (ISTATUS . EQ. - 3) NOTAPE = NOTAPE- 1

DO $9 \mathrm{I}=1$, NOTAPE

$\mathrm{K}=\mathbf{0}$

TAPE $=$ ITAPE $(\mathrm{I})$

DO $10 \mathrm{~J}=1,200$

IF (IRPX(J,1). EQ. o) Go TO 11

IF (IRPX(J,1). NE. TAPE) GO TO 10

$K=K+1$

$\operatorname{ORDER}(K)=\operatorname{IRPX}(0,2)$

10 CONTINUE

11 CALL ARRANGE(ORDER,K)

DO $12 \mathrm{~J}=1, \mathrm{~K}$

$I X=$ ORDER(J)

CALL RSHIFT(IX)

$I X=$ CONVERT $(I X)$

CALL SHIFTC(IX)

CALL CHECK(LIB)

$\operatorname{IBUF}(L I B)=I T A P E(I)$

CALL PACKR(IX,IBUP(LIB))

XSMOD

XSMOD

XSMOD

XSMOD

XSMOD

XSMOD

XSMOD

XSMOD

XSMOD

XSMOD

XSMOD

XSMOD

XSMOD

XSMOD

XSMOD

$\mathrm{XSMOD}$

XSMOD

XSMOD

XSMOD

XSMOD

XSMOD

XSMOD

XSMOD

XSMOD

XSMOD 
CALL CHECK(L.BB)

XSMOD $\quad 3157$

$\operatorname{IBUF}(\mathrm{LIB})=$ ORDER $(\mathrm{J})$

XSMOD $\quad 3158$

CALL CHECK(LIB)

$\operatorname{IBUF}(\mathrm{ILIB})=0$

CALL CHECK(LIB)

$\operatorname{IBUF}($ LIB $)=0$

50 WRITE (40) IBUF

END FILE 40

RETURN

END

SUBROUTINE CHECK(LIB)

COMMON /CHECKX/IBUF(64)

$\mathrm{LIB}=\mathrm{LIB}+\mathrm{I}$

IF (LJB . LE. 64) RETURN

WRITE (40) IBUF

LIB $=1$

RETURN

END

C -

SUBROUTINE ARRANGE(IX,KX)

DIMENSION IX(200)

$\mathbf{K}=\mathbf{K X}$

IF (K . LE. 1) RETURN

$K=K \cdot 1$

IF $(K . E Q, 0) \quad K=1$

$2 \quad J=0$

DO $1 \mathrm{I}=1, \mathrm{~K}$

IF (IX(I) . LE. IX(1+1)) GO TO 1

$J=1$

ITEMP $=I X(I)$

$I X(I)=I X(I+1)$

$I X(I+1)=I T E M P$

1 CONTINUE

IF (] . EQ. O) RETURN

GO TO 2

END

C

INTEGER FUNCTION CONYERT(INTX)

INT $=$ INTX

$\mathrm{K}=1$

$j P=10$

1 IF (INT/JP, EQ O O) GO TO 2

$K=K+1$

$J P=J P * 10$

GO TO 1

$2 \quad$ CONVERT $=55555555555555555555 \mathrm{~B}$

DO $3 I=1, K$

$\mathrm{JP}=\mathrm{JP} / 10$

$\mathrm{NDIG}=[\mathrm{NT} / \mathrm{JP}$

$16=6^{*} \mathrm{I}$

CALL DIGIT(CONVERT,NDIG,16)

INT = INT - NDIG*JP

RETURN

END

SUBROUTINE READ40

INTEGER RIGHT,FIELDR

DIMENSION BUF(82), IBUF(64),NAMESR(2)

DIMENSION NTAPE(10),ISET(506)

DATA NAMESR /7HSAVEAND, IOHRECALLDATA/

NEED TO USE CLASP LAIS BECAUSE THIS ROUTINE - NOT IN - OPENS LAIS

3159

XSMOD $\quad 3160$

XSMOD $\quad 316$

XSMOD $\quad 3162$

XSMOD $\quad 3163$

XSMOD $\quad 3164$

XSMOD $\quad 3165$

XSMOD $\quad 3166$

XSMOD $\quad 3167$

XSMOD $\quad 3168$

XSMOD $\quad 3169$

XSMOD $\quad 3170$

XSMOD 3'71

XSMOD 3172

XSMOD $\quad 3173$

XSMOD $\quad 3174$

XSMOD $\quad 3175$

XSMOD $\quad 3176$

XSMOD $\quad 3177$

XSMOD $\quad 3178$

XSMOD $\quad 3179$

XSMOD $\quad 3180$

XSMOD $\quad 3181$

XSMOD $\quad 3182$

XSMOD $\quad 3183$

XSMOD $\quad 3184$

XSMOD $\quad 3185$

XSMOD $\quad 3186$

XSMOD $\quad 3187$

XSMOD $\quad 3188$

XSMOD $\quad 3159$

XSMOD $\quad 3190$

XSMOD 3191

XSMOD 3192

XSMOD 3193

XSMOD $\quad 3194$

XSMOD 3195

XSMOD $\quad 3196$

XSMOD $\quad 3197$

XSMOD $\quad 3198$

XSMOD $\quad 3199$

XSMOD $\quad 3200$

XSMOD 3201

XSMOD $\quad 3202$

XSMOD $\quad 3203$

XSMOD $\quad 3204$

XSMOD $\quad 3205$

XSMOD $\quad 3206$

XSMOD $\quad 3207$

XSMOD $\quad 3208$

XSMOD $\quad 3209$

XSMOD $\quad 3210$

XSMOD $\quad 3211$

XSMOD $\quad 3212$

XSMOD $\quad 3213$

XSMOD $\quad 3214$

XSMOD $\quad 3215$

XSMOD $\quad 3216$

EQUIVALENCE(DTPATHL(494), LAIS)

ABOVE EQUIVALENCE MAY BE SUJECT TO CHANGE WHENLVER CLASP IS

XSMOD

3217

XSMOD $\quad 3218$

RECOMPILED

494=756B $=$ LOCF OF I3LOCK DT10002- LOCF OF BLOCK DT00001+61B

XSMOD

3219

FROM CLASP MAP.... LOCF(DT10002) $=34335 \mathrm{~B}$

FROM CLASP MAP.... LOCF(DTOOOO1)=33440B

XSMOD

3221

XSMOD $\quad 3222$

CAL.I. SETPARM(3,61HTAPL40,BUR,82)

RI:WIND 40

RL:AD (40) IHUI:

NOTAPE: $=$ IBUF(2)

XSMOD

3223

XSMOD $\quad 3224$

XSMOD $\quad 3225$

XSMOD $\quad 3226$

I,AIS $=1$

XSMOD

3227 
CALL. OPENFI(LAIS, 2,NAMESR,0,1,1)

XSMOD

40) NTAPE(I) $=\operatorname{IBUF}(I+2)$

$k=1$

$J=$ NOTAPE +3

DO $501=1$, NOTAPE

ISET $(K)=$ NTAPE(I)

RIGHT $=1$

NRIIS $=1$

$42 \quad J=J+1$

IF (J.LE. 64) GO TO 43

READ (40) IBUF

$\mathrm{J}=1$

43 NRHS $=$ NRHS + RIGHT -1

$44 \quad$ RIGHT $=$ FIELDR $(\operatorname{IBUF}(\mathrm{J}))$

$K=K+1$

IF (K.GT. 506) GO TO 60

$\operatorname{ISET}(\mathrm{K})=\operatorname{IRUF}(1)$

CALL PACKR(NRHS,ISET(K))

$\mathrm{J}=\mathrm{J}+1$

IF (J . LE. 64) GO TO 45

READ (40) IBUF

$J=1$

45 IF (IBUF(J) . NE. O) GO TO 42

$\mathrm{J}=\mathrm{J}+\mathrm{I}$

$K=K+1$

IF (K.GT. 506) GO TO 60

IF (IBUF(J) EQ. o) GO TO 61

50 CONTINUE

GO TO 61

60 PRINT 100

100 FORMAT(1H0,5X,48H****TOO MANY DATA RECALL CARDS JOB ABORTED****)

CALL PP(3HABT,0,0)

$61 \quad$ ISET $(K)=0$

CALL STOSET(ISET,- LAIS,506)

CALL SAVEFI(LAIS)

62 CONTINUE

LAIS $=1$

CALL FINDDI(LAIS, 2,NAMESR,0,1,1)

IF (LAIS , GT. O) GO TO 63

PRINT 101

101 FORMAT(1H0,5X,51H****CANT FIND LAIS FILE JOB ABORTED*****)

CALL PP(3HABT, 0,0$)$

63 CONTINUE

RETURN

END

IDENT PACKAGE

ENTRY DIGIT

DIGIT

BSS 1

$\mathrm{SA} 3 \quad \mathrm{~B} 3$

$S B 3 \quad X 3$

SB4 60

$\mathrm{MX} 454$

SA1 B1

SA2 B2

$5 \times 2 \quad \times 2+33 B$

SB. $\quad B 4-B 3$

$\mathrm{LX2} B 4, \mathrm{X} 2$

LX4 B4,X4

BX1 X4*X1

BX6 $\mathrm{X1}+\mathrm{X} 2$

SÁ́ B1

ZR BO,DIGIT

ENTRY PACKR

PACKR

\begin{tabular}{ll} 
BSS & 1 \\
MX1 & \multicolumn{1}{c}{30} \\
SA2 & B2 \\
BX2 & $\mathrm{X} 1 \cdot \mathrm{X2}$ \\
SA1 & B1 \\
BX6 & $\mathrm{X} 1+\mathrm{X} 2$
\end{tabular}

XSMOD $\quad 3231$

XSMOD $\quad 3232$

XSMOD $\quad 3233$

XSMOD $\quad 3234$

XSMOD $\quad 3235$

XSMOD $\quad 3236$

XSMOD $\quad 3237$

XSMOD $\quad 3238$

XSMOD $\quad 3239$

XSMOD $\quad 3240$

XSMOD $\quad 3241$

XSMOD $\quad 3242$

XSMOD $\quad 3243$

XSMOD $\quad 3244$

XSMOD $\quad 3245$

XSMOD $\quad 3246$

XSMOD $\quad 3247$

XSMOD $\quad 3248$

XSMOD $\quad 3249$

XSMOD 3250

$X S M O D \quad 3251$

XSMOD $\quad 3252$

XSMOD $\quad 3253$

XSMOD $\quad 3254$

XSMOD $\quad 3255$

XSMOD $\quad 3256$

XSMOD $\quad 3257$

XSMOD $\quad 3258$

XSMOD $\quad 3259$

XSMOD $\quad 3260$

XSMOD $\quad 3261$

XSMOD $\quad 3262$

XSMOD $\quad 3263$

XSMOD $\quad 3264$

XSMOD $\quad 3265$

XSMOD $\quad 3266$

XSMOD $\quad 3267$

XSMOD $\quad 3268$

XSMOD $\quad 3269$

XSMOD $\quad 3270$

XSMOD $\quad 3271$

XSMOD $\quad 3272$

XSMOD $\quad 3273$

XSMOD $\quad 3274$

XSMOD $\quad 3275$

XSMOD $\quad 3276$

XSMOD $\quad 3277$

XSMOD $\quad 3278$

XSMOD $\quad 3279$

XSMOOD 3280

XSMOD $\quad 3281$

XSMOD $\quad 3282$

XSMOD

XSMOD $\quad 3284$

XSMOD $\quad 3285$

XSMOD $\quad 3286$

XSMOD $\quad 3287$

XSMOD $\quad 3288$

XSMOD 3289

XSMOD 3290

XSMOD 3291

XSMOD 3292

XSMOD 3293

XSMOD $\quad 3294$

XSMOD $\quad 3295$

XSMOD $\quad 3296$

XSMOD 3297

XSMOD 3298 


\begin{tabular}{|c|c|c|c|c|}
\hline & & SA6 & XSMOD & 3299 \\
\hline & & BO,PACKR & XSMOD & 3300 \\
\hline & & ENTRY LSHIFT & XSMOD & 3301 \\
\hline \multirow[t]{7}{*}{ LSHIF } & $\mathbf{T}$ & BSS 1 & XSMOD & 3302 \\
\hline & & 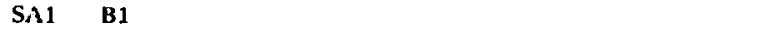 & XSMOD & $; 303$ \\
\hline & & LXI & XSMOD & 3504 \\
\hline & & BX6 & XSMOD & 3305 \\
\hline & & SA6 & XSMOD & 3306 \\
\hline & & BO,LSHIFT & XSMOD & 3307 \\
\hline & & ENTRY RSHIFT & XSMOD & 3308 \\
\hline \multirow[t]{7}{*}{ RSHIF } & $\mathbf{T}$ & BSS 1 & XSMOD & 3309 \\
\hline & & SA1 & XSMOD & 3310 \\
\hline & & AX1 & XSMOD & 3311 \\
\hline & & BX6 & XSMOD & 3312 \\
\hline & & SA6 & XSMOD & 3313 \\
\hline & & BO,PSHIFT & XSMOD & 3314 \\
\hline & & ENTRY SHIFTC & XSMOD & 3315 \\
\hline \multirow[t]{5}{*}{ SHIFT } & C & BSS & XSMOD & 3316 \\
\hline & & SA1 & XSMOD & 3317 \\
\hline & & MX2 & XSMOD & 3318 \\
\hline & & $\mathbf{S X 3}$ & XSMOD & 3319 \\
\hline & & LX3 & XSMOD & 3320 \\
\hline \multirow{9}{*}{ START } & $\mathbf{x}$ & LXI & XSMOD & 3321 \\
\hline & & $\mathrm{X} 2 * \mathrm{X} 1$ & XSMOD & 3322 \\
\hline & & $\mathrm{x} 4-\mathrm{X} 3$ & XSMOD & 3323 \\
\hline & & X4,STARTX & XSMOD & 3324 \\
\hline & & 30 & XSMUD & 3325 \\
\hline & & $-X 2 * X 1$ & XSMOD & 3326 \\
\hline & & SA6 & XSMOD & 3327 \\
\hline & & BO,SHIFTC & XSMOD & 3328 \\
\hline & & ENTRY FIELDR & XSMOD & 3329 \\
\hline \multirow[t]{12}{*}{ FIELD } & $\mathbf{R}$ & BSS 1 & XSMOD & 3330 \\
\hline & & MX1 & XSMOD & 3331 \\
\hline & & SA2 & XSMOD & 3332 \\
\hline & & $-x 1 * x 2$ & XSMOD & 3333 \\
\hline & & BO,FIE LDR & XSMOD & 3334 \\
\hline & & END & XSMOD & 3335 \\
\hline & & IDENT SHIFTL & XSMOD & 3336 \\
\hline & & AUTHOR - R. J. CULLEN & XSMOD & 3337 \\
\hline & & COPIED MANUALLY FROM LISTING BY W. E. SCHILLING & XSMOD & 3338 \\
\hline & & & XSMOD & 3339 \\
\hline & & ENTRY SHIFTL,SHIFTR & XSMOD & 3340 \\
\hline & & VFD $\quad 36 / 0 H S H I F T L, 24 / 2$ & XSMOD & 3341 \\
\hline \multirow[t]{13}{*}{ SHIFT } & $\mathbf{L}$ & VFD & XSMOD & 3342 \\
\hline & & SA1 & XSMOD & 3343 \\
\hline & & SA2 & XSMOD & 3344 \\
\hline & & BX6 & XSMOD & 3345 \\
\hline & & X2,SHIFTL & XSMOD & 3346 \\
\hline & & $\mathrm{MX6}$ & $X S M O D$ & 3347 \\
\hline & & X2- 1 & XSMOD & 3348 \\
\hline & & $\mathrm{B} 2, \mathrm{X} 6$ & XSMOD & 3349 \\
\hline & & $-X 6 * X 1$ & XSMOD & 3350 \\
\hline & & $\mathrm{B2}, \mathrm{X} 1$ & XSMOD & 3351 \\
\hline & & LX6 & XSMOD & 3352 \\
\hline & & SHIFTL & XSMOD & 3353 \\
\hline & & 36/OHSHIFTR,24/2 & XSMOD & 3354 \\
\hline \multirow[t]{15}{*}{ SHIFT } & $\mathrm{R}$ & $60 / 0$ & XSMOD & 3355 \\
\hline & & SA1 B1 & XSMOD & 3356 \\
\hline & & SA2 & XSMOD & 3357 \\
\hline & & BX6 & XSMOD & 3358 \\
\hline & & X2,SHIFTR & XSMOD & 3359 \\
\hline & & MX6 & XSMOD & 3360 \\
\hline & & SB2 & XSMOD & 3361 \\
\hline & & B2,X1 & XSMOD & 3362 \\
\hline & & B 2-1 & XSMOD & 3363 \\
\hline & & $\mathrm{B2}, \mathrm{X} 6$ & XSMOD & 3364 \\
\hline & & $-X 6 * \times 1$ & XSMOD & 3365 \\
\hline & & SHIFTR & XSMOD & 3366 \\
\hline & & END & XSMOD & 3367 \\
\hline & END & MODULE: & XSMOD & 3368 \\
\hline & ENI & 108 & XSMOD & 3369 \\
\hline
\end{tabular}

\footnotetext{
\& US OOVERNMENT PAINTING OFFICE: 1974 - 784.529/39
}

$\mathrm{JJ}: 250(45)$ 